\title{
TEACHERS' PROFESSIONAL IDENTITY
}

A study into how teachers in one Slovenian primary school talk about their professional identity and work following participation in NLP-based CPD in comparison with other teachers

\section{EdD Dissertation}

The Open University

TATJANA DRAGOVIC

October 2009 
To all the teachers around the world 


\section{TABLE OF CONTENTS}

TABLE OF CONTENTS

LIST OF TABLES

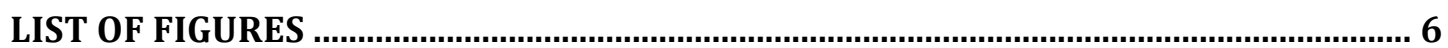

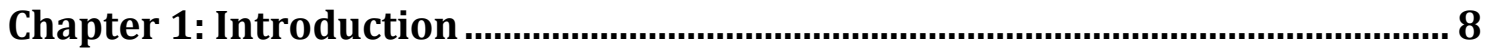

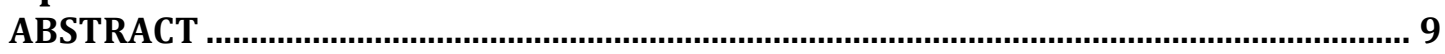

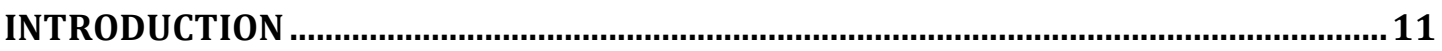

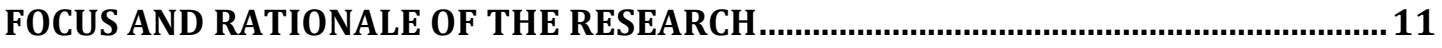

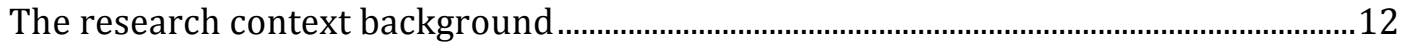

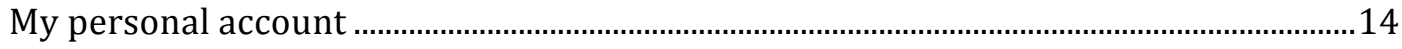

Placing the research question within the wider context of educational practice..........20

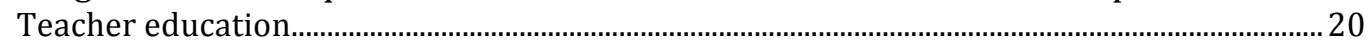

THE DEVELOPMENT OF THE RESEARCH QUESTION AND NARROWING THE

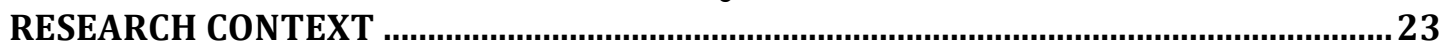

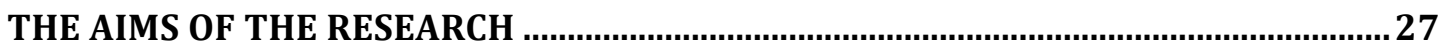

THE RESEARCHER'S VOICE AND THE PARALLEL REFLECTION ON THE TEACHERS'

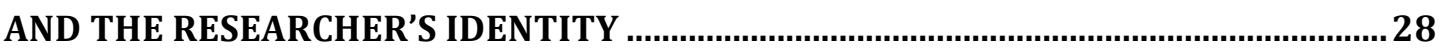

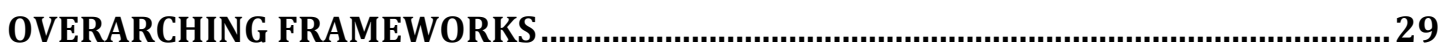

Epistemological and ontological framework …….............................................................2

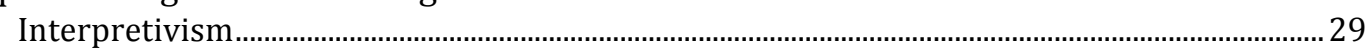

Conceptual and theoretical framework …………………................................................. 30 Constructive critical theory ………………………………………………………………………..... 30

Social Constructivism ......................................................................................................................... 32

Methodological framework ................................................................................................. 33

Constructive action research ……………………………………………………………………….... 33

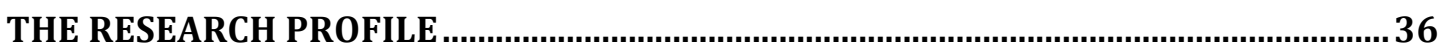

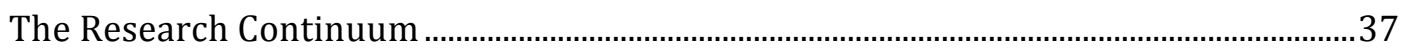

THE STRUCTURE OF THE DISSERTATION................................................................. 37

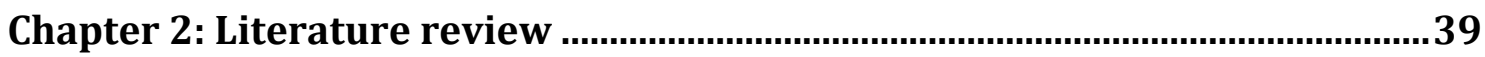

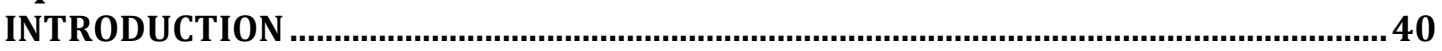

Identifying the relevant research areas/key concepts........................................................40

Approach and aim of the review in connection to the research focus.............................41

CONTINUING PROFESSIONAL DEVELOPMENT AND PERSONAL DEVELOPMENT ....43

PERSONAL DEVELOPMENT AND NEURO-LINGUISTIC PROGRAMMING ....................50

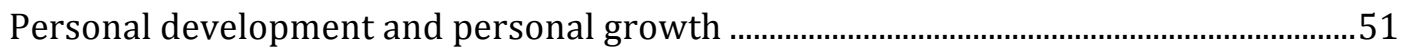

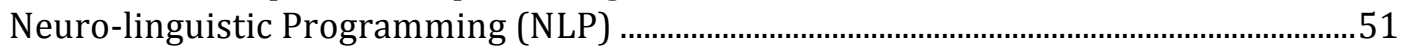

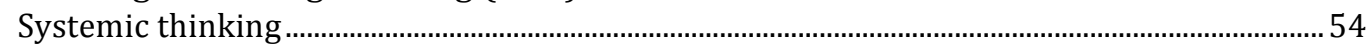

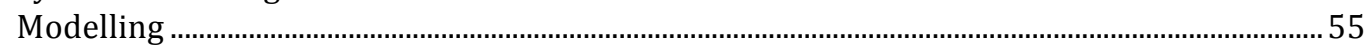

Cognitive apprenticeship, Modelling and Legitimate Peripheral Participation..........................56

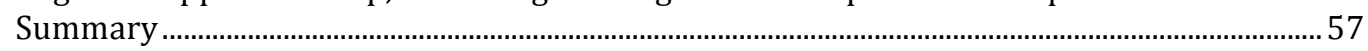

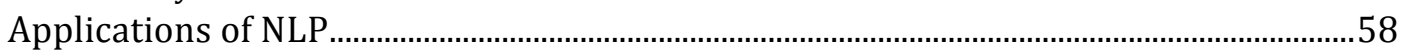

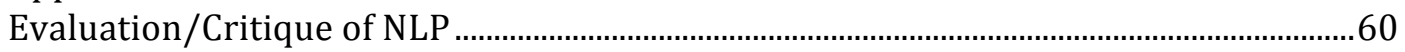

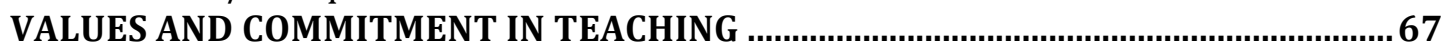

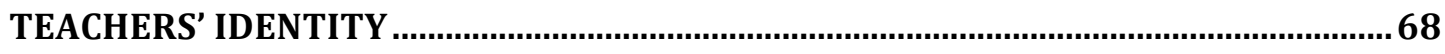

The notion of identity and different attempts to define it .................................................68

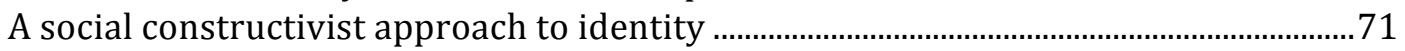

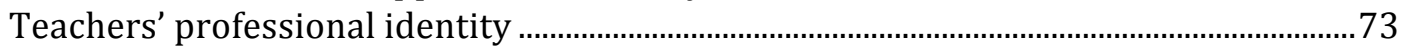

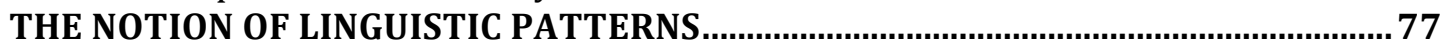

Positive, neutral and negative statements ...................................................................

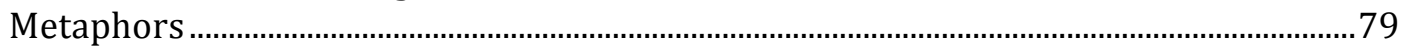

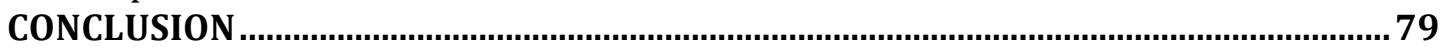




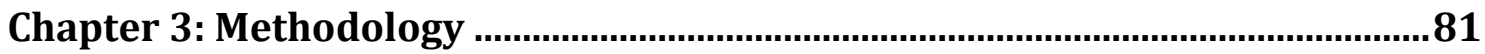

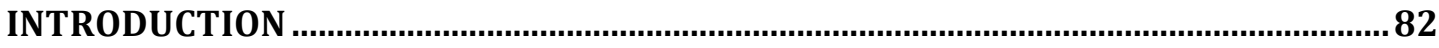

PLACING THE RESEARCH WITHIN THE WIDER METHODOLOGICAL

CONTEXT/DISCUSSION OF RESEARCH METHODOLOGIES AND METHODS.................83

Introducing basic terminology ....................................................................................... 83

Overview of the qualitative-quantitative debate and its philosophical underpinnings

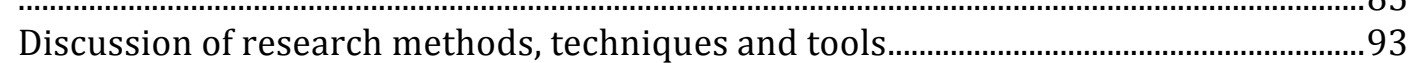

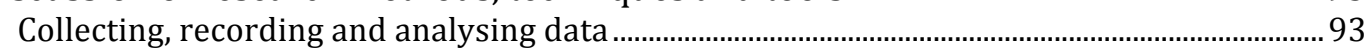

The development of the research sequence .................................................................................97

VALIDITY, GENERALISABILITY AND RELIABILITY VS. TRUSTWORTHINESS...........99

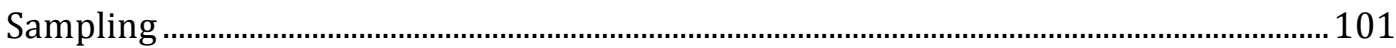

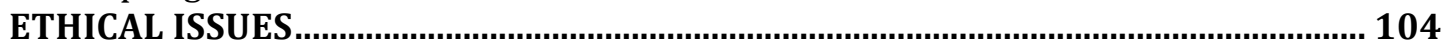

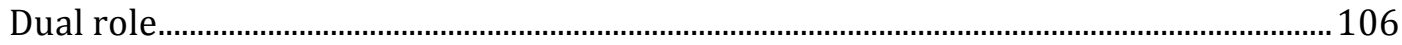

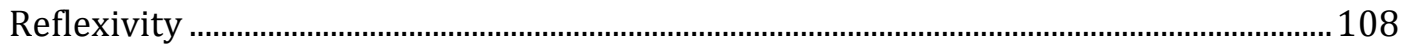

CONCLUSION

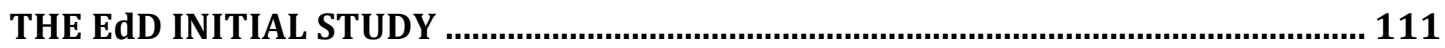

Pre - Initial study - The design of the questions ................................................................. 113

Non-participant observations................................................................................................... 114

The semi-structured interviews .................................................................................................. 117

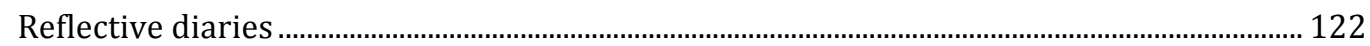

CONCLUSION OR WHAT HAVE I LEARNED FROM THE INITIAL STUDY ................... 124

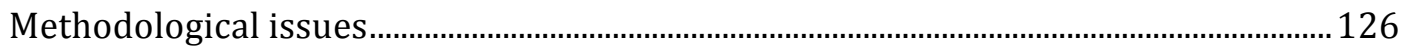

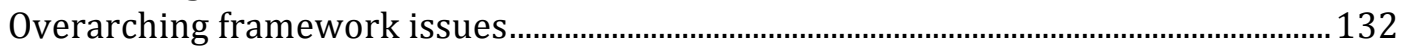

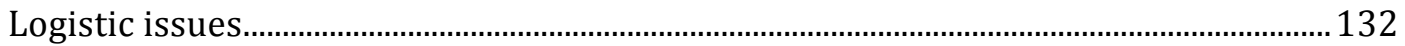

HOW THE MAIN RESEARCH WAS INFORMED BY THE PILOT STUDY ...................... 135

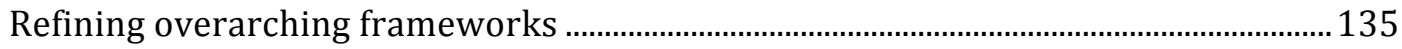

Refining the conceptual framework ...................................................................................... 135

Refining the methodological framework …………………....................................................... 135

Chapter 4: Overarching frameworks .................................................................... 137

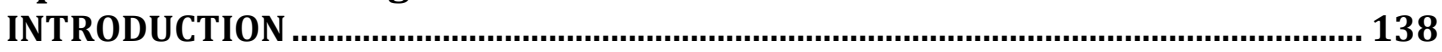

EXPLORING CRITICAL THEORY AS A CONCEPTUAL FRAMEWORK ......................... 138

Advantages and disadvantages of critical theory framework .......................................... 145

EXPLORING ACTION RESEARCH AS A METHODOLOGICAL FRAMEWORK............... 146

Advantages and disadvantages of an action research framework.................................157

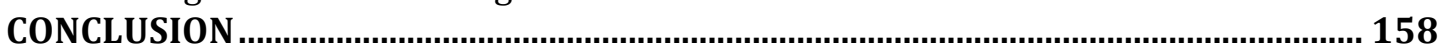

Chapter 5: Data presentation and analysis .....................................................160

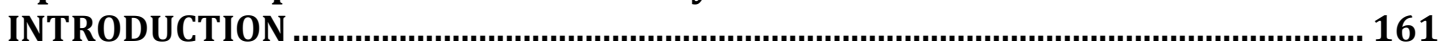

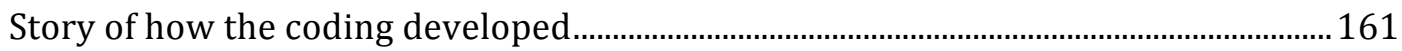

Coding process ................................................................................................................. 164

Primary coding - Creating a reading guide .......................................................................... 165

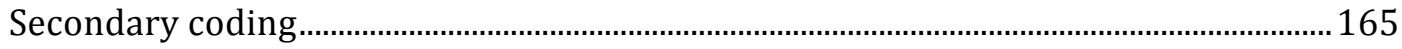

Extended primary coding................................................................................................ 168

Linguistic spectrum detected across all the categories and across all data-collection

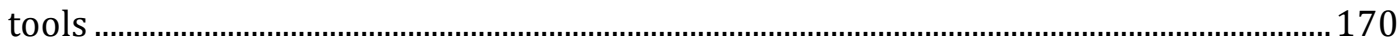

Individual content-based spectra for each category ...................................................... 171

Graphic synthesis of primary and secondary coding (next page) .................................... 177

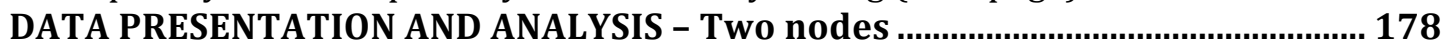

Node 1: Teachers' identity ................................................................................................. 180

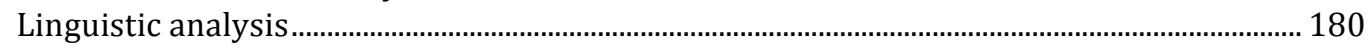

Summary of comparative linguistic analysis - Node 1 (Teachers' identity) ............................ 183

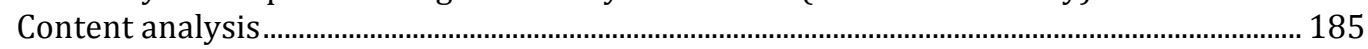

Summary of the comparative content analysis of Node 1 (Teachers' identity) ..................... 199

Node 2: Teachers' work ........................................................................................................... 199 


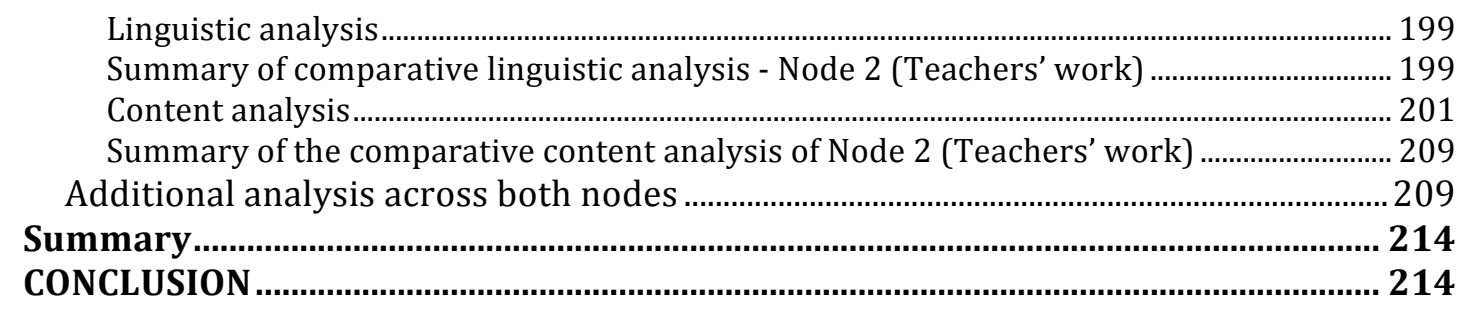

Chapter 6: Discussion of findings ..................................................................... 216

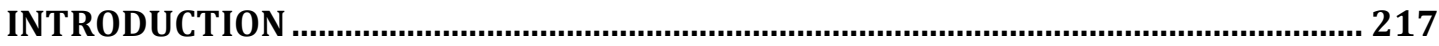

FINDINGS RELATED TO THE RESEARCH QUESTION ................................................... 217

How did the two groups talk about their identity and work? ...........................................218

FINDINGS RELATED TO LITERATURE AND PREVIOUS RESEARCH ......................... 230

Cluster 1: CPD, Personal development, NLP and linguistic patterns .............................2230

Cluster 2: Identity, Professional identity, Teachers' identity, Commitment and values

FINDINGS RELATED TO OVERARCHING FRAMEWORKS
Methodological framework
Conceptual and theoretical frameworks
Epistemological framework
Summary

Chapter 7: Conclusion - Looking back and looking ahead................................. 243

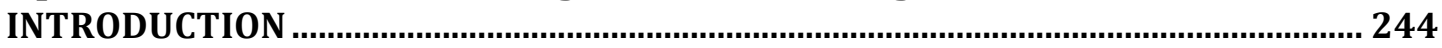

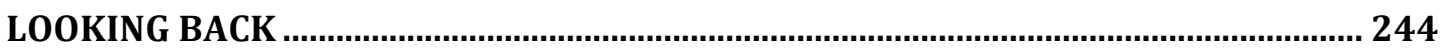

Returning to the research question using the conclusions from the data analysis and

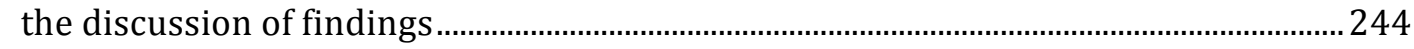

Researcher's reflection on the research process ...............................................................246

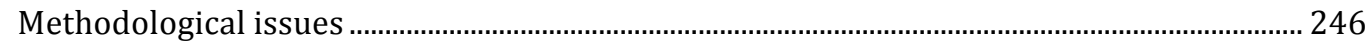

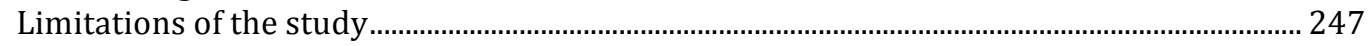

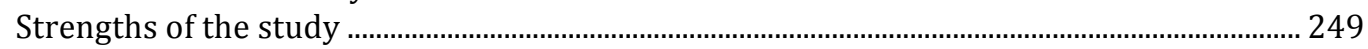

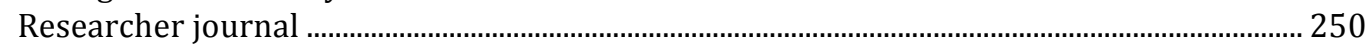

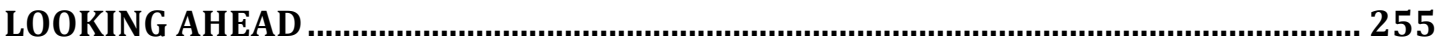

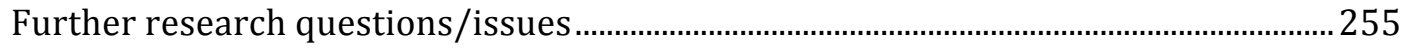

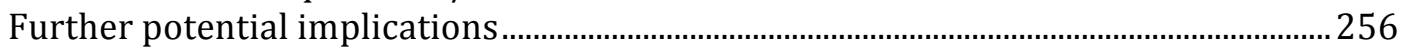

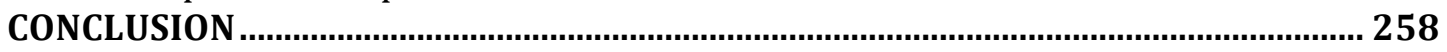

REFERENCES

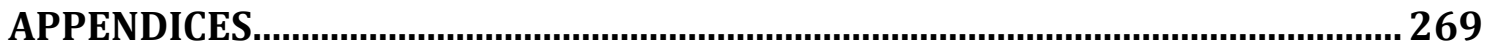

Appendix 1 - The contents of the personal development trainings for teachers........ 270

Appendix 2 - Semi-structured interview schedule ................................................................. 272

Appendix 2a - Semi-structured interview schedule - Slovenian version .........................273

Appendix 3 - An extract from the transcript of semi-structured interview (in English)

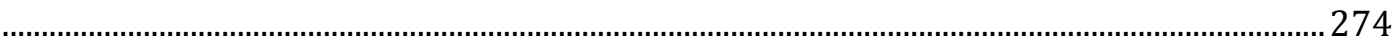

Appendix 4 - An extract from a coded semi-structured interview................................... 275

Appendix 5 - A sample of coded reading guide (semi-structured interview) ..............2276

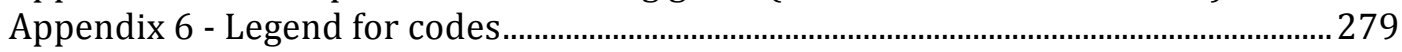

Appendix 7 - A sample of linguistic (and content) coding for Node 2 (Teachers' work)

Ap

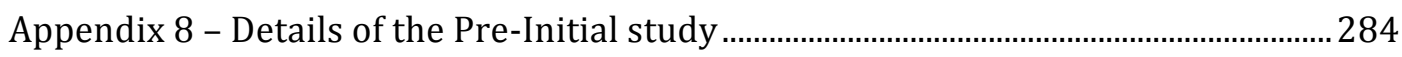

Appendix 9 - Illustrative examples from the Initial study ............................................... 285 


\section{LIST OF TABLES}

Table 1 Overall project in Slovenia

Table 2 On knowledge formation and knowledge practices: acting and understanding

(based on Booth, 2005).

Table 3 Data collection table

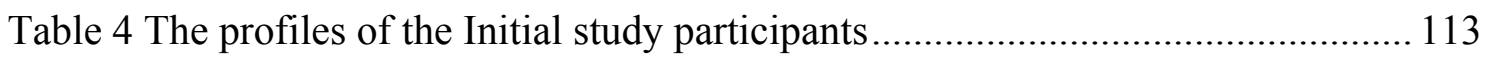

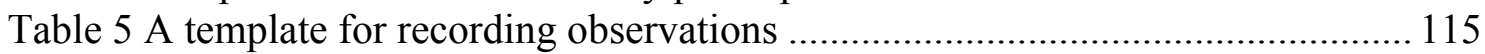

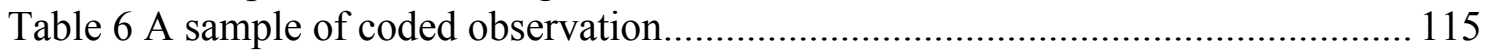

Table 7 Similarities and differences between the Good Work project interview protocol

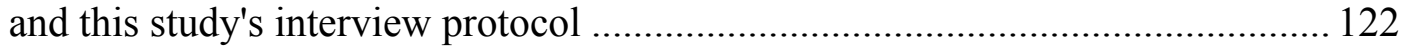

Table 8 A sample of the coded reflective diary (Initial study) ................................... 123

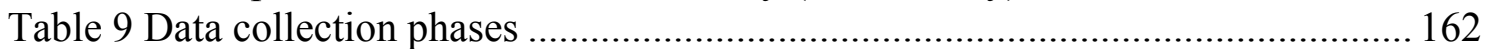

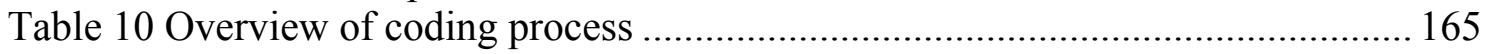

Table 11 Tabular (bilingual) representation of double coding (Teacher 5, semi-

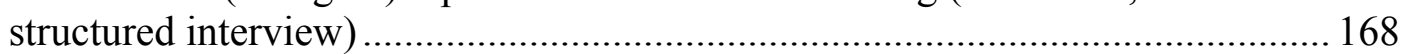

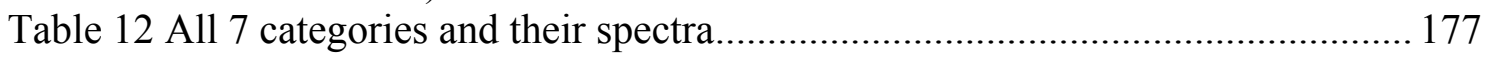

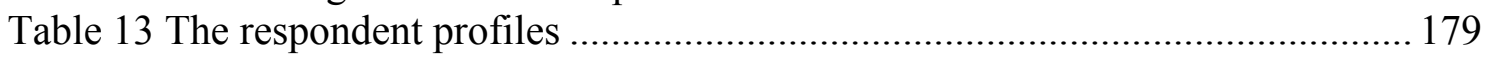

Table 14 Legend of abbreviations for data collection tools....................................... 179

Table 15 Legend for anonymising both groups of teachers........................................ 179

Table 16 A sample of linguistic coding of Node 1 (Teachers' identity) for both groups

Table 17 Evidence range of frequency of linguistic patterns - Node 1 (Teachers'

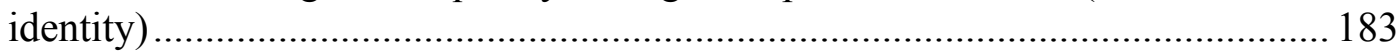

Table 18 Classification examples of statements according to neurological levels....... 189

Table 19 Numerical analysis of teachers' statements (based on Neurological levels

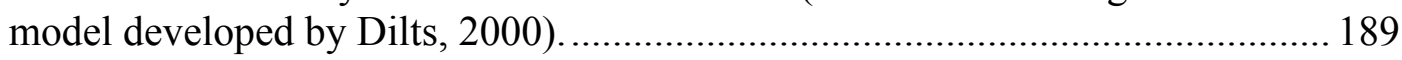

Table 20 Recorded statements connected to Neurological levels................................ 191

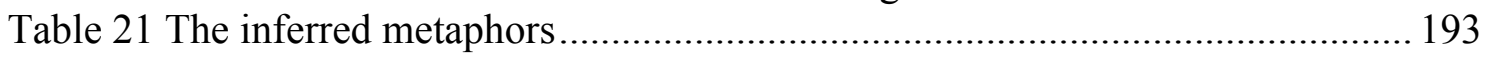

Table 22 Similarities and differences between the groups - Comparative content analysis - Node 1 (Teachers' identity)

Table 23 Evidence range of frequency of linguistic patterns - Node 2 (Teachers' work)

Table 24 Numerical analysis of Category 2 - Job satisfaction...................................2 203

Table 25 Numerical analysis of attribution styles for Category 2 - Job satisfaction .... 204

Table 26 Similarities and differences between the groups - Comparative content analysis - Node 2 (Teachers' work) .................................................................. 209

Table 27 Teachers' reactions in video stimulated interviews/feedback sessions.......... 210

Table 28 Similarities and differences between the groups - Comparative linguistic and content analysis - Node 1 (Teachers' identity) and Node 2 (Teachers' work) ...... 214

Table 29 Numerical analysis of teachers' statements (based on Neurological levels model developed by Dilts, 2000).....

\section{LIST OF FIGURES}

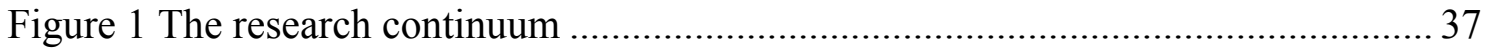

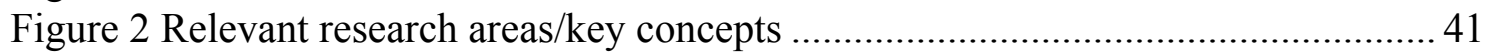




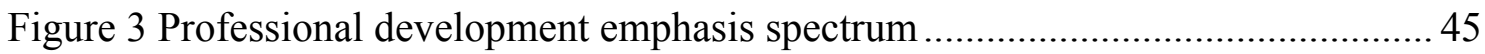

Figure 4 Dilts' neurological levels (drawing based on Dilts, 1990) ............................. 48

Figure 5 Methodological concept pairs adapted from Redman (1999) ......................... 91

Figure 6 The four core processes of Action Research (Kuhne \& Quigley, 1997)........ 149

Figure 7 The researcher's involvement/detachment spectrum .................................. 155

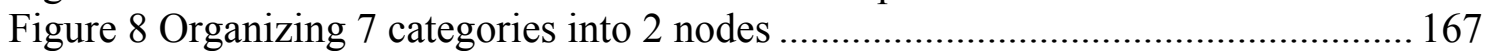

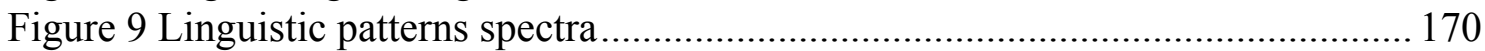

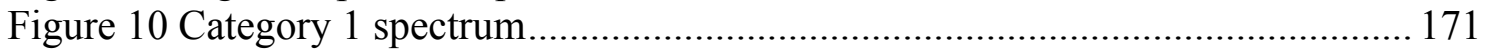

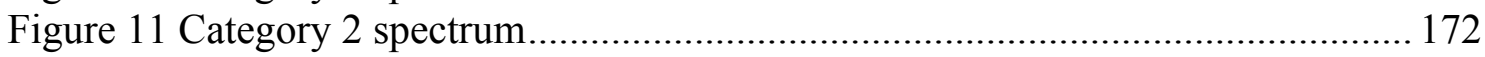

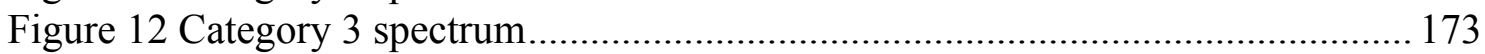

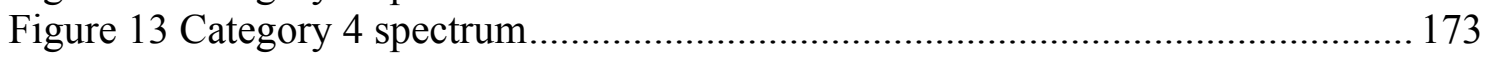

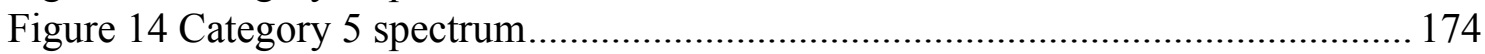

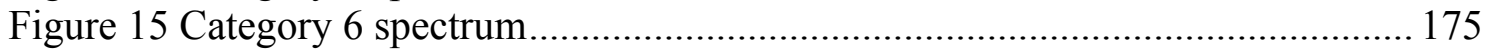

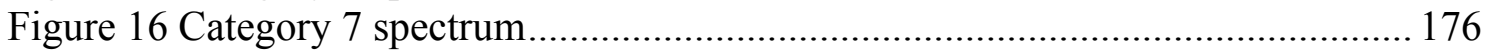

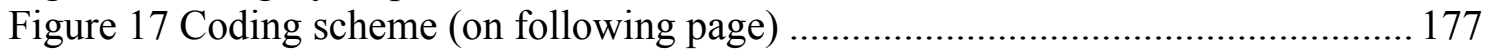




\section{Chapter 1: Introduction}

"A great work is never finished, it is just abandoned".

Picasso 


\begin{abstract}
The study investigates how teachers in one Slovenian primary school talk about their professional identity and work following participation in Neuro-linguistic Programming (NLP) based CPD in comparison with other teachers. NLP is usually defined as a behavioural model and a set of explicit techniques, developed by Bandler and Grinder (1976) by studying patterns created in interaction between brain, language and body. This study has defined NLP as an approach to developing professional practice through modelling.
\end{abstract}

The background to the study was the researcher's personal experience of being a teacher in the midst of the conflicts in ex-Yugoslavia in the 1990s and the main aim has been to explore the teachers' subjective experiences and representations of their professional identity and their work with a hope of developing the professional practice. The study examined comparatively two groups of teachers (14 Slovenian primary school teachers) looking for similarities and differences in the way they talk about their professional identity and their work.

The epistemological position of the study is interpretivism combined with several overarching frameworks including 'constructive' critical theory and a 'constructive' action research approach. Semi-structured interviews, non-participant structured observations, reflective diaries and video-stimulated interviews were used for data collection and the data was coded both deductively and inductively.

The study showed significant differences and some similarities between the two groups of teachers and their way of talking about professional identity and their work. The teachers who attended NLP-based CPD tended to see themselves as nurturers/carers and awakeners, underpinning their professional identity with values such as fun, 
curiosity and enjoyment. The teachers who did not attend NLP-based CPD emphasized the importance of being an instructor, underpinning it with values such as responsibility, equality and fairness. Evidence suggests that teachers who attended NLP-based CPD talk about themselves as more self-sustained and in more positive terms than other teachers. They also appear more prepared to maintain their professional identity irrespective of personal, social or political changes/critical events. There was also evidence of similarities in the two groups' perception of the teacher identity as being multifaceted and teaching being a calling. The study can have interesting implications for the design of continuing professional development (CPD) courses, where less focus on skills and knowledge and more focus on beliefs, values and identity might be more effective. 


\section{INTRODUCTION}

This thesis maps out a four-year long journey into teachers' subjective experiences and mental representations of their professional identity and their work. The complexity of the study evolves around a variety of levels ranging from personal and political to methodological ones. Acknowledging Martyn Hammersley's comment that "research is not a fixed and predictable enterprise; to a large extent, it is a process of discovery" (Hammersley, 2001) this four-year long process of discovery has been documented mostly in narrative form. Presenting the study as a 'story' may not have been the only option, but it was found to be the most appropriate in this context as the study evolved on the way. It was far from a project that was planned in details at the start and subsequently executed according to plan with the findings emerging as expected, but rather a complex interactive or transactional process that 'developed' and 'grew' on the way.

\section{FOCUS AND RATIONALE OF THE RESEARCH}

The reason for the research focus being on teachers and their work is, first of all, my personal experience of being a teacher in the midst of the ex-Yugoslavia conflicts in the early 1990s. It was then that I realised the far-reaching influence teachers had on their pupils, both as professionals and as human beings, and at the same time I found myself completely unprepared for being a teacher in such a critical (war) situation. The second reason was that the Slovenian government immediately after gaining independence in 1991 acknowledged the challenges and workloads that teachers were facing, and began 
to offer funding for personal development training for primary and secondary school teachers. I was involved in the design and delivery of ten such government financed personal development training modules in three primary and one secondary school in Slovenia in the early 90 s and continue to be involved at the time of writing this thesis (2009). A more detailed account of the background to the research project follows below.

\section{The research context background}

In order to provide an overview of my research project, I would like to present some background information about how the idea for this project was born. The study has been carried out in Slovenia, where, during the last seventeen years, I have been developing/designing and delivering continuing professional development (CPD) modules for teaching staff in a number of primary and secondary schools. A brief overview of socio-political context might be needed here. In 1991, i.e. eighteen years ago, Slovenia gained independence as the first republic that used to be part of Yugoslavia. The Yugoslav educational system was mostly based on a 'classic' Russian approach with a very strong emphasis on (teachers') subject-related knowledge and with a lesser (or nearly non-existing) focus on teachers' personal development. Even though Slovenia gained its independence relatively smoothly (compared to some other exrepublics of Yugoslavia) it still had its own ten-day long war that affected the population including the Slovenian teachers. The 'newly-born' Slovenian government was determined to increase effectiveness of education, jurisdiction and medicine. For example, teachers all over the country got the right to spend five days per academic year on their own further education either for professional or personal development. There was a wide selection of courses related to professional development on offer (mainly 
connected to teachers' pedagogy and subject-knowledge in a true Russian/Eastern European manner as mentioned above) and very few related to personal development (such were rarely offered in ex-Yugoslavia). After being successful at the tender, the Slovenian further education college I was working for was invited to design and deliver CPD modules focused on personal development (so-called 'soft skills'). There are a few reasons why we were successful. Firstly, at that time there were not many in-service teacher education providers that could provide personal development modules. Secondly even if they could, the Ministry decided to choose the providers that had certificates/diplomas/licences to deliver personal development based CPD. That narrowed the choice even further since at that time there were just a few teacher educators with formal or non-formal education in the field of any of the educational or psychological modalities for personal development. I happened to have been one of the few teacher educators with a licence that enabled me to deliver personal development modules called Neurolinguistic Programming (NLP - elaborated later). Thus the licence as an NLP Trainer acquired from the Society of NLP in the USA after a 3-year long education granted us an opportunity to design a project of which the study is a part. The original aim of that project was to investigate the effects of personal development modules for teachers on their attitude towards their work and the way they cope with it as well as to contribute to teachers' personal development, to help them cope with their workload, to improve their attitude towards work and consequently their effectiveness in the classrooms. The CPD modules were financed by the Slovenian Ministry of Education, Department for Adult Education, and were included in the annual catalogue of permanent and continuing education of pedagogical and andragogical workers in Slovenia, which meant that teachers, who attended the modules, got so-called "pedagogical points", i.e. credit relevant for promotion and future studies. This is 
something that has to be and is taken into account, since it shed some light on the motivation for the so-called self-selection issue discussed later in the dissertation.

The personal development modules were developed by my colleagues and me in a Further Education college in Slovenia that I work for, and were offered in a tender to the Ministry of Education and were approved as a 5-year long pilot project starting in 1998

The original overall project had three phases:

\begin{tabular}{|l|l|l|}
\hline Phase & Title & Time/Length \\
\hline Phase 1 & Personal development modules for teachers & 5 years \\
& & training hours) \\
\hline Phase 2 & Professional and personal development modules (PPD & 2 modules each of 2 days (40 training \\
& modules) for school management & hours) \\
\hline Phase 3 & Guidance and counselling for teachers and for school & For a year after the 5-year project has \\
& management & been completed \\
\hline
\end{tabular}

Table 1 Overall project in Slovenia

This study accounts for phase 1 of the overall project. It is planned that phases 2 and 3 will be explored further in future research projects in Slovenia.

\section{My personal account}

As mentioned earlier, my own personal experience of being a teacher in the midst of the conflicts in ex-Yugoslavia contributed significantly to my interest or rather passionate commitment to teachers' identity and work. The following personal account may help shed some light on and provide a deeper understanding of the choice of research topic. 
Providing such a personal account it is perhaps important to be aware that it is an account that has been created after the events and many authors have demonstrated how such accounts may contain 'fictive elements'. Clements (1999) refers to the 'fictive voice' in autobiographical research by which the teller, through critique, may 'arrive at an accurate recreation of one's professional past' (p. 21). White $(1973,1978)$ has demonstrated how history writing inevitably contains literary elements, because this is simply the way in which we can make sense of otherwise chaotic experiences and events. In "Metahistory" (1973) he demonstrated how the historical accounts of the French revolution by four leading historians contained four different literary plots, i.e. romance, tragedy, comedy and satire depending on the preferred tropes of the authors. The reader may keep this in mind while reading my account below.

On a more personal note, it feels almost like a betrayal to even attempt to write academically about an intimate and painful personal experience. How does one academically write about feeling lost, ashamed of not being able to help one's learners understand and rise beyond everyday political games, about losing one's country, home, friends, family members and, above all, about losing one's own self? One does not. One cannot. At least I cannot. I am sure that the colleagues around the world, who teach creative writing would know how to frame a narrative such as this one. I am also sure I should be able to use what I have learned from studying Anglo-American literature to make this account flow smoothly and elegantly. And yet I cannot. At least not yet. It seems too early, even though it is now 17 years since I fled from Serbia. That alone says a lot. I have tried to talk and present on the issue many times and every time I had to fight tears to be able to get to the end of the story. Whenever I hear others talk about the issue of teachers' identity I silently cry in the audience. What is it that is still so painful 17 years later? Taking a distance for a moment, I could say that one way of thinking 
about it is to say that it takes a long time to forge a professional identity, and a very short time to lose it, and that it seems to take much longer to regain it than to forge it. But am I now talking only about a professional identity? Or am I talking about a sense of self? Or both? I do not know. I do know though that these concepts are very clearly closely interwoven.

As Hargreaves (1993) says

- $\quad$ [T] eachers don't just have jobs. They have professional and personal lives as well. Although it seems trite to say this, many failed efforts in in-service training, teacher development and educational change more widely are precisely attributable to this neglect of the teacher as a person - to abstracting the teacher's skills from the teacher's self, the technical aspects of the teacher's work from the commitments embedded in the teacher's life. Understanding the teacher means understanding the person the teacher is ( $\mathrm{p}$. viii).

How can someone from the 'outside' understand a teacher caught up in the turmoil in ex-Yugoslavia in the early 1990s, where everyone was suddenly taking sides that had not existed just a few years or even months earlier? Suddenly childhood friends, colleagues and even family members found themselves on opposite sides. Almost overnight the country that used to be called Yugoslavia fell apart and the new republics started fighting each other in several 'civil' or 'independence' wars. As is often the case in such situations, you are forced to choose sides (though actually others would already choose sides for you depending on where you were born or your presumed religious faith). Having worked at the same time as a primary school teacher and a radio journalist and having received serious threats for not behaving according to the ruling 
political 'philosophy', I faced one of the most difficult decision of my life: to stay and compromise on basic values and beliefs about what constitutes good professional and ethical work or to leave and forget about any commitments to learners and to education in general. It was what psychiatry/psychotherapy would call a 'double-bind', when you are 'damned if you do, and damned if you don't'. The last straw was when my boyfriend was drafted for the Serbian army. We finally decided to leave, or rather we 'smuggled' ourselves out of the country feeling bad about leaving, feeling bad about not being able to stop the madness and feeling helpless.

We found ourselves arriving in Slovenia, the furthest we could get without any serious difficulties. The rest of the world was closed due to sanctions. How is it to be a Serbian disillusioned teacher in Slovenia where the Yugoslav/Serbian tanks had been on the streets recently against the local population? What I felt was actually a mixture of many strong feelings. I was obviously frightened and yet I felt liberated having managed to get out of Serbia. At the same time we had serious issues to deal with: First, getting a status that would allow us to work (that excluded a refugee status that would have provided us with basic food and shelter, but no more). Secondly, we needed to find someone, who would employ people from Serbia, who were basically considered 'outcasts' in the political situation at the time. On the one hand I wanted to work, to teach, to BE a teacher again and at the same time I felt ashamed of not 'being there' for the students I had left behind, and, on the other hand, I did not feel as a teacher any more. I started out selling newspapers on the street. I could not apply to teach in primary schools because I did not speak the language. After a while I regained a little bit of courage to try to find a teaching job in the private sector. This was not an easy task, when at the time I was considered the 'enemy', being a Serb in Slovenia, where Serbian tanks had recently been threatening the local population. Employers found it 
hard to defend employing a Serb both towards government officials (needing to apply for permission) and towards their other employees. Nevertheless, I managed to find teaching institutions that were willing to employ me as a part-time English teacher, and slowly I managed to demonstrate my skills and advance, while learning to speak the local language. As a consequence of my employment in the private educational sector, my own professional development moved in a new direction: into adult teaching and into personal and professional development and teacher-education. This again, combined with the personal experiences of having my identity as a teacher challenged, has led to a strong interest in exploring the topic of this dissertation.

How does one regain one's identity as a teacher? I believe I forged my teacher's identity while I was educated to be a teacher, however no initial teacher education programme, no continuing professional development (CPD) programme had prepared me for regaining it. How does one do that? In my case, it started happening in four ways, firstly through teaching and learning, through being reflective about what happened, through simply 'being', and surviving. This first strategy (through teaching and learning) could be called a modified 'learning by doing' approach, which became 'regaining a teacher's identity by teaching'. To teach was very demanding and yet it was healing at the same time. The second strategy (being reflective about what happened) opened up 'space' for exploring the 'reflective practitioner' concept (Schön, 1983) on a completely different level. The third and fourth strategies may seem to be one and the same and yet they are not: Surviving is not a guarantee for 'being', and 'being' is not a guarantee for surviving. I know many teachers in the war-affected areas of ex-Yugoslavia, who survived but stopped 'being' (being teachers or being their own selves). There are also teachers in the same region, who managed to continue being teachers, but have not really survived the value-clash they experienced. Once I started teaching again, it took 
some time before I could feel that I could make a difference for the learners, and when I rediscovered this, I found that I was now contributing not just my professional knowledge of the subject. It was something else too, it was my life story and who I have become due to experiencing it. It was about a 'personal touch', there was now an even greater commitment to helping learners become free-thinking, independent, satisfied, committed human beings. Five years after arriving in Slovenia, I was fortunate enough to be invited to design and deliver CPD programmes for teachers in Slovenia. Since then I design and deliver CPD programmes that touch on teachers' professional identity and that work on their personal development through reflective and experiential modules in order to prepare them for any critical situation, but hopefully not for a warrelated one.

As Van den Berg (2002) explains: ... [teacher identities] can be conceptualised as the result of an interaction between the personal experience of teachers and the social, cultural and institutional environment in which they function on a daily basis" (p. 579).

Krejsler (2005) has also pointed out that nowadays in order to uphold the authority of the profession it is no longer sufficient that the professional solely refers to his/her professional knowledge and the ability to apply that knowledge to specific and welldefined diagnoses or instrumental needs of the client. She/he is increasingly expected to be able to act as a fellow human being as well. One should furthermore not forget the pupils' perspective. This has been brought to the forefront by Rudduck and Flutter (2000) emphasising "how regimes and relationships shape their [the pupils'] sense of status as individual learners and as members of the community and, consequently, affect their sense of commitment to learning in school" (p. 76). In this study, however, the focus is on the teachers' perspective. 


\section{Placing the research question within the wider context of educational practice}

\section{Teacher education}

Perhaps it will be helpful to briefly explore or at least open a discussion of what formal (and informal) teacher education programmes can do for teachers in similar situations as presented above in the personal account section.

Nias (1989) wrote that people feel threatened when they face changes that influence their self-image and consequently their personal and professional identity and the changes one faces while being confronted with war definitely fall into that category. Hargreaves (1998) emphasises the link between teachers' emotion and the wider contexts:

"Teacher emotions are professionally affected by the micro-politics of their schools in terms of their principal's behaviour, their experiences of change, and so on... these micro-politics of the school are in turn embedded within major micro-political forces of leadership, change and political reforms that have equally significant consequences for the emotions of teaching and teacher development (pp.326-327).

These statements beg an important question: How could teacher education, be it initial teacher education or CPD, cater for teachers' professional identity creation (and its maintenance and development)? 
Hargreaves (1993) warns that it cannot be achieved through the neglect of the teacher as a person and through abstracting the teacher's skills from the teacher's self. From a personal development perspective the question about teachers' professional identity to be answered might not be only (as suggested by Beijaard et al., 2003): Who am I at this moment?, but perhaps even more important ones, e.g. in the initial teacher education phase: Who do I want to become? and in the CPD phase: Who am I becoming at this moment? And who have I become?

If one keeps in mind the close link between teaching and learning, how can we (both as teachers and teacher educators) ensure that by forging, maintaining and developing our professional identity we make space for our students (and future teachers) to develop not as self-contained or transcendental individuals, but social actors with a 'selfreferential capacity' (Barnett, 1997). Should we do it through the curriculum or through the way the curriculum is delivered or through more educational research into all the above-mentioned issues. Crème (1999) gives an example of how a short but significant first year course on 'Critical Reading: interdisciplinary study skills' at Sussex University became "one of those courses that can change people's lives". On the other hand, educational research projects such as the Good Work Project (Gardner et al., 2001) might shed additional light on the whole issue of ensuring creation, maintenance and development of professional identity in general. The Good Work Project is a largescale research study co-directed by Mihaly Csikszentmihalyi of the Claremont Graduate University, William Damon of Stanford University, and Howard Gardner of Harvard University. The ultimate goal of the project is "to identify and to promote ways in which individuals at the cutting-edge of their professions can carry out work that is ethical and socially responsible" (Good Work Project website). Gardner and his 
colleagues particularly emphasize 'compromised work' that happens across many professions and moves away from ethical and social responsible ways of carrying out one's work. The project has included research of different professions from genetics and journalism to education.

I have personally experienced how demanding it was to do my job ethically (as a teacher and as a journalist) during turbulent and unstable political conditions (in Serbia) and had to flee or risk enduring serious consequences. Many of my colleagues and family members who are teachers that stayed in Serbia informed me through personal correspondence that they had to, at least for some time, resort to carrying out 'compromised work' (personal correspondence).

There are probably no simple answers to the questions about what formal (and informal) teacher education programmes can do to prepare teachers for critical situations may they arise from personal, social, cultural or political contexts. However, as long as teachers and teacher educators around the world keep discussing, exploring as well as trying to address the issue through more concrete actions, there is hope that, while teaching, we can all "sense persons being created, learnings being initiated, future citizens rising to meet the challenge of unknown worlds" (Rogers, 1998, p.205). Rogers' recipe appears simpler than it is: "here are teachers, risking themselves, being themselves, trusting their students, adventuring into the existential unknown, taking the subjective leap" (ibid.). As mentioned above it might not be straightforward to answer how teacher education programmes can prepare teachers for critical situations however perhaps even a small-scale study on teachers' perception of their identity and their work might shed some light on which of the diverse range of possible contents of teacher education programmes might be useful for teachers. And above all, there might be a need to 
explore teachers' perception of their professional identity and their work as opposed to the level of their professional knowledge and skills, which are usually the topics of teacher education programmes. It seems worth exploring whether teachers' perception of their professional identity and their work have an impact on the process of "persons being created, learnings being initiated, future citizens rising to meet the challenge of unknown worlds" (ibid.).

\section{THE DEVELOPMENT OF THE RESEARCH QUESTION AND NARROWING THE RESEARCH CONTEXT}

Even though my personal account and wider research context on teacher education might have explained why the focus of the research/study is on teachers' professional identity and their work, it is still important to remember that the overall project in Slovenia was commissioned by the Ministry of Education which set its own aims and focus.

Keeping in mind that the aim of the overall project as well as the initial research idea was "an investigation of the effects of personal growth modules for teachers on their attitude towards their work and the way they cope with it" (p.3) it may be useful to provide an account of the journey from the initial to the final wording of the research question. The first rewording and rephrasing came from exploration of the core issues related to my research proposal such as 'personal growth' vs. 'personal development' and 'teachers' professionalism'. As a consequence of that exploration, the research question changed focus from a 'cause-effect' thinking frame presupposing effects of the personal development trainings to a more concrete account of teachers' subjective experiences and their subjective views on the personal development modules and the 
way they see their work: How do teachers perceive the relationship between personal development modules and the way they see their work?

During the initial literature search, continued reflection process, helpful supervision and the collected data from the Initial study another key issue that was obviously present, but not verbalised, was "unwrapped". The issue of teachers' identity appeared based on the preliminary analysis of the collected data from the Initial study and the study's rationale. This led to the words "and professional identity" being added to the research question and the new formulation: How do teachers perceive the relationship between personal development trainings and the way they see their work and their professional identity?

The exploration of potential research methodologies and methods led to revisiting my supervisor's feedback to one of my early progress reports which read: “...one other way of thinking of the study is that it may be something to do with the nature of THIS particular training..." (Craft's upper case). Having examined the content of all ten modules (Appendix 1) out of which two are entirely based on Neuro-linguistic programming (a description of Neuro-linguistic Programming (NLP) is provided below), three are partly based on NLP and five are not NLP related, I have realized that the NLP elements are a distinctive feature of this programme in comparison with other CPD programmes in Slovenia. Thus the original focus of the study has been changed from covering all ten modules to covering only NLP-related modules. NLP here stands for Neuro-linguistic Programming, a behavioural model, and set of explicit skills and techniques, developed by Richard Bandler and John Grinder (1976). NLP studies the patterns or the "programming" created by the interaction between the brain, language and the body (Dilts, 2000). With the new distinctive element of NLP being added to the 
question, the research refocused on "how do teachers perceive the relationship between NLP-based personal development modules and the way they see their work and their professional identity?"

As it was planned in the early stages of the development of the study to have a comparison group, that is, to include also the teachers who did not attend the personal development modules, the issue of the role of the comparison group emerged. The formulation of the question as it was, with its focus on the relationship between NLP based personal development modules and the way teachers see their work and their professional identity, left no space for any significant contribution from the group of teachers who did not attend NLP-based CPD. Thus, after discussion with my supervisor about how to achieve relevant contributions from the comparison group and how to contextualise the study it has been attempted to remove any assumptions of a causal relationship. The actual data and preliminary analysis of the Initial study informed the final formulation of the research question:

"How do teachers in one Slovenian primary school talk about their professional identity and work following participation in NLP-based CPD in comparison with other teachers?"

There are important reasons for keeping 'in one Slovenian primary school' in the research question. One is that the study is taking place in one primary school within a certain cultural, social and linguistic context and any findings can only be taken to apply within that particular context. A reason 'within' this is that Slovenia went through certain historical experiences taking part (albeit briefly and reluctantly) in the conflicts of ex-Yugoslavia (see e.g. Cohen and Dragovic-Soso, 2007), and the teachers in 
Slovenia may 'talk' differently from their colleagues in the other countries that have not recently experienced political or military turmoil.

After the main research question had been formulated, the exploration of potential subquestions commenced. The reviewed literature as well as the contents of the NLP-based modules pointed in different directions for the formulation of the sub-questions in the realm of either different definitions of teachers' identity or different aspects of and attitudes towards their work. However, the aim of the study was to explore the way teachers talk about their professional identity and their work without necessarily presupposing any answers and the disadvantage of having sub-questions would be to narrow even further the research focus.

Having realised that the choice of data-collection methods and data analysis frameworks will lead to inevitable data-reduction at this point, the deliberate choice of not adding any additional sub-questions was made in order to allow for as divergent data-collection as possible and for as few limiting frameworks as possible.

The development of the research question has taken many different paths, and at the same time, the scope of the research has become narrower due to the reformulation of the question. However, even though this might have consequences for generalisability, it may have also contributed to a more focussed study of the talk, i.e. a more linguistic analysis of teachers' thinking patterns, and thus might have broadened the teachers' opportunities to voice their own thoughts and enriched the findings. The consequence of the gradual refocusing of the research question was a broad, ever-changing and extensive literature search. 


\section{THE AIMS OF THE RESEARCH}

Having provided the above account of the development of the research question it is worth stating that the overall aim is to describe and explore teachers' subjective experiences and mental representations of their professional identity and their work with the hope to develop the professional practice further.

Since one of the definitions of Neuro-linguistic Programming (NLP) encompasses NLP as the study of the structure of subjective experience (Bandler and Grinder, 1975), it reinforces one of the aims of the study, which is to lend a voice to the teachers and thus explore with them their subjective experiences of having a teachers' identity and carrying out a teachers' work.

The broad epistemological perspective of the study is interpretivist, a point that will be elaborated further later on. The study is not aiming to provide 'accurate' accounts of the teachers' identities and their work, but rather of the teachers' interpretation of their professional identity and their work. The study does not either aim to develop a theory about the 'best' way of contributing to the development and maintaining of teachers' professional identity and their attitude towards work. Rather, it aims to put 'in place' a few of the pieces of the big 'puzzle' relating to the role of CPD in teachers' personal and professional development. My belief both as a teacher and as a teacher-educator is that an understanding of the role of CPD can be best achieved by listening to the voices of those who do the job on a daily basis - the teachers themselves. 


\section{THE RESEARCHER'S VOICE AND THE PARALLEL REFLECTION ON THE TEACHERS' AND THE RESEARCHER'S IDENTITY}

Continuing on the same note of lending a voice to the teachers it is important to note here that there is also the researcher's voice to be taken into account. It is important to acknowledge the issues relating to my own values and beliefs, my own passionate interest in the topic and my own personal background (as described earlier). That very same background speaks perhaps louder than anything else and I would like to be as transparent about this as possible. Thus, I openly declare that I am not " an objective, authoritative, politically neutral observer, standing outside and above the text" as Bruner (1993, p.1) would put it, I am rather "historically positioned and locally situated as an all-too-human observer of the human condition" (ibid.). This is in accordance with the overall interpretivist epistemological framework of the study. Again, a more detailed account of my epistemological and ontological position will follow later.

Even though I have taken all possible steps to provide an interpretation of the data that is as close to the teachers' subjective experience as possible I also must acknowledge my own position, i.e. my own dual role (as a teacher educator and as a researcher) in this context. The ethical issues connected to this situation are discussed in more detail in Chapter 3. However, the significance of this dual role needs to be noted and addressed early on as well as during the data analysis and in the final stage of discussion of findings and overall reflection on the study.

Finally, following on from the brief description of my background, there is a similarity between my own teacher's identity and the researched teachers' identity. The majority of the teachers involved in the study have experienced what it means to be a teacher 
during a war situation thus sharing similar political experiences in the 1990s in exYugoslavia (though they were not refugees). While carrying out the research I kept a researcher's journal, as I had asked the teachers to do. And the research itself was a journey of personal and professional development for me as a researcher and as a teacher and has contributed to a strengthening of my own identity as a teacher.

\section{OVERARCHING FRAMEWORKS}

It may be helpful already now to briefly locate the present study in terms of the overarching frameworks applied.

\section{Epistemological and ontological framework}

\section{Interpretivism}

The broad epistemological perspective taken in this research project is interpretivism, also known by the label interactionism and symbolic interactionism (Blumer, 1969; Hammersley, 1989). Burgess, Sieminski and Arthur (2006) summarise the interpretivist position in the following way:

"[it is] a view which argues that there are no absolutes, but that all phenomena can be studied and interpreted in different ways, mainly because people differ, and realities are not abstract objects but dependent on the inter-subjectivity between people. The key element of interpretivism is that it is defined or constituted in terms of human beings attributing meaning to, or interpreting phenomena under investigation. The role of communication, symbols and 
language is fundamental to social life from an interpretivist's point of view" (p. $55)$.

This is the basic epistemological framework for this study. It is focusing on how teachers construct their identity by examining how they talk about it and about their work. The ontological position is perhaps a little harder to define, though it could still be said to be in alignment with interpretivism, which has its roots in pragmatism and thus remains fairly 'agnostic' with regards to the nature of 'reality'. These issues will be discussed more in-depth later on in Chapter 3.

\section{Conceptual and theoretical framework}

\section{Constructive critical theory}

As mentioned above the research seems to have some 'political' elements and thus critical theory could appear to be a 'logical' choice as an overarching conceptual framework for the study. However, even though it may appear to be an obvious choice, it was not one that was made early on in the study. Quite the contrary, the idea only appeared after the Initial study. The reasons for not adopting critical theory as a conceptual framework early on were the following:

a) I was personally very sceptical of critical theory, and

b) the study does not entirely 'fit' the main characteristics of a critical theory approach. 
The first reason could best be summarized in the following way. If one takes into account that the present study is carried out as a consequence of a critical situation that could be seen as caused, partly at least, by Marxist ideology (after all it was a combination of Marxism and pan-nationalism that had underpinned the repressive regime in Yugoslavia), it is perhaps understandable that the researcher is somewhat sceptical of a research tradition, that has roots in, and still has many proponents of Marxism within it. To this could be added that it never appealed to me to conduct research starting out with a predefined view of the world with political undertones.

As far as the second reason is concerned it is worth noting that there are both temporal and destructive elements in critical theory that do not fit the study very well. The typical focus of critical theory approach is on the past and what is 'wrong' as described by Horkheimer (1997), whereas the approach I am suggesting in this study is more present and future oriented and thus more 'constructive' in the way that it focuses on what can be 'constructed' in the future based on a description of the present state. In other words it advocates an 'outcome' focus rather than a 'problem' focus. I have later found that Habermas (1978) has more of such a positive outlook seeking to change the world for the better.

I have chosen to emphasise the constructive perspective by labelling the chosen approach 'constructive critical theory', which differs from conventional critical theory in its positive focus as well as in the temporal element being present and future oriented rather than past-oriented. The distinctive elements of a constructive critical theory are elaborated further in Chapter 4. 


\section{$\underline{\text { Social Constructivism }}$}

Since one of the main topics of the study is teachers' identity, it was necessary to adopt a certain theoretical framework in connection to the notion of identity. Again, the further description and discussion of the theoretical framework in connection to identity is presented in Chapter 2 .

I have chosen to adopt a social constructivist approach to the notion of identity starting from the idea that identity is not a static entity but rather an ever-evolving, fluid and ever-changing entity that is continually shaped and reshaped through interactions with others. Such an approach is also quite clearly in alignment with an interpretivist epistemological position as outlined above. I am purposefully calling it social constructivism rather than social constructionism, because I prefer the social constructivist perspective on learning theory, seeing identity as a learned phenomenon in interaction with the environment. Social constructionism involves a scepticism about or refutation of the existence of the 'real world' (see e.g. the groundbreaking work by Berger and Luckmann (1966). Since I do not fully identify with a social constructionist perspective, I prefer to distinguish between accepting that identity (and many other social phenomena) is socially constructed, and accepting that 'reality' is socially constructed. For the purposes of setting clear boundaries related to this study, the focus is only on the notion of identity being socially constructed thus avoiding a lengthy discussion about the existence of the 'real world' (these issues are discussed in more detail in Chapter 2). 


\section{Methodological framework}

\section{Constructive action research}

Overall, the study is rooted in an interpretivist paradigm, as discussed above, where epistemological relativism is embraced and the focus is on examining communication and language and meaning-making. However, it became clear after the Initial study that a reflection-oriented approach was useful, even though it was not originally planned to be there. Even though reflection is only one of the four core processes of the actionresearch cycle, the idea of employing an action-research approach appeared. It has been discussed with my supervisor and presented at the EdD Residential school, where the first feedback and challenges emerged. Dr. Haggarty raised the point that there was not causality built into the study in the sense that certain actions will bring certain effects (Haggarty, personal communication at EdD Residential school). It is a matter of debate then, whether the study can be considered 'action research'.

As Kemmis and McTaggart (1984) summarize action research, it can be thought of as an open, ongoing process based on putting new ideas to the test. It involves

"trying new ideas in practice as a means of improvement and as a means of increasing knowledge about the curriculum, teaching, and learning. The result is improvement in what happens in the classroom and school, and a better articulation and justification of the educational rationale for what goes on. Action research provides a way of working which links theory and practice into the one whole: ideas-in-action” (p.5) 
Going with such a definition, the study is not an action-research study. However, if we think of action research in the way Carr and Kemmis (1986) define it as "simply a form of self-reflective enquiry undertaken by participants in social situations in order to improve the rationality and justice of their own practices, their understanding of these practices, and the situations in which the practices are carried out" (cited in Hammersley, 2004, p.162), then the study could be considered an action research study. Whether it should be considered action research thus depends on how narrowly one defines action research.

Also, similar to the overarching conceptual framework of critical theory, an action research approach often appears to have a built-in 'what is wrong' starting point. Again, in my study I would prefer to adopt a more 'constructive' perspective on actionresearch, choosing to start from a 'what is the present state' frame and move towards an exploration of a potential 'desired state'. Thus I would like to suggest another label for the study, namely that of 'constructive action research'. It may be argued that most action research in practice is constructive, but I would like to emphasise that this is central to the study.

On the other hand, the analysis presented in Chapter 4 locates the study within action research cycles that are 'larger' than the study itself. The study has 'entered' an action research cycle in the middle rather than at the beginning and I have also personally gone through action research cycles that started long before the study commenced. Thus, the study does not necessarily follow the traditional action research format, but rather could be said to involve several levels of 'action research cycles', one in which the study is only a part, one complete cycle that forms the study, and an individual version of it for the researcher. 
Hammersley (2004) concludes in his examination of action research that "the core idea of action research is that there should be an intimate relationship between inquiry and practical or political activities - such that the focus of inquiry arises out of, and its results feed back into, the activity concerned “ (p.165). Defined in this way there is certainly a match with the present study, since it started from the political context, continued with a practical activity of exploring teachers' professional identity and will hopefully feed back to the teachers, school and the policy makers findings about how teachers trained in personal development trainings talk about their professional identity as compared to those, who were not trained in that way. Thus another ambitious offer of a 'constructive action research' approach has been attempted.

A summary of the introductory chapter is presented below both in the form of a verbal summary and a graphical illustration of the research process. 


\section{THE RESEARCH PROFILE}

Research Question: How do teachers in one Slovenian primary school talk about their professional identity and work following participation in NLPbased CPD in comparison with other teachers?

\section{Overarching Frameworks:}

Epistemological: Interpretivism;

Conceptual and Theoretical:

Constructive critical theory approach (CCT), Identity as a Social construct (Social Constructivism);

Methodological: Constructive action research (CAR)

Methodology/Methods: Comparative Qualitative study. Data-collection methods: Observations, semi-structured interviews, reflective diaries and video- stimulated follow-up interviews with feedback sessions. Sample: two groups of seven teachers i.e. 14 primary school teachers. Data corpus: 14 observations, 14 semi-structured interviews, 54 reflective diaries, 14 video-stimulated follow-up interviews

\section{Data Analysis Frameworks: Two} nodes: Teachers' professional identity (TI) and Teachers' work (TW). Seven categories and their spectra, a mixture of inductive and deductive coding

\section{Discussion of findings frameworks:}

Three frameworks:
a) The research question
b) Substantial literature
c) Overarching frameworks 


\section{The Research Continuum}

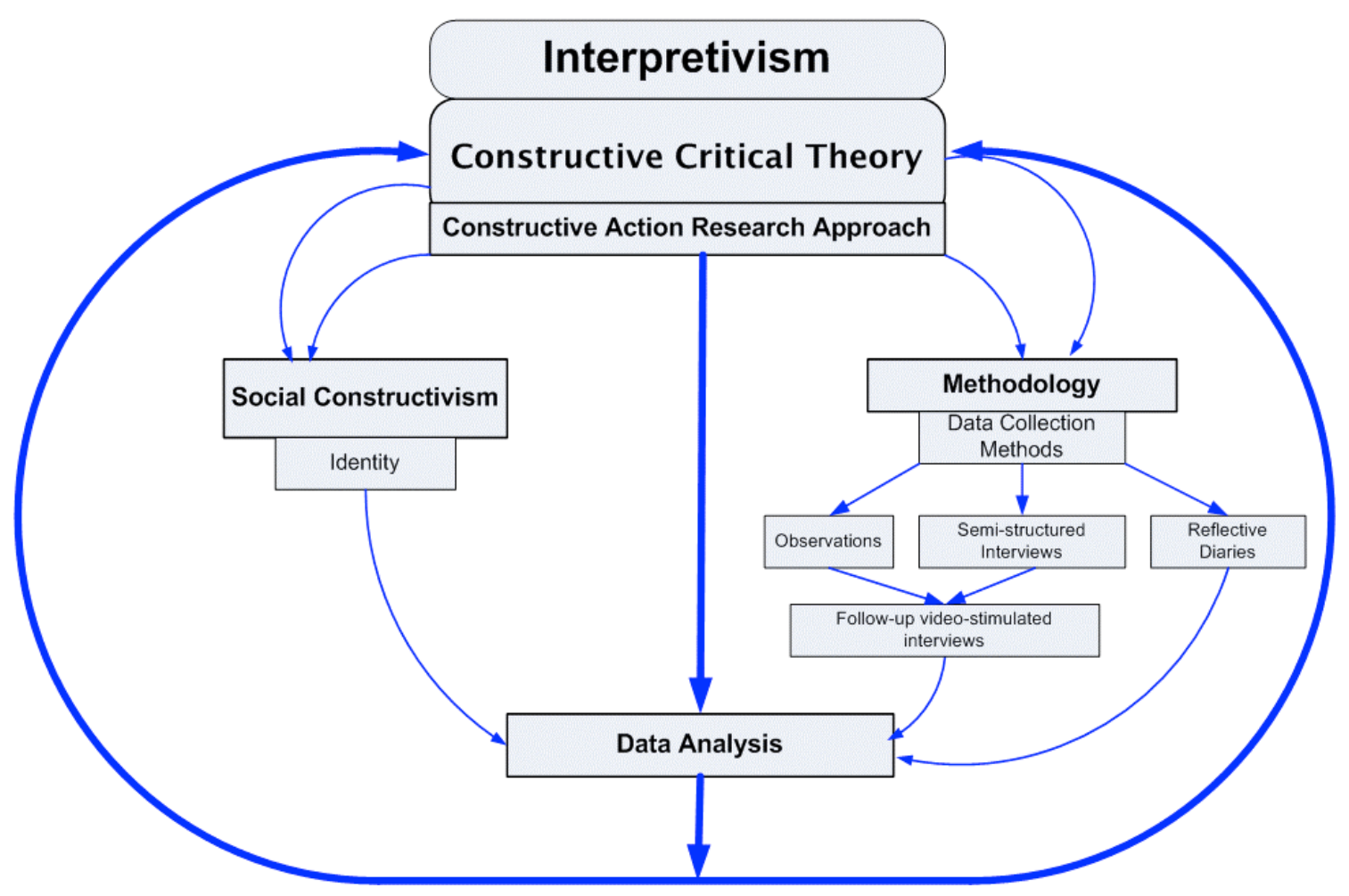

Figure 1 The research continuum

\section{THE STRUCTURE OF THE DISSERTATION}

The following is an overview of the structure of the dissertation with brief indications of the content in each of the following chapters.

In Chapter 1 the introductory story about the wider research context, the research focus and rationale, the development of the research question as well as the overarching epistemological, conceptual, theoretical and methodological frameworks and the research continuum are presented. 
Chapter 2 continues the narrative of different accounts of the relevant literature and research in the fields of continuing professional development (CPD), personal development, Neuro-linguistic programming (NLP) and teachers' identity.

Chapter 3 argues for the chosen methodology and data-collection methods through telling a story of different potential methodological 'tracks' that the study could have employed, and giving the reasons and justifications why it did not. This chapter also presents the journey of the Initial study and how it informed the main study.

Chapter 4 describes in detail how the overarching theoretical/conceptual frameworks were developed and renamed for the purposes of the study.

Chapter 5 introduces the story behind the data analysis including the coding scheme with its inductive and deductive coding, creating a coded reading guide, developing themes/categories, the spectra of subthemes/subcategories and two main nodes. This chapter also presents data both in a numerical and illustrative way.

Chapter 6 discusses the analysed data presented in the form of two main nodes through three different analytical frameworks i.e. the research question itself, substantial literature and overarching frameworks.

Chapter 7 looks back and ahead at the same time by returning to the research question itself as well as offering the researcher's reflections on the whole journey and some ideas for future research and implications for educational practice. 


\section{Chapter 2: Literature review}




\section{INTRODUCTION}

This chapter presents a literature review focussing on the study's key concepts encompassing continuing professional development (CPD), personal development, Neuro-linguistic programming (NLP) and teachers' professional identity. The chapter discusses the above-mentioned topics mainly from the perspective of the research study focus.

\section{Identifying the relevant research areas/key concepts}

This section explains the process of expanding the two key concepts in the research question into the two clusters and thus sets the structure for the chapter. During the phase of the development of the research question the process of identifying key concepts and consequently key research areas commenced. The final wording of the research question "How do teachers in one Slovenian primary school talk about their professional identity and work following participation in NLP-based CPD in comparison with other teachers?" introduced at first two key concepts namely Neurolinguistic programming and teachers' professional identity. However, once the work on a more in-depth review had started, it became clear that the two concepts are multilayered, and that their multifaceted nature encompasses further concepts within the two concepts leading eventually to two clusters of concepts. By 'zooming in and out' (to use a photographic/cinematographic metaphor) on and around the two previously mentioned concepts several important concepts came into focus. The process of 'zooming out' of Neuro-linguistic programming brought in an overarching concept of 'continuing professional development' (CPD) with several sub-elements such as the concept of 
'personal development'. 'Zooming in' within Neuro-linguistic programming, on the other hand, narrowed the focus to 'linguistic patterns' (a core part of NLP, which will be accounted for in more detail later in the chapter). Zooming out' of teachers' professional identity has redirected the focus from teachers' identity to the notion of 'identity' in general and 'professional identity' in particular, whereas 'zooming in' on teachers' identity revealed the role of values and commitments as part of teachers' work, which is also mentioned in the research question. Thus the key concepts and key research areas in connection to the study could be placed in two clusters as presented below:

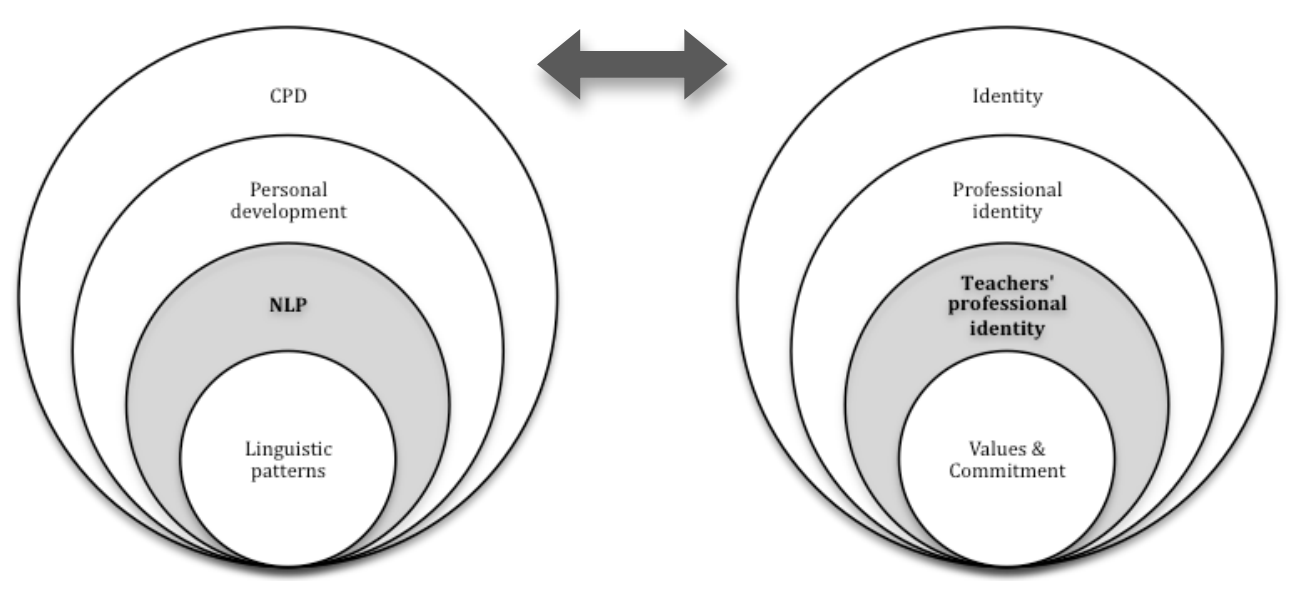

Figure 2 Relevant research areas/key concepts

\section{Approach and aim of the review in connection to the research focus}

This review provides an overview and analysis of selected literature in several distinct theoretical and research fields, those of 'Continuing Professional Development' (CPD), 'Personal Development', and 'Neuro-linguistic programming' (NLP) on the one hand, and 'teachers' professional identity' and 'identity related issues' on the other. No major study has explored the ways in which NLP-trained teachers talk about their work and 
their professional identity. One of the aims of the study is to contribute to bridging that gap.

It should be noted that although the study was carried out in Slovenia, none of the reviewed literature is drawn from Slovenian sources. This is due, first of all, to a lack of Slovenian research in the fields of NLP, CPD and teachers' professional identity, and secondly, to the researcher's personal experience over the last decade of moving around Europe and educating teachers from a wide range of other countries (e.g. Serbia, France, Brazil, Germany, Taiwan) and in that way getting the personal realisation that teachers' issues are very similar irrespective of cultural or national borders. This is not to say that there are no (e.g. cultural) particularities about Slovenian teacher education, but rather that non-Slovenian literature is highly relevant for the topic under investigation, though obviously it would have been useful to bring in other research from the same region if this had been possible. At the same time, critical awareness of potential cultural differences between the reviewed literature and the Slovenian context is maintained throughout the study and the boundary-setting 'in one Slovenian primary school' is included in the research question.

The review also provides a critical commentary on the above mentioned research fields through the perspective of the research study focus, although it obviously cannot provide an exhaustive account of all existing literature on the topics. 


\section{CONTINUING PROFESSIONAL DEVELOPMENT AND PERSONAL DEVELOPMENT}

Friedman and Philips (2004) claim that although Continuing Professional Development (CPD) is widely promoted through the policies and programmes of UK professional associations, it is still "an ambiguous concept" (p.361). One may reasonably wonder whether the real issue is ambiguity of the concept of CPD or the challenge of making an attempt to reach an agreed definition of CPD. Trying to define what continuing professional development (CPD) is, might prove to be a more demanding task than it looks at first sight. As Craft (2000) reminds us, and my personal experience confirms, professional development is a continuing "many-pathed process". Friedman and Philips (2004) conducted a study into professionals' thoughts on the definition and value of CPD, which included interviews with 30 professionals as well as focus groups with a further 40 professionals. Friedman and Philips found that there was a gap between how professionals and their respective professional associations view CPD. According to their findings, professionals have a "limited" (Friedman and Philips, 2004, p.361) view of CPD - seeing it as training, a means of keeping up-to-date, or a way to build a career. It is worth noting that the teachers involved in the study, who enrolled in the CPD programme, knew that the programme had been accredited by the Slovenian Ministry of Education and thus was 'credit-bearing' and beneficial for their career progress. On the other hand, still according to Friedman and Philips, professional associations claim that CPD is part of lifelong learning, a means of gaining career security and a means of personal development. Apparently the idea of CPD as life-long learning or even, as has more recently been suggested, life-wide learning (suggesting learning as an essential aspect of our whole life) (Reeve et al., 2002; Alheit, 1995) is what professional associations advocate. 
Since this study suggested that there is a discrepancy between professionals' and professional associations' views on CPD, it may be worth exploring other authors' views. In order to approximate a definition and clarify the benefits of CPD one may reasonably start by unwrapping the purposes of professional development. Bolam (1986, cited in Craft, 2000) stresses five purposes:

whole staff, team, department or faculty performance an individual teacher's practice an individual teacher's role or career an individual teacher's professional knowledge an individual teacher's personal education or growth (Craft, 2000, p.17)

The last listed purpose addresses personal education or growth, and thus introduces personal development as an important element of professional development. Many authors would certainly see personal development as being a sub-set of continuing professional development. Craft (2000) argues that "time for such personal education is a good way for someone to recharge their batteries and it can be argued that a teacher who is excited and motivated by the experience of their own learning is likely to be in a strong position to communicate the excitement of learning to pupils" (p.19).

However, even though the value of personal education or growth has been recognized at least by some authors, there is nevertheless a tendency in the literature on continuing professional development to emphasize the teachers' skills, knowledge and education as crucial fields for improvement through professional development (see e.g. Joyce and Showers, 1996). It is worth noting that there are different approaches to professional development, some of which focus on the development of professional skills, whereas 
others take into account beliefs, values and commitment, which will be discussed later. The variety of approaches can be viewed as spread out on a spectrum as shown in Figure 1 below, where most authors are located at the skills/knowledge end of the spectrum.

Figure 3 Professional development emphasis spectrum

To zoom further out from 'Personal Development' we reach the concept of 'Continuing Professional Development' (CPD), a topic that Craft has explored extensively in her book "Continuing Professional Development" (2000). There are many reasons for undertaking professional development, such as:

- to improve the job performance skills of the whole staff or groups of staff

- to improve the job performance skills of an individual teacher

- to extend the experience of an individual teacher for career development or promotion purposes

- to develop professional knowledge and understanding of an individual teacher

- $\quad$ to extend the personal or general education of an individual

- to make staff feel valued

- to promote job satisfaction

- $\quad$ to develop an enhanced view of the job

- $\quad$ to enable teachers to anticipate and prepare for change

- to clarify the whole school or department's policy (Craft, 2000, p.10) 
This list, in a way, opens it out again as it includes personal development, however the choice of 'education' rather than 'personal development' or 'professional identity' suggests these may be developed only indirectly. Also skills, knowledge and education are again emphasized. One may raise a question about whether professional development activities are designed to help people develop and change, and if that is the case whether the development and change do and/or should go beyond skills, knowledge and education. Having said that, it might be worth noting that recent research (see Day, 2000) has supported the idea of a synthesis of personal and professional development and lifelong learning. Keeping in mind the rationale of this study, the political change and critical events (a war situation) are the threads both in the researcher's personal experience and the researched teachers' experience. The Slovenian government's aim to offer personal development trainings as part of professional development modules for teachers, who have just gone through the political and potentially personal changes, shows some resemblance with the above mentioned support for the idea of a synthesis of personal and professional development.

Since the study, that was carried out in Slovenia, is focused on NLP-based CPD, I have decided to use one of the models from Neuro-linguistic programming (an analytical discussion of NLP presented later) as an analytical framework to examine the nature and level of focus of aspects of the presented literature. The chosen model is named 'neurological levels' and it has been developed by Dilts (2000) on the basis of Bateson's (1972/2000) hierarchies of classification. Bateson pointed out that in the processes of learning and change (which, according to Day (1999), can be considered key characteristics of personal and professional development), there are natural hierarchies of classification. He refers to them as "logical categories of learning and 
communication" (1972, p.279). Dilts (2000) modified Bateson's categories of learning and changed them into six 'neurological levels'.

1. environment (this level involves the specific external conditions in which our behaviours and interactions take place),

2. behaviour (this level refers to the behavioural activities or results that occur within the environment),

3. capabilities/skills/strategies (this level involves how we are perceiving and directing our actions),

4. beliefs, values (this level provides the reinforcement, motivation and permission that supports or denies capabilities),

5. identity (this level consolidates whole system of beliefs and values into a sense of self) and

6. mission (this level relates to the fact that we are a part of a larger system that reaches beyond ourselves as individuals to our family, community, profession and global systems) (Dilts, 2000) 


\section{Neurological Levels}

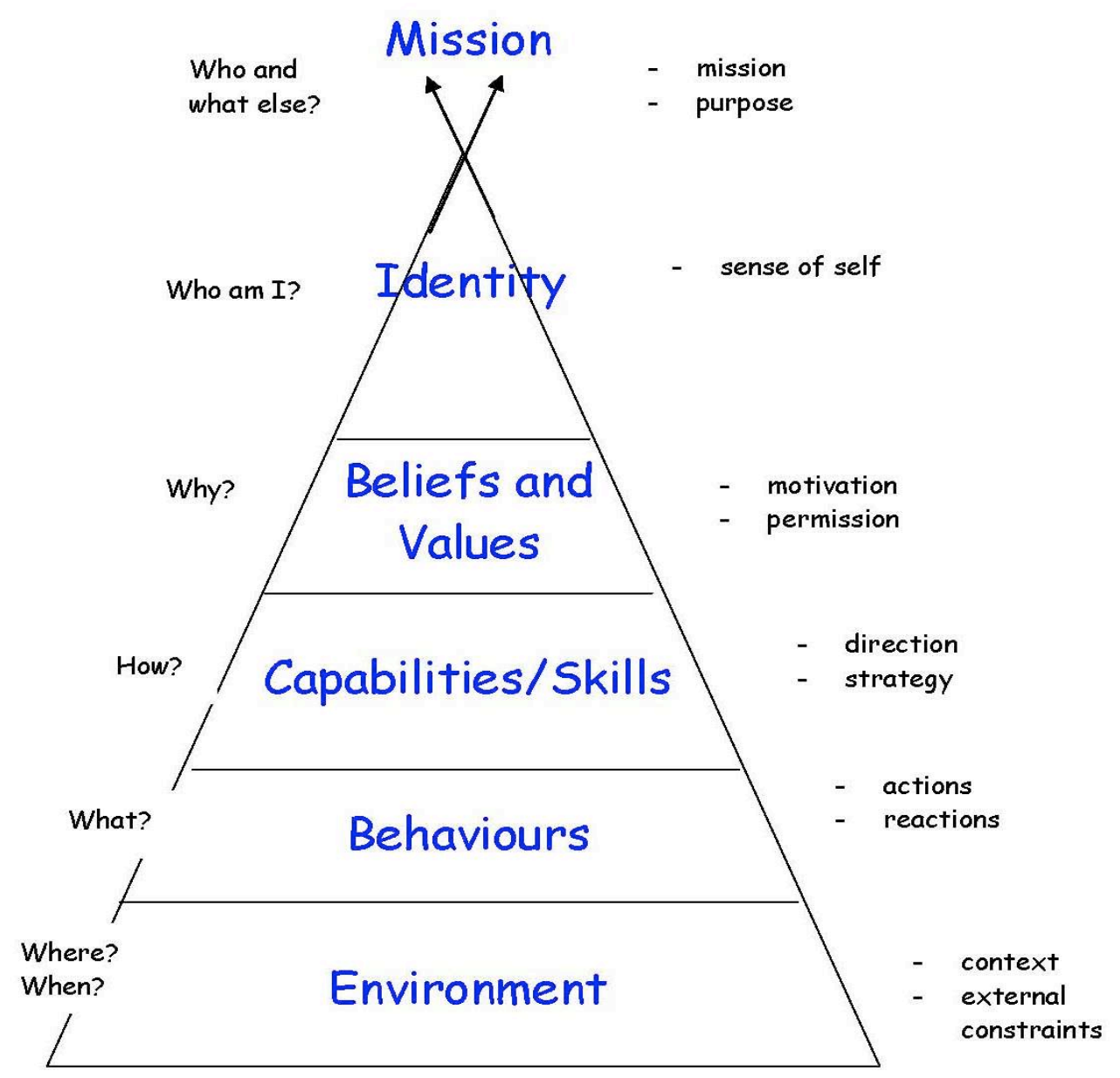

Figure 4 Dilts' neurological levels (drawing based on Dilts, 1990)

Both Bateson (1972/2000) and Dilts (2000) advocate so-called "alignment" of all levels in order to achieve personal congruence and balance that may lead to, for example, an enjoyable and exciting process of learning. Having mentioned earlier that in the majority of the literature on CPD there is a tendency to emphasize the teachers' skills, knowledge and education (see Figure 3), I have pointed out that other 'neurological levels' have been less represented in the CPD literature. It would be fair to say, though, 
that whereas some professional development literature tends to focus on professional skills and knowledge there is a vast amount of literature, which does acknowledge and seeks to understand the roles, beliefs, motivations and commitments of teachers and thus address 'higher' neurological levels (see e.g. Louis, 1994; Woods et al., 1997).

This study is thus focusing on the 'higher levels' by exploring how teachers talk about their professional identity and their work, particularly their beliefs, values and commitment connected to their work. The mentioned notions such as identity, beliefs and values belong to the top part of the triangular representation of neurological levels. However, it might be important to emphasize that there is no hierarchical relationship among the different levels and the expression 'higher levels' refers merely to their graphical position rather than to any judgement of their importance. One may, of course, consider some more important than others in certain contexts.

The literature that focuses on the 'higher' levels is more examining students' expectations of teachers than teachers' professional development. Different approaches to professional development include also different perspectives, one from the teachers' point of view encompassing pedagogy, teaching and learning as processes, and another from the students' point of view encompassing their expectations in the classroom and their ideas of the characteristics of effective teachers. It can be argued that these two perspectives are not comparable and that even though they are depicting the "same story", they derive from different situations. However, the NLP-based analytical framework of 'neurological levels' would, in the hypothetical analysis of both literature on pedagogy, teaching and learning processes, and the literature on students' expectations, find a gap between what professional development is usually designed to develop (skills, knowledge, awareness and application (Joyce and Showers, 1988, cited 
in Craft, 2000, p.27)) and students' expectations (cheerfulness, sense of humour, encouragement, helpfulness (see Taylor, 1962; Nash, 1976)). One (NLP-based) way of explaining the gap would be that the majority of effective teacher's characteristics are skills and/or behaviour-based (see Joyce and Showers, 1996), whereas the students' expectations of effective teachers tend to be on belief, value and identity levels. Such a comparison may not be entirely adequate, although one commentator, Brown (2004), stresses that "for teachers to develop their professionalism, it is important for them to reflect on their teaching and to be able to see things from different viewpoints or perspectives" (p.518).

In order to explore further connections between different perspectives, personal development, which has been described above as a sub set of CPD, and Neuro-linguistic programming, which is included in the research question, an introduction of NLP and the literature connected to it is presented in the next section.

\section{PERSONAL DEVELOPMENT AND NEURO-LINGUISTIC PROGRAMMING}

Since some literature on Neuro-linguistic programming (particularly from the management development field, see Dowlen, 1996) emphasizes personal growth as a 'product' of NLP trainings, before this chapter embarks on exploring personal development and NLP, the on-going debate about the concepts of 'personal development' and 'personal growth' deserves further consideration. 


\section{Personal development and personal growth}

Irving and Williams (1999) made an effort to clarify the above-mentioned concepts. They claimed that both personal development and personal growth are about change, where the former refers to change that can be planned, while the latter cannot. As such personal growth may be an outcome of any development. It is what happens to individuals as a result of their own experience and personal development work. Personal development may be a purposeful activity, deliberately entered into, whereas personal growth 'happens'. In their conclusion, Irving and Williams (1999) emphasised that personal growth and personal development are not synonymous. They identified parameters of personal development as being directional and context-bound, which should allow, for example, personal development trainings to be structured and evaluated. Teachers may need to both personally develop and grow as persons, and these are intertwined, but identifiably different processes. In the context of the study in Slovenia, the original project commissioned by the Slovenian Ministry of Education focused on personal development of teachers through carefully evaluated and accredited CPD programmes that for that purpose specifically included personal development elements.

\section{Neuro-linguistic Programming (NLP)}

Neuro-linguistic programming (NLP), on the other hand, started out with a strong focus on both personal development and personal growth of therapy clients treated by therapists, who were renowned professional experts (Satir in family therapy, Pearls in Gestalt therapy and Erickson in hypnotherapy, see Bandler and Grinder, 1975). It has since then been developed further and applied in a variety of fields such as education, coaching, marketing, and communication skills. There have been many attempts to 
define NLP (see McCormick, 1984; Baddeley, 1989) and there might be some similarities between the 'ambiguity' (Friedman and Philips, 2004) of the concept of CPD mentioned earlier and the concept of NLP. NLP has frequently been described as a behavioural model, involving a set of explicit skills and techniques, established by Bandler and Grinder (1975). Certainly, the behaviour and skill focus reappears in some of the existing definitions of NLP. According to Dilts (2000), on the other hand, NeuroLinguistic Programming studies the patterns or 'programming' created by the interaction between the brain, language and the body (hence its name). NLP has also been defined as "an extraordinarily complex model of human cognition and behaviour and of how to identify behavioural and communication patterns" (Dowlen, 1996, p.31). Alternatively, George (1996) refers to NLP as an 'advanced communication model' with its strong focus on language patterns and their effects on people. NLP could therefore, among other things, be considered a practical model of communication, which provides us with a way of thinking about people and the process of communication, and which provides the 'tools to identify the structure of successful communication in education, therapy, management, health and elsewhere' (De Luynes, 1995, cited in Brown, 2004). On the other hand, Craft (2001) has argued that NLP is not a theory or even a model, but rather a set of strategies. In their response to her article, Tosey and Mathison (2003) chose to refer to NLP as a form of transdisciplinary knowledge. Brown (2004) claims that a major theme of NLP is to enhance individuals' understanding of themselves and others, particularly their communication preferences and what motivates them, and that this represents a potentially powerful tool for teachers to use in "improving their understanding of themselves and their students" (p.518).

The above suggested 'definitions' however still leaves it undetermined whether NLP should be seen as a theory, a model or a set of strategies. The above accounts of NLP 
fall into a category of explanations of 'what NLP does' rather than clear accounts of 'what NLP is'. Baddeley notes that it is hard to define NLP because it attempts to synthesize "theoretical and practical borrowings from many sources" (1989, cited in Dowlen, 1996, p.31) and some of these sources are theoretically antagonistic. One example of antagonism is Chomsky's theory, which is generally considered to imply and advocate a nativist theory of learning, whereas most other theories embrace empiricist learning theories (Bandura's social learning theory is anything but nativist). Indeed NLP would make little sense from a nativist perspective, but that does not preclude borrowing extensively from Chomsky's linguistic theories and models.

As an 'insider' in the field of NLP (as a licensed NLP Trainer) I felt the consequences of the above mentioned antagonism by being at the same time critical and accepting of NLP. On one hand it was clear to me, what was also noted by Kudliskis and Burden, (2009) that "NLP draws from a range and synthesis of well established ideas" (p.172); on the other hand, some of them seemed to be contradicting each other thus contributing to the lack of coherence and possibly to the lack of sound theory in NLP approach.

Dowlen (1996) argues that the complexity and antagonistic nature of NLP are acknowledged as contributing to the difficulty of definition, however, it is noted that NLP serves a reference role by gathering techniques together under its own 'label'. Although NLP did 'borrow' theories, models and techniques from other fields, it has also, through close observations of the studied phenomena (such as eye movements, imagery etc., see McClendon, 1989) developed a large amount of 'own' strategies and techniques for better communication, presentation, decision-making and choice. 
The above account has hardly provided a definitive answer to the question of whether NLP should be seen as a theory, a model or a set of strategies? The following accounts of 'systemic thinking', 'modelling' and 'cognitive apprenticeships', all aspects of NLP are meant to try to bring us closer to an answer to this question.

\section{Systemic thinking}

Systemic thinking is a 'complex' way of thinking in mutual feedback among actors and factors involved, understanding that any change will change the whole system. NLP seeks to find the 'leverage', i.e. the element where desired change of the system is achieved most efficiently. One of the reasons observations were added to the data gathering tools in the study is exactly the wish to create awareness both in teachers and the researcher through mutual feedback (in the video-stimulated follow-up interviews) where the 'leverage' might be, that is, which element either in classroom interaction or in the congruence/incongruence between the observed and described phenomena is crucial for potential and desired change. One of the contemporary theories (called second order cybernetics) that influenced this systemic thinking was a movement studying how observers construct cybernetic models of other cybernetic systems. A second-order cyberneticist working with an organism or social system recognizes that a system acts as an agent in its own right, interacting with another agent, the observer (Heylighen and Joslyn, 2001). To understand this process, we need a 'cybernetics of cybernetics', i.e. a 'meta' or 'second-order' cybernetics. These cyberneticians' emphasis on such epistemological, psychological and social issues was a welcome complement to the reductionist climate (see e.g. Ashby1956/1965; McCulloch, 1995), which followed on the great progress in science and engineering of the day. 


\section{Modelling}

Modelling has already been mentioned above and is the name Bandler and Grinder attaches to the process of 'observation and replication' used in the original study of 'excellent' therapists (see Bandler and Grinder, 1975). Einspruch and Forman (1985) emphasize in their examination of modelling that in their view, when modelling another person the modeller 'suspends' his or her own beliefs and adopts the structure of the physiology, language, strategies, and beliefs of the person being modelled. The original purpose of modelling in NLP was the transfer of skills and behaviour of successful therapists (who in general were not consciously aware of how they achieved the successful outcomes), but it has been extended to the acquisition of elements from any logical level. When the modeller is able to behaviourally reproduce the patterns (of the behaviour, the communication, and the behavioural outcomes) of the person being modelled, then a process takes place in which the modeller modifies, temporarily at least, his or her own belief system and at the same time integrates the beliefs of the person being modelled. It could be said that there are some affinities of Einspruch and Forman's description of modelling with Vygotskian social constructivism (1934/1986) and also with Piaget's notions of assimilation and accommodation (Piaget and Inhelder, 1969). It is, however, still an important difference between these that in modelling the modeller has clearly defined aims and purposes, i.e. in modelling one 'picks and chooses' which elements to 'assimilate', whereas in Vygotsky's and Piaget's models these are non-deliberate processes from the learners' perspective.

There are also similarities between modelling and 'cognitive apprenticeship' and Lave and Wenger's ideas of learning taking place in what they term 'legitimate peripheral participation', which are outlined below. 


\section{Cognitive apprenticeship, Modelling and Legitimate Peripheral Participation}

As modelling was aiming to elicit 'unconscious' skills, i.e. skills that e.g. the three modelled successful therapists were using, but were not aware of consciously, it can also be seen to have affinities with what Collins et al. (Collins et al., 1987; Collins and Brown, 1989) call 'cognitive apprenticeship'. According to Collins et al., those who are masters of a skill fail to take into account the implicit processes involved in complex tasks when teaching them to novices. The 'cognitive apprenticeships' are designed to bring the tacit processes into the open, so that students can observe, enact and practice the skills. Similar ideas are key to Lave and Wenger's (1991) perhaps somewhat idealised picture of apprenticeships, where they provide a theoretical framework for what actually (in their view) is happening in master-apprentice relationships. They describe the apprenticeship as 'legitimate peripheral participation' in a 'community of practice' where the apprentice with time learns to speak, think and act as a community member, and gradually learns by demonstration and 'centripetal participation' (where the apprentice gradually moves towards the centre of knowledge (ibid.)), rather than by instruction. Whereas Lave and Wenger describe this process in somewhat idealising terms, where the apprentice apparently learns 'all by him/herself' by being allowed to be present, and to an increasing extent, participate, from an NLP point of view the 'mastery' can be extracted by an expert in modelling through observation and interviews and be 'boiled down' to a 'recipe' that can transferred to others much more efficiently.

An important difference in comparison with Lave and Wenger's notion of 'legitimate peripheral participation', is that modelling is a deliberate activity by a trained modeller with a clear-cut and specific purpose, i.e. that of being able to replicate the success of the modelled individual. Perhaps the most important difference is that in NLP there is 
an element of self-modelling, that is, elicitation of 'success/mastery elements' by the master himself. This element is used in the research process of this study. If the teachers involved in the study realize, through reflective accounts of the observed classroom interaction (which is shown to them in the video-stimulated follow-up interviews), where the leverage for potential change for the better might be found, then the study could have an added value for them. Thus the role of the video-stimulated follow-up interviews, besides their role in respondent validation, may contribute to the development of self-modelling skills.

\section{Summary}

Having explored the two important elements of NLP, i.e. systemic thinking with its focus on the co-creation of change through mutual feedback by the observer and the observed, and modelling with its focus on the conscious realization and replication of success, other questions appear: How do these two elements contribute to a clarification of the definition of NLP? Do they describe what NLP does or what NLP is?

Systemic thinking seems to represent quite well the underpinnings of the dynamic and relational nature of NLP as well as the epistemological and ontological assumptions held within it (discussed later). Modelling, on the other hand, seems to represent the main 'learning tool' quite well, i.e. the process of acquiring a model's successful behaviour, beliefs and 'being'. In the context of the study, modelling teachers' talk may be an effective way of gathering information about teachers' accounts of their professional identity and work. The whole idea of modelling teachers' talk is meant as a kind of 'linguistic and content modelling' that is elaborated further in Chapter 5. 
In order to move from the perspective of what NLP does or use to what NLP is, it can be helpful to consider that in early NLP the focus was on observing, i.e. modelling excellent practitioners in the therapeutic field in order to elicit the key concepts of their successful practice. Thus all the above mentioned attempts of defining NLP as a set of strategies, models and/or techniques appear to be definitions of the elicited key concepts of excellent practice through modelling whereas NLP itself could be better defined as an approach to developing professional practice through modelling. This 'working definition' of NLP certainly fits with the rationale for this dissertation with its focus on exploring teachers' subjective experience of their work and their professional identity in order to develop professional practice.

Such a definition opens a question of how NLP elements are applied in CPD across different professions, and in spite of NLP elements being included in many professional development programmes, no research has been carried out into its contribution to CPD.

\section{Applications of NLP}

NLP has, above, been defined as an approach to developing professional practice through modelling. Such an approach can certainly be useful in many different areas. Tosey and Mathison (2003) state that they have found NLP of immense value, not only in their professional practice in higher education, but also "as a topic for research, and as a prospective tool for qualitative research" (p.372). I would like to suggest that NLP modelling might be used as a qualitative research tool for the purposes of 'linguistic modelling'. Tosey and Mathison (2003) have also expressed their belief that NLP holds great potential for education at all levels, while also acknowledging the need for research into, and critical evaluation of, NLP (p.373). Also Craft (2001), who has otherwise expressed scepticism about NLP, points out that NLP has had a significant 
impact "in the workplace and in the world of training for continuing professional development for adults" (p.127).

The following are examples of how NLP can be applied to specific fields:

A number of UK NHS regional authorities use NLP for staff training at various levels, for training in rapport and communication in the workplace and with patients, and for personal development in management training (NHS Institute for innovation and improvement). The Society of Medical NLP delivers courses for health professionals for techniques to be used in clinical practice in consultations. These techniques were originally based on modelling GPs, who communicate successfully with patients. Their courses are accredited for PDP and CPD. The European Federation of Allergies and Airways Diseases Patients Association in cooperation with the pharmaceutical company AstraZeneca has supported an NLP-based programme "Building an Alliance with Your Asthma Patients - Communication Techniques" through an educational grant. Guy's, King's \& St. Thomas's Hospitals Medical \& Dental Schools (Guy's, 2007) from January of 2003, started offering a Special Study Module (SSM) in NLP to medical students in their first clinical year. Nevertheless there has been no research work to look at the effectiveness of NLP as experienced by those involved in it.

The wide application of NLP in the business world resulted in scores of management and leadership trainings as well as business magazine and journal articles. Dowlen (1996) investigates different authors, who considered NLP in relation to a different aspect of management development. Milne (1988) addressed executive career counselling, Harris (1992) dealt with the development of IT consultants, Johnson (1993) discussed management coaching, Kamp (1992) addressed management development in 
general and Alder (1992) discussed developments in management and organizational theory. Dowlen (1996) concludes in his examination that these authors claim effective results and "assuming their accounts are reliable, the reported views of programme participants are some measure of validation for the claims made. The continued development of NLP over a period of more than 20 years would also suggest that it has something to offer" (ibid, p.30).

\section{Evaluation/Critique of NLP}

Even though there are some evidence that NLP can offer something valuable without being either 'coherent' or 'well-founded', the main academic criticism has remained its questionable coherence as a theory. In the case of this study, it is even more relevant to explore NLP's coherence and theoretical underpinnings since I am investigating teachers who attended NLP-based CPD and other teachers' view of their professional identity. It may be crucial to be able to understand the underpinning assumptions of NLP that teachers who attended NLP-based CPD might have adopted and later, for example, exhibit in the interviews.

In order to examine NLP through a theory lens, a brief introduction of different approaches to theory will be considered. Furthermore the section engages with different approaches to and understandings of theory in an evolving way. The engagement takes place on different levels from practical (discussing whether theory is seen as relevant) to more philosophical ones (discussing whether epistemology guides activity and whether practitioners are aware of their epistemological foundations). In between these discussions constant references are made to NLP and its (in)coherence. 
Booth (2005) offers an overview, which divides processes related to knowledge into knowledge formation and knowledge practices. Thus, for Booth, science and theory belong to the realm of understanding and commitment in relation to knowledge formation, whereas research belongs to the doing/acting realm. This division may prove useful as a starting point from which NLP's coherence and theoretical underpinnings are analysed.

\begin{tabular}{|l|l|l|}
\hline & Knowledge formation & Knowledge practices \\
\hline Doing/Acting & Research (empirical studies) & Method \\
\hline Understanding/Commitment & Science/Theory & Methodology \\
\hline
\end{tabular}

Table 2 On knowledge formation and knowledge practices: acting and understanding (based on Booth, 2005)

I would agree with Craft (2001) in her definition of theories as "over-arching approaches to explanation, which encompass a range of models. Theories provide fundamental assumptions which then underpin the workings of models of understanding" (p.130). This definition of theory will be taken as the standpoint of the researcher in the study. Savickas (1994), on the other hand, views theory as a 'portmanteau term', and yet describes its core meaning as a systematic and organised set of propositions. On the other hand, Kidd et al. (1994) believe theory varies in kind and range, from "sophisticated overarching theories" to "systems of interrelated concepts" (p.386). It is worth noting that Kidd et al. themselves apply 'theoretical' to a variety of terms apparently interchangeably: 'approaches', 'models', 'frameworks', and 'principles' (p.392).

In order to get closer to an understanding of whether NLP has or is a theory, it might be fruitful to explore what the authors in the field of therapy and/or counselling (which, after all, were the original fields studied and observed by the NLP founders) say in 
relation to the theory/practice debate. Collin (1998) argues that it is questionable as to whether practitioners recognize, have a need for or are willing to create theory. They often express considerable unease with and ambivalence towards research and theory, dismissing the value of theory, and being seemingly 'hostile' to it (Kidd et al., 1994, p.391).

Keeney and Sprenkle (1992) refer to the relationship between theory and clinical practice as an issue that repeatedly permeates serious discussion of family therapy. They even mention Bandler and Grinder saying that "for example, Whitaker, Haley, and Bandler and Grinder have all protested, in different ways, that theory can hinder clinical work". Keeney and Sprenkle (1992) claim that it is impossible to have no epistemology, for even the idea that one has no epistemology arises from a particular epistemology. They agree, however, that when therapists argue that 'theory' is not immediately useful to clinical practice, they are partly right in the sense that a theory of therapy is on a different logical level from therapeutic action.

At another level Irving and Williams (1995) suggest that counsellors in general "are not aware of the theories they use to inform their actions" (p.108). That leads to another question of whether, even if NLP were to have 'own' theoretical underpinnings and epistemological frameworks, practitioners would be aware of them. After all, Schön (1983) argues that pure and applied theory, which provides the basis for the practitioner's diagnosis and problem-solving, and the skills and attitudes to apply them to a particular client's needs, constitute 'professional knowledge' or expertise. Watson (1994) claims that "theory has done its job when its key messages have been communicated, internalized and assimilated as working assumptions” (p. 392). 
Craft (2001) argued that Neuro-linguistic Programming involves "awareness of both one's own theoretical foundations as well as one's performance, in practice. Thus, it can be seen as a theory of action" (p.130). Ultimately though, Craft concluded that NLP is not a theory at all, because it does not focus on one over-arching approach to explanation, but rather with its powerful emphasis on practical outcomes, is fundamentally a set of strategies” (p.131). Perhaps one could say that NLP makes explicit a model of understanding and is focused on performance, but does not focus on the overarching approach to explanation rather on the set of strategies at a pragmatic level. Kudliskis and Burden (2009) suggest that "it may be better to consider NLP as a model rather than a theory" (p.172).

Based on the discussion above, it seems that in NLP any theory is suspended until practical sensory specific data starts being collected (similar to grounded theory, see Glaser and Strauss, 1968). Only then does an ad hoc theory building start. It might be a way forward to say that NLP is a highly pragmatic and relativist approach to studying, communicating with, and acting in, the world. As NLP sets pragmatism and flexibility above all else, then this will, almost by definition, imply that any 'hard line' theory would just 'get in the way'. Thus, if one looks for theoretical coherence in NLP, it is likely that such coherence may only be found in the basic aim of seeking flexibility (Ashby's law of requisite variety (1958) is often referred to in NLP), assuming relativism and constructivism and having a strong focus on studying, acquiring and transferring excellence.

Based on the discussion above, it could perhaps be concluded that NLP is underpinned by what could be called an 'ad hoc theoretical framework'. It is one where pragmatism and epistemological relativism 'rule' and the rest is a series of 'working assumptions' 
that all serve the purpose of creating the desired (practical) outcomes. Thus, perhaps the only reliable 'theory' of NLP is an adherence to pragmatism, relativism and constructivism.

It could be said that NLP is an alternative approach to the generation of knowledge (as compared to a conventional hypothetico-deductive/empiricist approach), an 'alternative epistemology of practice' which would, according to Booth (2005) mentioned in the beginning of the section, belong more to the doing/acting quadrant than to the understanding/commitment one. Several attempts in this direction can be found in the literature, but it is not clear how they relate to one another. The perhaps best known is what Schön (1983) calls 'reflective practice' (p.295-6). Practitioners, it is suggested, should develop critical thinking (Irving and Williams, 1995) and 'map-making' skills that is, the ability to identify and challenge assumptions, recognize the implications of context, imagine and explore alternatives, and engage in reflection (Brookfield, 1987) and use them in a continuing awareness of their own practice. It seems like all of the above-mentioned might easily apply to NLP practitioners. Schön (1983) argues that practitioners need to become not only 'reflective', but also researchers and theorists themselves, using approaches appropriate to their practice. Thomas (1993) sees practitioners as 'practical theorists' (p.211) who have to fit together knowledge from various sources to 'inform practice in fruitful and productive ways' (p.214) 'Practical theory' is thus the 'personal theory' or constructs, but explicitly informed by the theories from the relevant field. It makes a valuable bridge between the concepts of theory and practice and suggests that, though disparate, they become intertwined. Savickas (1994) refers to this as an 'intimate relationship', one of 'mutual shaping' and suggests that theory and practice may not be dichotomous but a continuum. Hence, a theory is constructed through its use and thus called 'practical theory' and it might be 
the answer to whether NLP is/has a theory or not. If it is to be claimed that NLP has/is a theory, perhaps it should be defined along the lines of 'practical theory' that got constructed through its use, thus emphasizing the importance of the practice itself.

The 'fathers' of NLP, Bandler and Grinder, prefer referring to NLP as 'the study of the structure of subjective experience' (1975) emphasizing that they were actually eliciting, i.e. modelling, structural patterns of individuals' subjective experiences. The present study is interested in teachers' subjective experiences of their professional identity and their work and was eliciting/modelling patterns in their talk about the above-mentioned concepts. There is an obvious thread of subjective experience in both NLP and this study and it is no surprise that the study has employed an interpretivist (as elaborated in the next chapter) approach as the most adequate for exploring the topic.

In the above analysis and discussion of NLP, it has been shown to be a complex task to define it. Several 'definitions' have been mentioned, but the one(s) that I have found most useful for the purposes of CPD is that it is both an approach to developing successful practice through modelling and a 'practical theory'. To model good practice in a very practical manner was what Bandler and Grinder, the founders or 'inventors' of NLP, set out to do, when they modelled three successful therapists. The theoretical 'backdrop' of NLP has also been examined above. It was found that it is a highly pragmatic approach that sets pragmatism above any models or theories. It has been identified as constructivist and epistemologically relativist and ontologically close to phenomenology (the focus is on the subjective individual experience and the 'reality' of everything else is suspended). Thus the choice of qualitative data gathering tools explained in the next chapter (such as semi-structured interviews and reflective diaries 
contributing to the exploration of the teachers' subjective experience) is along the lines of the characteristics of NLP.

The discussion also clarified that based on the conclusion above it is little surprise that, as Kudliskis and Burden (2009) put it, "a scientific explanation of NLP does not exist" (p.177). The above lack of theoretical coherence could lead to the lack of evidencebased research, thus putting NLP in the position of existing as a phenomenon that resists the idea that reality can be viewed and measured objectively (Kudliskis and Burden, 2009)). Obviously if we apply positivist criteria for scientific evidence, the effectiveness of NLP is hard to demonstrate. It might be up to the NLP practitioners and academics that are interested in the exploration of different personal development oriented modalities to contribute to the greater 'researchability' of NLP by carrying out qualitative studies. However, evidence that such studies may or may not provide for efficacy or coherence of NLP will again not meet the requirements of positivist scientific methodology. As long as its founders prefer to refer to their creation as 'magic' rather than a coherent theory, model or set of strategies, there is little hope that NLP will be widely researched by the academia. On the other hand, Kudliskis and Burden (2009) point out that "at the moment it would appear that NLP has, at best, a limited theoretical underpinning framework supported by 'soft' research evidence" (p.177). They are also quite hopeful when they explain that even though there is no available 'scientific' explanation of NLP right now, there might be one in the future. They take their optimism even further when they suggest that "the fact that something 'magical' can happen when individuals are guided in their reflections of, and about, beliefs and thought patterns does not mean that because science cannot explain it, it is not worthy of consideration or merit" (p.177). 


\section{VALUES AND COMMITMENT IN TEACHING}

Louis (1994) is among the authors who change the focus from skills, knowledge and procedures to talking about "values, both at the grand level ('caring for kids') and at the daily level" (p.8) as crucial for teaching. Woods et al. (1997) add their piece to this exploration of what NLP refers to as the 'higher' neurological levels by claiming that "teaching is a matter of values. People teach because they believe in something. They have an image of the "good society"' (p.152). Keeping this in mind, a question arises about how to teach in the midst of war and have an image of the 'good society'. It may be argued that teachers' personal and professional development is as much connected to their values, commitment and their identity as to their professional knowledge, skills and procedures. Otherwise, as already pointed out in the introduction to the dissertation, Hargreaves (1993) would emphasize that “teachers don't just have jobs. They have professional and personal lives as well" (p.viii).

Closely related to 'values' is the notion of 'commitment'. In her research with primary school teachers, Nias (1989) describes the teachers as so committed that they were "inextricably bound up with the teacher role and could not switch off at the end of the school day to another life and another persona" (p. 146). Moran (2009) found, while examining the role commitment played in the careers of 36 writers of fiction, that commitment has different roles depending on the type of writer (she distinguished between 'genre conformers' for whom commitment compensates (keeps them going), 'experimentalists' for whom commitment defies and 'domain transformers' for whom commitment impassions. It could be interesting to carry out a similar examination of the role of commitment on schoolteachers (though this shall not be attempted here). There 
does not, however, seem to be any doubt that commitment is a key element in teachers' lives. Haigh (1995) has suggested that the 'isomorphic identity' can be problematic for teachers as they can easily get their sense of personal worth mixed up with their professional competence. On the other hand, Hargreaves (1999) points out that personal and professional elements are intertwined and that for teachers' commitment, enthusiasm and morale, "their hopes and dreams, their opportunities and aspirations, or the frustrations of these things are also important" (p.vii). It is necessary to explore how all these claims about intertwining personal and professional elements, the importance of values and commitment relate to teachers' professional identity.

\section{TEACHERS' IDENTITY}

In the last decade, teachers' professional identity has emerged as a separate research area (e.g. Bullough, 1997; Knowles, 1992). To account for what is meant by teachers' professional identity, several authors have drawn on definitions of identity used in social science and philosophy.

\section{The notion of identity and different attempts to define it}

The works of the symbolic interactionist Mead (1934) and the psychologist Erikson (1968) are of particular interest in this regard. Mead used the concept of identity in relationship with the concept of self. According to him, the self can arise only in a social setting where there is social communication. Erikson outlined a changing concept of identity stressing that identity is not something one has, but something that develops during one's whole life. Thus identity turns out to be a relational phenomenon. 
While researching literature on identity it has been found that authors use the terms 'identity' and 'self' as almost interchangeable. And even though many authors agree that the notion of identity is experiencing a 'renaissance' recently (see Sfard and Prusak, 2005; Hoffman, 1998), a search for a clear definition of the notion of identity continues.

According to Mead (1934), for example, the 'substantial' self that he connects or even identifies with identity is in his view formulated early in life through many and varied interactions with significant others. To aid a sharper definition, it both compares and contrasts with others; and for protection purposes it has a survival kit that resists assaults on the self-designed to destroy or to change it. 'Situational' selves on occasions may be part of this defence apparatus, because they allow the individual to adapt to different situations while preserving intact the innermost 'core'. It is the substantial selves that should be aimed at for substantial change and development during personal and professional development, and these are not changed easily. If one adopts this perspective on teachers' professional identity, many attempts to contribute to the development of their identity through professional and personal development programmes would prove to be fruitless due to the fact that the 'substantial' self is not changed easily.

Nias' (1989) concern is also with the 'self', particularly its realization in teaching, which is of course relevant for my study. Its pedigree, as already mentioned, is symbolic interactionist and particularly the above-mentioned 'Meadean conceptions' of the 'self'. Within that framework her book is a notable contribution, as it provides a considerable amount of material on the nature of the 'I' and the 'Me' as seen by teachers. Nias makes a distinction between the 'substantial' self, a kind of inner, unchanging, core and the 'situational' self, that is, different selves that are adaptations to particular situations. Her 
concern is with tracing the linkages and tensions between the two as evidenced within teaching and within this the ' $\mathrm{I}$ ' receives as much attention as the 'Me'.

On the other hand, other authors, as for example Ivanic (1998) use a more 'straightforward' approach and define identity as "the everyday word for people's sense of who they are" (p.10). Epstein (1978) moves the notion of identity from Ivanic's lexical approach (it is the everyday word) to the more process-oriented one, when advocating that "identity represents the process by which the person seeks to integrate his various statuses and roles, as well as his diverse experiences, into a coherent image of self' (p.101). Gee (2001) contributes his bit to a process-oriented definition of identity, when he claims that identity development can best be characterized as an ongoing process, a process of interpreting oneself as a certain kind of person and being recognized as such in a given context.

Several authors apply a so-called 'narrative approach' to the notion of identity. Holland, Skinner, and Cain (1998) draw attention to people's stories by emphasizing that "people tell others who they are, but even more importantly, they tell themselves and they try to act as though they are who they say they are. These self-understandings, especially those with strong emotional resonance for the teller, are what we refer to as identities" (p.3). Even Gee (2001), mentioned earlier, introduces narrativization in combination with "discursive space" (p.111) and claims that together they constitute a "core identity" (ibid.). Two authors that very convincingly advocate for a narrative approach to the notion of identity are Sfard and Prusak (2005). They define identity as "a set of reifying, significant, endorsable stories about a person" (p.14). Furthermore, they extend the definition by splitting the narratives further into two subsets which they decide to name "actual identity, consisting of stories about the actual state of affairs, 
and designated identity, consisting of narratives presenting a state of affairs which, for one reason or another, is expected to be the case, if not now then in the future." (Sfard and Prusak, 2005, p.18)

Wenger (1998), on the other hand, opposes this narrative approach and refuses to accept that identity is either reflective or discursive. He acknowledges the role of words and at the same time rejects the idea that they are anything more than just words:

We often think about our identities as self-images because we talk about ourselves and each other - and even think about ourselves and each other - in words. These words are important, no doubt, but they are not the full, livid experience of engagement in practice (p.151)

Giddens (1991) and Beck et al (1994) as a contrast to Wenger, see identity as a reflexive rewriting of the self, brought about by the continuous self-monitoring processes of modernity. Identity is always relational and increasingly fragmented. Lyotard (1979) sums this up well (playing with John Donne's famous proverb): 'No self is an island; each exists in a fabric of relations". (p.15) Even though there is a wide spectrum of different attempts of defining identity and many more that have not been mentioned here, Lyotard's account of the self existing in a fabric of relations can be used as an introduction to social constructivist approach to identity.

\section{A social constructivist approach to identity}

Depending on whether one takes a psychological or sociological perspective as a starting point, social constructionism/constructivism can, put simply, be thought of as 
either fostering meaning-making or as a theory of knowledge with the focus on unwrapping the ways in which individuals and groups construct their perceived reality (Steffe \& Gale, 1995; Burr, 2003). Social constructionism/constructivism is rooted in Hegel's ideas and developed further by Durkheim (Durkheim and Giddens, 1972). It may be useful to explain the use of the two terms here: constructionism and constructivism.

One way of explaining them would be to say that constructionism is usually used when referring to its social perspective whereas constructivism has a more psychological and educational flare particularly when used as referring to learning theory. Papert and Harel (1991) offer their understanding of the distinctions and similarities between the two terms by saying:

Constructionism--the $\mathrm{N}$ word as opposed to the V word--shares constructivism's connotation of learning as "building knowledge structures" irrespective of the circumstances of the learning. It then adds the idea that this happens especially felicitously in a context where the learner is consciously engaged in constructing a public entity, whether it's a sand castle on the beach or a theory of the universe. (Papert and Harel, 1991)

In this study the $\mathrm{V}$ word, i.e. the term social constructivism will be used when referring to the specific approach towards the notion identity including the idea that identity is a learned phenomenon in interaction with environment. In other words, this approach to identity emphasizes that identity is an entity ever-evolving and changing through our interaction with the world and that it is actually a construct that continues being constructed over and over again. This idea is aligned with above mentioned Lyotard's 
account of existing in a fabric of relations. Similar to this is also the other idea that the socially constructed reality is seen as an ongoing, dynamic process; reality is reproduced by people acting on their interpretations and their knowledge of it. If that is the case with the construction of reality, then the similar dynamic process of constant creation and re-creation of one's identity might be happening. Or as some authors put it (see Holland and Lave, 2001; Bauman, 1996; Roth, 2004) identity is thought of as manmade and as constantly created and re-created in interactions between people.

\section{Teachers' professional identity}

Beijaard et al. (2004), who made an analysis of studies about teachers' professional identity, see identity as an answer to the question: "Who am I at this moment?", thus acknowledging that it is an entity that changes over time.

Beijaard et al. (2004) defined teachers' professional identity in the following way:

- professional identity is seen as an ongoing process of integration of the 'personal' and the 'professional' sides of becoming and being a teacher

- professional identity is not a stable entity; it cannot be interpreted as fixed or unitary

- professional identity implies both person and context

- professional identity is multifaceted

- professional identity may consist of many sub-identities that may conflict or align with each other

- agency is an important element of professional identity, meaning that teachers have to be active in the process of professional development. 
These relatively recent findings about features of teachers' professional identity are not fully in accordance with previous work done in the same field such as, for example the previously mentioned work of Nias (1989). Of course, one can justifiably contemplate how much of Nias' concern is due to her own theoretical framework and how much to her concern with primary teachers.

On the other hand, given the significance of 'interaction' in the formation of teachers' identities, MacLure (1993) again, just like Beijaard (2003), warns against holding the view that identities comprise a 'core' or 'essential' self. Through her research she demonstrated through close discourse analytic work of interviews conducted with teachers, how teacher identities are "less stable, less convergent and less coherent than is often implied in research literature" (p.320).

Helsby (1999) in a study of secondary schools and Menter et al. (1997) in a primary school study, found that teachers' professional identities, in which their values were embedded, were undermined and even changed by educational reforms.

Speaking of changes, Woods' (1981) metaphor of 'making and breaking the teacher role' may prove useful here, particularly for an examination of my personal experience of needing to flee Serbia in the early 90 s, feeling that I was not allowed to be a teacher in the turbulent political and (civil) war times. Some of the colleagues that stayed, nowadays confess (in personal communication) that they had to sacrifice their understanding of professionalism and change their professional identity as teachers in order to keep their jobs. 
If a professional identity, including a teacher's identity, is not as static, singular and 'core' as Nias (1989) suggested, then there is an opportunity to extend, develop and even change it through professional and personal development.

Strauss (1962) offers a model of personal change or development that would challenge the 'substantial self' laid down in the multitude of interactions occurring in early life. In his discussion of 'transformations of identity', one meets with new concepts and new classifications, and old ones being modified. Transformations involve "radical change of action and person" since they "connote shifts in perceiving, remembering and valuing" (p.66). They necessitate "new evolutions: of self and others, of events, acts and objects; and the transformation of perception is irreversible; once having changed, there is no going back" (ibid.).

It remains open, however, for now, whether such a personal change or development may be achieved through professional and personal development programmes since no major research study has explored the relationship between personal or professional development programmes and the way in which teachers perceive their professional identity.

Wenger (1998) introduces the idea of professional identity as being forged within the context of the profession, but that it transcends its boundaries by saying that 'the experience of identity in practice is a way of being in the world" (p.151). In his later book Wenger (2006) talks about identity as 'learned experience of agency’ (p.19) and of being 'learning citizens' - so he sees learning as a social process with a strong ethical dimension, discussing the relationship between agency and structure as the locus of learning, seeing the $21^{\text {st }}$ century as a century of 'identity'. 
Going back to teachers' identity, it is worth noting that Beijaard (1995) mentions four main features related to the study of teachers' professional identities. These are 'identity in general', 'the subject one teaches', 'relationship with pupils', and 'role/role conception'. However, having mentioned uncertainty and change earlier, a further feature not mentioned that could and should have been considered when examining teachers' identity is the significance of contexts may they be social, cultural or political.

Having said that, it would be fair to mention that several researchers (Nias, 1989, 1996; Hargreaves, 1994; Sumsion, 2002) have realized that teacher identities are not only constructed from the more technical aspects of teaching (i.e. classroom management, teaching skills, subject knowledge) but as Van Den Berg (2002) explains: ...[teacher identities] can be conceptualised as the result of an interaction between the personal experience of teachers and the social, cultural and institutional environment in which they function on a daily basis" (p. 579). To this can be added that these identities are usually constructed using narrative/biographical accounts which would be easily 'backed up' by previously mentioned Sfard's and Prusak's (2005) ideas about narratives/stories being central to identity.

Kelchtermans (1993) found that 'teachers' professional development', understood as a learning process throughout their career experiences, culminates in a personal interpretative framework, encompassing two major fields: a conception about themselves as a teacher and a system of knowledge and beliefs concerning 'teaching' as a professional activity (p.447). Within a 'personal interpretative framework' Kelchtermans introduces the concepts of 'the personal self' (i.e. ways in which teachers conceive of themselves as teachers) and 'the subjective educational theory' (i.e. the 
teacher's 'personal teaching style'). Their self-image, self-esteem, job motivation, task perceptions and future perspectives determine ways in which teachers develop a 'personal meaning system' and a 'personal teaching style'. Teachers' subjective educational theory is developed mainly by reflection on classroom practices' (ibid., p.452).

Analysing how professionals talk about their work and professional identity will, subsequently, clarify how professional practice is handled today by a language that links professional knowledge, skills, values, commitment and identity to the individual personality of the professional (Krejsler, 2002; Popkewitz and Brennan, 1998, p.13).

\section{THE NOTION OF LINGUISTIC PATTERNS}

Since this study set out to explore how professionals (in this case teachers) talk about their professional identity and their work, it might be useful to account for different connotations of linguistic/language patterns.

There are several ways of examining 'talk'. One option would be to consider language a transparent medium and assume that 'words mean what they say' and what people say is a more or less true reflection of reality. Another approach would be to focus on the talk and consequently language itself and how it is used (which is what is done in a wide range of discourse analysis research from conversation analysis and sociolinguistics to Foucauldian discourse analysis (see e.g. Wetherell et al., 2001). An approach, which could be said to place itself somewhere between the above mentioned two 'extremes' is semiotics, which is the study of meaning (see e.g. Chandler, 2002). In this study such a linguistic analysis will be applied to some aspects of language that can 
be indicative of attitudes, beliefs and values, and that can be used to differentiate patterns of thought.

On one hand, a linguistic analysis based on semiotic elements can be used as a tool for examining in relative detail the language patterns used by the teachers, when they talk about their identity and teaching. This part leans on the work of Austin (1962), who sees statements as acts, with which people 'do things' in order to achieve something, as well as on the pioneering work done by Lakoff and Johnson (1980) on metaphors.

On the other hand, the study will also carry out a broader examination of the teachers' 'talk' looking at how they construct their professional and personal identity. As Sfard and Prusak (2005, p.14) said identity is "a set of reifying, significant, endorsable stories about a person".

Linguistic analysis and the use of language patterns for introducing change is also a key part of NLP, where 'linguistic' even has become part of the name of the approach, and one of the founders of the approach was at the time assistant professor of linguistics specialising in Chomsky's transformational grammar focussing on syntax (Grinder \& Elgin, 1973).

\section{Positive, neutral and negative statements}

There are different ways of looking at linguistic patterns that are present in talk. One way consists of evaluation and expression using positive, neutral or negative words/expressions (for a discussion of such evaluation patterns, see Cepik, 2006). A determination of whether patterns are positive, neutral or negative may to some extent 
be a subjective assessment, but most would agree that if someone says 'I hate my job' it is a negative statement, whereas 'I love my job' would be the opposite. Most statements are far less obvious and a lot of talk use metaphorical language (see section below on metaphors).

\section{Metaphors}

Lakoff and Johnson (1980) published a book with the title "Metaphors we live by" (and several other books with similar topics, see e.g. Lakoff, 1987) in which the main argument is that our conceptual system is metaphorical. They demonstrated that examining the metaphors embedded in the language is a way of uncovering our conceptual systems. Metaphors in the world of education are frequent and they can be useful in explorations of different educational phenomena. As an example of how such an analysis can be fruitful within the topic of this study (teachers' professional identity) I can mention Bowring-Carr (1993), who shows how the increasingly used metaphor of teachers 'delivering' the curriculum may be taken to imply a reduction of teachers' role from 'initiative-taker' to mere 'messenger'.

\section{CONCLUSION}

This review has aimed at providing an overview and analysis of literature from the theoretical and research fields of professional and personal development, Neurolinguistic programming and teachers' professional identity, and has shown how definitions of professional and personal development as well as of the teachers' identity vary according to either theoretical or research framework applied by different authors. 
It has also shown, on one hand, how connected professional and personal development may be, and on the other how both professional and personal development may be connected to teachers' professional identity by taking them beyond the levels of pure behaviour, skills, procedures and knowledge.

The review has also briefly accounted for the perspective taken on linguistic analysis, which is a key part of the data analysis.

Having summarised the discussion of NLP, it is hopefully clearer now, how exploring the influence of familiarising schoolteachers with such an approach as part of their CPD may be a worthwhile project. NLP as an approach to developing professional practice is likely to have an influence on the teachers' professional identity both through its relativist and pragmatist outlook and through the teachers' self-modelling (which is a core part of NLP). 


\section{Chapter 3: Methodology}




\section{INTRODUCTION}

It is often argued that one's starting point must be to clarify one's epistemological and ontological perspective(s). This is a point that I would want to question at the outset. I have found that it is both possible and necessary to be flexible with regards to the choice of epistemological/ontological perspective depending on the context of research. In many natural sciences, e.g. chemistry, it would not make sense to apply an interpretivist perspective, but rather a quite rigorous empiricist perspective. Within the social sciences (including educational research), on the other hand, a wider range of perspectives may be useful depending on the questions asked and the objects of investigation. In this chapter I will argue for the choice of an interpretivist/phenomenological perspective in the Meadean/Blumerian (Mead, 1934; Blumer, 1969; Hammersley, 1989) tradition, where the main argument will be that it is the most useful and sensible perspective to take given the topic of investigation being to describe and explore teachers' subjective experiences and mental representations of their professional identity and their work. I am aware that it could be argued that by the choice of topic and aims I have already chosen an interpretivist/pragmatic perspective and this may be true. It would then also be true that the choice of overall perspective is in alignment with the research topic.

In order to design a study informed both by the adopted theoretical/conceptual frameworks and the existing literature on CPD, personal development, NLP and teachers' professional identity I needed to decide on the most suitable research methodologies as well as the techniques for data collection. Once the research question was clearly formulated, a second issue to be considered before embarking on a 
discussion of research methodologies and methods is a question, which Booth (2005) has asked relating to the identification of the object of research. As the object of the study is the way in which teachers who attended NLP-based CPD and those who did not talk about their work and their professional identity, the follow-up question emerges "how does one approach making these new knowledge claims about the object of inquiry?"(ibid., p.325). This is what this chapter will be focusing on, i.e. 'how' to approach making the new knowledge claims, which the study hopefully has produced and 'why' adopt the proposed approaches. The chapter also discusses the Initial study and how the main research was informed by the insights gathered from the Initial study. This is the reason the Initial study is discussed in this chapter rather than in a later chapter on findings.

\section{PLACING THE RESEARCH WITHIN THE WIDER METHODOLOGICAL CONTEXT/DISCUSSION OF RESEARCH METHODOLOGIES AND METHODS}

\section{Introducing basic terminology}

It is not a rare case that authors use different names while categorizing research methodologies depending on the criteria they use as well as on the level of analysis. For example, Guba and Lincoln (1998) talk about positivism, post-positivism, critical theory and constructivism, Scott (1996), on the other hand, refers to positivism, post-positivism and interpretivism/hermeneutics while Denzin and Lincoln (1998) refer to positivism, post-positivism, postmodernism and post-structuralism. Smith (1998) considers positivism a subcategory of empiricism and labels the mainly qualitative perspectives 'idealist' approaches, suggesting the sub-categories of neo-Kantianism, rational choice 
theory/praxeology and hermeneutics/phenomenology. Hermeneutics and phenomenology are also labelled 'interpretive approaches' by Smith (p.161). The interpretivist approaches are often contrasted with reference to their focus on the inside knowledge of what it is like for a social actor and on 'understanding' from the inside, rather than 'explaining' from the outside (the latter would be the focus of e.g. Marx and Durkheim). To these approaches Smith adds a 'third way', which focuses on language and discourse, such as discourse analysis and post-structuralism and finally realism as a research approach.

Before embarking on a discussion of similarly or differently named research methodologies, and arguing for the one I have chosen, it might be worth considering what is meant by methodology and by methods. Booth (2005) introduces both terms in the following way:

"A method is seen as a recognized and appropriate way of pursuing knowledge that can illuminate the object of inquiry through research practices, doing the research. Methodology, on the other hand, comprises the grounds on which the method is (or methods are) understood, the epistemological, ontological, discursive commitments and ethical considerations that underpin the method and are demanded by the scientific discipline" (Booth, 2005, p.326).

Keeping Booth's definitions in mind, one can easily draw the conclusion that the relationship between research methodologies and methods is rather straightforward. It is, however, important to emphasize that a research methodology should provide a rationale and, in part, a justification for the methods that are selected and the way they are used (Stierer and Antoniou, 2004). 


\section{Overview of the qualitative-quantitative debate and its philosophical underpinnings}

As Lund (2005) states, the debate has been a many-sided one, ranging from particular themes about methods for collecting and analysing data to ontological and epistemological issues. He also raises issues about whether the qualitative and quantitative approaches should be regarded as two paradigms, being based on incompatible and incommensurable philosophical assumptions, or "be conceived as methodological variants within the same paradigm" (ibid., p.115).

Burgess et al. (2006) define paradigms, in general, as a set of beliefs that deals with ultimates and first principles. Kuhn (1996), considered the inventor of the concept of paradigm as a concept of methodology/epistemology, defines paradigms as frameworks within which 'normal science' is conducted. Paradigms are incommensurable because the criteria for what is true knowledge of one paradigm are internal and cannot be applied to other paradigms, the implication being that there is no such thing as universally true knowledge (Kuhn, 1996).

Lund (2005) holds that the differences between qualitative and quantitative research in psychology and education often are greatly exaggerated. While different empirical procedures are used, the two strands should be considered grounded on similar perspectives with respect to ontological and epistemological questions about reality and knowledge construction. 
The following overview of approaches to knowledge construction is mainly based on Smith (1998) and Redman (1999):

1. Empiricism (originating in positivism): Positivism (traditional, standard and logical) and falsificationism.

2. Idealism:

a) The neo-Kantian approaches (e.g. Menger, Weber, Durkheim) that see mental constructs (e.g. ideal types) as a means of simplifying and organizing the complex evidence in the social world. These approaches do not exclude the possibility of establishing general laws nor, in general, the use of quantitative methods.

b) Rational choice theory, game theory and praxeology (e.g. Morgenstern, von Neumann and Hayek), which typically see human beings as rational actors trying to maximize perceived benefits and minimize perceived costs. These approaches differ from most other qualitative approaches in that they take a quite detached perspective and attempt to provide simple, universally valid descriptions of social relations.

c) Hermeneutics and phenomenology (e.g. Dilthey, Husserl and Schütz), taking the idealist position to an extreme claiming that the objects of analysis are the products of our subjective interpretations and interactions, and there is no way researchers (as people inhabiting the social world) can be detached from the social world they are studying. The dominant approach within this group is often labelled ethnography. The focus is on collective meanings, which are produced in interaction and of which the researcher is an inseparable part. 
3. Conventionalism/relativism (with Kuhn and Feyerabend as the main proponents of the two respective approaches). These do not suggest any particular approach, but rather question or challenge the hegemony of any one approach.

4. Approaches focussing on language/discourse (e.g. discourse analysis in all its varieties, conversational analysis, interactional sociolinguistics, structuralism and post-structuralism). These approaches can be considered a sub-domain under the idealist approaches.

5. In addition to the above, one can identify approaches such as realism and a variety of feminist approaches (where these latter may apply methodology from any of the above mentioned).

Burgess et al. (2006) use a slightly different matrix for what they label paradigms in educational research:

1. Positivism

2. Post-positivism (identification of some knowledge claims as more likely to be true than others is possible. It often combines qualitative and quantitative approaches to data collection and analysis).

3. Interpretivism (there are no absolutes, but all phenomena can be studied and interpreted in different ways, and "realities are not abstract objects but dependent on the intersubjectivity between people") (p.6).

4. Critical/constructivist (feminist) (providing greater understanding and an explanatory framework of inequalities).

5. Post-modern (focus on breaking down conventional boundaries -"grand theories" could be replaced with situational narratives). 
The following is a brief discussion of the reasoning behind the choices of methodology made for this study, which at the same time provides an overview of available methods.

Empiricist approaches have been used very successfully for centuries in the natural sciences and, indeed, positivism could be considered an attempt to transfer this success to the social sciences (leading advocates of these approaches are e.g. Carnap, Ayer, Hempel and Popper (see e.g. Smith, 1998)). The supporters of this approach emphasize the need for 'objectivity', which requires a separation of the subject (the researcher) and the objects under study.

Historically, positivist attempts at replicating the natural scientific methods in social research were applauded and considered successful. Later it became clear how hard it is to keep values and facts separate in social science (see, e.g. Gould, 1981, and Eysenck, 1971). It also had to be acknowledged that the positivist assumption of nominalism was unsustainable, i.e. the meanings of social scientific concepts (e.g. 'family'), were not as straightforward as e.g. in molecular science (e.g. oxygen). Furthermore, the closed system approach of the natural sciences was not easy to apply to social research, where the objects are people, who cannot be isolated from a multitude of influences such as inner mental life, past experiences, the influence of any experimental environment etc. (and the results of such experiments were usually not easily applicable to 'natural' situations). Finally, the subject-object problem, i.e. the fact that the researcher is part of the social environment e.g. simply by being a human being has proven to be a complicating element in many empiricist studies.

If the above criticisms were not sufficient to discard an empiricist/quantitative approach to this study, there are other practical reasons to do so: the sample available for the 
present study is too small (14 teachers) for a reliable identification of correlations and furthermore, I am interested in exploring the ways in which NLP-based CPD attendees/teachers and other teachers talk about their work and their professional identity through interpretation of textual data provided by the teachers themselves and interpreted by me, a professional involved in the field.

From the opposite viewpoint it could be said that this study cannot 'satisfy' basic empiricist 'requirements'. First of all, because I neither can nor wish to impose any kind of closure since the aim of the research is to explore teachers' subjective experiences and perceptions in their natural environment. Secondly, the study involves collecting data concerning the teachers' emotions that are likely to be hard to quantify. Thirdly, I am, as the researcher in this study, highly involved in the object of study, being situated, generally, and having a dual role as a teacher-educator and researcher. Thus involvement is obvious and can only be acknowledged and furthermore seen as a strength since the involvement may provide the potential for enhancing validity due to my broader contextual understanding of part of the sample from which to make my inferences. Also in respondent validation we might have perhaps a greater chance of understanding one another's perspectives accurately given the existing relationships.

Given the above discussion it would make sense to look closer at other approaches. It was mainly as a reaction against positivist and empiricist approaches that such alternative approaches were developed, both philosophically and methodologically (Smith, 1998). The philosophical current behind qualitative approaches is idealism, which can trace its roots back to Plato, and more recently to Kant (1966), stressing the importance of ideas or mental constructs as a precondition for our knowledge of the world. 
Though both neo-Kantian and detached qualitative approaches, such as rational choice theory, have made important research contributions, it is with the hermeneutic/phenomenological branch that most qualitative researchers identify themselves and this is also where this study belongs. The formulation of my research question ('How do teachers in one Slovenian primary school talk about their professional identity and work following participation in NLP-based CPD in comparison with other teachers?') seems to be begging for an interpretative stance. Nias (1989), whose research in primary teachers talking resembles my study in many ways, justified her educational research in the following way: "My justification, if one is needed, is that neither pupils' nor adult observers' accounts can fully capture the lived realities of teaching as an occupation; that can be done only by allowing teachers to voice their own thoughts and feelings." (p.2). In this study I am also focussing on thoughts and feelings and I find it hard to see how these can be captured effectively and in-depth by any other approach than an interpretive one.

Another way of locating the present study methodologically is to try to locate it on four continua (adapting a set of concept pairs suggested by Redman (1999), where clearly the study would be located to the left on all four continua. The emphasis would be on understanding, getting quite involved in the process (though it is not a participant observation study), acknowledging the complexity of the issues (not trying to over-simplify) and that facts and values cannot be kept separate. An extreme opposite to this study would be a typical positivist study as the ones already mentioned by Gould (1981) and Eysenck (1971). 


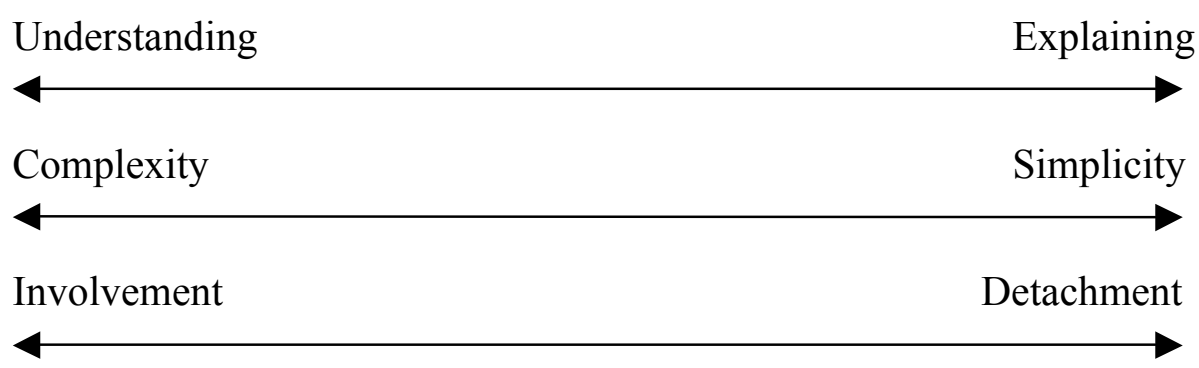

Facts and values inseparable $\quad$ Facts and values can/must be kept separate

Figure 5 Methodological concept pairs adapted from Redman (1999)

Phenomenological/interpretative researchers typically view themselves as instruments of data collection. Feelings, impressions and judgements are all a part of data collection. Personal interpretation plays a major role in terms of understanding and analysing the data and the findings are often presented as verbal descriptions. This approach accepts that science is theory-laden and value-laden and that it is possible to acquire knowledge about phenomena that are not directly observable. This last observation makes it even more obvious that this approach is the 'right' one for this study since the study is exploring teachers' value-laden subjective experience of their work and professional identity of which the latter may be considered less directly observable.

Even though the study clearly employs an interpretivist approach, this does not mean that it should not embrace methodological pluralism. The study does not apply a 'mixed approach', i.e. combining empiricist and idealist methods in one study (see e.g. Rex and Moore, 1967), however it does employ a so-called comparison group. I have chosen to involve a comparison group with the purpose of comparing the ways teachers talk about their work and their professional identities between a group of teachers who attended NLP-based CPD and those who did not. Initially there was a thought to employ a 'control group' i.e. the group of teachers that did not attend NLP-based CPD would 
form a control group. The label 'control group', however, would indicate an experimental design of the study, which is not the case. The use of control groups usually allows researchers to eliminate and isolate confounding variables and bias. The term 'control group' is well known particularly from medical research where groups of patients are given placebo treatment. The purpose of such experimental control groups is to provide a constant with which to compare the group of participants that are subjected to 'real' treatment (the independent variable). The famous 'placebo effect' is in such cases an example of the way in which a 'non treatment' (e.g. giving medication that should have no effect) ends up having an effect and thus becomes a confounding variable. Since the study is interpretative and exploratory and not experimental, it does not fulfill the basic criteria for the employment of 'control group'. That is why the label 'comparison group' has been chosen since it signals a less rigorous comparison with lesser claims of reliability and validity and with stronger focus on exploration of potential similarities and differences between the two groups. I also decided to quantify some of the data, although the study is phenomenological/interpretative. Perhaps a few words should be dedicated to the issue of whether the study is 'ethnographic'. This term is used quite broadly to the extent that it sometimes appears to simply mean 'qualitative'. I have chosen to consider ethnography a more narrow term, where it refers to a study of collective meanings closely related to anthropology. It could be argued that I apply similar methods to ethnography and that to some extent I am studying teachers as a 'people' or a 'culture', but this is certainly not the key purpose of the study.

Similarly, although some aspects of the study come close to approaches used in discursive approaches (and indeed applies linguistic analysis), this study does not, as most discursive approaches, have a focus only on how the participants talk, but rather 
both on how on what they say. In the early phase of the study these approaches looked likely to find some application in this study, as a lot of the analytical work is of linguistic data. It was decided, however, that there would be risks involved in this due to the 'double-foreign language issue' (my mother tongue is Serbian, the research is carried out in Slovenian and the dissertation is written in English), which is further elaborated in this and the following chapters.

To sum up, given the discussion above, it has become clear that the approach is interpretative. However, some elements of other approaches might be present (comparison group, quantified data) for the sake of providing useful insights into the subject matter of the study.

\section{Discussion of research methods, techniques and tools}

\section{Collecting, recording and analysing data}

There is a wide range of different options for collecting data, and it has often been suggested that one should start out choosing one's epistemological standpoint, e.g. empiricist or interpretivist, and then design the study accordingly, i.e. applying the methods used within the chosen approach. Lund (2005), however, has emphasised the importance of defining one's research before choosing research methods by asking the following questions:

- Is the research descriptive or causal?

- Is the research exploratory or hypothesis testing?

It could be said that these questions will, in any case, force a choice of epistemological standpoint, but still with the difference that a research idea has already been developed. 
Keeping in mind the final wording of my research questions ('How do teachers in one Slovenian primary school talk about their professional identity and work following participation in NLP-based CPD in comparison with other teachers?') one might argue that there is no causality included in the question. Thus, it would seem obvious that the study would be mainly descriptive and exploratory. Even though there might have been built-in implicit hypotheses in the previous formulations of the research question, the most recent formulation seems to be (relatively) 'hypothesis-free'. However it is worth noting that there is still a slight hint of hidden hypothesis both in the fact that the question addresses two groups presupposing the potential differences and/or similarities and in the emphasis on NLP.

It may be useful to keep in mind the methods traditionally used by the two main research 'strands' e.g. questionnaires and surveys (quantitative research); structured observations, structured interviews, documents (used by both quantitative and qualitative research though in different ways, and above all with different overarching theoretical positions); unstructured or semi-structured interviews, reflective diaries, unstructured observations, group discussions (qualitative research).

Each of these groups of tools has their advantages and disadvantages depending on the aim of the research, its contexts and nature. These will lead back to the discussion above on empiricism versus phenomenological/interpretative approaches, where the empiricist approach has strength in providing internal reliability and validity, and some would accept their claims to objectivity. On the other hand the approach will simplify the social 'reality' and not provide an in-depth understanding of it. A way of trying to seek a middle ground between the approaches would be to have some pre-established coding systems and have a plan for what to look for. 
In this study I have decided to look for certain types of data that are pre-categorised, but at the same time, to try to keep an open mind to 'emerging' themes, i.e. themes that may appear unexpectedly.

Both qualitative and quantitative methodologies produce a mass of data, which need to be sorted and managed in order to be useful for the study. In order to ensure rigour and reliability, this process needs to be well planned.

For example, in semi- or unstructured interviews the amount of unstructured data means that an organizing system is needed so that the material can be divided into manageable chunks that can be categorized. Stroh (2000) suggests that this is usually done through a coding procedure in which chunks of text are labelled, or coded, and then stored by these codes.

Based on the aim of the study to explore teachers' subjective accounts of their professional identity and their work, it becomes clear that the use of questionnaire or survey would limit that exploration. The consideration of different data-collection methods led to the following decision making process. First semi-structured interviews were chosen since that format introduces pre-determined categories and at the same time leaves enough space and freedom for personal accounts. Unstructured interviews and pure inductive coding were considered briefly, however there were several reasons for not employing them and for choosing a semi-structured approach and a combination of deductive and inductive coding:

a) Economy: they would generate a vast unstructured data corpus, which would lead to a demanding coding process. 
b) Focus: since the research question includes a focus on NLP, it would be beneficial to explore the content of the NLP-based modules and their impact or lack of it on the teachers.

Furthermore, semi-structured interviews can provide a wide variety of valuable information only if the questions are carefully designed and asked, and the data analysis is thoroughly conceptualised. The qualitative researcher needs to 'fine-tune' the self (OU E835 Study Guide, 1996, p.90). In order to successfully encourage the interviewees to talk in their terms about their professional identity and their work the 'right' questions should be asked and the 'right' way of asking them should be developed.

Further consideration of additional data-collection tools took place and it was decided to test unstructured non-participant classroom observations prior to carrying out semistructured interviews and reflective diaries after both observations and interviews had been carried out. There are different reasons for choosing the above-mentioned combination of different data-collection tools. The main one is that the examples of teachers' subjective experiences will be collected through semi-structured interviews, reflective diaries and observations in order to establish a good platform for both reflective/subjective experience documented by the subjects of the study, and purely observational approach undertaken by the researcher. The other reason is provision of triangulation by employing three different sources for teachers' subjective experience of their professional identity and their work. The unstructured classroom observations prior to carrying out semi-structured interviews were chosen to 'set the tone' and give concrete examples for interviews. The reflective diaries were to contribute to the "free 
flow' of the teachers' thoughts that would thus not be prompted by any question or comment posed by the researcher. The Initial study added yet another layer in datacollection tools by sparking a consideration of the mixture of video-stimulated followup interviews and feedback sessions.

\section{The development of the research sequence}

The setting

The research was carried out in the 'pilot' school - a primary school in Slovenia, where 14 teachers during the last five years have attended all ten CPD programme modules. The school is a 'typical' suburban Slovenian primary school (educating 6-15 year olds) in the area with 30 fully employed teachers and 583 students. There are two groups of teachers, 14 who have attended the personal development training and 16 who have not (thus the latter could form a comparison group). The original plan and its changes after the Initial study described later in the chapter are presented in the table below: 


\begin{tabular}{|c|c|c|c|}
\hline Purpose of data collection & DATA COLLECTION & PARTICIPANTS & LOGISTICS \\
\hline $\begin{array}{l}\text { To explore the teachers' ideas } \\
\text { about their professional identity } \\
\text { and their work }\end{array}$ & $\begin{array}{l}\text { Semi-structured } \\
\text { interviews }\end{array}$ & $\begin{array}{l}\text { Originally planned: } 16 \text { teachers who } \\
\text { attended NLP-based CPD and } 14 \\
\text { other teachers } \\
\text { New plan after the Initial Study: } \\
7 \text { teachers (NLP-based CPD } \\
\text { attendees) } \\
7 \text { other teachers }\end{array}$ & $\begin{array}{l}\text { Length: Up to an hour long } \\
\text { face to face interviews } \\
\text { Recording: Video (digital) } \\
\text { Location: the school training } \\
\text { room }\end{array}$ \\
\hline $\begin{array}{l}\text { To give a chance to the } \\
\text { teachers to freely write about } \\
\text { their thoughts and ideas about } \\
\text { their everyday life as teachers } \\
\text { (without any interferences } \\
\text { coming form the researcher in } \\
\text { the form of questions or } \\
\text { comments). }\end{array}$ & Reflective diaries & $\begin{array}{l}\text { Originally planned: } \\
\text { 5-7 teachers (NLP-based CPD } \\
\text { attendees) } \\
5-7 \text { other teachers } \\
\text { New plan after the Initial Study: } \\
3 \text { teachers (NLP-based CPD } \\
\text { attendees) } \\
3 \text { other teachers }\end{array}$ & $\begin{array}{l}\text { Frequency: } 1 \text { reflective diary } \\
\text { per week (on Fridays) } \\
\text { Duration: Half a term ( } 9 \\
\text { weeks) }\end{array}$ \\
\hline $\begin{array}{l}\text { To observe the teachers 'in } \\
\text { action', in their natural setting } \\
\text { and note down concrete } \\
\text { events/episodes in connection } \\
\text { with the above-mentioned } \\
\text { themed topics in order to have } \\
\text { 'a spring board' for discussing } \\
\text { them }\end{array}$ & $\begin{array}{l}\text { Non-participant } \\
\text { unstructured observations } \\
\text { New plan after the } \\
\text { Initial study: } \\
\text { Non-participant semi- } \\
\text { structured observations }\end{array}$ & $\begin{array}{l}\text { Originally planned: } \\
16 \text { teachers (NLP-based CPD } \\
\text { attendees) and } 14 \text { other teachers } \\
\text { New plan after the Initial study: } \\
7 \text { teachers (NLP-based CPD } \\
\text { attendees) } \\
7 \text { other teachers }\end{array}$ & $\begin{array}{l}\text { Timing: prior to interviews } \\
\text { Recording: Video (digital) } \\
\text { Length: } 45 \text { minutes }\end{array}$ \\
\hline $\begin{array}{l}\text { To explore the level of } \\
\text { congruence between what was } \\
\text { said in the interviews/written in } \\
\text { the reflective diaries and } \\
\text { demonstrated in the classroom }\end{array}$ & $\begin{array}{l}\text { Decided on after the } \\
\text { Initial Study: } \\
\text { Individual video- } \\
\text { stimulated follow-up } \\
\text { interviews and feedback } \\
\text { sessions (respondent } \\
\text { validation) }\end{array}$ & $\begin{array}{l}7 \text { teachers (NLP-based CPD } \\
\text { attendees) } \\
7 \text { other teachers }\end{array}$ & $\begin{array}{l}\text { Timing: after carrying out } \\
\text { observations and semi- } \\
\text { structured interviews and } \\
\text { collecting reflective diaries and } \\
\text { after preliminary data-analysis } \\
\text { Length: Up to an hour } \\
\text { Recording: Audio (digital) }\end{array}$ \\
\hline
\end{tabular}

Table 3 Data collection table 


\section{VALIDITY, GENERALISABILITY AND RELIABILITY VS. TRUSTWORTHINESS}

This section accounts for two different ways of looking at the quality of research. On one hand it discusses the application of the criteria of empiricism, which are usually referred to as 'reliability' and 'validity', to a study that is predominantly qualitative, and on the other hand the consideration of an alternative set of criteria, which has been labelled 'trustworthiness'.

Reliability is mostly connected to quantitative research (precision, accuracy), where validity is also considered a measure for logical consistency and comprehensiveness in terms of the construction and content of the research methods and the execution.

The reliability of my findings depends on the quality of my methods of data collection, analysis and descriptions. The question of reliability in qualitative research focuses on the replicability of observations and on whether other researchers using similar methodologies would make similar observations and draw similar conclusions.

Of course, including only one local school in the study limits the validity and the generalisability of my findings. Yet, hopefully teachers reading the results of the research might recognise similar situations arising in their own professional settings nationally, and internationally. Such recognition might validate the findings of small one school-based projects and highlights the relevance of researching a few cases in depth, as suggested by Graue and Walsh (1998). 
Collaboration (asking informants to comment on the analysis and the findings) provides a second interpretation of the data, which may provide additional validation thus supporting the findings of the research. Video-stimulated interviews/feedback sessions are employed to have exactly that role.

As far as reliability is concerned, Graue and Walsh (1998) claim that much of the world is not readily measurable and that a good narrative description is often more accurate than a measurement description. I believe the strength of measurement is precision rather than accuracy.

In the paragraphs above I have attempted to look at my study applying empiricist criteria for the quality of research. Several authors have questioned the applicability of the empiricist concept of validity in qualitative research. Hammersley (1992) suggests we should rather focus on 'confidence in results'. Furthermore, Ely et al. (1991) have challenged both reliability and validity as measures of research quality and have suggested that we replace them with the criteria of trustworthiness, quality and rigour. The rigour of the approach can be seen as resulting from a close fit between the epistemological and ontological position, and the methods chosen for data collection and analysis (see Gavin, 2008).

Lincoln and Guba (1985) refer to credibility, transferability, and dependability/confirmability as criteria for qualitative research.

Credibility, according to Lincoln and Guba can be approached through six means:

- prolonged engagement

- persistent observation 
- triangulation,

- negative case analysis,

- $\quad$ peer checking

- member checking

In present study it has been possible to apply all six means to varying extent.

Transferability can be approached through what Geertz (1973) calls 'thick description' enabling potential generalisation from rich examples of the particular.

This has also been possible in the present study as is demonstrated in the description of the findings (see Chapter 5 and Chapter 6).

Finally, confirmability emerges from providing a clear and explicit analytic trail that enables others to follow the stages of analysis and research decisions made.

I have aimed at achieving this through explicit documentation of the coding process and narrative account of the whole research process (see Chapter 5).

Thus, applying Lincoln and Guba's (1985) criteria it should be possible to be quite confident about the present study.

On the other hand, I believe no one's efforts to organize another's thoughts can ever be free of distortion, but if teachers themselves recognize their own truths in what I show them as transcripts of their interviews, this would be a satisfactory validation.

\section{Sampling}

Sampling was another issue to address: First of all, the school was not chosen because it was 'representative' of Slovenian educational settings, but rather it was chosen by the 
Slovenian Ministry of Education to be a 'pilot' school for a broader 5-year long project (as explained in Chapter 1). Each educational setting is unique, although different settings will undoubtedly have similarities due to the nature of curriculum content and current trends in teaching.

Another sampling that happened (although this was not originally planned) is that of teachers that will be involved in the study. Originally it was planned to include all the teachers (30) in the school, but after conducting the Initial study, the conclusion was drawn that the number is too high. In order to choose how many and which teachers to interview and ask to keep diary, one needs to decide on selection criteria. In the early phase of the research planning, one of the possible ideas was to ask for volunteers (and still trying to get as diverse representatives within volunteers as possible in terms of age, career length, taught subject, key stage and gender). This would provide a probability sample attempting a systematic random sampling although what the study was exploring are the particularities, which may not be attempted to be generalized beyond the individuals involved in the study. Representative sampling in the study of this kind is probably not very feasible.

As mentioned above due to changes introduced after the Initial study, the original plan of interviewing all non- and all NLP-trained teachers has changed to aiming for interviewing 7 teachers from each group. Hence, the preliminary talks with the school management were held in the beginning of October 2006 and the variety of potential strategies for respondent selection had been developed, such as:

1. The psychologist emailing all the teachers (30) and asking for 7 volunteers from each group. 
2. The psychologist publishing a message on the school staff notice board and asking for a response either by email or personally in her office (in order to avoid endangering anonymity).

3. The researcher giving a short presentation for all teachers and asking for volunteers (main issues here: a) finding a time when all 30 teachers are present in the school and have a 20-minute slot; b) handling potentially higher or smaller number of volunteers)

After discussing with my supervisor and the school management, the strategies listed as 1 and 2 above were combined. An additional selection of the respondents was integrated in the above-mentioned one: the selection of the respondents, who kept reflective diaries for half a term (nine weeks). For the sake of triangulation, it was necessary to include the same teachers in all three data-collections: interviews, observations and reflective diaries. Following the success of the respondent selection in the first phase it was decided to adopt the same strategy, just in this case it was the researcher emailing the already chosen teachers (14) and asking for 3 volunteers from each group.

It was decided early on that the 'pilot' teachers should not be included in the main research due to reasons of potential 'cross-contamination' as described later in this chapter.

Another issue to be addressed is the issue of self-selection. The fact that the choice of attending a CPD programme based on NLP was left to the teachers themselves and they voluntarily decided to take that path leaves the door open for speculation that there might be a 'confounding' variable involved, where the NLP-based CPD attendees might have certain characteristics prior to the trainings, and the other teachers would have 
other characteristics. This concern can partly be dismissed, because the other teachers also expressed a wish to participate in the NLP-based CPD programme, but could not enrol due to the group size limitation ( $\max 16)$ imposed both by the Slovenian Ministry of Education and the CPD programme provider. Thus the first 16 teachers, who wrote their names down formed the group that was later included in the CPD programme. The school psychologist informed me that 28 (out of a total of 30 ) teachers wished to take part in the NLP-based CPD programme. This reduces considerably the risk of bias due to differences among the participants before the trainings took place.

As mentioned in the Introduction to the dissertation the CPD modules were financed by the Slovenian Ministry of Education, Department for Adult Education and were included in the annual catalogue of permanent and continuing education of pedagogical and andragogical workers in Slovenia, which meant that teachers, who attended the programme, got so-called 'pedagogical points', i.e. credit relevant for their promotions and future studies. Thus 'pedagogical points' or career enhancement might be credited as an additional motivational trigger.

\section{ETHICAL ISSUES}

In any social research ethical issues are inevitable. In order to demonstrate ethical responsibility, one needs to aim for clarity in terms of how the study has been designed, data collected and analysed, and how it has been written up with the main aim to properly protect and inform all involved participants. In this study I have followed the ethical guidelines of the British Educational Research Association (BERA Revised Ethical Guidelines for Educational Research, 2004) and the Open University Research Ethics procedures (Open University Research Ethics procedures website). 
As Graue and Walsh (1998) says: being ethical requires being honest with all involved, and this involves all participants knowing exactly why the research is taking place. An agreement (written or oral) must be made, which should make reference to:

- confidentiality (identities)

- the process of interviewing itself

- what if a participant changes his/her mind about taking part

- who to talk to if a participant has complaints

In the case of this study, an oral agreement with teachers was made, and showing my analysis of teachers' interviews and diaries to the 'authors' and obtaining their comments during the video-stimulated follow-up interviews have strengthened the validity of the study.

Before my research began, the school management had informed the teachers, on behalf of the Slovenian Ministry of Education, about their involvement in the overall project and research. The teachers had the opportunity to decline involvement. I gave assurance that all recorded material would be for personal research purposes only and that my work would ensure anonymity of the teachers and the school. During the course of the study I was obtaining information about individuals, and it was necessary to assure them that their feelings, attitudes and their privacy would be respected. The teachers got the promise that any part of their accounts could be omitted from the data if they were to wish so during the feedback sessions (where they validated my data analysis and findings). 
Gaining access is always a demanding issue irrespective of whether the access is easy or less easy. The participants of this study all showed enthusiasm and even pride in being able to take part in the study. It is important, however, to note that 'too eager' participants may also be problematic. It could be, e.g. that the participants have a shared wish to change the Slovenian educational system in a certain direction as well as aim to 'please the researcher'. This was something to be monitored throughout all the phases of the study particularly with the group of the NLP-trained teachers with whom I had established rapport during the course of the CPD programme. Even though the potential "please the researcher" syndrome needed to be noted and addressed early on, it was even more important to do so during the data analysis and in the final stage of discussion of findings and overall reflection on the study.

Furthermore, I need to acknowledge that I may unconsciously have a hope that is shared by the Ministry of Education to get to the point, where we, who are involved in professional and personal development of teachers in Slovenia, can claim that we are moving towards an important change of the educational system on the 'macro' level, i.e. that we are "changing the teaching profession" (Fullan, 2001, p.265), or at least aiming for changes on the 'micro' level including the individuals' construction of realities.

\section{Dual role}

It is also necessary to consider my dual role (as teacher-educator and researcher - to which could be added that I was indirectly carrying out work for the government). First of all, it needs to be said that all research is situated, even when it may be less apparent than in this study. Secondly, there are several ways to counter these risks: The collected 
data will be presented openly with a clear account of how analyses and interpretations were made, and how any conclusions were drawn, in order to make it possible for peers to make their own assessments.

The combination of interviews, observations, reflective diaries, video-stimulated interviews and feedback sessions could, furthermore, have the additional benefit of facilitating a triangulation process.

Orland-Barak (2002) reintroduced the dilemma of researcher's dual role while exploring the theoretical sensitivity in her own research. She has developed the idea of dual role further into 'competing selves' of the researcher thus adding complexity to the already complex concept.

While discussing Orland-Barak's article during the EdD Research Methodology Day I was fortunate to discover Strauss and Corbin's (1990) claims that the researcher can be aware of the subtleties of the meaning of data based on different sources, ranging from previous reading, research, documents to "professional experience... if the researcher is fortunate enough to have had this experience" (p.42). This has shed some light on my 'dual role' or 'competing selves' and twisted a dilemma into a feeling of privilege rather than disadvantage.

Even though the idea of multiple researcher's selves has already appeared in the past (Connelly and Clandin, 1990; Day, 1998), Blumenthal (1999) has added another twist to it by introducing the concept of the Divided Self. The concept is introduced as a methodological approach for interpreting how people produce stories differently "depending on which identity is placed at the fore" (ibid., p.380). 
The comment made by Professor Murphy during the EdD Research Methodology Day about my choice of data-gathering tools has contributed considerably to an exploration of my dual role. She suggested that my influence on the respondents would be diminished when the teachers write reflective diaries, as this would happen without my presence. Her comment paved the way for a more relaxed and open-minded approach to dealing with my dual role in the study.

\section{Reflexivity}

Bias is an issue in any type of research, whether quantitative or qualitative. We are all to some extent products of an environment that shapes and distorts our perceptions in subtle and numerous ways (a famous example of such distortion is provided by Hanson (1965)).

An important way of dealing with ethical concerns is the researcher's own reflexivity, which may contribute to the transparency of the research and its methodology. Throughout the research process one needs to take a reflexive stance, so that the implications of methods, values, biases and decisions for the knowledge about the social world one generates are considered. As I collected, analysed and wrote up my data I was aware of and acknowledged the role of myself as the researcher in the construction of knowledge. Shacklock and Smyth (1998) consider reflexivity to be the conscious revelation of the role of beliefs and values held by the researcher in the selection of a research methodology for knowledge generation and its production as a research account. Finlay (2002) offers different variants of reflexivity of which one is 
introspection. When Maslow (1966) asserted that "there is no substitute for experience, none of all” (p.45), he pointed researchers towards self-dialogue and discovery.

I agree with Flood (1999), who said that "without some degree of reflexivity any research is blind and without purpose" (p.35). Taken as a whole, in its various guises, reflexivity has the potential (among many others) to be a valuable tool to examine the impact of the position, perspective and presence of the researcher. For all the difficulties inherent in the task, to avoid reflexive analysis altogether is likely to "compromise the research" (Finlay, 2002, p.227). I believe reflexivity can encourage researchers to provide honest and ethical accounts of their research.

On the other hand, Haywood and Mac an Ghaill (1998) warn researchers of the gap that can emerge from abstract theorizing on research methodology and its relation to the dynamic process of doing research.

The challenge for researchers using introspection is to use personal revelation not as an end in itself but as a springboard for interpretations and more general insight. In this sense, the researcher moves beyond 'benign introspection' (Woolgar, 1988, p.22) to become more explicit about the link between "knowledge claims, personal experiences of both participant and researcher, and the social context" (Finlay, 2002 p.215). I believe that this kind of reflexivity was more than welcome in my case considering the socio-political background of the whole project in Slovenia that goes beyond the study that I carried out. The greatest contribution to my own reflexivity was keeping a researcher's journal. It was a springboard for many insights and deep exploration of the reciprocity between my own subjective experience of teacher's professional identity and the respondents' ideas, opinion and accounts of their professional identity and their 
work. Thus my own reflective journal contributed to my own professional development both as a teacher and as a researcher. I have found myself adopting the action-research cycle that is described later in Chapter 4.

Overall, I believe that it is through a consideration of ethical issues and dilemmas in the process of conducting research that I extended my professional knowledge as an educator and developed my reflexive practice.

\section{CONCLUSION}

Based on the epistemological and methodological discussion above it will have become clear that I am an advocate of methodological pluralism. It will also have become fairly clear that the study has predominantly been following the interpretative tradition, acknowledging that in a study of the type that was being undertaken it would not make practical sense to try to stay detached from a field I am highly involved in. The scope of the study, furthermore, would not make a reliable quantitative study feasible, but most importantly, a quantitative study would not be likely to provide an in-depth exploration of the question I am asking, i.e. 'How do teachers in one Slovenian primary school talk about their professional identity and work following participation in NLP-based CPD in comparison with other teachers?' Thus interpretative qualitative research methods will be applied, first of all semi-structured interviews and (non-participant) unstructured observations. Additionally, reflective diaries will be used to acquire a deeper insight into the internal processes of the participants. Finally the video-stimulated follow-up interviews in the combination with feedback sessions add their contribution to both triangulation of the data and respondent validation. 


\section{THE EdD INITIAL STUDY}

As mentioned above, I have decided to include a discussion of the Initial study in the Methodology chapter because the outcomes of the Initial study has had a considerable impact on the methods and procedures applied to the main study.

Even though a semi-structured interview schedule had already been tested, as part of my MA study, I planned to design a new schedule and test it due to the changes made to the formulation of the research question. At the same time, I was interested in testing video and audio recording to determine which technology would be most adequate. There is a risk of reactivity due to video recording, which could be countered adding participant validation to the researcher's assessment. The plan of involving the teachers in either a video-stimulated follow-up interview or in a feedback discussion would provide a means of triangulation to allow assessments based on observations and transcripts to be clarified by the participants' own perception of the situation (Hargreaves et al. 1975, cited in E835 Study Guide, p.98). I was also aware that the use of video recording might lead to an illusion that revisiting the recording would enhance my understanding of the situation as suggested by Pimm (1994). I was interested in testing non-participant unstructured observations of the lessons prior to the interviews in order to check if they might be useful for the researcher (for 'getting into the right state' and to obtain an opportunity to refer to some of the observed events) and for the respondent/interviewee. It needs to be acknowledged that a researcher's presence alters the 'normality' of the situation and that the teacher and children may react to it in a variety of ways. I expected the planned Initial study would help me to firm up my research question and methodology. The additional aim of the Initial study was to test my idea of having a 
comparison group. I was interested in testing whether the collected data would give any support (through similarities or differences) for employing a comparison group.

I also decided to explore adding reflective diaries as an additional data source, both because working with diaries adds to the interpretivist stance I am taking and because of the potential of triangulation as well as trying to achieve a combination of subjective/objective data collection tools - seeing the other two (interviews and observations) as deeply connected to researchers' co-participation whereas diaries are solely respondents' product (though in the process of data reduction and analysis a researcher resumes a 'power position').

In the Initial EdD study it was attempted to choose teachers who would not take part in the main study. The respondents in the Initial study were asked not to talk about the content of the interview questions with their colleagues in order to avoid so-called 'cross contamination' and not to meet with the participants during the main study since they would already be familiar with the interview questions.

The Initial study consisted of testing the following data collection methods:

\section{Unstructured non-participant observations}

2. Semi-structured interviews

3. Reflective diaries

Each method was trialled with two participants, one NLP-based CPD attendee and one other teacher, where the other teacher was not the same for all three data collection phases (see Table 4). The sampling could be considered a convenience sample (Cohen 
et al., 2004) since the teachers took part in the Initial study simply because they were available at the time. The profiles of the participants were as follows:

\section{Semi-structured interviews and non-participant observations}

\begin{tabular}{|l|l|l|l|l|}
\hline Participant & Subject & Year & Age/Gender & Career length \\
\hline $\begin{array}{l}\text { NLP-based CPD } \\
\text { attendee/teacher }\end{array}$ & Physical education & $\begin{array}{l}5^{\text {th }}-9^{\text {th }}(11-15 \text { yrs old })-\text { year } \\
5 \text { observed }\end{array}$ & $53 / F$ & 30 \\
\hline Other teacher & Physical education & $\begin{array}{l}5^{\text {th }}-9^{\text {th }}(11-15 \text { yrs old })-\text { year } \\
5 \text { observed }\end{array}$ & $40 / \mathrm{F}$ & 12 \\
\hline
\end{tabular}

\section{Reflective diaries}

\begin{tabular}{|l|l|l|l|l|}
\hline Participant & Subject & Year & Age/Gender & Career length \\
\hline $\begin{array}{l}\text { NLP-based CPD } \\
\text { attendee/ teacher }\end{array}$ & Physical education & $5^{\text {th }}-9^{\text {th }}(11-15$ yrs old $)$ & $53 / \mathrm{F}$ & 30 \\
\hline Other teacher & Mathematics & $4^{\text {th }}-6^{\text {th }}(10-12$ yrs old $)$ & $46 / \mathrm{F}$ & 24 \\
\hline
\end{tabular}

Table 4 The profiles of the Initial study participants

\section{Pre - Initial study - The design of the questions}

As mentioned earlier, due to the received supervisory feedback and further explorations and the reformulation of the research question, the focus and scope of the research changed from covering all ten CPD modules (as originally planned) to covering modules that are based on NLP. The design of the questions for the semi-structured interview schedule was based on the content of the NLP-based modules (see Appendix 1). Thus the interview schedule I developed covered seven major topics:

1. Self-description as a teacher;

2. Job satisfaction;

3. Attitude towards work;

4. Description of own communication skills;

5. Description of own motivation strategies/skills;

6. Strategies for handling 'demanding' situations;

7. Future plans

In order to ensure additional triangulation, while developing the questions for the semistructured interview schedule, I decided to ask my colleagues (from the Further 
Education college in Slovenia, where I work) for their opinion and an opportunity to test the questions (see Appendix 8 for more details) .

As a result of the Pre-Initial study one sub question and one questions were added:

1. "Has anything changed over the years?" was added to the questions number 4,5 and 10 (see Appendix 2).

2. "Is there anything you would like to add or explore further?"

Thus the final interview protocol included 9 areas and 12 questions (see Appendix 2/2a). The descriptions of how different data collection methods employed in the Initial study worked follows below. They are presented chronologically, i.e. following the original process of data-collection for the Initial study.

\section{Non-participant observations}

Even though the semi-structured interview schedule was ready for testing in the school, the observations scheme prior to the interviews needed more thorough preparation. In the early stage of the study I presented/designed a plan for carrying out unstructured non-participant observations with no follow-up standard analysis, however in order to get as precise and referential information as possible the design of a semi-structured observation was attempted. As mentioned earlier, the main purpose of testing nonparticipant observations was to examine whether they might be useful for the researcher (for getting into the 'right state' and to get an opportunity to refer to some of the observed events) and for the respondent. I realised that I might collect more useful information if I at least partly structured them so that I would be aware of which phenomena I needed to record. Thus the following plan for semi-structured non participant observations was made: 


\begin{tabular}{|l|l|l|}
\hline $\begin{array}{l}\text { Observed phenomena } \\
\text { (NLP-trained teacher/PE lesson) }\end{array}$ & Timing & Examples \\
\hline Communication skills & & \\
\hline Motivation strategies & & \\
\hline Handling demanding situations & & \\
\hline Other emerging phenomena & & \\
\hline
\end{tabular}

Table 5 A template for recording observations

The observed phenomena were derived from the topics of the interview questions i.e. the content of the NLP-based modules. The timing was included for easier tracking of the concrete examples of the phenomena. Both observation events were video recorded using a digital camera and they proved to provide valuable information and good references for a majority of the interview questions, particularly questions number 7,8 and 10 (see Appendix 2). Thus I could any time "back up" the interview question with a concrete observed example. The following examples might be illustrative:

\begin{tabular}{|l|l|l|}
\hline $\begin{array}{l}\text { Observed phenomenon } \\
\text { (NLP-trained teacher/PE lesson) }\end{array}$ & Timing & Examples \\
\hline Communication skills & $\begin{array}{l}13 \text { minutes into the } \\
\text { lesson }\end{array}$ & $\begin{array}{l}\text { Teacher: What are the rules in basketball? } \\
\text { Students: silence Teacher:...ok, forget that } \\
\text { question for now and just share in pairs what you } \\
\text { personally find most exciting about basketball... }\end{array}$ \\
\hline Handling demanding situations & $\begin{array}{l}19 \text { minutes into the } \\
\text { lesson }\end{array}$ & $\begin{array}{l}\text { (After a few students complained about the way } \\
\text { they got paired for practising basketball) } \\
\text { Teacher: ok, let's form a circle... and now run to } \\
\text { the person who is of approximately your height } \\
\text {.that's it and that is your pair ... off you go }\end{array}$ \\
\hline Motivation strategies & $\begin{array}{l}\text { Teacher:...you can do it your way, come on, } \\
\text { perhaps you will discover a completely new, } \\
\text { innovative way of doing "scissors" }\end{array}$ \\
\hline Other emerging phenomena & $\begin{array}{l}\text { n/a minutes into the } \\
\text { lesson }\end{array}$ & \\
\hline
\end{tabular}

Table 6 A sample of coded observation

After the Initial study was conducted, the usefulness of the semi-structured nonparticipant observations became obvious and I decided to develop them further beyond their role of a "prompt" for the semi-structured interviews. I started exploring the idea of reusing the video recordings of observation events in order to elicit additional information such as focus on the relation between what I observe teachers were doing and what they were saying in the interviews. In case of finding out significant pieces of information while revisiting the video recordings of the observations they might be 
brought out during the video-stimulated follow-up interviews and/or in discussions after the interviews.

\section{Issues connected to observations}

There was an ethical issue to consider since during the lesson observations the children were video-recorded. For the Initial study, the principal allowed video-recording since the parents of all the children had been informed that the school is involved in two international EU projects and one research study and that their children might be involved both in video-recordings and group discussions. The psychologist at the school promised to check the legislation in Slovenia whether an additional written parents' consent would be needed for the main study. After further consultations it became clear that the school already had acquired generic consent from the parents that allows the children to take part in academic research projects.

There were some logistic issues, as well. Due to the fact that the observed lessons were in Physical Education, some unexpected difficulties emerged such as the demanding task of video-recording and moving around the gym while trying to note down the observed phenomena and the timing. Another issue related to the wish to conduct the teacher interview immediately after the lesson observation, where it turned out to be complicated in practical terms. For the Initial study, I could only wait to be informed who of the teachers would have a break in between their lessons so that they could be interviewed after the observation of their lesson. In the Slovenian education system, there is no common lunch break for the teachers. The longest break during a school day is 20 minutes, which would not be sufficient for carrying out a semi-structured interview. Hence it would have taken a considerable effort to ensure that all the 
interviews (14) were to be conducted immediately after the observations. I believe there are advantages of carrying out interviews immediately after the observations since the observed phenomena are still 'fresh' both for the researcher and the interviewee, but I am also aware of a few disadvantages as it is pointed out below. The whole idea of the two data collection phases happening in immediate succession had to be reconsidered. This issue was resolved by drawing up a new plan, e.g. trying to conduct the interviews either later during the same day of the observation or the following day, and thus the lack of time for carrying out a brief analysis of the observations had also been resolved. This was the main disadvantage of carrying out observations and interviews one immediately after the other.

Using a very small digital camera proved to be a useful tool and the experience of overcoming the awareness of the camera in the classroom positively prepared the participants for video recorded semi-structured interviews.

\section{The semi-structured interviews}

The semi-structured interviews were carried out in the 'Equipment room' for Physical Education and were recorded using a web camera connected to a laptop computer. The first interview (with a teacher who did not attend NLP-based CPD) lasted 42 minutes and the second (with an NLP-based CPD attendee/teacher) 45 minutes.

After each interview, there was a brief 5-minute feedback session with each teacher consisting of an exploration of one single question: "How was it?" Both teachers emphasized that after first few minutes they got relaxed and felt free to talk and expressed concerns about getting interrupted by their colleagues (who were entering the room and addressing the interviewees). The non NLP-trained teacher was surprised that 
some of the questions made her think of some issues she had never thought of before. This comment made at this early stage of the study pointed towards the reflexivity process as a potential 'added value' of being interviewed.

The transcription of the Initial study interviews took around five hours for each interview and once completed it was not shown to the interviewees for practical reasons. In the main study the respondents were asked to review the transcripts and comment and make changes, should they wish to, and also to indicate material that they would consider 'off the record' (none of the participants wished to make changes or have any parts removed).

\section{Coding phases}

Since the transcription itself proved to be time consuming, I tried to find the most structured and time-efficient way to further organize the collected data. In the introductory chapter the Good Work Project (1997/2001) from Harvard Graduate School of Education was mentioned due to similarities found in their study and it was hoped that the project might provide me with ideas for my research. The Good Work Project is a large-scale research study co-directed by Mihaly Csikszentmihalyi of the Claremont Graduate University, William Damon of Stanford University, and Howard Gardner of Harvard University. The goal of the project is to "identify and to promote ways in which individuals at the cutting-edge of their professions can carry out work that is ethical and socially responsible" (Good Work Project website). The project attracted my attention due to my own personal experience of being faced with a traumatic dilemma whether to stay in Serbia and carry out my work, even if that meant in a non-ethical and socially irresponsible manner, or to leave and attempt ethically and 
socially responsible work elsewhere. The Good Work Project adopted a two-phase overall general coding process and I have decided to apply it to my study as this might at a later stage facilitate comparisons and collaboration. The coding process is described in detail in Chapter 5.

A brief analysis of the Initial study semi-structure interviews' data shed some light on two issues:

a) the use of metaphors in teachers' accounts

b) an emphasis on political elements found in teachers' accounts

Some illustrative examples (showing use of metaphors - life as a battle - and the presence of political elements in the teacher role) are presented in Appendix 9:

The data analysis also showed that there were more differences than similarities between the accounts of the two teachers (NLP-based CPD attendee and the teacher who did not attend). However, it is important to keep in mind that only two teachers were involved in the Initial study.

I also decided to arrange a mini feedback session after the interviews (by simply asking “How was it for you?') both to test it as additional data-collection tool and as a respondent validation process. The teachers involved in the Initial study were asked to give feedback on the interviewing process and both emphasized how the questions made them think about things they do not necessarily think about on a regular basis. Particularly the non-NLP teacher pointed out that both going through the interview and 
being given a chance to discuss it afterwards sparked some ideas for how to do things differently in the classroom (see Appendix 9).

The level of reflexivity and even the level of proactivity expressed by both teachers involved in the Initial study opened a new issue to be taken into account in the main study as discussed in the section below on 'What have I learned form the Initial study'.

\section{$\underline{\text { Issues connected to semi-structured interviews }}$}

The brief data analysis showed how valuable semi-structured interviews as a data collection tool may be, since they provided a huge amount of data that open opportunities for a variety of analyses. On the other hand, even though huge data production may be one of the greatest advantages of interviews, it can also be a disadvantage due to vast amount of semi- and unstructured data.

The Initial study has also brought up logistic issues such as the use of an inappropriate room, with so little space that it was hard to position a web camera to capture both the interviewee and the researcher.

Transcribing the interviews and analysing them highlighted the issue of needing to do both in the language in which the interviews were conducted (Slovene), analysing and then translating illustrative examples into English, which proved to be both demanding and extremely time-consuming and brought awareness of its influence on the timeplanning of the main study.

The setting up of the web-camera needed to be improved since it took quite a long time to position the camera and start the software. 
It should also be acknowledged that the teachers demonstrated more differences than similarities in their accounts of professional identity and their work. However this is not to say that potential similarities should not to be explored, quite the contrary. It has just proved to be worth exploring both in more detail later on in the study.

After the interviews had been conducted and partly analysed I asked my supervisor whether it would be appropriate to contact Dr. Howard Gardner, a co-researcher in the Good Work Project mentioned in the beginning of the dissertation. Gardner and colleagues have been asking similar questions in the US, Denmark and Latvia. I contacted him, and he and his colleagues have expressed interest in sharing with me both their interview protocol and findings from the interviews conducted with teachers based on the concept of 'good work' and expressed interest in hearing about my findings. Having compared their interview protocol and mine, I have found some similarities as well as some differences.

It was interesting to see that both the Good Work Project and my study share the overall focus on teachers' identity and their work, as well as on the pressures i.e. demanding situations, in their every day work. On the other hand, some of the questions from the Good Work Project interview protocol had a much wider focus than my study's interview protocol, which is probably easy to explain by the difference in the scope of the two studies. The Good Work Project expanded its focus from individual to institutional level and thus included Institutional Identity as an additional lens for analysing 'good work'. 


\begin{tabular}{|l|l|}
\hline Good Work Project interview protocol & My interview protocol \\
\hline \multicolumn{2}{|c|}{ Similarity } \\
\hline Overall focus on teachers' work & Focus on teachers' work \\
\hline Focus on the definition/role of the teacher & Focus on teachers' professional identity \\
\hline Focus on obstacles and pressures of teachers' work & Focus on strategies for handling demanding situations \\
\hline \multicolumn{2}{|c|}{ Difference } \\
\hline Focus on Institutional identity & Focus on teachers' professional identity \\
\hline
\end{tabular}

Table 7 Similarities and differences between the Good Work project interview protocol and this study's interview protocol

Even though I felt tempted to introduce at least two additional questions to explore any potential connection or lack of such between the teachers' professional identity and the Institutional identity, I decided not to. Due to the time and resource limitations and due to the rationale and my personal background a strong focus had been placed on individuals rather than institutions. However, this main difference between the two protocols sparked a reflective process (recorded in the researcher's journal) about the issue of teachers' professional identity and their work and inspired me to develop ideas and suggestions for further research in the final stage of my study as described in Chapter 7.

\section{Reflective diaries}

I had also partly tested reflective diaries having asked two teachers (one from the NLPbased CPD attendees/ group who was taking part in the whole Initial study and one from the group of other teachers who took part only in this part) to keep a reflective diary for one working week (five days) during the last week of November 2005. Having received the diaries, I discovered they were hand-written, which opened up questions of manageability of decoding. The diaries had been briefly analysed using a simple coding 2-category scheme (deductive coding) - i.e. the way they see their work and themselves as teachers, detecting adjectives, nouns, verbs or phrases ('exhausting day', 'fulfilling day', 'I was strict today', 'too generous today') and applying '+' , '-' and 'N' to each 
statement depending on whether the wordings have positive, negative or neutral connotations.

\begin{tabular}{|c|c|c|}
\hline CODES/SUBCATEGORIES & Examples-Teacher 1 & $\begin{array}{l}\text { Examples-Teacher } 2 \text { (NLP- } \\
\text { based CPD attendee/teacher) }\end{array}$ \\
\hline $\begin{array}{l}\text { Description of work (positive }(+), \\
\text { negative }(-), \text { neutral }(\mathbf{N}) \text { connotations) }\end{array}$ & $\begin{array}{l}\text { "exhausting day" (-) (day 1, line } \\
23) \\
\text { "easy day" (+) (day 5, line 5) } \\
\text { "everything went as usual, } \\
\text { ordinary" (N) (day 4, line } 12)\end{array}$ & $\begin{array}{l}\text { "a day I want to forget as soon as } \\
\text { possible" (-) (day 2, line } 2) \\
\text { "We had a great time today" }(+) \\
\text { (day 1, line } 18)\end{array}$ \\
\hline $\begin{array}{l}\text { Description of the self (positive }(+) \text {, } \\
\text { negative }(-) \text { neutral }(\mathbf{N}) \text { connotations }\end{array}$ & $\begin{array}{l}\text { "I believe I was fair..." (+) (day } \\
\text { 1, line 16) } \\
\text { "Perhaps I was too controlling, } \\
\text { but..." (-) (day } 5 \text {, line } 9)\end{array}$ & $\begin{array}{l}\text { "I know I was generous and that } \\
\text { is OK" }(+)(\text { day } 3 \text {, line 19) } \\
\text { "I was a policeman, not a } \\
\text { teacher..." }(-)(\text { day } 2, \text { line } 8)\end{array}$ \\
\hline
\end{tabular}

Table 8 A sample of the coded reflective diary (Initial study)

The plan was to show the diaries with highlighted words and expressions to the teachers and ask them for their opinions. This unfortunately did not happen during this initial study due to time-constraints. I was surprised by the large amount of material I received from the teachers, which brought up another issue, which is the number of teachers to ask to keep diaries, the time frame (for how long) and in what form (handwritten or electronic version). Last but not least, it has to be taken into account that all the diaries (as well as the interviews) would be in Slovenian, which would add to the amount of work, as the data would need to be translated into English.

Nias (1998) discussed the purposes of asking teachers to keep reflective diaries in her research and mentioned that one of them was "to flesh out individual accounts of perspective and practice" (p.6). Certainly, a more in-depth analysis is needed to establish a platform for exploring all the potential uses of the diaries, however already in the Initial study it was clear that they provided a complex multi-layered source of data. 


\section{$\underline{\text { Issues connected to reflective diaries }}$}

Having mentioned the multi-layered nature of the data collected through reflective diaries, it might be the right time to mention the downside of this. Since reflective diaries are often connected with the participants' intimate and private thoughts, further consideration of these was needed. The teachers were asked if they wished to exclude any parts of the diaries, but none of them felt any need to exclude any parts. In one-toone feedback sessions (combined with video-stimulated follow-up reviews/interviews) the relation between what was written in the diaries and said in the interviews and observed in the classrooms was explored together with the teachers.

\section{Issues connected to all data-gathering tools}

The Initial study provided me with a valuable and rich data corpus, which took considerable time and energy to code, organize ad analyse. Considering that there were only two teachers involved in the Initial study as opposed to 14 in the main study, the amount of analysed data in the main study with all the codes and subcategories would be overwhelming. Further consideration of the coding system as well as the organizing system for the collected data would need be taken into account.

\section{CONCLUSION OR WHAT HAVE I LEARNED FROM THE INITIAL}

\section{STUDY}

All three data collection methods/tools (observation, semi-structured interviews, reflective diaries) had proven to be extremely useful and adequate for the research question. They had shed light on different issues connected to the study itself such as: 
Methodological issues:

a) a need to rethink the value as well as the purpose and the role of some datacollection tools (observations, diaries and video-stimulated follow-up interviews and feedback sessions - potential new data-collection tools)

b) a need to take into account the emergence of metaphors and the potential use of them as research tool or data analysis frame

c) a need to further develop and synthesize coding system

d) a need to explore the use of my own journal i.e. researcher's reflective journal/diary

e) a need to take into account reflexive elements in teachers' accounts and consequently refine the methodological framework

Overarching framework issues:

a) a need to explore political elements in teachers' answers and consequently overarching conceptual framework

Logistic issues:

b) a need to explore logistics of carrying out different data-collection processes

c) a need to explore logistics of data-transcription and double-foreign language issue 
The above-mentioned issues were further explored:

\section{Methodological issues}

The value, the purpose and the role of some data-collection tools

The Initial study itself seemed to have been a valuable source of feedback both because testing data collection tools proved to be successful and because it opened new questions. The questions related to data collection tools refer to purposes and roles of the tools. In the research proposal and in the early stages of Year 1, semi-structured interviews were planned to be the main data-gathering tool, whereas observations together with reflective diaries were considered complementary ones. The Initial study had shown that the complementary data-collection proved to be more important than anticipated. The possible implications were multiple, from rethinking the status of the complementary data-gathering tools (which automatically leads to a more thorough analysis and interpretation of the data collected through observations and reflective diaries) to simply acknowledging the greater scope of importance of observations and diaries, but still limiting the complementary data analysis to its 'prompting' role for the main data collected through semi-structured interviews.

After thorough consideration and supervisory feedback, the decision about extending the role of additional data-gathering tools beyond its 'prompting' role was made. That meant that the observations would be used as a source for gathering events/episodes of previously established observable categories (communication skills, motivation skills, 
handling demanding situations) and consequently would be analysed before being used as a 'springboard' for carrying out semi-structured interviews.

The idea of using video-recorded observations further originated firstly from the teachers' reflexivity about what happened in the classroom. Secondly, I was thinking about the following question "Is there congruence between how teachers do their work (during the observed lessons) and the way they talk about their work and professional identity?" I decided it would be good to revisit the same teachers, show them some of the recordings, my observations and ask them about the moments, when there was a low or high degree of congruence by simply saying 'How does this X relate to what you said in the interview/diary about X?' Thus the observations will provide both triangulation and respondent validation.

Further extension of the use of video-recorded observations led to an additional datagathering tool: the video-stimulated follow-up interviews. Since I was aware of the usefulness of simple mini feedback sessions (sparked by the question "How was it for you?”) after the semi-structured interviews in the Initial study, I decided to experiment with the combination of follow-up interviews and feedback sessions. The plan was to show the teachers a preliminary analysis of their semi-structured interviews and reflective diaries and ask them for their feedback/validation. I 'played' with two ideas: a) follow-up group review/interview combined with feedback discussions or b) individual follow-up reviews/interviews and feedback discussions. Both could be useful and provide additional data. Supervisory advice suggested that I might also be interested in the teachers' discourse, when I talk in groups with them, even though I would be getting another language 'bath' - a collective one. However, due to the fact that the 
follow-up interviews became video-stimulated reviews/interviews combined with feedback discussions, there was a risk of breaching confidentiality if the recordings were to be shown to the whole group - hence the final decision on carrying out individual video-stimulated follow-up interviews combined with feedback discussions was made. The hope was that individual video-stimulated follow-up interviews and feedback discussions would yield a more in-depth understanding of the collected data.

It was also decided that reflective diaries would be analysed not only for language patterns (as tested in the Initial study) but also for all 7 previously established codes (and subsequent subcategories developed after the Initial study). The decision was made due to the realisation reached after the Initial study that the diaries provided vast amounts of data that went beyond the pure description of the working week (teachers were asked to record their thoughts, ideas, opinions while describing the working week). The trends of writing about their own selves as teachers, as guides, friends etc. and about their weeks as 'a battlefield', or 'a play' made me realise that the main themes of the study (teachers' professional identity and their work) were more present in the data than I anticipated. Thus the focus on how they talk (analysis of their language patterns) extended to what they literally said (content analysis).

The emergence of metaphors and the potential use of them as research tool or data analysis frame

The above mentioned extension from 'how' to 'what' the teachers said brought about the emergence of metaphors. Before the Initial study I did not anticipate metaphors to be extensively represented in the teachers' accounts. The Initial study shed some light on the use of metaphors among teachers. The experience with the Initial study led me to 
decide to explore the use of the analysis of metaphors as a potential research tool. Over the past decade many educational researchers have used metaphors as a useful tool in the analysis of interviews. Wallace (2003) mentions a few authors, such as Beavis and Thomas, Bear and Inbar as representatives of the advocates of the use of metaphors as a research tool. These authors, as well as Wallace, argue that people do not use metaphors consciously and therefore they can be 'a reliable indicator of personal or collective constructs' (Wallace, 2003, p. 101). Lakoff and Johnson (1980), who are considered leading authors in the field of analysis of metaphors, consider our conceptual system as, by its very nature, metaphorical. Their idea is that the embedded metaphors in the language we use can be seen as evidence of what our conceptual system is like (see also page 79 on metaphors).

\section{Further development and synthesis of the coding system}

Having been faced with a vast amount of data collected in the Initial study as well as new emergent subcategories and metaphors, it was obvious that the coding system needed to be further developed and synthesized. The idea of using two main focal points in the study: teachers' professional identity and teachers' work, as two nodes for further synthesizing of the collected data emerged. The story of primary and secondary coding with all its 'twists' is presented fully in Chapter 5.

The researcher's journal

While analysing the data collected through teachers' reflective diaries, the issue of the role of my own i.e. researcher's journal emerged. Originally, the idea was to keep my own diary in order to document the process of my own professional development. After 
the preliminary analysis of teachers' reflective diaries, the reciprocity of the exploration of my thoughts and ideas and the teachers' thoughts and ideas was identified. The reciprocity was not based on similarities of the thoughts and ideas described in my and the teachers' diaries, but rather on the level of our common reflexivity and overall proactivity to use some of our insights in our practices.

Thus the idea of using my own research journal as a means for documenting my own journey of professional development and exploration of my professional identity emerged.

Taking into account reflexive elements in teachers' accounts and refining the $\underline{\text { methodological framework }}$

As mentioned above and earlier in the account of the Initial study, the notion of reflexivity, or more precisely self-reflexivity, was noticed. The teacher who did not attend NLP-based CPD was open both about her own reflexivity and about her wish to change things in her own classroom activities as a consequence of being made aware of what she had done during her lesson, while being observed, and during the interview. That made me explore the idea of different uses of video-recorded observations, one of which was using the video-recorded observations to show parts of the recorded material and check the level of teachers' awareness about what they say and do in the classrooms.

That decision led to further explorations of the idea of a possible "added value" that might or might not happen in the study. As mentioned earlier, the examples of teachers' subjective experiences will be collected through semi-structured interviews, reflective 
diaries, observations and video-stimulated follow-up interviews and feedback sessions in order to establish a good platform for both reflective/subjective experience documented by the subjects of the study, and the purely observational approach undertaken by the researcher. One of the reasons for combining these two approaches was a hope of developing self-observational skills in the teachers by showing them what had been observed in their classes as compared to what has been subjectively expressed in the interviews and diaries. Thus the congruence level between the observed phenomena and subjective (uttered or written) accounts of them would be established and hopefully the research would, in the form of added value, contribute to the teachers' better self-observational and reflective skills. In other words the methodology adopted in the study might also contribute to the teachers' continuing professional development (CPD). The contribution of NLP to the above mentioned added value might be its main focus on development of professional practice through observations and 'selfobservations' (as described in Chapter 2).

Once the reflexive elements and the level of awareness were explored as well as the teacher (who did not attend NLP-based CPD) talking about changing her classroom activities due to the observations and interviews, the idea of employing an actionresearch framework was sparked. The idea of potential development of the above mentioned self-observation and reflective skills was close to the action-research framework and at the same time not necessarily aligned with the 'hard-line' requirements for an action research framework. Additional consideration of the action research framework is presented in Chapter 4. 


\section{Overarching framework issues}

The exploration of political elements in the teachers' answers and overarching conceptual framework

The Initial study brought some political elements back into the study. The reason I say 'back' is the obvious political background in the rationale of the study that was acknowledged early on. However, even though there was reasonable transparency about the political background of the study, it should be acknowledged that no political elements were anticipated in the teachers' accounts. The Initial study highlighted their presence in the teachers' accounts as well as a need to acknowledge the overall political framework. Thus, further consideration of a critical theory approach started to be explored and all the advantages and disadvantages of its potential employment. The full story of the exploration of critical theory is presented in Chapter 4.

\section{Logistic issues}

The logistics of carrying out the different data-collection processes

After having made decisions about the additional role of observations it became clear that there would be no need to carry out semi-structured interviews immediately after the observations. With the extended role of observations it was necessary to analyse them before carrying out semi-structured interviews and a new time-table with a new schedule for when which data-gathering tool will be used had to be designed. The idea was that the data-gathering process would have two phases (as described in Chapter 5) and that there would be a time-slot of one to three days between observations and semi- 
structured interviews.

\section{Exploration of the issues of data-transcription and double-foreign language}

Other issues that became apparent and needed to be considered, and reflected fell into the following categories:

Data transcription:

Transcriptions of the interviews and diaries needed to be in Slovenian language and the issue of their translation into English needed to be addressed. There were different solutions to the issue ranging from translating everything to translating only the illustrative examples or even translating it directly into English without a thorough Slovenian transcription. Since the school psychologist did not have complete information on how many teachers had easy access to computers at home, it was not easy to predict whether the reflective diaries would need to be transcribed and coded from handwritten or electronic text. Later on it was discovered that out of six teachers (three from each group) half of them were handwriting their diaries. Two teachers did not have easy access to a computer at home and one deliberately chose to handwrite arguing for 'better flow of words', when they are written rather than typed. After further consideration and supervision, it was decided to transcribe all the data in Slovenian and then translate illustrative examples into English.

The double foreign language issue: 
On top of the translation issue there was also the double foreign language issue. Both the study itself and writing up the thesis had been carried out and produced in languages that are not the researcher's native language. My native language is Serbian, whereas the study had been carried out in Slovenian and the thesis written up in English. The way of overcoming this was to consult a distinguished colleague from the Slovenian Further Education centre, who was both Slovenian and a teacher of the Slovenian language about any lexical dilemma I might encounter. The same strategy of asking for help from a distinguished British colleague was used for finding corresponding expressions in English. 


\section{HOW THE MAIN RESEARCH WAS INFORMED BY THE PILOT} STUDY

\section{Refining overarching frameworks}

The overall interpretive/phenomenological perspective has remained largely unaltered before and after the Initial study. On the other hand, the Initial study led to a refinement of the conceptual and methodological frameworks as described below.

\section{Refining the conceptual framework}

As a consequence of the insights emerging from the Initial Study, a critical theory approach as an overarching conceptual framework was considered. As it is demonstrated in next Chapter 4, a further analysis of the main study through the lens of a critical theory approach contributed to the consideration of a new form of critical theory named 'constructive critical theory approach'.

\section{Refining the methodological framework}

The presence of reflexive elements and the wish to introduce changes into their teaching practice in the teachers' accounts led to a consideration of an action-research framework. The added element of the researcher's own reflective journal/diary and the background of the overall project in Slovenia (of which the study is only one part) opened up yet another analysis of the study - this time through the lens of actionresearch. Chapter 4 documents the journey of exploring the action-research elements in 
the study and comes to the conclusion that the study does not 'live up to' the requirements for a 'hard-line' action research framework. Nonetheless it demonstrates elements of what could be called a 'constructive dual action-research framework' that takes into account all the cycles of action research both for respondents and for the researcher herself. Chapter 4 also situates the study within an over-arching interpretive/phenomenological framework. 


\section{Chapter 4: Overarching frameworks}




\section{INTRODUCTION}

In previous chapters, particularly in Chapter 3, I have argued for an interpretivist/phenomenological overall perspective. This stance was the one taken at the outset and it has been maintained throughout the project. This perspective has since been 'supplemented' by two other perspectives namely 'critical theory' and 'action research' that both have helped define more precisely the perspective taken in this study. Useful insights emerged from carrying out the Initial Study and sparked further explorations of overarching frameworks. The political elements in the teachers' accounts led to the consideration of a critical theory framework while the presence of reflexive elements caused further exploration of an action research framework. This chapter accounts for an exploration of the overarching frameworks for the study of how teachers in one Slovenian primary school talk about professional identity and their following participation in NLP-based CPD in comparison with other teachers. The first part of the chapter is focussing on a critical theory framework, exploring political elements as well as constructive elements in a critical theory perspective on the study. The second part explores an action research framework, its utilization, and suggests a different variety of action research.

\section{EXPLORING CRITICAL THEORY AS A CONCEPTUAL}

\section{FRAMEWORK}

Critical Theory offers a distinct philosophical approach and is historically rooted in German Idealism and its aftermath. It has a narrow and a broad meaning in philosophy and in the history of the social sciences. For the purposes of this dissertation, the focus will be on the critical theory in the narrow sense. Critical theory in the narrow sense 
designates several generations of German philosophers and social theorists in the Western European Marxist tradition known as the Frankfurt School (Kellner, 1989). According to these theorists, a 'critical' theory may be distinguished from a 'traditional' theory according to a specific practical purpose: a theory is critical to the extent that it seeks human emancipation, "to liberate human beings from the circumstances that enslave them" (Horkheimer 1982, p.244). Keeping in mind the rationale of this study there is certainly a connection between "the circumstances that enslave" (ibid.) and my experience of being a teacher in the midst of the wars in ex-Yugoslavia while not being allowed to do my work ethically. Given the emancipatory aims of critical theory, it could make a lot of sense to adopt such an approach in an exploration of how Slovenian teachers, who attended NLP-based CPD (personal development) after the ex-Yugoslavia wars in the early 1990s, talk about their professional identity as compared to those who did not receive any such training, in order to establish whether such trainings can contribute to a strengthening of their professional identity, so that teachers can become better prepared for 'critical situations' whether these arise from personal, social, cultural or political contexts.

There is clearly an element of 'critical' approach in the study itself, first of all based on a hope that is shared by the Slovenian Ministry of Education to get to a point, where we, who are involved in professional and personal development of teachers in Slovenia, can claim that we are moving towards an important change of the educational system on the 'macro' level, i.e. that we are "changing the teaching profession" (Fullan, 2001, p.265).

Or we might be aiming for changes on the 'micro' level including the individuals' construction of reality. Since the study is exploring teachers' subjective perception of their professional identity and their work, it would appear that an attempt to achieve a change on the 'micro' level is already present. On the other hand, the study aims, first of 
all, to explore the issues, rather than change anything. Yet, in spite of a transparent critical and political element in the study, does it have any strong affinities with the critical theory approach as Horkheimer describes it?

Horkheimer claims that a critical theory is adequate only if it meets three criteria: it must be explanatory, practical and normative, all at the same time. That is, it must explain what is wrong with current social reality, identify the actors to change it, and provide both clear norms for criticism and achievable practical goals for social transformation. Any truly critical theory of society, as Horkheimer further defined it, "has as its object human beings as producers of their own historical form of life" (Horkheimer 1993, p. 21).

It might be worthwhile to attempt to analyse this study's context, rationale and purpose according to the above mentioned three criteria:

1. Explanatory criterion: On the one hand, the Ministry of Education in Slovenia acknowledged the lack of personal development trainings for teachers in the times before the wars in ex-Yugoslavia in the early 1990s by offering an opportunity to tender for such trainings soon after the war that involved Slovenia. Indirectly, this might be taken as evidence that the then current social reality, including teacher trainings, did not cater for personal development of teachers. Personally, I felt how inadequately prepared I was for the critical situation of being a teacher in a state of war and how my professional subject knowledge and pedagogical knowledge was not sufficient to sustain my professional identity in those times. Thus both the Ministry of Education and the 
researcher did in a sense identify what was "wrong with current social reality" (Horkheimer 1993, p.21).

2. Practical criterion: By choosing the personal development training approach (and its provider) for teachers' development in Slovenia, the Ministry identified the actors to change what needed to be changed in the social reality of the Slovenian educational world in the early 1990s.

3. The normative criterion mentioned by Horkheimer (1993) has a prescriptive flavour to it and could seem to distance it from this study. Even though the study is exploring some of the possibilities of personal development trainings for creating, maintaining and developing teachers' professional identity, it is not prescribing or suggesting any concrete solution, i.e. action. At the same time, the study itself might address the issue of whether personal development trainings in Neuro-linguistic Programming have contributed to supporting and developing teachers' professional identity. Thus the study might offer or suggest (but perhaps not prescribe) a possible path to explore in order to develop, sustain and strengthen the teachers' professional identity.

In order to explore further the 'critical' flavour and its influence on education in general it might be interesting to discuss Skelton (2005) and his work. Although Skelton, who declares himself to be 'critical', in his book "Understanding teaching excellence in higher education: towards a critical approach"(2005) explored higher education teachers, whereas this study focuses on primary school teachers, there are characteristics that overlap and which make a cross-contextual comparison possible. First of all, although the role of a teacher within a wider education context may change according to the age of the learners, there is a common element and even responsibility in all the different roles of teachers. As Young points out “...new learners must develop their 
capacity as problem solvers - as discoverers. Otherwise, at the end of the formal schooling process, they will have had no practice in thinking for themselves" (Young, 1991, p.8).

Taking into account my personal reasons for carrying out this study and my hopes for a better teacher education leading to new generations of young, independently thinking citizens, Young's comment seems to fit the critical (and possibly political) frame of the study.

Skelton (2005) explores four 'ideal types' of understandings of teaching excellence in higher education: traditional, performative, psychologised and critical.

The critical 'ideal type' of teaching excellence is clearly Skelton's favoured type as he declares himself 'critical' and promotes a 'critical approach' throughout his book. It is one that commits itself to critical understandings of teaching excellence, which are associated with "the goals of freedom, justice and student empowerment" (p. 33). It is, furthermore, informed by "a range of critical theories (for example, critical theory itself, neo-Marxism, feminism, anti-racism, Freireism)" (p. 32). As Skelton says, "[t]he role of the teacher is to act as a critical or transformative intellectual... who disturbs the student's current epistemological understandings and interpretations of reality by offering new insights and theories" (p. 33). Furthermore, 'teaching cannot simply be reduced to technical or practical matters; it inevitably involves moral questions about what it means to be educated" (p. 34).

Skelton thus advocates a political agenda and combines it with a sceptical/critical approach, attributing to this approach a series of values and approaches e.g. freedom, 
student empowerment and emancipation. Interestingly, he contrasts the critical stance with "absolutism (an enduring truth or essence) and radical perspectivism (anything goes), since both negate the confrontation with one's inability to choose choice itself and the personal responsibility imbued with the exercise of self-will” (p. 11).

Skelton also embraces Barnett's (1997) idea of 'critical being'. Barnett's notion of "critical being" integrates the intellect, the self, and action. According to Barnett, teachers who refuse to accept 'received wisdom', who develop an informed personal perspective, who take responsibility for this perspective and are prepared to act in accordance with their beliefs and values, place themselves at some risk. The 'negotiation of/with the self' involves a dialogue about the extent to which one can realize personal values and commitments in situations that are already "constituted and constrained" (Skelton, 2005, p.13). Barnett (1997) advocates preparations for a 'critical life' as the major purpose and goal of higher education, a quality that encompasses 'critical reason', critical self reflection' and 'critical action'. He gives as an example the Chinese student, who stood in front of a tank in Tiananmen Square (broadcast on TV all over the world), which he interprets as a 'critical action' carried out from a sense of personal "authenticity".

The dilemma teachers (including myself) faced in the area of ex-Yugoslavia during and after the 1990s wars can be seen as linked to Barnett's concept of 'negotiation of/with the self'. Many of those who developed an informed personal perspective and were prepared to act in accordance with their beliefs and values took an enormous risk. 
If, indeed, the major purpose and goal of higher education is to prepare the students for a critical life, the question is whether teachers, having gone through higher education, are prepared for such a 'critical life'? Have we been prepared for changes be they social, political or personal? I can certainly speak for myself and confirm that I was not prepared. Nias (1989) advocates that changes that may influence our self-image brings a threat to people, and as mentioned earlier, Hargreaves (1998) expanded the idea further by claiming that teachers' emotions are professionally affected by both micro and macro-politics (Hargreaves, 1998, pp.326-327).

There are, however, sceptical and critical elements in Skelton's approach that I personally feel uncomfortable with. At this point it might be fair to note that postmodern critical theory (Crebbin, 1997) acknowledges that social understandings are not made anew, but are partly dependent upon the values, priorities and cultural definitions of prior social contestations. On the other hand, just like in Skelton's account, there is a strong destructive element, particularly in the post-modern critical theory approach. The emphasis is on what is wrong and what needs to be disqualified as invalid. That is exactly where the present study differs from a typical critical theory approach as described below.

There are both temporal and destructive elements in critical theory that do not entirely fit this study. The usual focus of critical theory is on the past and what is 'wrong' (Horkheimer, 1993), whereas the approach I am suggesting in the study is more present and future oriented and thus more 'constructive' in the way that it focuses on what can be 'constructed' in the future based on a description of the present state. In other words it advocates an 'outcome' focus rather than a 'problem' focus. Finally, if one takes into account that the present study is carried out as a consequence of a critical situation that 
could be considered caused, partly at least, by Marxist ideology, it is perhaps understandable that I was somewhat sceptical of a research tradition, that still has many proponents of Marxism among them.

This study attempts, in part on political grounds and drawing on my own professional and personal experience, to offer a different and more "constructive" approach with its focus on the present and the future. It offers a snapshot of the present state, of how teachers talk about their professional identity and their work and identifies and discusses what can be done in the future. Hopefully, there will be no need to be prepared to defend/sustain one's professional identity in war times in the future. However, it would be good to explore what can be done now to be prepared for any abrupt change and critical situation in the future. It seems the future world will expect much more from teachers than just skills. Krejsler (2005) particularly emphasizes that nowadays in order to uphold the authority of the profession it is no longer sufficient that the professional solely refers to his/her professional knowledge and the ability to apply that knowledge to specific and well-defined diagnoses or instrumental needs of the client. They are increasingly expected to be able to act as fellow human beings as well.

\section{Advantages and disadvantages of critical theory framework}

The most important advantage of adopting a critical theory framework to the present study is its transparent focus on political elements. The study's rationale is based on political elements and the events during the wars in ex-Yugoslavia in the early 1990s, so there is a persuasive argument for applying a critical theory approach. 
The disadvantage of adopting a critical theory approach might be overemphasis on the political aspects of the study that might take focus away from the teachers, their accounts of professional identity and their work.

That is an additional reason, based on the discussion above, to have come to the conclusion of suggesting a 'constructive critical theory' approach, which with its present and particularly future orientation hopefully will keep the focus on the 'main actors' - the teachers themselves, their subjective accounts of professional identity and their work and above all on their wishes and plans for future actions regarding their practice.

\section{EXPLORING ACTION RESEARCH AS A METHODOLOGICAL FRAMEWORK}

The presence of reflexive elements in the teachers' accounts in the Initial study as well as the above-mentioned wish to change their own practice brought about the idea of exploring an action research framework. Even though many authors differ in how they define action research the social psychologist Kurt Lewin (1999) is quite unanimously considered the 'inventor' of action research.

Action research can be described as a form of inductive, practical research that focuses on gaining a better understanding of a practice problem or achieving a real change or improvement in the practice context. It is essentially a systematic process of practitioner problem-posing and problem-solving. Action research uses a trial-and-error approach when seeking to understand and resolve practice-based problems and issues (Kuhne and Quigley, p.23). The 'problem focus' that is strongly present in the description of action 
research seems to differ from the present study, which was characterised in the previous section as 'outcome focused' and future oriented. Again, the 'negative' or 'problem' oriented focus of action research is closer to the diagnostic approach rather than to the hopefully more 'neutral' and more outcome oriented focus of this study. The study is not focussing on solving a problem, but rather on the elicitation of the present state and on the potential construction of future improvements either in maintaining professional identity or in the teaching practice in general. Thus the 'constructive' element mentioned in the previous section on critical theory reappears. Even though it is fair to argue that any action research aims to 'construct' something new, it might also be fair to argue that this particular study cannot identify with the 'problem frame' that is the starting point of action research and that it focuses on what can be constructed in order to improve the present state.

The idea of action research was taken up in the field of education in the USA during the 1950s. Its focus was on enabling teachers to apply scientific methods to solve their practical classroom problems, and thereby improve the educational process. This action research movement had become more dispersed and diverse by the end of the 1950s, but the idea of classroom action research was revived by Stenhouse, Elliot and others, who were promoting the concept of the 'teacher as researcher' in Britain in the late 1960s and 1970s (Stenhouse, 1975; Elliot, 1991).

The distinctive elements of action research are summarized by Kemmis and McTaggart (1984), who describe it as an open, ongoing process based on putting new ideas to the test: It involves "trying new ideas in practice as a means of improvement and as a means of increasing knowledge about the curriculum, teaching, and learning. The result is improvement in what happens in the classroom and school, and a better articulation 
and justification of the educational rationale for what goes on. Action research provides a way of working which links theory and practice into the one whole: ideas-in-action" (p.5).

On the other hand, Carr and Kemmis (1986) define action research as "simply a form of self-reflective enquiry undertaken by participants in social situations in order to improve the rationality and justice of their own practices, their understanding of these practices, and the situations in which the practices are carried out." (cited in Hammersley, 2004, p. 162).

Kuhne and Quigley (1997) further describe action research as a "practical tool for professional development of adult educators" (p.24). Keeping in mind the present study and the elements of NLP included, it is interesting that both NLP and action research have been defined as tools for professional development (in Chapter 2 NLP was defined as an approach to development of professional practice).

On the other hand, Kuhne and Quigley (1997) suggest that action research might not be the best approach to studying a problem once you begin to understand the true nature of the issues involved. Some practice-based problems are so psychologically, emotionally, or politically charged that they require more than an action research study to either fully understand or change them. This may also be the case with the present study, which may be too politically or perhaps too psychologically and emotionally charged, particularly if we focus on both my personal reasons for carrying out the study and the war period experienced by all the teachers. 
Lewin (1999) portrayed action research as involving a spiral process in which a hypothetical solution to a problem is formulated and tried out, its level of success monitored, the proposed solution reformulated in light of this, the new strategy implemented and assessed and so forth. Keeping in mind the NLP elements in the present study, there is a striking resemblance between the above mentioned spiral process of the action research and systemic thinking, which is considered an integral part of NLP. As mentioned in Chapter 2, systemic thinking is a 'complex' way of thinking in mutual feedback among actors and factors involved, understanding that any change will change the whole system and thus get integrated in a newly formulated system. The "feed forward" part of systemic thinking resembles the fourth part of the four core processes of action research which are presented below. All four processes will be used for analysing the present study.

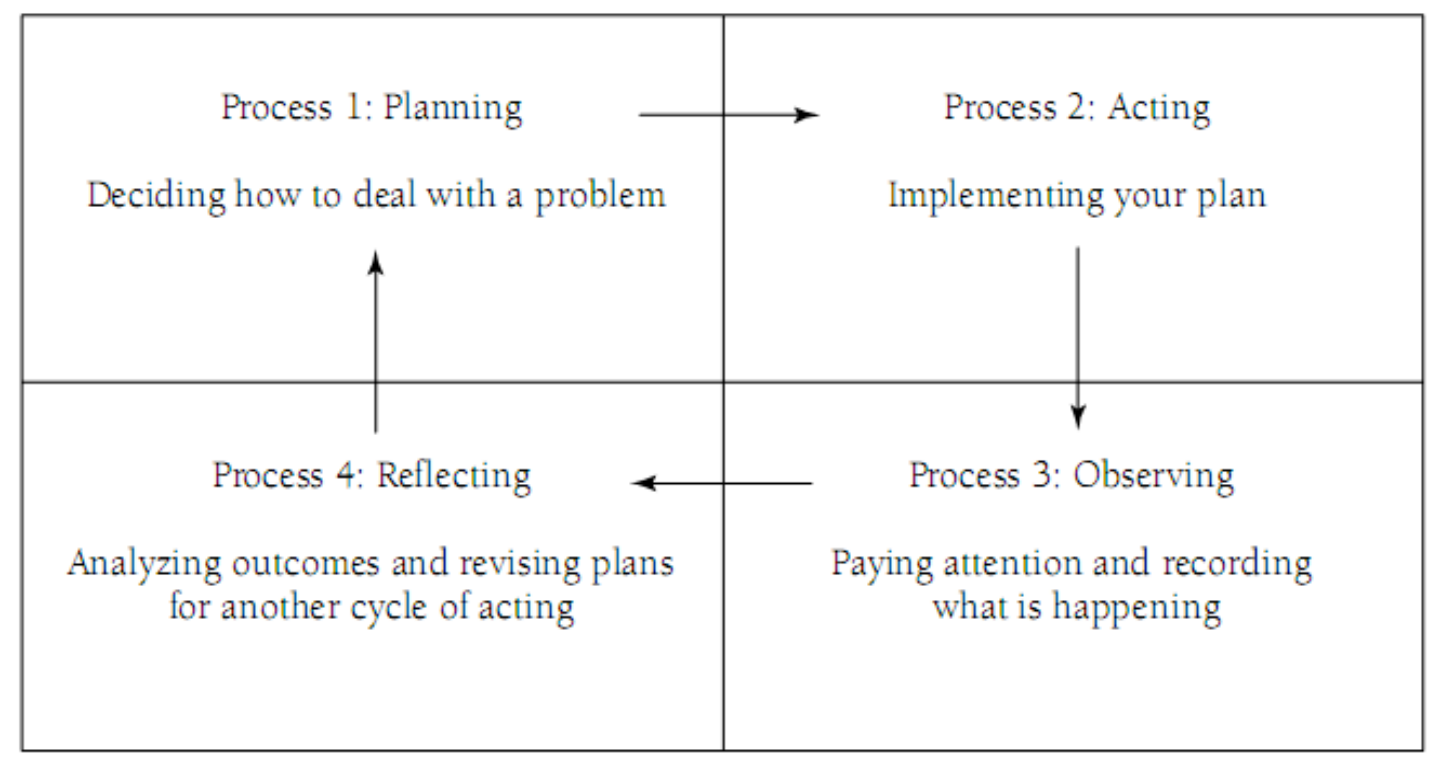

Figure 6 The four core processes of Action Research (Kuhne \& Quigley, 1997)

As Hammersley (2004) points out, a key notion is that the action research spiral promises closer and closer approximation to an ideal solution of the problem, based on a 
genuine theoretical understanding of the processes involved. Lewin viewed applied social science as a pursuit of practical improvement that is properly combined with a search for theoretical understanding. He famously declared that "there is nothing more practical than a good theory" (Lewin, 1951, p. 169). There was also a democratic element built into his conception of action research: the aim was to generate participation and 'self-management' among practitioners. The present study has produced a certain level of 'self-management' as an added value rather than as a planned action. As a consequence of the teachers' involvement in the study, and being interviewed, observed and asked to keep reflective diaries, they have started becoming more and more involved in the observation and self-observation process and in this way getting more actively involved in managing themselves both during classes and afterwards. The most striking example of this was during the video-stimulated followup interviews, when the teachers were shown the recorded observations and the analysed interviews and diaries (this is described later in details in Chapter 5). The teachers' becoming aware of their own patterns and of the level of congruence of what they said in the interviews or wrote in the diaries compared to what was observed in the classes resulted (for some of them) in a strong reflective process.

In order to examine whether the other three processes (besides the reflective) of the action research spiral are present in the study the more detailed analysis of the study through the lens of all four core processes has been attempted here:

1. Planning - Deciding how to deal with a problem: the study itself is part of a much larger plan designed by the Slovenian Ministry of Education. The purpose was to enhance education in general with a particular emphasis on teachers who (like many other professionals) went through particularly difficult times during 
the ex-Yugoslavia wars in the early 90s. Taking into account the researcher's personal experience, the problem was defined as being completely unprepared for 'critical situations' such as being a teacher in times of war. The Ministry decided to deal with the problem by offering personal development trainings for teachers realising that subject knowledge related trainings had not been sufficient in the past.

2. Action - Implementing your plan: The overall five-year project including ten modules of teacher trainings, two modules of school leadership trainings and guidance and counselling period could be labelled as an implementation phase. For the purpose of the analysis of the study the so-called phase 1 of the overall project (see Chapter 1) would fit an implementation phase.

3. Observation - Paying attention to and recording what is happening: The EdD study could be seen to fit this third phase. The research is taking into account teachers' subjective experience of their professional identity and their work. The examples of their subjective experiences are collected through an observational approach complemented by an explicitly analytical approach through semistructured interviews, reflective diaries and observations. The reasons for combining these two approaches is a hope to develop self-observational skills in the teachers by showing them what has been observed in their classes as compared to what has been subjectively expressed in the interviews and diaries. Thus the congruence level between the observed phenomena and the subjective (spoken or written) accounts of them was established and there was hope that the research would among other things contribute to the teachers' better selfobservational and reflective skills. And interestingly enough some changes have been registered during the data collection. Particularly during the videostimulated follow-up interviews and while showing the teachers recorded 
observations of their classes, some of them became aware of their own patterns and demonstrated high level of self-reflection.

4. Reflection - Analysing outcomes and revising plans for another cycle of acting: Once the data have been analysed and presented, there are further recommendations for future studies. In a way, that on its own might fit the fourth phase on the side of the researcher and this dissertation. An additional contribution to the fourth phase would be the above-mentioned systemic thinking approach and developed self-observational skills as part of NLP elements in the study.

The above analysis clearly locates the study within action research cycles that are 'larger' than just the study itself. The study has 'entered' the action research cycles in the middle rather than in the beginning (see for example the description of cycle 1) and I have also gone through my own action research cycles that started while teaching in Serbia long before the study commenced. Thus the action research follows a parallel process, which focuses on teachers/respondents' professional identity and at the same time on my own professional identity (while keeping my own jornal). Thus, the study does not necessarily follow the traditional action research format, but rather as described earlier a constructive and 'dual' action research format, which includes both the overall constructive action research approach to the study and an individual version of it for me.

When during the EdD Residential School (February 2008) I discussed the idea of categorizing my study as action research I was presented with constructive feedback by Dr. Haggarty suggesting that the study does not fulfil the criteria for action research, the main shortfall being the lack of evidence of pre/post activities that would allow for 
checking results and bringing about changes. I agree with Dr. Haggarty's comments, and yet it might be worth exploring this issue a little further by revisiting some of the accounts of action research presented earlier. If we think of action research only as summarized by Kemmis and McTaggart (1984), who describe it as an open, ongoing process based on putting new ideas to the test and on improvement in what happens in the classroom and the school, then the study does not lend enough evidence through its design to justify being called action research and thus is not an action-research study. However, if we think of action research along the lines presented by Carr and Kemmis (1986) who define it as "simply a form of self-reflective enquiry undertaken by participants in social situations in order to improve the rationality and justice of their own practices, their understanding of these practices, and the situations in which the practices are carried out" (cited in Hammersley, 2004, p. 162), then the study proved already in the phase of the Initial study that it is an action-research study.

Hammersley (2004) distinguishes between different types of action research, varying across several dimensions depending on whether it was carried out solely by practitioners or involving external agents; whether it is pursued individually or collectively; whether it is concerned with local and specific problems or with bringing about wider educational or social change; which methods it favours; what methodological or theoretical stances it draws on, for instance positivism, pragmatism, interpretivism, critical theory, or post-modernism (p 165). 
Using Hammersley's criteria the study might be categorized in the following way:

- It is carried out by someone who is both a practitioner and an external agent (the researcher's dual role).

- It is both individual and collective (by a researcher and all involved teachers),

- It is concerned with both local and specific problems and with bringing about wider educational or social change (studying a specific school in Slovenia and the educational system in Slovenia, on one hand, and the educational systems in the world, wherever there is a risk of 'critical situations' on the other).

- It draws on both interpretivism and critical theory and possibly other methodological and theoretical stances.

The above discussion of the study suggests that the 'types' of action research may not be as easily classified as suggested by Hammersley (2004), or perhaps it should be acknowledged that this study is not a 'classical' action research study.

Hammersley 'unpacks' the term action research in a brief linguistic analysis and concludes that the term action research is internally contradictory. He examines the two components of the term as representing, respectively, praxis (action) and theoria (research), in their ancient Greek sense. Theoria involves detachment from, and praxis immersion in, the events that make up human social life (Hammersley, 2004, p. 167). Lewin was perhaps aware of this 'contradiction' when he coined the already mentioned phrase "nothing more practical than a good theory" (1951, p.169).

The linguistic contradiction within the name of action research compares to a similar dilemma in the definition of NLP, where it is a matter of debate whether NLP is a theory or a practice. Craft (2001) suggested it could be considered "a theory of action" 
(p.130), which perhaps involves a similar 'contradiction', or seen in a more positive light: 'a powerful combination'. One might even think that adopting an action research approach would fit the content and nature of the study, since it also seeks to combine practical outcomes with theoretical ideas. It also combines 'detachment from' and 'immersion in' the educational context under investigation due to the researcher's dual role as being involved/immersed in the design and delivery of personal development trainings, and at the same time detached from the school context itself seeking to employ detached data-gathering tools.

All research is a construct and as researcher I am aware of the fact that I am involved in and contributing to the construct itself, and even though I claim my involvement is mainly in the past, I would like to be able to 'step out' of it in the present and try to let the data 'speak for themselves' (without denying my contribution to the analysis and interpretation).

On a detachment/involvement spectrum (se Figure 7), as a researcher I believe I was closer to the immersed 'end' while designing and delivering the personal development trainings, while at the time of data gathering, analysis and presentation I believe I have been closer to the detached 'end'.

Involved/Immersed

Detached

Figure 7 The researcher's involvement/detachment spectrum

In order to try to determine whether an action research approach was suitable for this study, it is worth examining the primary purpose and goals of action research. 
According to Hammersley (2004) the primary purpose of action research is not to produce academic theories based on action, nor to produce theories about action. As Reason and Bradbury (2001) puts it, it is not either to produce theoretical or empirical knowledge that can be applied in action, but rather "to liberate the human body, mind and spirit in the search for a better, freer world" (p. 2). Given this interpretation of the purpose of action research it has considerable similarities to critical theory.

Along the same lines, in the field of education, for Carr and Kemmis (1986) the goal of critical action research is to restructure professional practice and thereby to transform the education system and society at large, not simply to produce knowledge that is relevant to educational issues. If the primary purpose of action research is to liberate the human body, mind and spirit in the search for a better, freer world, then it would be in agreement with this study as it is the hope of the researcher that personal development trainings for teachers might help teachers to be better prepared for critical situations and thus create new generations of independent and free-thinking citizens. As already mentioned some of the aims for change of critical theory are in alignment with the aims of this study. It also seems clear that action research has similar aims. It would thus be worth considering if the two discussed perspectives share key values in terms of seeking change for the 'better'? Could action research be considered 'critical' in the sense that it starts out assuming that the present is not 'perfect' and seeks to improve it, just as critical theory does? I would just not want to embrace the assumption that seems to be a key element of both perspectives, i.e. that something is 'wrong' (whether it be with society as a whole or, say, with a particular type of lessons in a particular school) that needs to be 'fixed'. I am thus 'critical' of this 'negative' or 'deconstructive' aspect of both perspectives, particularly when critical theory often assumes a certain kind of future state, whether it be Marxist, feminist or otherwise, as an ideal state. 
Threfore, similarly to my suggestion of applying a 'constructive critical theory' framework I suggest using a 'constructive action research' framework which focuses on continuous/cyclical development and consequently improvement without necessary needing 'something to be wrong' as a trigger to employ an action research approach.

Hammersley (2004) concludes in his examination of action research that "the core idea of action research is that there should be an intimate relationship between inquiry and practical or political activities - such that the focus of inquiry arises out of, and its results feed back into, the activity concerned " (p.165). Defined in this way there is certainly a match with the present study, since it started from the political context, continued with a practical activity of exploring teachers' professional identity, and will hopefully feed back to the teachers, school and the policy makers findings about how teachers trained in personal development trainings talk about their professional identity as compared to those who were not trained in that way.

\section{Advantages and disadvantages of an action research framework}

The most important advantage of adopting an action research framework is its proactive nature and focus on the improvement of practice, which is perhaps less apparent, but nonetheless present in the rationale of the study.

The disadvantage of the action research approach might be its focus on the improvement of 'practice' rather than on helping individuals develop a professional identity that will support them in their decisions in critical situations. Thus the aims may be too 'small-chunk' in action research, whereas perhaps in critical theory (with a focus 
on large-scale social change) they may be too 'big-chunk' to fit the current investigation which focuses on a medium-range: teachers' identities.

In order to avoid losing the focus on the teachers themselves, the decision was made to employ a constructive (dual) action research framework, which will keep in mind the teachers' professional identity of respondents as well as that of the researcher herself.

\section{CONCLUSION}

Both critical theory and action research have a strong focus on change for the better in common and both are defined as having similar aims in terms of values, e.g. empowerment, democracy, liberation and equality. There is, however a difference in scope, where critical theory aims 'higher', whereas action research often focuses on the local context. There is also a difference in their traditions, where critical theory has historical roots in e.g. Marxism and feminism, whereas action research is rooted in a less 'political' professional development tradition. If one takes into account that the present study is carried out as a consequence of a critical situation that could be considered caused, partly at least, by Marxist ideology, and that it is focusing on professional development, it is perhaps understandable that these frameworks seem to be a good match for the study.

The present study set out to explore teachers' subjective experiences of their professional identity and the attitude towards their work in the aftermath of war in exYugoslavia. It is first and foremost an open-minded exploration. But it has to be acknowledged that, as in a considerable amount of social research (though often unstated), there is in this study a wish for a change for the better of society. It is in the 
overt desires for a change that the study is in agreement with both critical theory and action research. The study however offers a more constructive approach and hence the different naming of the frameworks: constructive critical theory and constructive (dual) action research. Both frameworks seem to offer a very good platform for exploring how teachers in one Slovenian primary school talk about their professional identity and work following participation in NLP-based CPD in comparison with other teachers. 


\section{Chapter 5: Data presentation and analysis}




\section{INTRODUCTION}

This chapter focuses on data presentation and analysis. Firstly, it tells the story of how the coding developed and how the collected data was 'reduced' and organized through primary and secondary coding. Secondly, it presents the collected data through the lens of two nodes: teachers' professional identity and teachers' work. The structure of the chapter encompasses the comparison of the two groups of teachers through the content and linguistic analysis of their accounts.

The chapter also offers data interpretation and preliminary discussion on the way, even though the summarized discussion of findings in relation to the research question, substantial literature and overarching frameworks is presented in Chapter 6. The reason for including some of the discussion already in this chapter is to follow the chronological narrative that was chosen for the thesis. Some parts of the discussion naturally occurred simultaneously with data analysis and thus have been recorded accordingly.

\section{Story of how the coding developed}

What follows is a chronological narrative of how the coding scheme (presented on page 177) was developed. Even though both inductive and deductive coding is described, particular attention was paid to the coding developed in interaction with the collected data.

Before embarking on explaining the story of how the coding scheme was developed it is worth noting that the data collection has been carried out in two phases. Phase one 
consisted of non-participant partly structured observations, semi-structured interviews and reflective diaries, whereas phase two encompassed video-stimulated follow-up interviews combined with feedback sessions (see Table 9).

\begin{tabular}{|c|c|}
\hline DATA COLLECTION - PHASE 1 & DATA COLLECTION - PHASE 2 \\
\hline $\begin{array}{l}\text { a) Non-participant semi structured observations } \\
\text { (of the lessons delivered by all } 14 \text { respondents) }\end{array}$ & $\begin{array}{l}\text { Video-stimulated follow-up interviews and } \\
\text { feedback sessions (carried out with all } 14 \\
\text { respondents individually after the preliminary data } \\
\text { analysis of the observations, semi-structured } \\
\text { interviews and reflective diaries) }\end{array}$ \\
\hline $\begin{array}{l}\text { b) Semi-structured interviews (carried out with all } \\
14 \text { respondents after the observations of the } \\
\text { lessons) }\end{array}$ & \\
\hline $\begin{array}{l}\text { Reflective diaries (collected after the semi- } \\
\text { structured interviews for nine weeks i.e. half } \\
\text { term in Slovenian education system - six } \\
\text { respondents - three from the NLP-based CPD } \\
\text { attendees/group and three from the group of } \\
\text { other teachers) }\end{array}$ & \\
\hline
\end{tabular}

Table 9 Data collection phases

The richness of the collected data due to manifold data collection methods has contributed to an interesting and evolving coding process. As soon as the data collection was complete, the first step was to engage in a process of data reduction and organisation. Nias (1981) in her study of teachers' talk sets an arbitrary limit of three to four illustrative comments, for any given point, when attempting to summarize the evidence sifted from one hundred and fifty lengthy interviews, twenty two diaries and several letters. Even though my data corpus is modest compared to Nias's, it anyway encompassed 14 semi-structured non-participant observations, 14 lengthy semistructured interviews, 54 reflective diaries and 14 video-stimulated follow-up interviews combined with feedback sessions. As is common in most qualitative research of this kind Nias had to omit more that she included. This is also the case in this study. In order to present the findings in a meaningful way, a researcher is faced with no alternative but to sort and classify the data, especially where data is of a diverse nature. However it is also important to be honest about data that has been omitted. In the case 
of this study, that is certainly true for some of the data that provided evidence for threads that could have been used for a discursive or narrative analysis. Unfortunately due to the 'double-foreign language' issue mentioned earlier in the methodology chapter, those threads had to be omitted. These issues are further discussed in the sections on ideas for further studies and on limitations of the study.

The primary coding was developed before the data collection started and originated in the contents of the NLP-based modules of personal development trainings delivered in the researched school. As mentioned in chapter 3 it was decided to employ a combination of deductive and inductive coding (rather than just inductive coding) for reasons of economy and in order to maintain the focus on the topic of the NLP. Out of ten modules, two were entirely NLP-based, three were partly NLP-based and five were non-NLP based. The following partly and entirely NLP-based modules were used as a frame for the creation of the original seven pre-determined categories (see Appendix 1 for the contents of all ten modules):

$1^{\text {st }}$ module: Satisfied teacher $=$ efficient teacher $(16$ hours $)-$ entirely NLP- based $2^{\text {nd }}$ module: Motivation strategies (for motivating others and self-motivation) (16 hours) - entirely NLP-based $5^{\text {th }}$ module: Communication skills in the classroom and everyday life (16 hours) -partly NLP-based

$6^{\text {th }}$ module: Rapport in the classroom and everyday life (16 hours) - partly NLP-based $8^{\text {th }}$ module: Classroom management (16 hours) - partly NLP-based

Based on the content of the chosen modules and the pre-initial study feedback, the original seven categories were developed, i.e. deductive coding was employed: 
1. Self-description as a teacher; $\left(1^{\text {st }}\right.$ module $)$

2. Job satisfaction; $\left(1^{\text {st }}\right.$ and $2^{\text {nd }}$ module $)$

3. Attitude towards work; ( $1^{\text {st }}$ module and $2^{\text {nd }}$ module $)$

4. Description of own communication skills; $\left(5^{\text {th }}\right.$ and $6^{\text {th }}$ module $)$

5. Description of own motivation strategies/skills; $\left(2^{\text {nd }}\right.$ module $)$

6. Strategies for handling 'demanding' situations; ( $8^{\text {th }}$ module)

7. Future plans (based on the pre-initial study feedback)

(see Appendix 2 for the complete interview protocol)

\section{Coding process}

As mentioned before in the thesis, the Initial study demonstrated how time-consuming the transcription itself was. In the introduction chapter the Good Work Project (1997/2001) from Harvard Graduate School of Education was mentioned due to similarities found in their study and it was hoped that the project might provide me with ideas for my research. Since the Good Work Project has adopted a coding process consisting of a reading guide and a coded reading guide the decision to apply it to my study was made, as this might at a later stage facilitate comparisons and collaboration.

However, once the coding process started, it was discovered through interaction with the collected data that it was more complex than originally thought (i.e. based only on the predetermined 7 categories). Thus the following section follows the so-called 3phase coding process as presented below: 


\begin{tabular}{|l|l|l|}
\hline Phase of coding & Outcomes & Type of coding \\
\hline $1^{\text {st/ }}$ (Primary) coding & 7 pre-determined categories & Deductive coding \\
\hline Extended $1^{\text {st }}$ (Primary) coding & Spectra of each category & Inductive coding \\
\hline 2nd (Secondary) coding & $\begin{array}{l}\text { 2 nodes: Teachers' identity (TI) and } \\
\text { Teachers' work (TW) }\end{array}$ & Deductive coding \\
\hline
\end{tabular}

Table 10 Overview of coding process

\section{Primary coding - Creating a reading guide}

Once all the interviews had been transcribed (see Appendix 3 - An extract from the transcript of semi-structured interview (in English), both interviews and reflective diaries were converted into a reading guide. The reading guide is actually a reordered transcript (Gardner et al., 1997/2001). The collected data were placed under the category it was considered belonging to. Even though it may sound like a simple task to reorder the materials into the previously mentioned 7 predetermined categories (selfdescription as a teacher; job satisfaction; attitude towards work; description of communication skills; description of motivation strategies/skills; strategies for handling demanding situations; future plans), there were cases of doubt, and some data had to be placed in two or more categories (see Appendix 5).

The reflective diaries were 'products' of free flow writing and therefore more demanding to code in the same structured way as the interviews. The only prompt the teachers got was to write at the end of each week about how the week was for them. However, it was possible to code them quite thoroughly using linguistic analysis and some of the pre-determined categories as these appeared and reappeared in all 54 diaries.

\section{Secondary coding}

Once the reading guide had been created, the data itself and the research question provided evidence for further, secondary coding. The research question addresses two 
main topics, i.e. teachers' professional identity and teachers' work and it was both gratifying and unsurprising that they emerge as nodes from the collected data. Thus the secondary coding through two main nodes was employed.

The two major topics appeared as two nodes throughout the collected data from all data-collection tools.

a) Teachers' identity

b) Teachers' work

Since the two nodes are the main topics of the study this process can be considered deductive coding. However, the teachers' accounts collected through three datacollection tools (semi-structured interviews, reflective diaries and video-stimulated follow-up interviews/feedback sessions) provided the organizing principle of seven categories into two nodes. The criteria for organizing the pre-determined categories originated in the data and therefore the process, which had an overall deductive character, does have some inductive elements, as well. The data led to the original seven categories to be merged into the two nodes in the following way: 


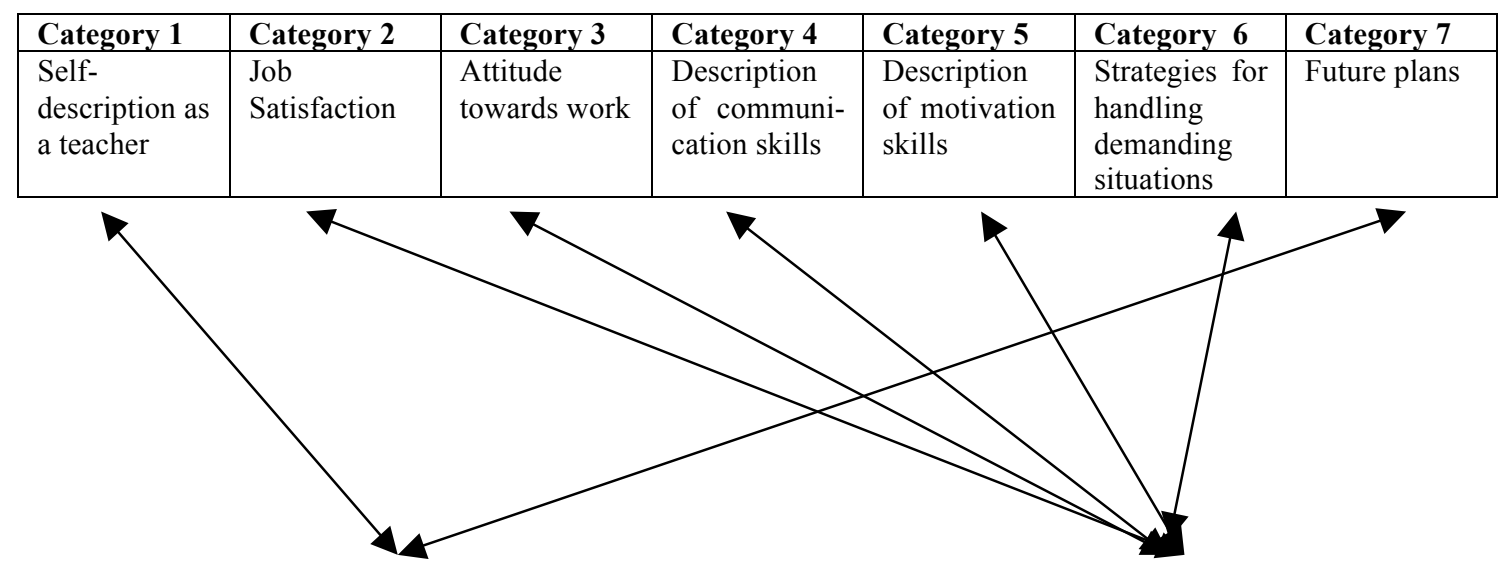

\begin{tabular}{|l|l|}
\hline NODE 1 & NODE 2 \\
\hline Teachers' professional identity - TI & Teachers' work - TW \\
\hline
\end{tabular}

Figure 8 Organizing 7 categories into 2 nodes

The first phase of double coding meant that the teachers' accounts were coded simultaneously (see Appendix 4) for seven categories and two nodes. Afterwards the double coding was transferred into tabular bi-lingual form as presented below for one of the teachers - from the group of other teachers- teacher 5 (T5) (see the full list of anonymised teachers' names on page 179 and see Appendix 6 for the full list of abbreviations for all 7 categories).

\begin{tabular}{|c|c|c|c|}
\hline Nodes & Category & Data (Slovenian) & Data (English) \\
\hline $\begin{array}{l}\text { Teachers' } \\
\text { identity } \\
\text { TI }\end{array}$ & $\begin{array}{l}\text { 1. Self-description as a } \\
\text { teacher (SDT) }\end{array}$ & $\begin{array}{l}\text { "da sem čim bolj poštena, pravična, } \\
\text { pa da utemeljim oceno, ki jo učenec } \\
\text { dobi..." (lines 29-30) }\end{array}$ & $\begin{array}{l}\text { "to be honest, fair, to justify } \\
\text { the mark I give ..." (lines } \\
29-30 \text { ) }\end{array}$ \\
\hline $\begin{array}{l}\text { Teachers' } \\
\text { work } \\
\text { TW }\end{array}$ & 2. Job satisfaction (JS) & $\begin{array}{l}\text { "No, recimo, če bi od } 1 \text { do } 5 \text {, če } \\
\text { lahko, bi rekla } 4 \ldots . \text { To pa zato, ker } \\
\text {... Večinoma sem zelo zadovoljna z } \\
\text { delom, z učenci in s sodelavci" (lines } \\
58-60 \text { ) }\end{array}$ & $\begin{array}{l}\text { "Well, if I can use the } 1 \text { to } 5 \\
\text { scale, I would say } \\
4 \ldots \text { Mostly I am satisfied } \\
\text { with my work, with my } \\
\text { pupils, and my colleagues" } \\
\text { (lines 58-60) }\end{array}$ \\
\hline $\begin{array}{l}\text { Teachers' } \\
\text { work } \\
\text { TW }\end{array}$ & $\begin{array}{l}\text { 3. Attitude towards work } \\
\text { (ATW) }\end{array}$ & $\begin{array}{l}\text { “...mislim, da zelo resno pristopam } \mathrm{k} \\
\text { temu delu s pripravami, s pogovori s } \\
\text { sodelavci, pa mislim, da sem zelo } \\
\text { odgovorna do svojega dela, saj to se } \\
\text { od mene pricakuje, da vzamem svoje } \\
\text { delo resno" (lines } 76-78 \text { ) }\end{array}$ & $\begin{array}{l}\text { "I think I am quite serious } \\
\text { about my work, with all the } \\
\text { preparations, talking to my } \\
\text { colleagues, I think I have a } \\
\text { responsible attitude towards } \\
\text { my work, after all that is } \\
\text { what is expected from me, I }\end{array}$ \\
\hline
\end{tabular}




\begin{tabular}{|c|c|c|c|}
\hline & & & $\begin{array}{l}\text { am obliged to take it } \\
\text { seriously" (lines } 76-78 \text { ) }\end{array}$ \\
\hline $\begin{array}{l}\text { Teachers' } \\
\text { work } \\
\text { TW }\end{array}$ & $\begin{array}{l}\text { 4. Description of } \\
\text { communication skills (CS) }\end{array}$ & $\begin{array}{l}\text { "Se mi zdi, da ta »jaz« sporočila, da } \\
\text { meni, no vsaj zaenkrat zelo } \\
\text { pomagajo, če kar povem, tako kot je" } \\
\text { (lines } 113-114 \text { ) }\end{array}$ & $\begin{array}{l}\text { "I think that the »I" } \\
\text { messages help, at least they } \\
\text { help me to say things as } \\
\text { they are" (lines 113-114) }\end{array}$ \\
\hline $\begin{array}{l}\text { Teachers' } \\
\text { work } \\
\text { TW }\end{array}$ & $\begin{array}{l}\text { 5. Motivation strategies } \\
\text { (MS) }\end{array}$ & $\begin{array}{l}\text { "Poskušam priti do njega pa ga } \\
\text { vprašat a se mu ne ljubi, a mu je to } \\
\text { zanimivo, potem pa izhajam iz tega, } \\
\text { če se mu ne ljubi, da mu rečem, da } \\
\text { marsikdaj v življenju bo še kaj pa se } \\
\text { mu ne bo dalo pa bo vseeno treba to } \\
\text { narediti" (lines 92-95) }\end{array}$ & $\begin{array}{l}\text { "I approach him, ask } \\
\text { whether he does not feel } \\
\text { like it, or does not find it } \\
\text { interesting and then I say } \\
\text { that there might be other } \\
\text { things in life he does not } \\
\text { feel like but needs to do } \\
\text { anyway" (lines 92-95) }\end{array}$ \\
\hline $\begin{array}{l}\text { Teachers' } \\
\text { work } \\
\text { TW }\end{array}$ & $\begin{array}{l}\text { 6. Strategies for handling } \\
\text { 'demanding' situations } \\
\text { (DS) }\end{array}$ & $\begin{array}{l}\text { "Zdaj pa mene to tako zlahka razjezi, } \\
\text { kako naj jaz zdaj to njemu na drug } \\
\text { način pa na tretji način pa na } \\
\text { katerikoli način povem, da mu } \\
\text { razložim" (125-126) }\end{array}$ & $\begin{array}{l}\text { "Now that makes me angry } \\
\text { easily and then how do I tell } \\
\text { him, explain it to him in a } \\
\text { different way" (125-126) }\end{array}$ \\
\hline $\begin{array}{l}\text { Teachers' } \\
\text { identity } \\
\text { TI }\end{array}$ & 7. Future plans (FP) & $\begin{array}{l}\text { "..si zelim razvoj in spremembo, da } \\
\text { pridobim naziv recimo mentor ali pa } \\
\text { potem še naprej svetovalec" (148- } \\
149)\end{array}$ & $\begin{array}{l}\text { "I want development and a } \\
\text { change, to get promoted to } \\
\text { mentor or later to } \\
\text { adviser"(148-149) }\end{array}$ \\
\hline
\end{tabular}

Table 11 Tabular (bilingual) representation of double coding (Teacher 5, semi-structured interview)

Even though the double coding was more than enough work to do to analyse the collected data, I could not ignore the vast data corpus that was bursting with patterns based both on the content and the linguistic form of the teachers' accounts.

\section{Extended primary coding}

The richness of the collected data simply required further content and linguistic analysis of the teachers' accounts. The collected data showed that each of the seven categories defined in the primary coding phase tended to have their own spectra or subcategories.

Since the research question is asking HOW teachers talk, I first paid attention to the linguistic patterns the teachers used (in semi-structured and follow-up interviews and reflective diaries) and then also to WHAT they said. Keeping in mind that the two above described nodes were partly pre-determined by the research question itself, the 
further development of the spectra or sub-categories of the seven categories proved to have more analytical 'bite'.

Based on the research question: "How do teachers in one Slovenian primary school TALK about their professional identity and work following participation in NLP-based CPD in comparison with other teachers?" it might look easy to draw a conclusion that a discourse or even a conversation analysis would be the most appropriate framework for data analysis. Even though both frameworks would certainly yield interesting data analysis, one of the main reasons for not employing them was (as mentioned in Chapter 3) that the researcher is a native speaker of Serbian, while having carried out the research in Slovene and writing the thesis in English. This 'double foreign language' issue is not to be under-estimated as already noted after the Initial study. Much of the data that could lend its support to the discourse analysis was 'lost in translation' due to different syntax rules. The other approach that could have been taken is a narrative analysis, which would take the research into a more literature oriented direction. Even though that direction would be equally exciting, once it had been briefly tested, it proved to be as vulnerable to the 'double foreign language issue' as discourse analysis. Thus a simple linguistic analysis that is closest to the overarching framework of Neurolinguistic programming has been attempted with a main focus on the words used and their positive/neutral/negative connotations, personal/impersonal language patterns or metaphorical expressions.

The following spectra emerged from further interaction with the collected data and thus the inductive coding process started. The collected data was subjected to linguistic and content 'modelling' where all the patterns (based on linguistic form or on the content of 
teachers' accounts) were recorded. Once no more new patterns could be found in the teachers account the continua presented below were created.

\section{Linguistic spectrum detected across all the categories and across all data- collection tools}

(See the graphic representation of the complete coding scheme on page Error!

\section{Bookmark not defined.)}

\section{Linguistic patterns}

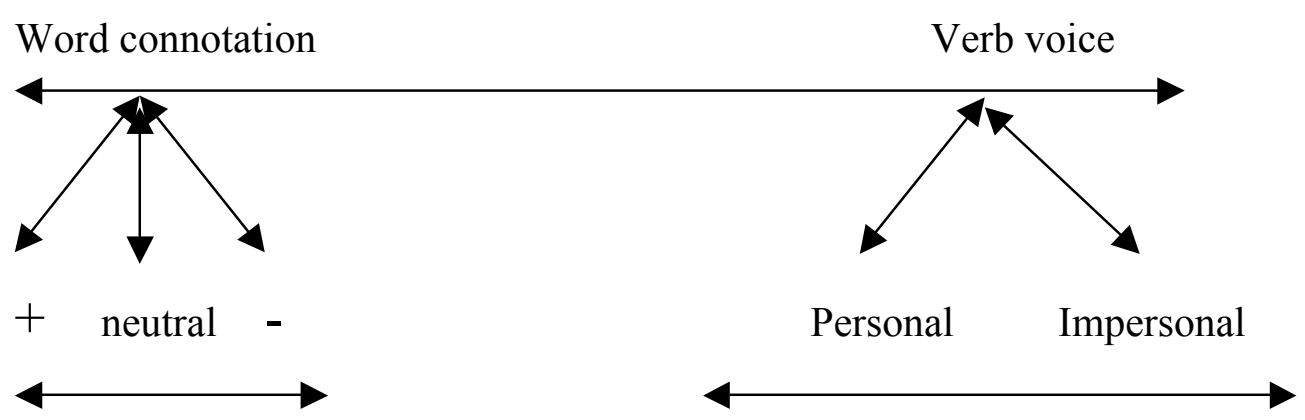

Figure 9 Linguistic patterns spectra

The first spectrum regarding HOW teachers talk emerged from the linguistic analysis of the teachers' use of the word connotations and verb voice. It was noticeable that some teachers resorted to the choice of words that have slight negative connotations while others would rather pick a word with neutral or positive connotation (see Chapter 2).

Some illustrative examples:

\footnotetext{
"I know some people would say I am a monster sometimes" (word with negative connotation, T3, line 8, Semi-structured interview)

"I see myself as a teacher and that's it" (word with neutral connotation, T2, line 14, Reflective diary 7)

"I am like a sunshine" (word with positive connotation, NT3, line 17, Semi-structured interview)
}

On the other hand, some teachers regularly used so-called "I" sentences, whereas others tended to avoid any subject-based sentences, i.e. they used either passive voice or impersonal form. 
Some illustrative examples:

"I talked to them about the topic and then I asked them to come up with their ideas" (personal voice, NT1, line 38, Reflective diary 3)

"It is expected that one should be a little strict" (impersonal voice, T5, line 10, Semi-structured interview)

Thus the data similar to the cited ones provided the first spectrum that went across all the categories and all data collection tools.

The further spectra for each category developed from the content analysis of teachers' answers in semi-structured interviews, their accounts in reflective diaries and videostimulated follow-up interviews.

\section{Individual content-based spectra for each category}

\section{Category 1: Self-description as a teacher}

Identity description

Behaviour description

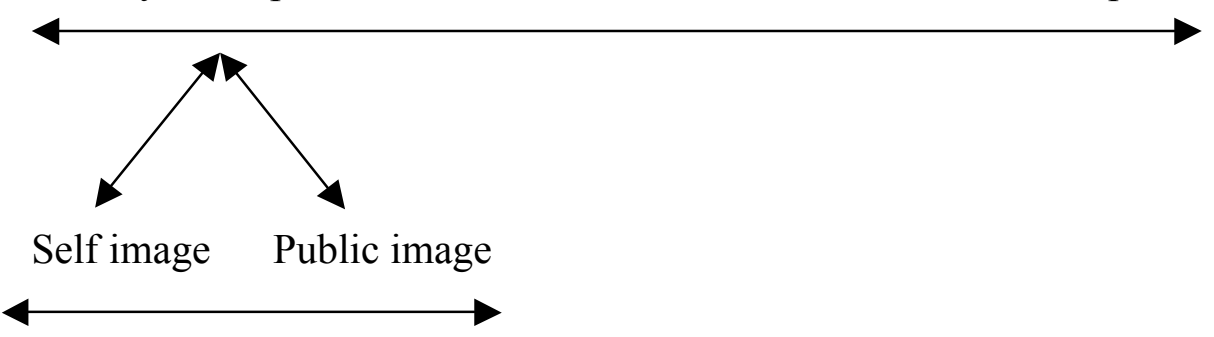

Figure 10 Category 1 spectrum

The first category 'Self-description as a teacher' yielded many different answers and the main subgroups emerged in the form of either identity or behaviour description. Even though the question was 'How would you describe yourself as a teacher?' some teachers described what they do and how they behave in their classrooms rather than their teacher's identity. 
"I am actually like their friend" (Id description, NT3, line 23, Video-stimulated follow-up interview)

"...to describe myself as a teacher? Well, I look after children, I make sure they stay safe" (Behaviour description, T2, line 10, Semi-structured interview)

Identity description was further developed into two additional subgroups of self-image and public image sparked by the additional question "How would you think others would describe you as a teacher?"

"I always think of myself as a guide of my pupils (ID description, self-image) but sometimes I get comments from my colleagues that I am an over-dominant and ambitious boss of my class (laughter)" (ID description, public image, T5, line 14, Semi-structured interview)

\section{Category 2: Job satisfaction}

Satisfaction presence

Lack of satisfaction
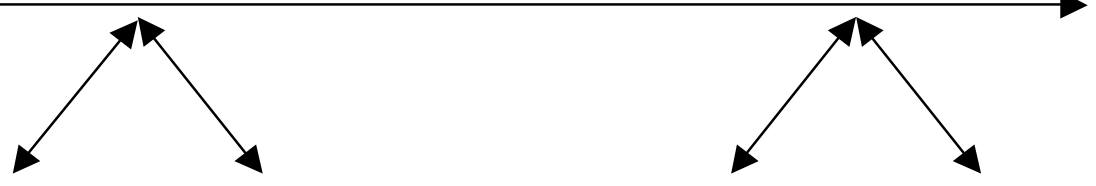

Focus on self Focus on others

Focus on self

Focus on others

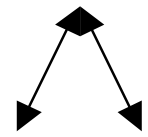

On school On wider society

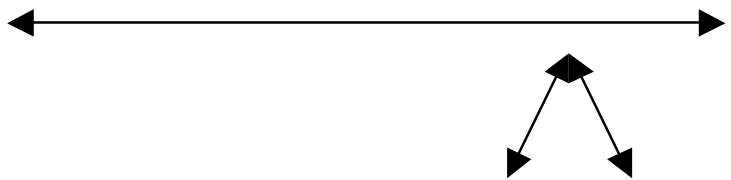

On school On wider society

Figure 11 Category 2 spectrum

The second category prompted by the question" How would you describe the level of satisfaction with your work?" brought two clear-cut answers of either presence or lack of job satisfaction. However, a further question "Has it changed over the years?" prompted the accounts that showed that both presence and lack of job satisfaction offered different foci, i.e. on self or on others, the latter one including school or wider society (i.e. on self, on others, on school or wider society).

Some illustrative examples: 
"I know it is about me and my current state whether I feel satisfied or not and right now I am not satisfied" (Lack of satisfaction/Focus on self, NT7, line 31, Semi-structured interview)

"If I compare this school with the previous one I worked in, this is a much better community, a cosy, domestic, safe one and I am quite happy here" (Satisfaction presence/focus on school, NT6, line 40-41, Semi-structured interview)

"How can I be satisfied in these politically and economically uncertain times?" (Lack of satisfaction/on wider society, T7, line 17, Reflective diary 9)

\section{Category 3: Attitude towards work}

Obligation

Fulfilling calling

Figure 12 Category 3 spectrum

The answers to the question about attitude towards work fell into two different

categories: obligation and fulfilling calling.

Some illustrative examples:

"I think I am quite serious about my work, with all the preparations, talking to my colleagues, I think I have a responsible attitude towards my work, after all that is what is expected from me, I am obliged to take it seriously" (Obligation, T5, lines 76-78, Semi-structured interview)

"I wake up and feel happy that there is another day and I know that there are children or young people there waiting for me to share with them what I know about physical education and not just that, about life, as well. To cheer them up, to calm them down. To be there for them when they need somebody to talk to or just somebody to listen to, and on top of that to teach them and learn from them is my 'happy thought' (laughter) and I feel that is what I am here for, that is my work" (Fulfilling calling, NT6, lines 79-83, Semi-structured interview)

\section{Category 4: Description of communication skills}

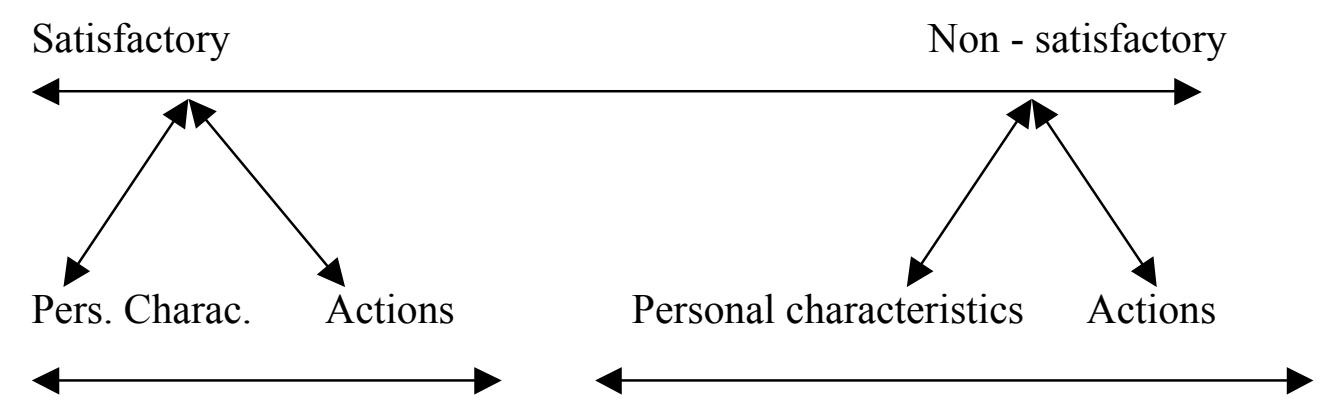

Figure 13 Category 4 spectrum 
The majority of teachers answered the question about their communication skills in a rather straight-forward manner by categorizing them as either satisfactory or nonsatisfactory. However, the closer content analysis emphasized their thoughts about whether communication skills are part of personal characteristics or something that consists of actions that can be learned, practiced and thus improved.

Some illustrative examples:

"No, I am not very good at communication skills, I suppose one needs to be born with that gift and I discovered very early that I am more talented for natural science" (Nonsatisfactory/personal characteristics, T4, line 52-53, Video-stimulated follow-up interview)

"I am getting better and better and I am using many skills I have acquired at many workshops... it is a matter of practice and I decided to introduce one little thing every lesson - to take action. For example I have introduced 'moaning time' for 10 minutes on Wednesdays when all the pupils can say what they are not happy with (laughter) and it works miracles, we are all more relaxed after that and I make sure I do something about what they say"

(Satisfactory/actions, NT4, lines 29-33, Semi-structured interviews)

\section{Category 5: Description of motivations skill/strategies}

Self-motivation skills

Motivating others
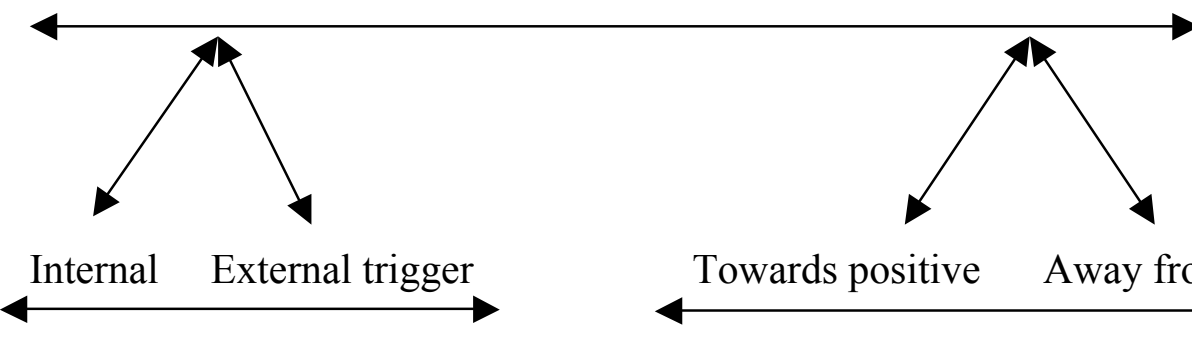

Towards positive Away from negative

Figure 14 Category 5 spectrum

The questions about motivation skills/strategies (How do you motivate yourself? And

How do you motivate your students?) prompted the teachers' answers to fall into two categories: self-motivation strategies and motivating others. Like in other categories, further content analysis showed distinctions in answers about self-motivation skills and about motivating others. Self-motivation strategies were described in terms of whether the trigger for the motivation came from the teachers themselves or from the outside 
world, whereas the strategies for motivating others were more along the lines of motivating others towards a positive outcome or away from a potential negative outcome.

Some illustrative examples:

"I motivate myself by thinking of all the nice things I can do today, how many children I will help today etc." (Self-motivation skills/Internal trigger, NT7, lines 33-34, Semi-structured interviews)

"Oh, what a day, I really need to wake up into a sunny day or to the tempting smell of freshly made coffee to feel full of energy and to keep going and today was not a day like that at all" (Self-motivation skills/external trigger, T2, lines 1-2, Reflective diary 2)

"You can do it your way, come on, perhaps you will discover a completely new, innovative way of doing "scissors" and that will be fun, your unique way, perhaps we will name it after you imagine that..." (Motivating others/towards positive, NT4, 28 minutes into the lesson, Nonparticipant semi-structured observation)

"One needs to inform them about the negative consequences and it is fair to tell them what will happen if they do not cooperate and provide home works - all my pupils know that, I told them" (Motivating others/Away from negative, T6, lines 45-47, Video-stimulated follow-up interview)

\section{Category 6: Strategies for handling demanding situations}

Attitude towards demanding situations
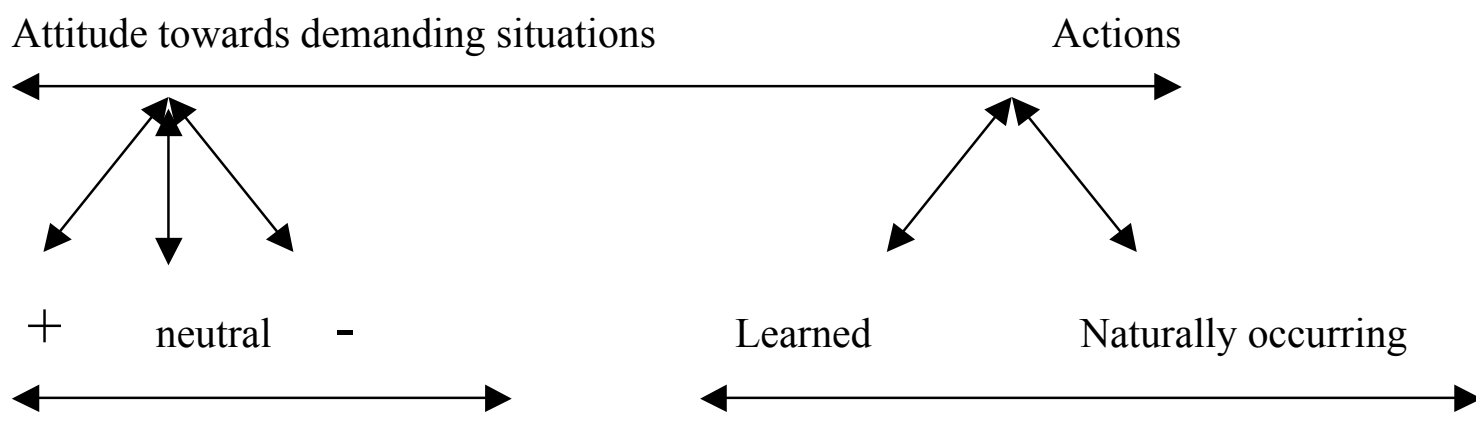

Figure 15 Category 6 spectrum

Teachers' accounts of their strategies for handling demanding situations resulted in them either adopting a personal approach and talking about their attitude towards demanding situations or adopting a more pragmatic stance and talking about what exactly they do, which actions they take in the demanding situations. 
Attitude towards demanding situations was coded for positive, negative or neutral whereas further content analysis of the actions' descriptions offered the distinction between learned and naturally occurring strategies.

Some illustrative examples:

“Oh, I don't like demanding situations, they exhaust me and they are usually a waste of time and once situations get really demanding one rarely resolves anything anyway" (Attitude towards demanding situations/negative, $\mathrm{T} 7$, lines 46-47, Semi-structured interview)

"It is an opportunity to learn and grow, I take them as something normal and positive" (Attitude towards demanding situations/positive, NT6, line 35, Semi-structured interview)

"Many years ago, I would get paralysed but I have learned how to overcome them and I use a lot of positive thinking and so-called pacing and as we could see it works" (Actions/Learned, NT4, lines 15-16, Video-stimulated follow-up interview)

"I seem to have a talent for sorting things out, don't ask me what I do because I am not sure I know, I just intuitively do what I think is right and it usually ends up being OK for all. I don't need to think about it really, it just happens right there and then, just like that" (Actions/Naturally occurring, T1, lines 29-31, Semi-structured interview)

\section{Category 7: Future plans}

Change
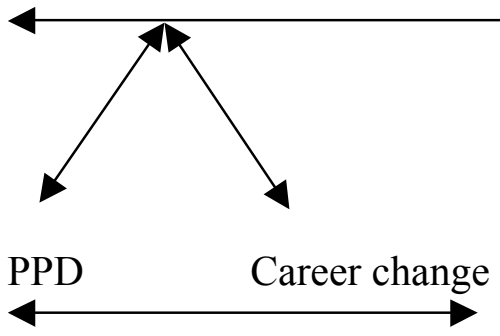

Figure 16 Category 7 spectrum

Teachers expressed their future plans in the form of their wishes to either preserve continuity in their work or to pursue work-related changes. Some of them showed interest in changing their career, whereas some saw changes as their further development in the form of professional and personal development within the same teaching career.

Some illustrative examples: 
"I want development and change, to get promoted to mentor or later to adviser" (Change/PPD, T5, lines148-149, Semi-structured interview)

"I just want to continue being a teacher without any disturbances..." (Continuity, T7, line 112, Semi-structured interview)

"Well, ideally I would like to stop teaching and get back to my original dream of becoming a nurse" (Change/Career Change, T2, line 134, Semi-structured interview)

All seven categories and their spectra form the 'heart' of the analytical story of the

study. They are presented in the following table:

\begin{tabular}{|l|l|}
\hline CATEGORIES & SPECTRA/SUBCATEGORIES \\
\hline 1. Self-description as a teacher & $\begin{array}{l}\text { A) Identity descriptions (self image and } \\
\text { assumed public/external image) } \\
\text { B) Behaviour description }\end{array}$ \\
\hline 2. Job satisfaction & $\begin{array}{l}\text { A) Satisfaction presence (focus on the self, } \\
\text { focus on the school, focus on wider society, focus } \\
\text { on others); } \\
\text { B) Lack of satisfaction (focus on the self, focus } \\
\text { on the school, focus on wider society, focus on } \\
\text { others) }\end{array}$ \\
\hline 3. Attitude towards work & A) Obligation; B) Fulfilling calling; \\
\hline 4. Description of communication skills & $\begin{array}{l}\text { A) Satisfactory (personal } \\
\text { characteristics/actions); } \\
\text { B) Non satisfactory (personal } \\
\text { characteristics/actions) }\end{array}$ \\
\hline 5. Description of motivation skills/strategies & $\begin{array}{l}\text { A) Self motivation skills/strategies } \\
\text { (internal/external trigger); } \\
\text { B) Strategies for motivating others (towards } \\
\text { positive/away from negative); }\end{array}$ \\
\hline 6. Strategies for handling demanding situations & $\begin{array}{l}\text { A) Attitude towards demanding situations } \\
\text { (positive, negative, neutral); B) Action (Learned; } \\
\text { Naturally/spontaneously occurring); }\end{array}$ \\
\hline 7. Future plans & $\begin{array}{l}\text { A) Change (Professional and personal } \\
\text { development, career change); } \\
\text { B) Continuity }\end{array}$ \\
\hline
\end{tabular}

Table 12 All 7 categories and their spectra

Once the two nodes and linguistic patterns were added to the above table a complex but useful and rewarding coding scheme appeared (as presented below). It is the coding scheme that took into account both WHAT teachers said about their professional identity and their work and also HOW they said it.

\section{Graphic synthesis of primary and secondary coding (next page)}


Even though the two nodes, i.e. identity and work, are the main threads that appeared throughout all data-collection tools and also in the research question it was the detailed analysis of the seven categories and their spectra that provided the main direction of the analytic story.

The coding process proved to be quite successful, though I am aware of the danger of coding becoming an end in itself, resulting in data reduction, where the richness of the data is lost through shunting it into categories. However, Coffey and Atkinson (1996) stress that coding qualitative data can be conceptualised as an exercise in data complication (p.32), where the identification of contradictions, absences and incoherence is given as much importance as the recognition of similarities and ordered patterns, thus stimulating critical reflection and enquiry. Some such contradictions and incoherence also appeared in my data, which led to additional reflection and enquiry as recorded in the researcher's journal and even further data analysis as presented later in this chapter.

\section{DATA PRESENTATION AND ANALYSIS - Two nodes}

The data is presented through two main nodes and through the lens of comparison of the two groups of teachers (NLP-based CPD attendees/teachers and other teachers). All data has been subjected to both content and linguistic analysis. This section accounts firstly for linguistic and content analysis of each Node and secondly it provides additional analyses that go across both nodes. 
The profiles of the two groups were the following:

\begin{tabular}{|l|l|l|}
\hline & NLP-based CPD attendees/ group & \multicolumn{1}{|c|}{ Other group } \\
\hline Number of teachers & 7 & 7 \\
\hline Career length & $\begin{array}{l}18-34 \text { years (mean career length } \\
26)\end{array}$ & $\begin{array}{l}6-32 \text { years (mean career length } \\
19)\end{array}$ \\
\hline Gender & 7 female & 6 female and 1 male \\
\hline Year & Year 1-9 & Year 1-9 \\
\hline Subjects & $\begin{array}{l}1 \mathrm{PE}, 2 \text { mathematics/physics, 1 } \\
\text { biology/chemistry, 1 history/ethics } \\
\text { and 2 Slovenian }\end{array}$ & $\begin{array}{l}1 \text { generalist, } 1 \mathrm{PE}, 1 \\
\text { mathematics/computer science, } 1 \\
\text { history, 1 chemistry, 2 Slovenian }\end{array}$ \\
\hline
\end{tabular}

Table 13 The respondent profiles

The data collection tools are represented by abbreviations according to the following key:

\begin{tabular}{|l|l|}
\hline Data collection tool & Abbreviation \\
\hline Non-participant semi-structured observations & O \\
\hline Semi-structured interviews & SSI \\
\hline Reflective diaries & RD \\
\hline $\begin{array}{l}\text { Video-stimulated follow-up interviews with feedback } \\
\text { sessions }\end{array}$ & VSI/FB \\
\hline
\end{tabular}

Table 14 Legend of abbreviations for data collection tools

The teachers' names were anonymised in the following way:

\begin{tabular}{|l|l|}
\hline Other Teachers & NLP-based CPD attendees/teachers \\
\hline Teacher 1 (T1) & NLP-based CPD attendee/ Teacher 1 (NT 1) \\
\hline Teacher 2 (T2) & NLP-based CPD attendee/Teacher 2 (NT 2) \\
\hline Teacher 3 (T3) & NLP-based CPD attendee/ Teacher 3 (NT 3) \\
\hline Teacher 4 (T4) & NLP-based CPD attendee/Teacher 4 (NT 4) \\
\hline Teacher 5 (T5) & NLP-based CPD attendee/Teacher 5 (NT 5) \\
\hline Teacher 6 (T6) & NLP-based CPD attendee/ Teacher 6 (NT 6) \\
\hline Teacher 7 (T7) & NLP-based CPD attendee/Teacher 7 (NT 7) \\
\hline
\end{tabular}

Table 15 Legend for anonymising both groups of teachers

The full legend of the abbreviations of the complex coding system can be found in Appendix 6.

\footnotetext{
${ }^{1}$ Slovenian primary school education encompasses 9 years of schooling (6-14 years old) whereas the secondary education lasts 4 years (14-18 years old)
} 


\section{Node 1: Teachers' identity}

\section{Linguistic analysis}

Here is a sample of a comparative analysis of the accounts of two groups of teachers

and their linguistic patterns in Node 1 - Teachers' identity i.e. categories 1 and 7: Self-

description of a teacher and Future plans.

\begin{tabular}{|c|c|c|c|}
\hline \multicolumn{2}{|l|}{ Sample statement } & \multicolumn{2}{|l|}{ Suggested coding } \\
\hline \multicolumn{2}{|l|}{ "I am like a sunshine" } & \multicolumn{2}{|c|}{$(+)-$ positive connotations of the chosen words } \\
\hline \multicolumn{2}{|l|}{ "I am a monster sometimes" } & \multicolumn{2}{|c|}{$(-)$ - negative connotation of the chosen words } \\
\hline \multicolumn{2}{|c|}{ "I am just a teacher and that's it" } & \multicolumn{2}{|c|}{ (N) - neutral connotation of the chosen words } \\
\hline \multicolumn{2}{|c|}{$\begin{array}{l}\text { "I don't know how to answer that...ok, I believe that } \\
\text {..." }\end{array}$} & \multicolumn{2}{|c|}{ (PL) - Personal language pattern (verb voice) } \\
\hline \multicolumn{2}{|c|}{ "It is expected that one should be a little strict..." } & \multicolumn{2}{|c|}{ (IL) - Impersonal language pattern (verb voice) } \\
\hline $\begin{array}{ll}\text { CATEGORIES } & \text { AND } \\
\text { SUBCATEGORIES } & \\
\end{array}$ & OTHER TE & IERS & 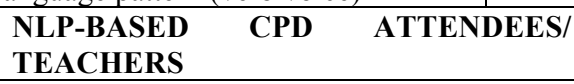 \\
\hline 1. Self-description as a teacher & A) Identity d & iptions: & A) Identity descriptions: \\
\hline $\begin{array}{l}\text { A) Identity description: self image } \\
\text { word connotation patterns: positive }(+) \\
\text { negative }(-) \text {, neutral }(\mathrm{N}) \text { connotations and } \\
\text { verb voice patterns: personal }(\mathrm{I}, \mathrm{me} \\
\text { myself)/impersonal (every teacher, } \\
\text { person, one, people, passive form) }\end{array}$ & $\begin{array}{l}\text { Self image: } \\
\text { "I am fair (+) } \\
\text { (SDT/id) (T1, } \\
\text { "I am just a te } \\
\text { many things ( } \\
\text { line 9, RD2) } \\
\text { "I see myself } \\
\text { there to guide } \\
\text { (T3, line 4, Ss } \\
\text { "As a teacher } \\
\text { guard' (N/-) a } \\
\text { demanding an } \\
\text { many other th } \\
\text { (T5, line 7, S } \\
\text { "I am here to } \\
\text { (PL) and som } \\
\text { nightmare (-) } \\
\text { SSI) } \\
\text { "One needs to } \\
\text { bad guy' (-) ir } \\
\text { and instruct, } 9 \\
\text { (SDT/id) (T7, }\end{array}$ & $\begin{array}{l}\text { stubborn (-) (PL) } \\
6, \text { SSI) } \\
\text { er which includes } \\
\text { PL)(SDT/id) (T2, } \\
\text { n instructor who is } \\
\text { (PL)(SDT/id)... } \\
\text { needs to be 'on } \\
\text { e time and that is } \\
\text { ne needs to be } \\
\text { (IL) (SDT/id) } \\
\text { heir guide (N) } \\
\text { hes I am their } \\
\text { T/id) (T5, line 11, } \\
\text { a little bit of 'a } \\
\text { der to teach them } \\
\text { (N) (IL) } \\
5 \text {, VSI) }\end{array}$ & $\begin{array}{l}\text { Self image: } \\
\text { "I am very understanding (+) and flexible } \\
\text { (+) (PL) (SDT/id) (NT1, line 4, SSI) } \\
\text { "I am sometimes too tired (-) (PL) (SDT/id) } \\
\text { (NT2, line 7, RD4) } \\
\text { "I am actually like their friend (+) and } \\
\text { like... I have many other roles (PL) } \\
\text { (SDT/id) (NT3, line 23. VSI) } \\
\text { "aaahhh, I am a nurturer, I guess (+) (PL) } \\
\text { (SDT/id) (NT4, line 6, SSI) } \\
\text { "I am also their angel guardian, like a } \\
\text { 'parent' (+) (PL) (SDT/id) (NT5, line 13, } \\
\text { RD1) } \\
\text { "Once you decide to be a teacher, it } \\
\text { involves being loving and a carer (+) (IL) } \\
\text { (SDT/id) (NT6, line 3-4, SSI) } \\
\text { "I would describe myself as a helper (+) and } \\
\text { a companion (N) on their journey (PL) } \\
\text { (SDT/id) (NT7, line 12, SSI) } \\
\text { "Today I felt as a teacher in the real sense of } \\
\text { that word, (N) (PL) and much more than } \\
\text { just that - honest, caring, helper, supporter, } \\
\text { encouraging, and also an awakener (+). I am } \\
\text { who I am and it is inseparable with my } \\
\text { profession" (SDT/id) (NT7, line 4-5, RD5) }\end{array}$ \\
\hline $\begin{array}{l}\text { Identity description: assumed } \\
\text { public/external image word } \\
\text { connotation patterns: positive }(+) \\
\text { negative(-) neutral }(\mathbf{N}) \text { connotations and } \\
\text { verb voice patterns: personal }(\mathrm{I}, \text { me } \\
\text { myself)/impersonal (every teacher, } \\
\text { person, people, passive form) language }\end{array}$ & $\begin{array}{l}\text { Assumed pul } \\
\text { "I don't know } \\
\text { (PL)...you ne } \\
\text { (SDT/pi) (T1, } \\
\text { "It is not publ }\end{array}$ & $\begin{array}{l}\text { external image: } \\
\text { w to answer that } \\
\text { o ask others" (N) } \\
13, \text { SSI) } \\
\text { known, nobody }\end{array}$ & $\begin{array}{l}\text { Assumed public/external image: } \\
\text { "I believe as reliable }(+) \text { and cooperative }(+) \\
(\text { PL) (SDT/pi) (NT1, line 16, SSI) } \\
\text { "oh, yes and I am seen as over-meticulous (- } \\
) \ldots \text { it is only because I like being well- } \\
\text { organized (+) (IL) (SDT/pi) (NT2, line 11, }\end{array}$ \\
\hline
\end{tabular}




\begin{tabular}{|c|c|c|}
\hline patterns); & $\begin{array}{l}\text { ever said anything (N) (IL) } \\
\text { (SDT/pi) (T2, line 15, SSI) } \\
\text { "I know some people would say I } \\
\text { am a monster (-) sometimes" (T3, } \\
\text { line 8, SSI) (SDT/pi) } \\
\text { "I am not sure anybody cares" } \\
(-) \text { (IL) (SDT/pi) (T4, line 10, SSI) } \\
\text { "It is known that other people are } \\
\text { more critical towards me and that } \\
\text { they judge me harshly but I don't } \\
\text { mind".(-) (IL) (SDT/pi) (T5, line } \\
22, \text { SSI) } \\
\text { "Others probably see me as quite an } \\
\text { ordinary teacher (N) (IL) but this } \\
\text { week majority of colleagues saw me } \\
\text { as extraordinary..." (+) (IL) } \\
(\text { SDT/pi) (T6, line 13, RD1) }\end{array}$ & $\begin{array}{l}\text { SSI) } \\
\text { "People say (IL) that I am like a sunshine } \\
(+)(\text { PL) (SDT/pi) (NT3, line 17, SSI) } \\
\text { “.. as a little bit nosy, I guess." (-) (PL) } \\
\text { (SDT/pi) (NT4, line 9, SSI) } \\
\text { "Sometimes my colleagues remind me that I } \\
\text { am creative and playful." (+)(PL) (SDT/pi) } \\
\text { (NT5, line 16, SSI) } \\
\text { "it is a public secret that my nickname is 'a } \\
\text { philanthropist'." (+) (SDT/pi) (NT6, line 9, } \\
\text { SSI) } \\
\text { "I am often teased that I am a catalyst - } \\
\text { quite appropriate for my science } \\
\text { background." (+) (SDT/pi) (NT7, line 17- } \\
\text { 18, SSI) }\end{array}$ \\
\hline $\begin{array}{l}\text { B) Behaviour descriptions word } \\
\text { connotation patterns positive }(+) \\
\text { negative }(-) \text {, neutral }(\mathbf{N}) \text { connotations and } \\
\text { verb voice patterns: personal }(\mathrm{I}, \mathrm{me} \\
\text { myself)/impersonal (every teacher, } \\
\text { person, passive form) language patterns }\end{array}$ & $\begin{array}{l}\text { B) Behaviour description: } \\
\text { "I explain my decisions thoroughly, } \\
\text { I teach them to understand } \\
\text { principles of life" (PL) (SDT/bd) } \\
\text { (T1, line 8-9, SSI) } \\
\text { "I look after children (+), I make } \\
\text { sure they stay safe (+) (SDT/bd) } \\
\text { (T2, line 10, SSI) } \\
\text { "It is expected to behave in a certain } \\
\text { manner, to set examples for them, } \\
\text { to educate them and to prepare them } \\
\text { for everything in life" (IL) } \\
\text { (SDT/bd) (T4, line 5, SSI) }\end{array}$ & $\begin{array}{l}\text { B) Behaviour description: } \\
\text { "Sometimes I entertain them }(+) \text {, talk to } \\
\text { them }(+) \text {, listen to them }(+) . .(\text { PL) } \\
(\mathrm{SDT} / \mathrm{bd})(\mathrm{NT} 1, \text { line } 7, \mathrm{SSI})\end{array}$ \\
\hline \multicolumn{3}{|l|}{ 7. Future plans } \\
\hline A) Change: PPD & $\begin{array}{l}\text { "I want development }(+) \text { and a } \\
\text { change, to get promoted to a mentor } \\
\text { or later to an adviser (PL) } \\
(\mathrm{C} / \mathrm{PPD})(\mathrm{T} 5, \text { lines } 148-149, \mathrm{SSI})\end{array}$ & $\begin{array}{l}\text { "I would like to learn more about new stuff, } \\
\text { to be able to mentor new colleagues." (PL) } \\
\text { (C/PPD) (NT1, line 112, SSI) } \\
\text { "My plan is to finish my study and move } \\
\text { from being a teacher of one subject to being } \\
\text { a teacher of two subjects." (PL) (C/PPD) } \\
\text { (NT3, line 123-124, SSI) } \\
\text { "I don't have a concrete plan yet. I want to } \\
\text { continue learning more about maths and I } \\
\text { am still thinking of how to start some } \\
\text { additional study circles where I could share } \\
\text { with pupils, colleagues and parents my } \\
\text { enthusiasm (+) for the subject." (PL) } \\
\text { (C/PPD) (NT 5, lines 93-96, SSI) }\end{array}$ \\
\hline Change: Career change & $\begin{array}{l}\text { "Well, ideally I would like to stop } \\
\text { teaching and get back to my } \\
\text { original dream (+) of becoming a } \\
\text { nurse (PL) (C/CC) T2, line 134, } \\
\text { SSI) }\end{array}$ & \\
\hline B) Continuity & $\begin{array}{l}\text { "I just want to continue being a } \\
\text { teacher without any disturbance (-) } \\
\text { (PL) (CON) (T1, line 112, SSI) } \\
\text { "Since it might be even more } \\
\text { demanding (-) in other professions } \\
\text { in these uncertain }(-) \text { times, I think } \\
\text { it is quite safe (+) to just stay here." } \\
\text { (IL) (CON) (T3, lines 96-98, SSI) }\end{array}$ & \\
\hline
\end{tabular}


Table 16 A sample of linguistic coding of Node 1 (Teachers' identity) for both groups

Once all the data was coded, a detailed linguistic analysis was carried out and some patterns emerged. In order to get as specific as possible a representation of the linguistic patterns in the teachers' accounts, an attempt of quantifying the data was made. As with any other large qualitative data corpus, it was not easy to represent the data numerically. Hence a very simple key was used based on the numbers of the descriptive words (nouns, adjectives, adverbs) with neutral, positive or negative connotations in relation to the overall number of the used descriptive words (when talking about their identity and future plans). It was demanding to decide how to categorize the numbers of words without risking either oversimplification or a loss of any significant (considerable or slight) similarities and differences in the teachers' accounts. Thus, the decision was made to distribute the categories as evenly as possible following a simple mathematical formula $(100 \%=33.3 \%+33.3 \%+33.3 \%)$.

Thus the summary of the numerical linguistic analysis was based on the evidence range of the frequency of linguistic patterns in the coded teachers' accounts. The tabular form of the data quantification is presented below. 
Summary of comparative linguistic analysis - Node 1 (Teachers' identity)

\section{Key/Legend}

Under $33.3 \%$ of all the used nouns, adjectives, adverbs $=$ weak range

Between $33.3 \%$ and $66.6 \%$ of all the used nouns, adjectives, adverbs $=$ medium range

Over $66.6 \%$ of all the used nouns, adjectives, adverbs $=$ strong range

\begin{tabular}{|l|l|l|}
\hline NODE 1 - Teachers' identity & Other teachers & $\begin{array}{l}\text { NLP-based CPD } \\
\text { attendees/teachers }\end{array}$ \\
\hline $\begin{array}{l}\text { Presence of neutral word } \\
\text { connotations }\end{array}$ & $\begin{array}{l}\text { Medium }(42.6 \%-49 \text { words out of } \\
115 \text { words) }\end{array}$ & $\begin{array}{l}\text { Weak }(20.5 \%-27 \text { words out of } \\
132)\end{array}$ \\
\hline $\begin{array}{l}\text { Presence of positive word } \\
\text { connotations }\end{array}$ & Weak (13\%- 15 words out of 115) & $\begin{array}{l}\text { Strong }(73.5 \%-97 \text { words out of } \\
132)\end{array}$ \\
\hline $\begin{array}{l}\text { Presence of negative word } \\
\text { connotations }\end{array}$ & $\begin{array}{l}\text { Medium (44.3\% - 51 words out of } \\
115)\end{array}$ & Weak (6\%-8 words out of 132) \\
\hline $\begin{array}{l}\text { Presence of impersonal language } \\
\text { patterns }\end{array}$ & Medium (57\%) & Medium (34\%) \\
\hline $\begin{array}{l}\text { Presence of personal language } \\
\text { patterns }\end{array}$ & Medium (43\%) & Medium (66\%) \\
\hline
\end{tabular}

Table 17 Evidence range of frequency of linguistic patterns - Node 1 (Teachers' identity)

The numerical linguistic analysis shed light on the following patterns for Node 1 -

\section{Teachers' identity (TI):}

NLP-based CPD attendees/teachers tended to use more words with positive

connotations while talking about both their self-image, their assumed public image and their future plans, however they also used neutral words. The frequency of words with negative connotation was very low (as shown in Table 17 above).

NLP-based CPD attendees/ teachers' accounts of their self-description as a teacher and public image of a teacher included the following words with positive and neutral connotations: understanding, flexible, friend, guardian angel, helper, supporter, caring, awakener, teacher.

Other teachers, on the other hand, used more neutral words and words with negative connotations whereas words with positive connotations were rarely used. 
Other teachers' accounts included the following words with neutral and negative connotations: teacher, being 'on guard', guide, instructor, monster, bad guy, nightmare.

A fascinating difference between the two groups appeared in the frequency of use of words with positive connotations. The discrepancy in evidence range is quite noticeable and it might be explained in many different ways as discussed in the next chapter.

It was also interesting to note that there was no significant variation tendency towards the use of personal or impersonal language patterns among teachers (the evidence range of frequency of the use of personal and/or impersonal verb voice tended to fall into the medium range category for both groups - see the table 17 above). The fact that there was no significant difference between the two groups in the use of personal and impersonal language patterns might be partly explained by the lack of a formal passive voice (which would fall into a category of impersonal verb voice) in the Slovenian language. Unfortunately, translated samples of teachers' accounts do not project truly the linguistic form used in the Slovenian language. On the other hand, it might be worth exploring further the small (but still quite clear) difference in the frequency of use of personal and impersonal language patterns. Other teachers showed the tendency to use almost equally frequently personal and impersonal verb voice, whereas NLP-based CPD attendees/ teachers used slightly more frequently personal verb voice. The question arises as to whether personal verb voice demonstrates a more agentive and empowered voice. Beijaard et al. (2004), while defining teachers' identity, clearly pointed out that "agency is an important element of professional identity" (p. 122). It cannot be claimed that the use of 'I' sentences and first person verb form alone indicate a higher level of teachers' agency. However one could suspect that that engagement and agency, which Beijaard et al. define as "meaning that teachers have to be active in the process of 
professional development" (ibid.) are less likely to be present in the behaviour of the teachers that tend to talk in 'an impersonal voice'.

\section{Content analysis}

The data belonging to Node 1 was further coded and analysed based on the spectra/subcategories (see table 12). From a more thorough content analysis the following similarities and differences between the two groups emerged:

\section{Similarity: Teacher's identity as multifaceted}

"I am just a teacher and then again that includes many things ... (T2, line 9, RD2)

“As a teacher one needs to be 'on guard' all the time and that is demanding and one needs to be many other things, a role model, a strict educator, an understanding colleague... (T1, line 7-9, SSI)

"I am actually like their friend and like... I have many other roles ... (NT3, line 23. VSI)

"Today I felt as a teacher in the real sense of that word and much more than just that - full of honesty, caring, helper, supporter, encouraging, and also an awakener. I am who I am and it is inseparable from my profession" (NT7, line 4-5, RD5)

I would describe myself as a helper and a companion on their journey (NT7, line 12, SSI)

Beijaard et al. (2004) defined teachers' professional identity among other things as 'multifaceted' ( $p$ 112). This multi-layered character of teachers' identity is also quite in accordance with what Beijaard (1995) refers to as four main features related to teachers' professional identities: identity in general, the subject one teaches, relationship with pupils, and role/role conception.

It is interesting to note that at least two of the above mentioned features (relationship with pupils and role/role conception) were quite strongly represented in teachers' accounts in both groups. The majority of teachers in both groups were focused on their identities based on their relationship with pupils (e.g. friend, helper etc.) and the roles they have in their every day work (e.g. 'on guard', role model, a strict educator etc). It is fascinating to note that none of the teachers described themselves in relation to the subject they teach. That would be more understandable had there been more 'generalist' 
teachers included in the study due to the fact that they would be teaching all the subjects in the first four years and thus not necessarily identifying themselves with any particular subject $^{2}$.

Identity in general (Beijaard, 1995) was mentioned usually in connection to beliefs and values the teachers held about either teaching/learning or life in general (presented later). This is in accordance with Woods et al. (1997) claiming that "teaching is a matter of values" (p.152). However, once teachers' beliefs and values in connection to teaching/learning and their perception of their professional identity got unpacked the following differences between the groups appeared:

\section{Differences:}

a) Identity in general and teacher's professional identity: separated vs intertwined

Keeping in mind the research question "How do teachers in one Slovenian primary school TALK about their professional identity and work following the participation in NLP-based CPD in comparison with other teachers?" it was fascinating to detect the differences in the teachers' perception of the relationship between their identity in general and their professional identity.

Other teachers pointed out in different ways that they leave behind their teachers' identity when they go home and that they clearly see their identity in general separated from their professional identity.

${ }^{2}$ Generalist teachers in primary education in Slovenia teach all the subjects for the first 4 years, subject specialist teachers teach their own subject from year 5 to year 9 . 
“Thank God I have learned to leave behind my teacher's identity when I get home - after all it belongs to the school environment. Otherwise I would just continue thinking about what happened in school". (T2, lines 3-5, RD3)

"Another week gone... I believe I did well. Could I have been even better? Probably, but there is only so much time available. I have other things in my life, I am not just a teacher.” (T4, lines 1-3, RD 4)

On the other hand, NLP-trained teachers emphasized the intertwining nature of their identity in general in relation to their professional identity.

"I am who I am and it is inseparable with my profession." (NT7, line 5, RD5)

"This was an interesting week. My whole family teased me that I kept collecting examples for my teaching all the time. For me it is fun. How could I not? I believe in connecting my subject with every day life and I cannot forget I am a teacher. My pupils learn best from real life examples." (NT1, lines 1-5, RD2)

This is in accordance with what Nias (1989) describes in her research in which she points out that the teachers were "inextricably bound up with the teacher role and could not switch off at the end of the school day to another life and another persona" (p. 146). Haigh (1995) refers to this phenomenon as 'isomorphic identity' and suggests that it can be problematic for teachers as they can easily get their sense of personal worth mixed up with their professional competence. It is worth exploring in further research (as mentioned in the final chapter) whether the intertwining of identity in general and professional identity is beneficial or not. It might be argued though that Haigh's comment refers to the comparison of personal worth on one hand and professional competence on the other rather than to two different levels of identity - identity in general and professional identity. As mentioned in the literature review when analysing literature on continuing professional identity (CPD) through the so-called neurological levels (see Chapter 2), there is a difference between capabilities, strategies, skills, competence and identity. Capabilities, skills and competence focus on what we can and what we DO, whereas identity focuses on who we are and who we can BE. Since teachers' identity is the focus of this study, it was natural to unpack the content of the 
above-mentioned common theme of the multifaceted character of teachers' identity. The unpacking however led to the discovery of further differences in the perception of what the multifaceted nature of teachers' identity encompasses:

b) An instructor, guide vs. a role of a nurturer, carer, supporter, parent

c) Behaviour focus vs. Identity focus

d) Values: responsibility, equality, fairness, safety vs. fun, enjoyment, curiosity, safety

When the multifaceted nature of teacher's identity was further analysed, it was discovered that while teachers talked about their professional identity, they mentioned their beliefs and values about teaching/learning and life as well as used many metaphors. It was also discovered that other teachers focused on their behaviour, strategies, skills, competence when talking about their identity whereas NLP-based CPD attendees/ teachers focused more on identity itself. This fits well with Haigh's (1995) comment mentioned above (competence vs. personal worth).

Since the literature on CPD has been reviewed through the lens of the NLP model called 'neurological levels' and since one of the noted differences between the groups was 'Behaviour focus vs. Identity focus' (two of six neurological levels), I have decided to use it again as an analytical framework to analyse the data. The chosen model, as mentioned in the literature review, was developed by Dilts (2000) on the basis of Bateson's (1972/2000) hierarchies of classification. Dilts (2000) modified Bateson's logical levels of learning and change into six 'neurological levels': environment, behaviour, capabilities/skills, beliefs/values, identity and mission (see Figure 4 in Chapter 2). 
The teachers' statements were literally classified using Dilts' model of neurological levels and a numerical analysis gave the following result:

\begin{tabular}{|l|l|}
\hline Example Statement & Neurological level suggested by statement \\
\hline $\begin{array}{l}\text { "The country we live in does not provide good } \\
\text { conditions" }\end{array}$ & Environment \\
\hline $\begin{array}{l}\text { "and I talk to all of them, address each individual, if } \\
\text { necessary tell them off " }\end{array}$ & Behaviour \\
\hline $\begin{array}{l}\text { "I am sure I am capable of creating a good atmosphere } \\
\text { in the classroom by engaging children and..." }\end{array}$ & Capabilities/Strategies \\
\hline "For me teaching is like dancing" & Beliefs/Values \\
\hline "I see myself as a carer, nurturer, as a parent to them. & Identity \\
\hline $\begin{array}{l}\text { "I feel I have been called for this profession, to make } \\
\text { this world a better place to live in" }\end{array}$ & Mission \\
\hline
\end{tabular}

Table 18 Classification examples of statements according to neurological levels

\begin{tabular}{|l|c|c|}
\hline Neurological levels & $\begin{array}{l}\text { NLP-based CPD attendees/ } \\
\text { teachers (number of statements) }\end{array}$ & $\begin{array}{l}\text { Other teachers (number of } \\
\text { statements) }\end{array}$ \\
\hline Environment & 24 & 117 \\
\hline Behaviour & 47 & 239 \\
\hline Capabilities/Skills & 186 & 103 \\
\hline Beliefs/Values & 204 & 129 \\
\hline Identity & 217 & 64 \\
\hline Mission & 32 & 14 \\
\hline
\end{tabular}

Table 19 Numerical analysis of teachers' statements (based on Neurological levels model developed by Dilts, 2000).

The quantified data from the table is used as a springboard for discussion of findings in Chapter 6. However, some of the most in-depth analyses are qualitative in nature, that is, they do not utilize numerical data, even though the above numerical analysis shows a significant difference between the two groups of teachers. Since the focus of Node 1 is Teachers' professional identity, only the teachers' statements that provided a description of their identity were further analysed. Those statements were categorized as belonging to all of the above-mentioned levels except Environment. Although there were many statements connected to the Environment level, they referred more to the teachers' job satisfaction and are analysed and discussed later in the section on Node 2 (Teachers' work). 
Firstly, it was noticeable that other teachers used more behaviour based sentences when asked "How could you describe yourself as a teacher?", thus indicating behaviour focus versus identity focus. This might explain the earlier mentioned separation between identity in general and professional identity. It can be assumed that if the professional identity is perceived and expressed in behaviour based statements ('I ask them questions, I answer their questions, I present new topics...(T6, line 6, SSI)), then it is easier to separate it from identity in general since it is unlikely that certain activities would happen out of the classroom setting. On the other hand, Barnett's (1997) notion of 'critical being' integrates the intellect, the self, and action. Thus behaviour based statements about one's (professional) identity might strongly rely on 'the action' part. NLP-trained teachers showed less tendency to talk about their professional identity in terms of their behaviour and focused more on their beliefs/values, identity and mission thus relying more on the 'intellect and the self' part of Barnett's idea. However, this is not to say that one group used only behaviour based statements and the other only beliefs/values and identity statements, but rather that the frequency of their use of certain neurological levels were different.

Here are some of the examples:

\begin{tabular}{|c|c|c|}
\hline STATEMENTS & Other teachers & NLP-based CPD attendees/teachers \\
\hline 2. Behaviour & $\begin{array}{l}\text { "To describe myself as a teacher... well, you } \\
\text { know I do what teachers do and I talk to all of } \\
\text { them, address each individual, if necessary tell } \\
\text { them off." (T3, lines } 8-9, \text { SSI) }\end{array}$ & $\begin{array}{l}\text { "Well, as a teacher I enter my classroom } \\
\text { with a smile." (NT1, lines 5-7, SSI) }\end{array}$ \\
\hline 3. Capabilities/Skills & $\begin{array}{l}\text { "As a teacher I am sure I am capable of } \\
\text { creating a good atmosphere in the classroom } \\
\text { by engaging children and..." (T6, lines 14-15, } \\
\text { SSI) }\end{array}$ & $\begin{array}{l}\text { "I rely on my 'human skills' as a teacher } \\
\text { (laughter), I can reach them as a human } \\
\text { being first and then it is easy to be their } \\
\text { teacher." (NT7, lines } 14-15, \text { SSI) }\end{array}$ \\
\hline \multicolumn{3}{|c|}{ 管 } \\
\hline A) About teaching & $\begin{array}{l}\text { "Being a teacher ...it is demanding, I mean, } \\
\text { teaching is a great responsibility, it needs to be } \\
\text { systematic, well-organized, well-planned, } \\
\text { focused on the outcome, effective " (T1, lines } \\
18-19, \mathrm{SSI})\end{array}$ & $\begin{array}{l}\text { "I believe being a teacher is all about how } \\
\text { enjoyable and fun I make it for them - } \\
\text { teaching should be interesting for me and } \\
\text { for them, something new, something that } \\
\text { brings excitement so that they can't wait for } \\
\text { me to start" (NT5, lines } 25-27 \text {, SSI) }\end{array}$ \\
\hline B) About learning & $\begin{array}{l}\text { "...a lot is expected from me and a lot is } \\
\text { expected from them. If they don't pay } \\
\text { attention during lessons, they will never learn } \\
\text { it and then they lose motivation and next time } \\
\text { learning becomes sweat and toil...it is like }\end{array}$ & $\begin{array}{l}\text { "I make sure they feel free to try things out, } \\
\text { create new exercises, moves, it is liberating } \\
\text { and inspiring for them and then learning } \\
\text { happens, somehow by the way, even when } \\
\text { they work hard, I mean physically hard, all }\end{array}$ \\
\hline
\end{tabular}




\begin{tabular}{|c|c|c|}
\hline & $\begin{array}{l}\text { fighting and not knowing when and if you will } \\
\text { win and I am their companion in that fight" } \\
\text { (T4, lines } 34-36, \mathrm{SSI} \text { ) }\end{array}$ & 45 minutes" (NT2, lines 63-65, SSI) \\
\hline C) General & $\begin{array}{l}\text { "...but that's how it is in life for girls or } \\
\text { women. They may as well learn the rules of } \\
\text { life now. Equality, whether it is fair or not. I } \\
\text { need to apply the same criteria when grading } \\
\text { their performance, even if they are smaller and } \\
\text { physically weaker sometimes..." (T2, lines } \\
52-54, \mathrm{SSI} \text { ) }\end{array}$ & $\begin{array}{l}\text { "Ah, all I need is to feel happy and when I } \\
\text { am a happy person, I can enjoy more } \\
\text {...everywhere, at work, at home... I can be } \\
\text { playful, curious, daring, exploring and safe } \\
\text { at the same time - it's wonderful..." (NT4, } \\
\text { lines } 76-78, \mathrm{SSI})\end{array}$ \\
\hline 5. Identity & $\begin{array}{l}\text { I see myself as an instructor who is there to } \\
\text { guide ... (T3, line } 4, \mathrm{SSI}) \\
\text { "As a teacher one needs to be 'on guard' all } \\
\text { the time and that is demanding and one needs } \\
\text { to be many other things" (T5, line } 7, \mathrm{SSI}) \\
\text { "I am here to be their guide and sometimes I } \\
\text { am their nightmare" (T5, line } 11, \mathrm{SSI}) \\
\text { "One needs to be a little bit of 'a bad guy' in } \\
\text { order to teach them and instruct, guide" (T7, } \\
\text { line } 5, \mathrm{VSI} \text { ) }\end{array}$ & $\begin{array}{l}\text { "I am actually like their friend" (NT3, line } \\
23, \text { VSI) } \\
\text { "aaahhh, I am a nurturer, I guess (NT4, } \\
\text { line 6, SSI) } \\
\text { "Today I felt as a teacher in the real sense of } \\
\text { that word, and much more than just that - } \\
\text { full of honesty, caring, helper, supporter, } \\
\text { encouraging, and also an awakener." (NT7, } \\
\text { line 4-5, RD5) }\end{array}$ \\
\hline 6. Mission & $\begin{array}{l}\text { "I like being with children and I always } \\
\text { wanted to do something for them and to be } \\
\text { able to instruct them how to develop both } \\
\text { physically and intellectually and to } \\
\text { demonstrate to them a healthy life style full of } \\
\text { physical activities and to teach them how to } \\
\text { perform those activities in a safe way ..aahh - } \\
\text { that sounds like a very good way of spending } \\
\text { my working life" (T2, lines } 74-78, \mathrm{SSI})\end{array}$ & $\begin{array}{l}\text { "I wake up and feel happy that there is } \\
\text { another day and I know that there are } \\
\text { children or young people there waiting for } \\
\text { me to share with them what I know about } \\
\text { my subject and not just that, about life, as } \\
\text { well. To cheer them up, to calm them down. } \\
\text { To be there for them when they need } \\
\text { somebody to talk to or just somebody to } \\
\text { listen to them and on top of that to teach } \\
\text { them and learn from them is my 'happy } \\
\text { thought' (laughter)" (NT6, lines 79-83, SSI) }\end{array}$ \\
\hline
\end{tabular}

Table 20 Recorded statements connected to Neurological levels

Secondly some contradictions were found in the content of the statements and, as mentioned earlier in the thesis, Coffey and Atkinson (1996) advocate that the identification of contradictions, absences and incoherence should be given as much importance as the recognition of similarities and ordered patterns. Hence a further data analysis has been carried out in order to 'unwrap' the statements.

As already mentioned in the literature review, Lakoff and Johnson in "Metaphors We Live By" (1980) demonstrated in detail how metaphors are the building blocks of our conceptual systems, which again structure what and how we perceive and understand the world. This groundbreaking work was an inspiration for a semiotic analysis of the metaphors used in the teachers' descriptions of their behaviour, strategies, beliefs/values, identity and missions. It showed a series of interesting contradictions. In 
the description of their identity and what they believe teaching is about, the other teachers have used words like 'demanding', 'responsibility', 'systematic', 'wellorganized', 'well-planned', 'focused on the outcome' and 'effective' almost all of which infer characteristics and features which could be seen as reflecting an 'efficiency model' of teaching. On the other hand, the NLP-based CPD attendees/ teachers described their opinion about teaching using the words enjoyable, fun, interesting, exciting, new which may easily be connected to features of what could be called 'exploratory play'.

Beliefs connected to learning also showed a considerable variation in the use of words by the two groups of teachers. The other teachers talked about paying attention, losing motivation, sweat, toil, fighting, winning and thus implicitly introduced a metaphor of learning as a battle. The NLP-based CPD attendees/ teachers opted for expressions such as free, trying out, creating, being happy, liberating, inspiring, working hard that resembled a conception of 'learning as related to art'.

General beliefs and values were described as 'rules', and 'applying criteria' by the other teachers and expressions such as feeling happy, enjoy, playful, curious, daring, exploring and safe by the NLP-based CPD attendees/ teachers. The inferred metaphors could be characterised as 'life is like a regime' and 'life is like play', respectively.

The other teachers described their mission using the following words: like children, to do something for them, instruct, develop, demonstrate, teach and perform, suggesting the role of an instructor/pedagogue, whereas the NLP-based CPD attendees/ teachers depicted their mission/calling with following words and expressions: wake up, feel happy, children or young people, waiting for me, share, know, life, cheer them up, calm them down, be there for them, need, to talk, to listen, teach, learn and happy thought 
which all fit very well with a description of a parent or a carer/nurturer. Once the teachers' own words such as helper and awakener were added, the following table of inferred metaphors was created.

\begin{tabular}{|l|l|}
\hline OTHER TEACHERS & NLP-BASED CPD ATTENDEES/ TEACHERS \\
\hline Role of an instructor/pedagogue, guide & Role of a parent/carer/nurturer, helper, awakener \\
\hline Teaching as efficiency model & Teaching as exploratory game \\
\hline Learning as a battle & Learning as art \\
\hline Life as a regime & Life as play \\
\hline
\end{tabular}

Table 21 The inferred metaphors

Metaphors in the world of education are frequent and they might be useful in explorations of different educational phenomena. As for teachers' professional identity it might be interesting to mention Bowring-Carr's (1993) point about how the increasingly used metaphor of teachers 'delivering' the curriculum may be taken to imply the reduction of teachers' role from initiative-taker to mere messenger. The question arises as to what influence teachers' perception of themselves as instructors and guides as opposed to the perception of themselves as helpers, carers, awakeners might have on their work, their job satisfaction and on how they deal with critical situations (such as the war-time the researcher and some of the respondents have gone through) in their profession. The goal of the Good Work Project mentioned earlier in the thesis is to "identify and to promote ways in which individuals at the cutting-edge of their professions can carry out work that is ethical and socially responsible" (Good Work Project website). Could it be argued that metaphors that imply that teachers' professional identity encompasses more than just usually taught elements (instruction and guidance) might contribute to the more socially responsible work? It would probably be a too bold a claim, which does not mean that the noted differences in the used metaphors should not be explored further in future studies. What could be argued, though, is that the metaphorical description of teachers' professional identity used by NLP-based CPD attendees/ teachers is quite in alignment with what was discovered 
about students' expectations of effective teachers' characteristics: cheerfulness, sense of humour, encouragement, helpfulness (see Taylor, 1962 and Nash, 1976).

The semiotic analysis of the statements categorized through neurological levels yielded some fascinating differences between the two groups of teachers, such as the thread in all analysed inferred metaphors by the other teachers being a shaped, orderly approach and a creative, playful and caring one for the NLP-based CPD attendees/ teachers. However the notion of self-selection should always be kept in mind as mentioned earlier in the thesis. The fact that the choice of attending CPD programmes based on NLP was left to teachers themselves and they voluntarily decided to take that path yet again leaves the door open for speculation as to whether their beliefs and/or values might have been different already before their attendance of NLP-based CPD programme. On the other hand, the other teachers showed a similar interest in the participating in NLPbased CPD programme, but could not enrol due to the group size limitation (max. 16) imposed both by the Slovenian Ministry of Education and the CPD programme provider. Thus the key difference in this respect was simply that those who were first to enrol got on the training programme. The extent to which there are other factors behind 'being quick to enrol' is hard to determine.

Another difference was noted about the teachers' values. Values like responsibility, equality, safety and fairness underpin the other teachers' mental representations of their identity and their work, whereas values like fun, curiosity, enjoyment and safety got registered among the NLP-based CPD attendees/ teachers. Again something that might be worth exploring in more depth in future studies. A very important question would be to ask: "Which values underpin the teachers' professional identity?" 
There were a few more differences in the perception of teachers' professional identity registered in teachers' accounts such as:

\section{e) Negative vs. Positive perception of own public image}

It was interesting to notice that the other teachers overall had a negative perception of their own public image as teachers, which was backed up by the numerous descriptive words with negative connotations (as already noted in the linguistic analysis of Node 1). The typical answers to the question "How do you think others would describe you as a teacher?" included the following statements:

"I know some people would say I am a monster sometimes" (T3, line 8, SSI)

"It is known that other people are more critical towards me and that they judge me harshly, but I don't mind" (T5, line 22, SSI)

The NLP-based CPD attendees/ teachers demonstrated a more positive perception of their public image as teachers, which was supported by words with positive connotations.

"People say that I am like a sunshine" (NT3, line 17, SSI)

"Sometimes my colleagues remind me that I am creative and playful.” (NT5, line 16, SSI)

"it is a public secret that my nickname is 'philanthropist'." (NT6, line 9, SSI)

Sfard and Prusak (2005) in their definition of identity focused on the narratives. In the case of the teachers in Slovenia, it might be significant how they talk about their professional identity and how they perceive their own public professional image both for how they function as teachers and whether they are satisfied as teachers. 
Sfard and Prusak (2005) even extended the narrative-based definition of identity by splitting the narratives further into two subsets which they decide to name "actual identity, consisting of stories about the actual state of affairs, and designated identity, consisting of narratives presenting a state of affairs which, for one reason or another, is expected to be the case" (p.18). Even though the authors had in mind a prospective, positive nature of the notion of designated identity as something that might happen in the future, it looks like the non NLP-based CPD attendees/ teachers linked their designated public identity to negative expectations based on the past and projected into the future. It might be the subject of a whole new study to explore what consequences the perception of one's own and one's public image as a professional has on one's work, i.e. on how ethical and socially responsible one's work is.

The NLP-based CPD attendees/ teachers demonstrated a more positive perception of their public image which brings us back to Lyotard's (1979) paraphrase of John Donne's proverb that 'No self is an island; each exists in a fabric of relations"( One can argue that Lyotard's account of the self existing in a fabric of relations can be used as a good foundation for a social constructivist approach to identity, which implies that identity/ies, including professional identity/ies, is/are a resource for interaction. The question remains for what kinds of interaction (e.g. with pupils, colleagues, etc.) the negative perception of one's public image as a professional can be a resource. Thus, some of the analysed data seems to rather raise more questions than provide answers. On the other hand, the study set out to explore HOW (NLP-based CPD attendees/teachers and other) teachers in one Slovenian primary school talk about their professional identity and their work. And those are the only answers it can provide: descriptive answers that might lead to more questions. And this might indeed be the case when looking at the summary of the comparative content analysis of Node 1 . 


\section{f) Continuity vs. Change in the future plans}

The last difference in Node 1 was connected to how the teachers from both groups talked about their future plans. There was an overall tendency in the group of other teachers to talk about continuity. However, there were a few comments about potential change in connection to moving to different careers, or staying in the teaching career, but getting promoted. The other teachers were partly interested in professional and personal development programmes in their plans for the future, provided that they would be able to get promoted to mentor or adviser status.

\footnotetext{
"I just want to continue being a teacher without any disturbance (T1, line 112, SSI)

"Since it might be even more demanding in other professions in these uncertain times, I think it is quite safe to just stay here." (T3, lines 96-98, SSI)

"I am quite happy as a primary school teacher, so no need for any particular changes in the future." (T6, lines 91-92), SSI

"Well, ideally I would like to stop teaching and get back to my original dream of becoming a nurse (T2, line 134, SSI)

"I want development and a change, to get promoted to a mentor or later to an adviser (T5, lines148-149, SSI)

On the other hand, the teachers from the group of NLP-based CPD attendees emphasized their overall wish for change in terms of gaining further knowledge and development in the form of CPD.
}

"My plan is to finish my study and move from being a teacher of one subject to being a teacher of two subjects." (NT3, line 123-124, SSI)

"I don't have a concrete plan yet. I want to continue learning more about maths and I am still thinking of how to start some additional study circles where I could share with pupils, colleagues and parents my enthusiasm for the subject." (NT 5, lines 93-96, SSI)

The noted difference between the groups is in alignment with the findings of Friedman and Philips (2004) as will be discussed in Chapter 6. 
Summary of the comparative content analysis of Node 1 (Teachers' identity)

\begin{tabular}{|l|l|}
\hline \multicolumn{1}{|c|}{ Other teachers } & NLP-based CPD attendees/ teachers \\
\hline \multicolumn{2}{|c|}{ Teacher's identity is multifaceted } \\
\hline \multicolumn{1}{|c|}{ Differences } \\
\hline Identity in general and teacher's identity are separated & $\begin{array}{l}\text { Identity in general and teacher's identity are } \\
\text { intertwined }\end{array}$ \\
\hline Behaviour focus & Identity focus \\
\hline A role of instructor/pedagogue and guide & A role of parent/carer, helper, awakener \\
\hline $\begin{array}{l}\text { Metaphors connected to beliefs about teaching, learning } \\
\text { and life in general = efficiency, battle, regime }\end{array}$ & $\begin{array}{l}\text { Metaphors connected to beliefs about teaching, learning } \\
\text { and life in general = exploratory game, art, play }\end{array}$ \\
\hline $\begin{array}{l}\text { Underpinning values = responsibility, equality, fairness, } \\
\text { safety }\end{array}$ & $\begin{array}{l}\text { Underpinning values = fun, curiosity, happiness, } \\
\text { learning, safety }\end{array}$ \\
\hline Negative perception of own public image as a teacher & Positive perception of own public image as a teacher \\
\hline Overall focus on continuity & Overall focus on change \\
\hline
\end{tabular}

Table 22 Similarities and differences between the groups - Comparative content analysis - Node 1 (Teachers' identity)

\section{Node 2: Teachers' work}

\section{Linguistic analysis}

The comparative linguistic analysis of Node 2 (see Appendix 7 for a sample) showed similar patterns to the ones noticed in Node 1.

The same approach to quantifying data as in Node 1 was applied - the summary of numerical linguistic analysis was based on the evidence range of frequency of linguistic patterns in the coded teachers' accounts. The ranges of frequency of linguistic patterns for the teachers are presented below in Table 23.

Summary of comparative linguistic analysis - Node 2 (Teachers' work)

\section{Key/Legend}

Under $33.3 \%$ of all the used nouns, adjectives, adverbs = weak range

Between $33.3 \%$ and $66.6 \%$ of all the used nouns, adjectives, adverbs $=$ medium range

Over $66.6 \%$ of all the used nouns, adjectives, adverbs = strong range

\begin{tabular}{|l|l|l|}
\hline NODE 2 - Teachers' work & Other teachers & $\begin{array}{l}\text { NLP-based CPD attendees/ } \\
\text { teachers }\end{array}$ \\
\hline $\begin{array}{l}\text { Presence of neutral word } \\
\text { connotations }\end{array}$ & Medium & Weak \\
\hline $\begin{array}{l}\text { Presence of positive word } \\
\text { connotations }\end{array}$ & Weak & Strong \\
\hline
\end{tabular}




\begin{tabular}{|l|l|l|}
\hline $\begin{array}{l}\text { Presence of negative word } \\
\text { connotations }\end{array}$ & Medium & Weak \\
\hline $\begin{array}{l}\text { Presence of impersonal language } \\
\text { patterns }\end{array}$ & Medium & Medium \\
\hline $\begin{array}{l}\text { Presence of personal language } \\
\text { patterns }\end{array}$ & Medium & Medium \\
\hline
\end{tabular}

Table 23 Evidence range of frequency of linguistic patterns - Node 2 (Teachers' work)

The numerical linguistic analysis showed similar patterns for Node 2 - Teachers' work (TW) to the previously observed ones in Node 1 - Teachers' identity (TI).

The NLP-based CPD attendees/ teachers again tended to use more words with positive connotations while talking about their job satisfaction, their attitude towards work and their skills/strategies in the fields of communication, motivation and handling demanding situations. The frequency of words with negative connotation was very low.

The NLP-based CPD attendees/ teachers' accounts of their job satisfaction, attitude towards work and their skills/strategies included the following words with positive and neutral connotations: calm, fulfilled, happy, better and better, innovative, unique.

The other teachers used again more neutral and words with negative connotations whereas words with positive connotations were rarely used.

The other teachers' accounts included the following words with neutral and negative connotations: negative consequences, exhaust, waste of time.

The same fascinating difference between the two groups appeared again in the frequency of the use of words with positive connotations. The discussion of the use of words with positive, neutral and/or negative connotations is presented in chapter 6 . 
The same pattern (from Node 1) of a lack of variation tendency towards the use of personal or impersonal language patterns among teachers reoccurred. itself. The same question based on Beijaard's (2004) idea that "agency is an important part of professional identity" (p. 122) may be posed: "Can teachers who talk in 'an impersonal voice' be active in the process of professional development and have agentive and empowered voice?"

Further content analysis based on different categories (and their spectra/subcategories) included in Node 2 - Teachers' work (TW) revealed some interesting tendencies.

\section{Content analysis}

The following similarities and differences between the two groups emerged:

\section{Similarity: Overall focus on the teachers' work being their calling}

Even though there were a few statements among the other teachers referring to the idea that their work is their obligation, the overall focus in both groups was on their work being their calling.

\footnotetext{
"I think I am quite serious about my work, with all the preparations, talking to my colleagues, I think I have a responsible attitude towards my work, after all that is what is expected from me, I am obliged to take it seriously and then it is not just an obligation, it is what I feel I am here for - on this planet to do good for future generations, for the world..." (T5, lines 76-80, SSI)

"I feel I have been called for this profession, to make this world a better place to live in" (T1, line 15, RD6)

"I wake up and feel happy that there is another day and I know that there are children or young people there waiting for me to share with them what I know about physical education and not just that, about life, as well. To cheer them up, to calm them down. To be there for them when they need somebody to talk to or just somebody to listen to them and on top of that to teach them and learn from them is my happy thought (laughter) and I feel that is what I am here for, that is my work" (NT6, lines 79-83, SSI)
} 
"I can't switch off my work any more, it has become my life style, part of me and that is how I think of it - it is mine, it fulfils me, it is with me all the time, it is my mission and it is good for everybody" (NT2, line 103-104, SSI)

This is in accordance with Woods et al.'s (1997) claim that "people teach because they believe in something. They have an image of the 'good society"' (p.152). Thinking of one's work as a calling probably contributes to the level of commitment and satisfaction. Hargreaves (1999) points out that personal and professional elements are intertwined and that for teachers' commitment, enthusiasm and morale "their hopes and dreams, their opportunities and aspirations, or the frustrations of these things are also important" (p.vii).

Keeping in mind this overall focus on the teachers' work being their calling and Woods et al. (1997) and Hargreaves's (1999) comments about the good society and what influences teachers' commitment, enthusiasm and morale, it would have been easy to assume that the level of job satisfaction in both groups would be high. However, just like in Node 1, some contradictions were found and consequently some differences between the groups were detected. Thus the interaction with the data demonstrated once again that in research one's assumptions should be set aside.

\section{Differences:}

\section{a) Job satisfaction vs. Lack of Job satisfaction}

\section{b) External attribution vs. Internal attribution}

In spite of both groups being united in their perception of the teachers' work being their calling, their assessment of job satisfaction level differed significantly. Not only did it 
differ, but it was also discovered that the causes for either job satisfaction or lack of it were attributed differently.

The preliminary numerical data analysis of category 2 "Job satisfaction" with its spectra/subcategories showed the following results:

\begin{tabular}{|l|c|l|}
\hline Job satisfaction presence & $\begin{array}{l}\text { NLP-based CPD attendees/ } \\
\text { teachers (numbers) }\end{array}$ & $\begin{array}{l}\text { Other teachers } \\
\text { (numbers) }\end{array}$ \\
\hline Focus on the self & 3 & 0 \\
\hline Focus on others & 0 & 0 \\
\hline Focus on the school & 1 & 1 \\
\hline Focus on wider society & 1 & $\mathbf{2}$ \\
\hline TOTAL number of teachers & $\mathbf{5}$ & 1 \\
\hline
\end{tabular}

\begin{tabular}{|l|c|l|}
\hline Lack of Job satisfaction & $\begin{array}{l}\text { NLP-based CPD attendees/ } \\
\text { teachers (numbers) }\end{array}$ & $\begin{array}{l}\text { Other teachers } \\
\text { (numbers) }\end{array}$ \\
\hline Focus on the self & 2 & 0 \\
\hline Focus on others & 0 & 2 \\
\hline Focus on the school & 0 & 1 \\
\hline Focus on wider society & 0 & 2 \\
\hline TOTAL number of teachers & $\mathbf{2}$ & $\mathbf{5}$ \\
\hline
\end{tabular}

Table 24 Numerical analysis of Category 2 - Job satisfaction

Since the numerical analysis of both groups of teachers showed important differences in the location of focus for job satisfaction, a further qualitative textual analysis of how teachers attribute their job satisfaction, or the lack of it, was carried out to explore attribution theory (Buchanan et al., 2002) dimensions of external versus internal attribution. Attribution theory originally was an empiricist attempt to study the patterns in how individuals account for their own and other people's actions (ibid.). Attribution theory traditionally tried to classify people's accounts along three separate distinctions. Firstly, whether an event is attributed to internal (dispositional) factors or to external (situational) factors. Secondly, whether the event is considered local or global in scope (i.e. whether it is considered a singular incident or something that happens also outside of the current context) and thirdly, whether it is considered stable or unstable (i.e. whether the event is considered to be an enduring or temporary phenomenon (ibid.). 
The main dimension is, however, whether the attribution is directed 'inwards' or 'outwards', and this is the dimension that the present study will focus on. However, whereas most studies in attribution theory have been experimental and empiricist, this study applied the attribution dimension 'internal' vs. 'external' to a textual analysis of the interviews and the reflective diaries.

The subcategories were re-categorized according to attribution theory in the following way:

1. Focus on the self $=$ internal attribution

2. Focus on others, focus on the school and focus on wider society $=$ external attribution

After classifying the teachers' statements with regards to internal/external attribution relating to job satisfaction the statements were counted and the predominant styles detected are presented below.

A numerical analysis of attribution theory categories gave the following results:

\begin{tabular}{|l|l|l|}
\hline $\begin{array}{l}\text { Job satisfaction presence + Lack } \\
\text { of job satisfaction }\end{array}$ & $\begin{array}{l}\text { NLP-based CPD attendees/ } \\
\text { teachers (numbers) }\end{array}$ & $\begin{array}{l}\text { Other teachers } \\
\text { (numbers) }\end{array}$ \\
\hline Internal factors (focus on the self) & 5 & 0 \\
\hline $\begin{array}{l}\text { External factors (focus on others, } \\
\text { focus on the school, focus on wider } \\
\text { society) }\end{array}$ & 2 & 7 \\
\hline TOTAL number of teachers & 7 & 7 \\
\hline
\end{tabular}

Table 25 Numerical analysis of attribution styles for Category 2 - Job satisfaction

The analysis shows a high number of NLP-based CPD attendees/ teachers that attributed their job satisfaction, or its absence, to the self.

\section{Internal factors (focus on the self):}

"Now when I am more experienced and mature, now when I have learned from life, from my own experiences... I can easily concentrate and enjoy in my work..." (NT5, SSI, lines 48-50) 
"There are days when I am extremely happy and satisfied and that coincides with how calm and peaceful I am on the inside. Then I can give to the students exactly what they need..." (NT1, $\mathrm{RD}$, lines 66-68)

"Sometimes I am too occupied with my own issues and it takes a lot of energy to deal with them and then I experience my work almost as a hindrance rather than a source of any satisfaction..." (NT3, VSI, lines 53-55)

\section{External factors (focus on others, focus on the school, focus on wider society):}

"Aaah, it is a great school to work for, all the colleagues are cooperative, students are eager to learn, what else can one wish for? Those are more than good reasons to be satisfied..." (NT6, SSI, lines 46-48)

"Nowadays everything is easier, the situation in the society is better and teaching profession is safer... I cannot complain, I am satisfied..." (NT4, SSI, lines 38-39)

None of the other teachers attributed either job satisfaction or dissatisfaction to internal factors.

\section{External factors (focus on others, focus on the school, focus on wider society):}

"Both students and colleagues are sometimes impossible... and there is nothing I can do, it is as it is, it is simply not possible to establish any proper communication..." (T4, SSI, lines 58-60)

"I hope with each new government things would get better, but nothing changes for the better, I cannot be satisfied as teacher with low salary ... no respect in the society any more, no change for better on the horizon any time soon..." (T3, SSI, lines 44-46)

"I have worked in many schools and this school is very well organized, the rules are clear, the students are informed properly, the leadership is there for the teachers, I am satisfied with all those things because they make my job easier..." (T6, SSI, lines 62-64)

A further qualitative textual analysis of how the teachers attribute their job satisfaction or the lack of it was carried out in order to examine how the teachers talk about their job satisfaction. One of the aims was to explore whether the teachers see themselves as active contributors to their job satisfaction (or the lack of it) or as passive 'receivers' of the current circumstances made up of external factors.

Some of the teachers were very aware of their own contribution to job satisfaction or to the lack of it, and some emphasized other external factors as reasons/causes. The 
internally focused teachers perhaps form a group of active teachers, whereas the externally focused teachers perhaps form a group of reactive or passive teachers. Even though both groups of teachers (the internally and externally focused) are aware of the need for changes for the better, the internally focused teachers think of themselves as agents of change for the better, whereas the externally focused teachers expect change to happen from the outside. There is a strong political element in the externally focused teachers ("I hope with each new government things would get better, but nothing changes for the better”), whereas there is a strong individual element (“...now when I have learned from life, from my own experiences...") in the internally focused teachers. One can speculate as to whether the combination of the war experience and personal development trainings have left some teachers 'wiser' and more internally focused while the others, who might have not been teachers during the wars in ex-Yugoslavia and did not attend personal development trainings, kept an external focus. The relatively small difference in length of work experience may have contributed to the difference in focus. Some of the other teachers are younger and thus were spared the war experience (see Table 13 on page 179).

However, the previously mentioned self-selection (where the first to enrol got on the training and those who expressed their interest slightly later became the comparison group) might mean that there was a difference in the extent to which personal development trainings appealed to the teachers. Thus those who participated in the NLP-based CPD could have been more inclined towards engagement in the classroom and their professional development in certain internally-focused and activist ways, leaving the NLP-based CPD and the war experience as other potential factors that may have reinforced, but did not 'cause' the attribution styles. 
Taking into account Barnett's (1997) notion of 'critical being' that integrates the intellect, the self, and action may provide yet another perspective on the above presented data. The internally focussed teachers have demonstrated a focus on the self, the intellect and the actions, and that they are in charge of creating changes for the better. The externally focused teachers demonstrated very little focus on the self, which, according to Barnett (ibid.), might mean that they are still to gain a 'critical being' attitude or identity.

One can speculate that if teachers point 'outwards' regarding job satisfaction, then they depend on the current social and political order for their well-being. Thus instead of being 'self-sustained teachers', i.e. teachers no matter what political or economic situation they live in, they become dependent on external factors and thus unprepared for critical situations. If teachers wait for external factors to get better in order to feel satisfied with their jobs, they are not in control of their own job satisfaction and cannot easily influence change for the better. Teachers, who 'point outwards', might discursively be more passive in relation to policies and practices compared to those 'pointing inwards', who might be more active.

The presence of a difference between the two groups in external vs. internal attribution was supported by the analysis of category 5 , i.e. strategies for self-motivation. The majority of the other teachers focused on external triggers, while NLP-based CPD attendees/ teachers focussed on internal triggers.

"I motivate myself by thinking of all the nice things I can do today, how many children I will help today etc." (MS/sm/it, NT7, lines 33-34, SSI)

"Oh, what a day, I really need to wake up into a sunny day or to the tempting smell of freshly made coffee to feel full of energy and to keep going and today was not a day like that at all" (MS/sm/et, T2, lines 1-2, RD 2) 
Wenger (1998) talks about "full, livid experience of engagement in practice" (p.151), and it may be the case that seeking externally for a source of job satisfaction or selfmotivation might deprive the teachers of exactly that, consequently leading to a more passive approach in their profession.

\section{c) Strategies/skills (communication, motivation, handling demanding situations):}

\section{part of personal characteristics/talent vs. acquirable/learnable}

Once the categories 4, 5 and 6 (strategies/skills for communication, motivation and handing demanding situations) were coded and analysed, the above-mentioned difference between a passive approach and its active counterpart was detected. The other teachers tended to think of strategies and skills in the mentioned fields as something one needs to be born with, whereas the NLP-based CPD attendees/ teachers expressed their belief that all those strategies are action based and acquirable/learnable.

\footnotetext{
"No, I am not very good at communication skills, I suppose one needs to be born with that gift and I discovered very early that I am more talented for natural science" (T4, line 52-53, VSI)

"I seem to have a talent for sorting things out, don't ask me what I do because I am not sure I know, I just intuitively do what I think is right and it usually ends up being OK for all. I don't need to think about it really, it just happens right there and then, just like that" (T1, lines 29-31, SSI)

"I am getting better and better and I am using many skills I have acquired at many workshops... it is a matter of practice and I decided to introduce one little thing every hour - to take action. For example I have introduced 'moaning time' for 10 minutes on Wednesdays when all the pupils can say what they are not happy with (laughter) and it works miracles, we are all more relaxed after that and I make sure I do something about what they say" (NT4, lines 29-33, $\mathrm{SSI})$
}

The same pattern of passivity vs. activity/agency reappears. If teachers believe that some of the skills/strategies that are needed in the classrooms (and out of them) are 'inborn' and based on talents, then there is nothing they (or anybody else) can do about them. They cannot be learned and acquired thus no change for better and no further 
development can be anticipated. That shrinks the role of CPD (and PPD) programmes to only a subject based focus. This attitude towards change of the status of certain strategies/skills at the same time indicates an attitude towards learning in general and indirectly toward professional identity of teachers (whose main field is teaching/learning). Wenger (2006) advocates even a direct connection between learning and identity claiming that identity is a "learned experience of agency" (p.19). He sees learning as a social process with a strong ethical dimension thus bringing in focus again on the topic of the Good Work Project, i.e. ethical and socially responsible dimensions of one's work.

Summary of the comparative content analysis of Node 2 (Teachers' work)

\begin{tabular}{|l|l|}
\hline \multicolumn{1}{|c|}{ Similarities } \\
\hline \multicolumn{1}{|c|}{ Other teachers } & NLP-based CPD attendees/ teachers \\
\hline \multicolumn{1}{|c|}{ Differences } \\
\hline \multicolumn{1}{|c|}{ Ovecus on their work being their calling } \\
\hline Lack of job satisfaction & Presence of job satisfaction \\
\hline $\begin{array}{l}\text { External attribution } \\
\text { (for job satisfaction/dissatisfaction and motivation) }\end{array}$ & $\begin{array}{l}\text { Internal attribution (for job satisfaction/dissatisfaction } \\
\text { and motivation) }\end{array}$ \\
\hline $\begin{array}{l}\text { Skills and strategies (communication, motivation, } \\
\text { handling demanding situations) are part of personal } \\
\text { characteristics/talent based }\end{array}$ & $\begin{array}{l}\text { Skills and strategies (communication, motivation, } \\
\text { handling demanding situations) are acquirable/learnable }\end{array}$ \\
\hline
\end{tabular}

Table 26 Similarities and differences between the groups - Comparative content analysis - Node 2 (Teachers' work)

Even though the research question is focused on how teachers TALK I decided, after both nodes were analysed, to examine the congruence level between teachers' talk and their actions in the classrooms. For that I needed to revisit my observations and the video-stimulated follow-up interviews with feedback sessions. The video recorded observations proved to be extremely useful in the following analysis.

\section{Additional analysis across both nodes}

During the individual video-stimulated follow-up interviews the level of congruence between what was said (semi-structured interviews) or written (reflective diaries) and 
what was demonstrated during the observed classes was explored. Some of the parts of the recorded classes were watched together with the respective teacher and commented on both by the researcher and the teacher. One of the additional reasons for carrying out both video stimulated interviews and feedback sessions was also to compare the researcher's interpretations with those of the teachers and thus try to achieve respondent validation. However, some additional patterns connected to teachers' reactions towards what they saw in the videos were discovered.

The teachers' reactions fell into two categories, which are numerically presented below:

a) a surprise (followed by either slight embarrassment or pride)

b) a defensive response

\begin{tabular}{|l|l|l|}
\hline $\begin{array}{l}\text { Teachers' reactions (video } \\
\text { stimulated interviews/feedback } \\
\text { sessions) }\end{array}$ & Other teachers & $\begin{array}{l}\text { NLP-based CPD attendees/ } \\
\text { teachers }\end{array}$ \\
\hline Surprise & 4 & \multicolumn{2}{|c|}{1} \\
\hline Defensive response & 3 & 7 \\
\hline TOTAL number of teachers & 7 & \multicolumn{2}{|c|}{} \\
\hline
\end{tabular}

Table 27 Teachers' reactions in video stimulated interviews/feedback sessions

Some of the illustrative examples of surprise included:

"Oh, my God, I would never think this is the way I handle demanding situations. I think the way I started was quite good but then... oh, no... I feel embarrassed, I can't believe I raised my voice like that... I would never think that..." (NT2, lines 15-17, VSI/FB)

"This is interesting and surprising... I have motivated that girl and I was not even aware that she was making faces and rolling her eyes... (laughter) I am happy with how it worked, I would like to remember this and repeat it..." (NT5, lines 22-24, VSI/FB)

Some of the illustrative examples of a defensive response included:

\footnotetext{
"Well, it does come across completely differently on the camera... I don't think I sounded quite as strict .... and after all that is my role ...to make sure the rules are followed and respected. What else could I do?" (T4, lines 17-19, VSI/FB)

"I think I reacted as I should have. After all, one cannot be nice and polite all the time. The boys were really annoying and all I did was to warn them and present all the negative consequences of their behaviour" (T6, lines 8-10, VSI/FB)
} 
Considering the four 'core processes' of action research, the third and fourth step, observation and reflection, could be applied in the discussion of above presented data.

Ten out of the 14 teachers expressed surprise while either being embarrassed or proud when presented with the recorded lessons and with the question "How does this $\mathrm{X}$ relate to what you said in the interview/diary about X?" The same teachers were more than eager to learn from either their own 'mistakes' (as they categorized some of their own actions) or their 'good practice actions'. Hammersley's (2004) definition of the 'core idea of action research' as having an 'intimate relationship between inquiry and practical or political activities - such that the focus of inquiry arises out of, and its results feed back into, the activity concerned“ (p.165) hits the right note with the above presented idea about learning from either mistakes or good practice actions. If the teachers are willing to develop their observational skills and learn form their own mistakes or good practice action, then Hammersley's idea about the results of inquiry being fed back to the activity concerned (in this case teaching) has been achieved. Furthermore, one can argue that the employed data collection tools contributed to some teachers' high level of self-observational/modelling skills. The fact that the teachers were invited to comment on what they saw in the videos already set the frame for reflexivity.

On the other hand the group of teachers that chose a defensive response showed very little reflexivity in their comments. This was, however, activity-dependent. It was also interesting to discover the teachers' focus on justification (I did that because...), even when their own 'good practice' examples were shown to them. Since their focus was on justifying their actions rather than on learning from their actions the third step 
(observation) of the four core processes in action research was taking place, whereas the fourth step (reflection) failed to take place.

The majority of the NLP-based CPD attendees/ teachers demonstrated surprise and presumably thereby also a high level of self-observational/modelling skills.

In Chapter 2 NLP was defined as an approach to developing successful practice through modelling. It can be argued that some glimpses of development of the respondents' practice based on their observations and modelling of their lessons were observed ("I would like to remember this and repeat it... (NT5, line 24, VSI/FB).

At the first sight it may not be crystal clear how this analysis may contribute to an exploration of how teachers talk about their identity and their work. However Kelchtermans (1993) clearly points out that teachers' professional development can be understood as a learning process. Using this as a departure point, the teachers who did not learn from their actions in the classrooms deprived themselves of professional development. And professional development according to Kelchtermans culminates in a personal interpretative framework, encompassing two major fields: a conception of themselves as a teacher and a system of knowledge and beliefs concerning 'teaching' as a professional activity (Kelchtermans, 1993, p.447). Thus both nodes in the study (teachers' identity and teachers' work) get synthesized through the teachers' professional development which was, by the way, the starting point of the study (NLP based trainings as part of a professional and personal development programme). 
The 'personal interpretative framework' mentioned above takes us back to the overarching interpretative framework, which focuses on interpretations rather than facts. Kelchtermans sees a personal interpretative framework as encompassing the concepts of 'the personal self' (i.e. ways in which teachers conceive of themselves as teachers) and 'the subjective educational theory' (i.e. the teacher's 'personal teaching style'). Their self-image, self-esteem, job motivation, task perceptions and future perspectives determine the ways in which teachers develop a 'personal meaning system' and a 'personal teaching style'. Both are mainly developed "by reflection on classroom practices" (Kelchtermans, 1993, p.452). With these thoughts, the study's key research fields of teachers' professional identity, teachers' work and NLP as CPD as well as the study's methodology get synthesized. 


\section{Summary}

The careful linguistic and content analysis of both nodes (Teachers' Identity and

Teachers' Work) resulted in the following similarities and differences.

\begin{tabular}{|l|l|}
\hline \multicolumn{1}{|c|}{ Other teachers } & NLP-based CPD attendees/ teachers \\
\hline \multicolumn{1}{|c|}{ Oeacher's identity is multifaceted } \\
\hline \multicolumn{1}{|c|}{ Overall tendency of using evenly } \\
\hline \multicolumn{1}{|c|}{ personal and impersonal verb voice } \\
\hline \multicolumn{1}{|c|}{ Differences } \\
\hline $\begin{array}{l}\text { The predominant use of words with negative and } \\
\text { neutral connotation }\end{array}$ & $\begin{array}{l}\text { The predominant use of words with positive and neutral } \\
\text { connotation }\end{array}$ \\
\hline Identity in general and teacher's identity are separated & $\begin{array}{l}\text { Identity in general and teacher's identity are } \\
\text { intertwined }\end{array}$ \\
\hline Behaviour focus & Identity focus \\
\hline A role of instructor/pedagogue and guide & A role of parent/carer, helper, awakener \\
\hline $\begin{array}{l}\text { Metaphors connected to beliefs about teaching, learning } \\
\text { and life in general = efficiency, battle, regime }\end{array}$ & $\begin{array}{l}\text { Metaphors connected to beliefs about teaching, learning } \\
\text { and life in general = exploratory game, art, play }\end{array}$ \\
\hline $\begin{array}{l}\text { Underpinning values = responsibility, equality, fairness, } \\
\text { safety }\end{array}$ & $\begin{array}{l}\text { Underpinning values = fun, curiosity, happiness, } \\
\text { learning, safety }\end{array}$ \\
\hline Negative perception of own public image as a teacher & Positive perception of own public image as a teacher \\
\hline Overall focus on continuity & Overall focus on change \\
\hline Lack of job satisfaction & Presence of job satisfaction \\
\hline $\begin{array}{l}\text { External attribution } \\
\text { (for job satisfaction/dissatisfaction and motivation) }\end{array}$ & $\begin{array}{l}\text { Internal attribution (for job satisfaction/dissatisfaction } \\
\text { and motivation) }\end{array}$ \\
\hline $\begin{array}{l}\text { Skills and strategies (communication, motivation, } \\
\text { handling demanding situations) are part of personal } \\
\text { characteristics/talent based }\end{array}$ & $\begin{array}{l}\text { Skills and strategies (communication, motivation, } \\
\text { handling demanding situations) are acquirable/learnable }\end{array}$ \\
\hline $\begin{array}{l}\text { Defensive response (no learning through self- } \\
\text { reflection) during video stimulated interviews }\end{array}$ & $\begin{array}{l}\text { Surprise response (learning through self-reflection) } \\
\text { during video stimulated interviews }\end{array}$ \\
\hline
\end{tabular}

Table 28 Similarities and differences between the groups - Comparative linguistic and content analysis Node 1 (Teachers' identity) and Node 2 (Teachers' work)

\section{CONCLUSION}

This chapter has aimed at providing an overview of the data and the data analysis as well as some preliminary discussion. The chronological narrative followed the development of the complex coding scheme and its application on the collected data. For easier readability the data presentation and analyses were divided into two main nodes (Teachers' identity and Teachers' work) both of which were exposed to comparative linguistic and content analyses. 
The data analysis has shown that there are some similarities as well as differences between the two groups of teachers. The most noticeable similarities included the multifaceted nature of teacher's identity and teachers' work being regarded as a calling rather than an obligation and merely a job. On the other hand, some of the differences encompassed various perceptions of teachers' identity from being a guide, instructor (the other teachers) to being a carer/nurturer/parent, helper, supporter and awakener. Another important difference found was that the other teachers are less agentive than the NLP-based CPD attendees/teachers. The other teachers also demonstrated they were more externally referential both for job satisfaction and self-motivation.

The last part of the chapter synthesized both nodes and concluded that the teachers' sense of self and their work, i.e. teaching, are mainly developed by reflection on their practice. This study's findings can hopefully contribute to that process. Although the data interpretation and preliminary discussion were offered 'along the way', a brief summary and a more structured discussion of findings through three lenses (research question, literature and overarching frameworks) is presented in Chapter 6. 


\section{Chapter 6: Discussion of findings}




\section{INTRODUCTION}

This chapter is largely a summary of the discussion of findings, though it also 'zooms out' to look at the broader picture. The previous chapter has already offered data interpretation and preliminary discussion on the way and this chapter structures the discussion around three focal points: the research question, the reviewed literature and previous research, and the overarching frameworks.

As Woods (1996) remarked, qualitative research is "concerned with exploring and describing people's perspectives and developing theory about them" (p.166). Lather (1986) proposes another criterion for assessing research, that of 'catalytic validity', which she defines as "the degree to which the research process reorients, focuses and energizes toward knowing reality in order to transform it" (p.272).

It is worth keeping in mind Guba and Lincoln's (1985) comment that "data are, so to speak, constructions offered by or in the sources; data analysis leads to a reconstruction of those constructions" (p.332). Hence, it is clear that all researchers can do is to create their theory through data analysis and discussion without any bold claims that they are presenting reality or even that they are close to understanding reality the way their respondents do. This is the platform for the following discussion of findings.

\section{FINDINGS RELATED TO THE RESEARCH QUESTION}

Before embarking on summarizing the findings in relation to the research question and the reviewed literature, it might be worth restating that the overall aim of the research 
was to describe and explore teachers' subjective experiences and mental representations of their professional identity and their work with the hope to develop professional practice further. The research question was "How do teachers in one Slovenian primary school talk about their professional identity and work following participation in NLPbased CPD in comparison with other teachers?"

\section{How did the two groups talk about their identity and work?}

The linguistic and content analysis of the subjective experiences and the mental representations of teachers' identity and their work elicited both some remarkable (although fewer) similarities and equally fascinating differences between the two groups (as listed in Table 28, Chapter 5, p.214).

A linguistic analysis of the accounts of the teachers who attended NLP-based CPD and those who did not showed similarities and differences particularly in two aspects:

a) When describing their perceptions of professional identity and their work the teachers who attended NLP-based CPD tended to use more words with positive and occasionally neutral connotation, whereas the other teachers used more words with negative (and neutral) connotation.

b) Both groups tended to use nearly equal amounts of personal and impersonal verb voices with slightly more frequent use of personal verb voices demonstrated by teachers who attended NLP-based CPD.

The presence of words with positive connotation in the teachers' accounts may indicate a more positive attitude towards their professional identity, work and possibly life in 
general and vice versa. This assumption is additionally backed up by findings about individual categories such as lack of job satisfaction among other teachers, who used more words with negative connotation. As already mentioned in Chapter 2, linguistic and semiotic aspects of language can be indicative of attitudes, beliefs and values, which then can be used to differentiate patterns of thoughts. If we take that into account, then the use of words with positive/negative connotation indicate different sets of beliefs and values among the teachers who attended NLP-based CPD and those who did not. The teachers' beliefs and values are discussed later in the chapter.

As mentioned in the previous chapter, the presence of agency, which Beijaard (2004) defines as part of teachers' professional identity, is questionable in the behaviour of the teachers who speak with 'an impersonal voice'. One could arguably ask what happens with their commitment, if they talk about their work and their professional identity 'from a distance', i.e. in sentences that avoid the 'I' form and rely more on 'they', 'one', 'you', etc. forms. The other teachers demonstrated more frequently a 'detached position', while NLP-based CPD attendees/ teachers used 'I' sentences, placing themselves in a closer position to whichever topic they talked about (their work, professional identity, communication skills, plans for the future etc).

In order to summarize the similarities and differences detected in the content analysis the neurological levels model (see Figure 4) is again used as an overarching synthesizing framework, and (as mentioned in the previous chapter) the table of numerical analysis of the teachers' accounts (Table 29 below) as a platform for discussion. The neurological levels model signposts the structure of the first part of the chapter. All of the above listed similarities and differences are addressed within the framework of neurological levels. 


\begin{tabular}{|l|c|c|}
\hline Neurological levels & $\begin{array}{l}\text { NLP-based CPD attendees/ } \\
\text { teachers (number of statements) }\end{array}$ & $\begin{array}{l}\text { Other teachers (number of } \\
\text { statements) }\end{array}$ \\
\hline Environment & 24 & 117 \\
\hline Behaviour & 47 & 239 \\
\hline Capabilities/Skills & 186 & 103 \\
\hline Beliefs/Values & 204 & 129 \\
\hline Identity & 217 & 64 \\
\hline Mission & 32 & 14 \\
\hline
\end{tabular}

Table 29 Numerical analysis of teachers' statements (based on Neurological levels model developed by Dilts, 2000)

\section{Environment}

Addressing the following differences:

- External vs. internal attribution

- Presence vs. Lack of job satisfaction

A numerical analysis of the teachers' statements about environment showed a significant difference between the two groups. The group of other teachers used nearly five times more statements about the environment thus demonstrating a strong focus on the (external) environment including both their school and wider society. As already mentioned in the previous chapter, the qualitative analysis of job satisfaction elicited an external attribution pattern (Buchanan et al., 2002), i.e. environment as the most frequent cause for lack of job satisfaction among other teachers. Further unpacking brought attention to exposed political elements. These are discussed further later in this chapter. The NLP-based CPD attendees/ teachers talked less about the environment within their accounts of professional identity and work and thus demonstrated a more internal attribution pattern. They also expressed a high level of job satisfaction. One may with good reason ask whether teachers, who focus on the external environment see themselves as active contributors to their job satisfaction (or the lack of it) or as passive 'receivers' of the current circumstances made up of external factors. It is possible to argue that the lack of job satisfaction is a consequence of strong external attribution. That also leads to a question of the self-sustainability of one's professional identity in 
critical situations caused by changes in the environment, be they of social, economical or political nature. This external attribution/referential pattern is in contradiction with Barnett's (1999) idea of the teaching process being a vehicle for developing students as 'social actors with self-referential capacity'. It might be worth restating the background for the study being the researcher's personal experience of being a teacher in the midst of the conflicts in ex-Yugoslavia in the 1990s (political changes in the external environment). All the constraints for doing one's job ethically and socially responsibly were in place during the war time and yet in critical situations (similar to this or any others) the presence of an external referential pattern might not be useful for sustaining one's professional identity, and even less useful for helping students develop into social actors with self-referential capacity (Barnett, 1999). One might reasonably argue that (hopefully) teachers do not find themselves frequently in the war-induced critical situations, however it is also questionable to claim that other economy, society or culture-induced critical situations are of any less importance for sustaining one's professional identity.

\section{Behaviour and Capabilities/Skills}

Addressing the following differences:

- Behaviour vs. Identity focus

- Skills = personal characteristic vs. Skills are acquirable/learnable

The numerical differences continued the same trend between the two groups when it comes to behaviour and capabilities/skills based sentences. The group of other teachers used five times more statements about behaviour and/or capabilities and skills. It is worth keeping in mind what was said in the literature review about a tendency in the literature on continuing professional development to emphasize the teachers' skills and knowledge as crucial fields for improvement through professional development (see e.g. 
Joyce and Showers, 1996). As noted in the beginning of the thesis there are different approaches to professional development, some of which focus on the development of professional skills, whereas others take into account beliefs, values and commitment. The variety of approaches can be viewed as spread out on a spectrum as shown in Figure 1 (page 37), where most authors are located at the skills/knowledge end of the spectrum and fewer at the beliefs/values end. It appears that the two groups of teachers also positioned themselves at opposite ends of the spectra with the other teachers located at the skills end and the NLP-based CPD attendees/teachers at the Beliefs/Values end (see Table 29 regarding numerical differences on Beliefs/Values level).

Another question appears: did the other teachers use more behaviour/skills sentences due to an exposure to previous CPD trainings and possibly a general emphasis on skills in teacher education? If this were to be the case, it would be indicative of an influential power of both initial and continuing teacher education on teachers' understanding and mental representation of their professional identity and work. If this were to be the case, it would also need to be taken into account by policy-makers and CPD providers. Many authors (as mentioned in Chapter 2) showed awareness of the risks involved in the teacher education being largely focused on skills. Hargreaves (1993) warned about the neglect of the teacher as a person and abstracting the teacher's skills from the teacher's self, whereas Skelton (2005) advocates that "teaching cannot simply be reduced to technical or practical matters" (p.34). In this perspective it would be easier to understand that the metaphors used by the other teachers for their professional identity were along the lines of instructors and guides as these fit the 'skill focused' (efficiency) model quite well. This is discussed further later. However it is also important to 
remember that the NLP-based CPD attendees/ teachers spent 21 days over a period of five years in a personal development based CPD programme.

Another contradiction was discovered while analysing the teachers' accounts - even though the other teachers talked extensively about skills/strategies, even when they were asked to describe themselves as teachers, a further qualitative analysis of Node 2 (Teachers' work) showed that they believed (communication, motivation etc.) skills were 'in-born' and not acquirable/learnable. This discrepancy brought up a question about agency again. How could teachers who believe that they cannot acquire/learn certain skills/strategies be actively engaged in their own and consequently their pupils' learning? Craft (2000) suggests that "a teacher, who is excited and motivated by the experience of their own learning is likely to be in a strong position to communicate the excitement of learning to pupils" (p.19). The NLP-based CPD attendees/ teachers, on the other hand, pointed out how they acquired/learned the above mentioned skills and used them regularly in their classrooms.

\section{Beliefs/Values}

Addressing the following differences:

- Metaphors: efficiency, battle, regime vs. exploratory game, art, play

- Values: responsibility, equality, fairness, safety vs. fun, curiosity, safety

The numerical difference between the two groups were smaller for the sentences on the Beliefs/Values level. The teachers' sentences were enriched with figurative language (metaphors). In Chapter 3 it was noted that it is not unusual to analyse metaphors in educational research. Wallace (2003) found the analysis of the metaphors in her study with successful PhD students extremely useful particularly for understanding the beliefs and value systems behind different kinds of examiners' and students' behaviour during and after the viva. She questions the ways some examiners interpret their role 
suggesting a direct link between the figurative language (metaphors) and roles we play or sub-identities we have. Just like in Wallace's study, the analysis of the teachers' metaphors was based on the belief that 'how we describe the world at some level reflects how we experience it" (de Botton, 1997, p.97). And this is in accordance with the aim of the research to describe and explore the teachers' subjective experiences and mental representations of their professional identity and their work through their talk, hoping that it reflects how they experience them.

As mentioned in Chapter 5, a series of metaphors related to the teachers' beliefs about teaching, learning and life in general were detected.

The other teachers seemed to use more efficiency model based metaphors. As already pointed out above it is no wonder that metaphors like that could find support in skill oriented identity/sub-identities such as instructor and guide (the teachers' accounts of their professional identity is presented below). The NLP-based CPD attendees/ teachers used more artistic, playful metaphors, which are backed up by the expressed professional identity along the lines of a friend, nurturer, companion etc. One could ask, how does one's perception of one's self being part of an efficiency-driven setting, as compared to being part of more creative and artistic setting, influence how we think of ourselves both in terms of identity in general and of professional identity (I am aware of this being highly speculative, but it could be worth a closer examination in the future).

Beside the differences in beliefs, the two groups of teachers also demonstrated different values that underpin their acts, thoughts and attitudes. The NLP-based CPD attendees/ teachers exposed values such as fun, curiosity, enjoyment and safety, whereas the other teachers mentioned responsibility, equality, fairness, safety. Different authors advocate 
a close relationship between values and one's profession, e.g. Woods et al. (1997) who claim that "teaching is a matter of values. People teach because they believe in something. They have an image of the "good society"' (p.152). According to that claim, the other teachers hold an image of the good society, which is efficient with lots of responsibility, equality, fairness and safety. On the other hand, NLP-based CPD attendees/ teachers hold an image of the good society, which is similar to an artistic, creative colony full of fun, enjoyment, curiosity and also here safety.

As mentioned in Chapter 2, closely related to 'values' is the notion of 'commitment'. Nias (1989) describes the teachers in her research as so committed that they were "inextricably bound up with the teacher role and could not switch off at the end of the school day to another life and another persona" (p. 146). In the previous chapter it was already mentioned that Haigh (1995) suggested that this 'isomorphic identity' can be problematic for teachers as they can easily get their sense of personal worth mixed up with their professional competence. The question is whether it is possible to keep personal and professional elements separated. The other teachers might find it easier to separate their professional identity and work that includes responsibility, fairness, equality from personal elements. On the other hand, the NLP-based CPD attendees/ teachers might be more prone to find it difficult to separate personal and professional elements since fun, enjoyment, curiosity could be and probably are present in personal contexts as well. According to Hargreaves (1999), personal and professional elements are intertwined and that for the teachers' commitment, enthusiasm and morale "their hopes and dreams, their opportunities and aspirations, or the frustrations of these things are also important" (p.vii). It is necessary to explore how all these claims about intertwining personal and professional elements, the importance of values and commitment, relate to teachers' professional identity. 


\section{Identity/Mission}

Addressing the following similarities:

- Teacher identity is multifaceted

- Teaching is calling

Addressing the following differences:

- Guide, instructor vs. helper, carer/nurturer, awakener

- Identity in general and teacher identity are separate vs. intertwined

- Negative perception of own public image as a teacher vs. positive perception

A numerical analysis of the statements about identity and mission showed again a quite clear difference between the groups as on almost all neurological levels (2-3 times more statements involving identity or mission level were used by the NLP-based CPD attendees/teachers). One can argue that the use of identity sentences (e.g. I am a helper, etc.) strengthens the sense of self and provides a closer relationship with our own identity/ies as compared to talking about our identity with the use of Behaviour/Skills sentences (e.g. "aaah I answer their questions, I ask them questions...”). Beijaard et al. (2003) even suggest that identity could be seen as an answer to the question: "Who am I at this moment?", thus clearly indicating that it is not seen as an answer to the question: "What am I doing at this moment?" On the other hand, the statements in both groups that did have identity form showed a quite remarkable similarity regarding the nature of the teacher identity, i.e that the teacher identity is multifaceted.

Beijaard et al. (2004) defined teachers' professional identity in the following way:

- professional identity is seen as an ongoing process of integration of the 'personal' and the 'professional' sides of becoming and being a teacher

- professional identity is not a stable entity; it cannot be interpreted as fixed or unitary

- professional identity implies both person and context

- professional identity is multifaceted 
- professional identity may consist of many sub-identities that may conflict or align with each other

- agency is an important element of professional identity, meaning that teachers have to be active in the process of professional development.

Of all the above elements of teacher's professional identity, the one about the multifaceted nature appeared in both groups. It can be explained by the teachers' understanding of the complexity of the teacher identity, particularly due to a quite rich experience among teachers in both groups (mean career length 22 years). Other elements of teacher identity emphasized by Beijaard et al. (2004) were not evenly supported by both groups. For example, Beijaard's idea of integration of personal and professional sides of becoming and being a teacher got support in the group of NLPbased CPD attendees/teachers, where the dominant opinion was that identity in general and teacher identity are intertwined, while the other group maintained the stance that they are separate. As mentioned before, Haigh (1995) warns of the risks of 'isomorphic identity', while Nias (1994) points out that the inability to switch off one's teacher identity also brings higher commitment to one's work. That brings us to another interesting finding of the comparative content analysis, which indicated that both groups share the view that teaching is a (fulfilling) calling and part of their mission. This finding is slightly contradictory when only one group (the NLP-based CPD attendees) acknowledged an integration of personal and professional within the professional identity. One would expect that the other teachers (who did not show an interest in integrating personal and professional elements in their teacher identity) would not choose their own work/job as part of their mission. 
This might be a good place to 'flag up' that some of the findings might be typical of the Slovenian cultural context. This is an issue to explore in future research (as discussed in Chapter 7) since all the literature and research reviewed for this study came from other (mostly Western European) countries and not from a Slovenian cultural context.

Even though there were many similarities between the two groups, the main difference came from the analysis of metaphors about their professional identity.

The other teachers described themselves as guides and instructors, who have an advantage of knowing what others need to know. The NLP-based CPD attendees/ teachers, on the other hand, used metaphors such as awakener, helper and nurturer/carer. Further unpacking showed that the teachers were adding new 'labels' for themselves in terms of their teaching. The other teachers described themselves as guides and at the same time as nightmares and/or 'bad guys', and thus supported Beijaard's claim that sometimes our sub-identities are in conflict with each other and sometimes aligned. The NLP-based CPD attendees/ teachers called themselves helpers and carers/nurturers, and there were no conflicting identities/subidentities. The described or elicited identities stayed aligned with one another. This overall alignment of different identities/subidentities may be contributing to the sustainability of the teachers' professional identity.

The sustainability of the teachers' professional identity may be significant, particularly if we take into account that Wenger (1998) introduces the idea of professional identity as being forged within the context of the profession, but that it transcends its boundaries by saying that "the experience of identity in practice is a way of being in the world" (p.151). 
Wenger's claim brings us to the last significant difference related to professional identity, which is the negative versus positive perception of one's own public image. If the experience of identity in practice is a way of being in the world, then one can ask what happens when somebody has a negative perception of own public image as a teacher? The group of other teachers showed a strong focus on a negative perception of their own public image and thus sparked speculations that their frequent use of words with negative connotation (as discussed in the beginning of this chapter) might be connected to how they perceive their own identity and how they predict others would perceive them.

Several authors apply a so-called 'narrative approach' to the notion of identity, and with regards to the issue of whether the teachers have a negative or a positive public image, it would be interesting to research further whether the perception of their public image would be supported by stories about them told by other people (e.g. colleagues). Holland, Lachicotte, Skinner, and Cain (1998) draw attention to people's stories by emphasizing that "people tell others who they are, but even more importantly, they tell themselves and they try to act as though they are who they say they are" (p. 3). Would that mean that some of the negative perceptions of one's own public image originate internally rather than externally, i.e. from the teachers themselves and not from their colleagues? This is something to explore further in future studies. The NLP-based CPD attendees/teachers expressed a positive perception of their own public image, and even referred to colleagues, who had reminded them of their own positive qualities as a teacher, as the example below shows.

"Sometimes my colleagues remind me that I am creative and playful." (NT5, line 16, SSI) 


\section{FINDINGS RELATED TO LITERATURE AND PREVIOUS RESEARCH}

While discussing, above, the findings in relation to the research question i.e. how teachers talked about their identity and their work, many authors from the literature review and from previous research were brought in. This section looks at the two identified clusters of key concepts/research areas of the study (see Chapter 2, Figure 2, p. 41). The two clusters of key concepts were developed by 'zooming in and out'. The first cluster had NLP at the centre and Personal development and CPD above, and linguistic patterns below. The second cluster had Teacher's professional identity at the centre and Professional identity and Identity above, and Values and commitment below.

\section{Cluster 1: CPD, Personal development, NLP and linguistic patterns}

In relation to CPD, one group of Slovenian teachers (the other teachers) confirmed what Friedman and Philips (2004) pointed out while discussing their findings, that professionals have a limited view of CPD - seeing it as training, a means of keeping upto-date, or a way to build a career. As noted earlier the other teachers were interested in professional and personal development programmes in their plans for the future, provided that they would be able to get promoted to mentor or adviser status. The group of NLP-based CPD attendees/ teachers had a clear idea that CPD programmes (with personal development elements) are bringing change for better and above all a process of learning and development. It was not surprising to hear these views after they had spent a few years attending a personal development (NLP) based CPD programme. Friedman and Philips (2004) complained that there is an apparent gap between how professionals and professional associations see CPD. Professionals, seeing it as training, a means of keeping 'up-to-date', or a way to build a career, whereas professional associations, on the other hand, see CPD as part of lifelong learning and personal 
development. The role of NLP elements as a CPD contribution to lifelong learning is still to be explored by further studies. However the present study has contributed to the realisation that the NLP-based CPD attendees/ teachers appear to talk about themselves as more self-sustained compared to the other teachers. They also appear more prepared to maintain their professional identity irrespective of personal, social or political changes/critical events. This can be seen e.g. in the typical internal attribution style of the NLP-based CPD attendees.

Some of the key elements of NLP are modelling and systemic thinking. Some traces of development of self-modelling skills and systemic thinking were observed among the teachers and these are discussed in more details later in this chapter. Systemic thinking is a 'complex' way of thinking in mutual feedback among actors and factors involved, understanding that any change will affect the whole system. NLP seeks to find the 'leverage', i.e. the 'factor', where a desired change of the system is achieved most efficiently. One of the reasons that observations were added to the data gathering tools in the study was the wish to create awareness both in the teachers and the researcher through mutual feedback (in the video-stimulated follow-up interviews), where the 'leverage' might be, that is, which element either in classroom interaction or in the congruence/incongruence between the observed and described phenomena is crucial for potential and desired change. More concrete findings related to modelling and systemic thinking can be found in the section on findings related to overarching frameworks.

The analysis of linguistic patterns was fruitful and brought about some interesting findings. For example, the question of agency in connection to the use of personal and/or impersonal verb voice as well as the use of words with positive, negative and neutral connotation as a (de)motivating factor. 
The above mentioned linguistic analysis of language patterns raised a question as to whether attending NLP based trainings helped the teachers express themselves in words with positive connotations. Unfortunately one of the weaknesses of the study is that there was no option available to carry out a so-called pre/post study. It is not easy to know whether the NLP-based CPD attendees/ teachers used words with positive connotation in the past before they attended the CPD programme.

\section{Cluster 2: Identity, Professional identity, Teachers' identity, Commitment and values}

Beijaard (1995) mentions four main features related to the study of teachers' professional identities. These are 'identity in general', 'the subject one teaches', 'relationship with pupils', and 'role/role conception'.

This study confirms that teachers see 'identity in general' either as an integral part of their teacher identity (the NLP-based CPD attendees) or as a separate entity (the other group). The majority of the descriptions of teacher identity fell into two of Beijaard's above mentioned features: 'relationship with students' and 'role/role conception'. 'Identity in general' was either considered integrated in 'teacher identity' or not considered at all, because it belonged to a different context. Identity connected to 'the subject one teaches' was barely mentioned at all. There may be a variety of reasons for that, from thinking of their professional identity as broader than the subject they teach, to feeling that teaching is their calling/mission no matter which subject they teach. These ideas are so far only 'qualified guessing', but worthwhile exploring in future research. 
The study also detected among the other teachers a tendency to have a negative perception of their own public image (the NLP-based CPD attendees/ teachers showed a positive perception). Identity is relational and increasingly fragmented. Lyotard's (1979) account of the self existing in a fabric of relations points out that we are attributing great importance to what we believe others see in us. An interesting attempt at creating a connection between attribution styles and perception of one's public image could be made. The NLP-based CPD attendees/ teachers showed strong internal attribution and still they had a strong positive perception of their own public image as a teacher, as if they used internal attribution to assess that they are good teachers and subsequently they trust that their colleagues would see the same. On the other hand, the other teachers showed a strong tendency towards external attribution, and it could seem as if they chose to have a negative perception of their own public image, so that they could 'protect' themselves from unpleasant surprises.

Sfard and Prusak (2005) define identity as "a set of reifying, significant, endorsable stories about a person" (p.14). Furthermore, they extend the definition by splitting the narratives further into two subsets, which they decide to name "actual identity, consisting of stories about the actual state of affairs, and designated identity, consisting of narratives presenting a state of affairs which, for one reason or another, is expected to be the case, if not now then in the future" (p.18). Although Sfard and Prusak do not talk about the possibility of having a designated identity with negative connotations, it might still be interesting to explore whether the negative perception of one's own public image can fall into that category. As already mentioned, Wenger (1998) introduces the idea of professional identity as being forged within the context of the profession, but that it transcends its boundaries, where "the experience of identity in practice is a way of being 
in the world" (p.151). This comment of Wenger makes it even more important to explore further the notion of perceptions of one's own public image and to investigate whether it will be reflected in one's way of 'being in the world'.

A fascinating similarity was found relating to the teachers' belief in their work as being a calling. The level of commitment to work that we consider our mission is much higher than if we just believe our work is an obligation. A strong feeling of commitment was noticeable in both groups in spite of quite different underpinning sets of values: responsibility, equality, fairness (other teachers) on one side and fun, enjoyment, curiosity (NLP-based CPD attendees) on the other side. Safety was the common value which perhaps can be explained by both groups seeing themselves in their role of a teacher as someone who looks after their students (guide, carer, parent).

\section{FINDINGS RELATED TO OVERARCHING FRAMEWORKS}

\section{Methodological framework}

Some of the findings would benefit from applying the overarching frameworks as synthesizing tools. That is certainly true for the appearance of selfobservational/modelling skills. This was clear to see during the video stimulated interviews and even more so in the reflective diaries.

As mentioned earlier in the thesis, I decided to combine semi-structured interviews, reflective diaries, non participant observations and video-stimulated follow-up interviews and feedback sessions in order to establish a broad platform for both 
reflective/subjective experience documented by the participants of the study, and the purely observational approach undertaken by the researcher. One of the reasons for combining these two approaches was a hope of developing self-observational/modelling skills in the teachers by showing them what had been observed in their classes as compared to what has been subjectively expressed in the interviews and diaries. Thus the congruence level between the observed phenomena and subjective (uttered or written) accounts of them would be established and hopefully the research would, in the form of 'added value', contribute to an improvement of the teachers' self-observational and reflective skills. In other words the methodology adopted in the study could itself contribute to the teachers' continuing professional development (CPD). The contribution of NLP to the above mentioned 'added value' might be its main focus on the development of professional practice through observations and 'self-observations' (as described in Chapter 2 in the literature review).

The achievement of this 'added value' of the study in the form of development of the teachers' reflection processes and self-modelling skills did take place. While carrying out the video stimulated interviews and the feedback sessions, many teachers from both groups (6 NLP-based CPD attendees and 2 from the other group) shared their awareness of their self-reflective process. Two important elements were found:

a) Development of self-modelling skills and systemic thinking due to the employed methodology

The 'added value' of the study occurred during the video stimulated interviews, when the teachers were exposed to watching their own selves and commenting. This happened due to the employed methodology and above all the data collection methods 
that allowed the teachers to take an observer/commentator and even a writer position. The reflective diaries contributed to the teachers modelling of their own practice.

Elements of systemic thinking were noticeable when 6 NLP-based CPD attendees and 2 other teachers looked for and found what they thought was 'leverage', i.e. the element where desired change of the system is achieved most efficiently. Each teacher found their own leverage point and was determined to test it in the classroom. As mentioned earlier, systemic thinking is a 'complex' way of thinking in mutual feedback among actors and factors involved, understanding that any change will affect the whole system. This phenomenon (teachers wanting to revise and test) was not anticipated until the Initial study provided the first insights into this possibility.

At the same time, the teachers' wish to introduce changes in the classroom may lead to improvement of the teaching practice and thus contribute to a constructive action research cycle. As explained at the beginning of the thesis, the usual negative or problem-oriented focus of action research is closer to a diagnostic approach. This study has a more explorative and outcome oriented focus, because it is not focussing on solving a problem, but rather on the elicitation of the present state and on the potential construction of future improvements, either in maintaining a professional identity or in the teaching practice in general.

The following example illustrates how a teacher managed to identify the leverage point by self-modelling her own practice rather than starting from a problem. She is picking up a small, but significant distinction that will make a change in her practice, she 'constructs' her desired state and/or action based on the current positive detail that came to her awareness through self-modelling skills. 
Illustrative example:

"This is interesting and surprising... I have motivated that girl and I was not even aware that she was making faces and rolling her eyes... (laughter) I am happy with how it worked, I would like to remember this and repeat it..." (NT5, lines 22-24, VSI/FB)

b) Development of reflexivity due to participation in the study

Some teachers (1 NLP-based CPD attendee and 5 other teachers) did not show any concrete signs of developing self-modelling skills, e.g. being able to comment on their practice and elicit patterns they would like to repeat and develop further. However, half of them expressed their surprise at how much more they think about their motivation strategy, their capability to handle demanding situations etc. than they did before they took part in the study. The usual comment was "Nobody ever asked me questions like that, those questions made me think...". We cannot know whether this trend will continue, or indeed whether it will be beneficial for them. It would be too bold to claim a priori that a reflexive process is beneficial for all teachers. On the contrary, Hammersley (1992) is eager to question reflection as beneficial: "Might not reflection on our activities sometimes result in incapacity rather than improvement? And even if more reflection on one's life is always desirable in principle, it is not always desirable in practice. This is because it always takes place at the expense of engagement in some other activity" (p.154).

\section{Conceptual and theoretical frameworks}

In the early phase of the study, the Initial study brought some political elements back into the study. The reason I say 'back' is because of the obvious political background in the rationale of the study that was acknowledged early on. Political elements also 
'brought' in a critical theory framework, or as I named it, a constructive critical theory framework, which (just like constructive action research) focuses on future 'constructions' rather than utilizing critical, past and problem orientation. The main study also brought to the fore some political elements.

Interestingly enough some of the teachers in the two groups were teachers back in the early 1990s in Slovenia (during the ex-Yugoslavia conflicts). Even though the political situation in Slovenia at present has been stable for over 18 years, it feels like some respondents could not help complaining about the uncertain times, the government, the policies, etc. It is true that some teachers did experience political changes that might still 'haunt' them (count me in!) and thus keep their focus on the past and on the 'problems' and creating a strong pattern that continues searching for problems. The teachers who exposed political elements, were from the group of other teachers, which is understandable given the findings from the analysis of attribution style related to the presence or lack of job satisfaction. None of the other teachers attributed either the presence or lack of job satisfaction internally (i.e. as something that is 'up to them'). All of them 'pointed their finger outwards'. This external attribution style is 'convenient' for focussing on political and/or other elements coming from the external environment.

Nias (1989) suggests that changes that may influence our self-image brings a threat to people, and, as mentioned earlier, Hargreaves (1998) expanded the idea further by claiming that teachers' emotions are professionally affected by both micro and macropolitics (Hargreaves, 1998, pp.326-327).

Hargreaves elaborated it further 
"Teacher emotions are professionally affected by the micro-politics of their schools in terms of their principal's behaviour, their experiences of change, and so on... these micro-politics of the school are in turn embedded within major micro-political forces of leadership, change and political reforms that have equally significant consequences for the emotions of teaching and teacher development. (Hargreaves, 1998, pp.326-327)

As long as external attribution remains the predominant style with other teachers, it is unlikely that there will be a shift from criticism of external political elements to exploration of any potential internal elements. Again, one needs to keep in mind that there is no evidence that the NLP-based CPD attendees/ teachers did not use internal attributions even before their participation in the NLP-based CPD programmes, however it is fair to say that the two groups have striking differences in their attribution styles. It would take at least a rigorously designed pre/post study to establish whether the CPD programme had any influence there.

The theoretical framework for the study was social constructivism, where it is constructivism with a ' $v$ ' and not with an ' $\mathrm{n}$ ' (as in constructionism), relating to the specific approach towards the notion of identity, including the idea that identity is a learned phenomenon in interaction with environment. There is a chance that once the so-called 'critical mass' of teachers who look for life-long learning and development is reached, they would form 'a community of practice' (Lave and Wenger, 1991) that would provide enough stimulation for externally referential teachers in order to transcend beyond a pure critical approach. 
It is also worth emphasizing the detected differences between the groups in the perception of the teachers' own public image as teachers (the other teachers expressing a negative and the NLP-based CPD attendees/ teachers a positive perception). Social constructivism as an overarching framework can provide a platform for the realisation that identity is a relational phenomenon and as such is not a fixed but a fluid and everchanging entity. As Lyotard (1979) sums it up well (playing with John Donne's famous proverb): 'No self is an island; each exists in a fabric of relations"'(p.15). The key to strengthening both the professional and personal identity might thus be to strengthen the community.

\section{Epistemological framework}

Having detected an 'added value' of the study for the teachers and their teaching practice and discussed political and relational elements included in teachers subjective experiences and mental representations of their professional identity and their work, it may be the right time to take a different perspective for a moment. The overall epistemological framework applied in this study is interpretivism, which is usually defined as "[it is] a view which argues that there are no absolutes, but that all phenomena can be studied and interpreted in different ways (Burgess et al., 2006, p.55).

The illustrative examples below demonstrate how teachers themselves can interpret roles from different perspectives and get different 'findings'.

"I always think of myself as a guide of my pupils (ID description, self-image) but sometimes I get comments from my colleagues that I am an over-dominant and ambitious boss of my class (laughter)" (ID/pi) (T5, line 14, SSI)

"I am here to be their guide and sometimes I am their nightmare" (SDT/id) (T5, line 11, SSI) 
People differ and there is no single reality, which leads us to the realisation that everything written so far could have been interpreted differently had different data collection methods been employed, had different meanings become attributed to the teachers' accounts, had there been another researcher etc. This is where researchers need to be aware of their 'power' and bias, transparently describe their choices and argue for their decisions. I do hope I have been sufficiently transparent about the choices and decisions I have made.

\section{Summary}

Even though it is not possible to generalize the findings very far beyond the two groups of teachers included in the study, it has to be acknowledged that there were both similarities and differences between the two groups.

The study showed that both groups of teachers talk about their professional identity as multifaceted and their work as their calling. The groups, however, showed some differences, as well. Some of the most striking ones include tendencies among the other teachers towards less positively connotated words, external reference, less agency and justifying own actions rather than learning from them. The NLP-based CPD attendees/ teachers used more words with positive connotations, expressed a more self-referential approach towards their job satisfaction and motivation strategies, and demonstrated more agency and a high level of reflection and learning from own actions. The differences in the use of metaphors, while talking about their professional identity and their work, were detected in the beliefs about teaching and learning being efficient and $a$ 
battle (other teachers) as opposed to an exploratory game and play (NLP-based CPD attendees/ teachers). Finally, the two groups see themselves differently in their role of a teacher. The other teachers talked about themselves as guides/instructors and the NLPbased CPD attendees/teachers as nurturers/carers and awakeners.

\section{CONCLUSION}

This chapter has aimed at providing a discussion of findings structured abound three different focal points: the research question, the reviewed literature and previous research, and overarching frameworks. The detected linguistic and content-based similarities and differences between the two groups of teachers were first addressed in relation to the research question. It was shown that the two groups talk differently about their professional identity and their work almost on all neurological levels (Dilts, 1990). Secondly, the two clusters of key concepts included in the research question (CPD, NLP and linguistic patterns on one hand and Identity, Teacher identity and Values on the other hand) provided a framework for a discussion of the findings. Some fascinating differences such as a negative perception of their own public image as a teacher (other teachers) as opposed to a positive one (NLP-based CPD attendees/ teachers) were discussed. In the concluding part, methodological, conceptual/ theoretical and epistemological overarching frameworks raised further questions related to the findings and opened questions to be considered further in the final chapter. 


\section{Chapter 7: Conclusion - Looking back and looking ahead}




\section{INTRODUCTION}

This final chapter presents two perspectives at the end of a long academic and practitioner journey: one that looks back and reflects on the whole journey of exploring teachers' identity and their work and another that looks ahead with ideas for future research and potential implications for professional practice and educational research.

\section{LOOKING BACK}

\section{Returning to the research question using the conclusions from the data analysis and the discussion of findings}

The research focus on teachers and their work originated in my personal experience of being a teacher in the midst of the conflicts in ex-Yugoslavia in the early 1990s. I realised the far-reaching influence teachers had on their pupils, both as professionals and as human beings, and at the same time I found myself completely unprepared for being a teacher in such a critical (war) situation.

Now, nearly two decades later, in a different country and in a different language, I have just completed this study that, in spite of its limited scope, might still shed some light and open further discussion on what could be done to strengthen the professional identity of teachers (so that teachers could be prepared for being teachers even in critical situations). 
The study set out to explore teachers' subjective experiences of their professional identity and their work with the hope to develop the professional practice further.

The main research question was:

"How do teachers in one Slovenian primary school talk about their professional identity and work following NLP-based CPD in comparison with other teachers?"

As mentioned in Chapter 1, one of the aims of the study was to lend a voice to the teachers and thus explore with them their subjective experiences of having a teacher's identity and carrying out a teacher's work. As Nias (1989) said “neither pupils' nor adult observers' accounts can fully capture the lived realities of teaching as an occupation; that can be done only by allowing teachers to voice their own thoughts and feelings" (p.2). The teachers from both groups in the study voiced their own thoughts, ideas, opinions and feelings, and an oversimplified answer to the main research question on 'how they talk about their professional identity and work' would be that they do it differently.

The linguistic and content analysis of teachers' talk resulted in only three similarities and 12 differences between the two groups (see Table 28, page 214). The study showed that NLP-based CPD attendees/teachers appear to talk about themselves as more selfsustained/self-referential, more agentive, more reflective and more positive compared to other teachers. While no definitive evidence-based explanation or claim can be offered as to what caused such a clear difference between the two groups, it is still worthwhile considering the role of the CPD modules that one group attended and the other did not. As mentioned earlier in the thesis, there are probably no simple answers to the questions 
about what formal (and informal) teacher education programmes can do to prepare teachers for critical situations may they arise from personal, social, cultural or political contexts. It would be fair to say that only tentative conclusions can be offered due to the small-scale single-site study as well as the lack of pre/post study opportunity and selfselection issue. Thus, the only tentative claim that can be made is that there are obvious differences between the two studied groups with respect to their perception of professional identity, their beliefs and values that underpin their work and their linguistic patterns. Unfortunately, it is not possible to claim that the above-mentioned differences stem from the fact that one group attended (NLP) personal development based CPD and the other did not. However, since the current study showed significant differences between the two groups, perhaps the role of personal development based CPD as contribution to lifelong learning should be considered and explored in further studies. The study was exploratory (and comparative) and hopefully it has opened a new platform for exploring the connection or the lack of it between personal development CPD and teachers' professional identity.

\section{Researcher's reflection on the research process}

\section{Methodological issues}

It is, first of all, important to consider what could have been done differently. Methodologically the study could have gone in many different directions:

a) larger sample and less in-depth exploration 
The teachers from all four schools in Slovenia that were included in the personal development based CPD programmes (see Chapter 1) could have been considered as respondents in the study.

b) smaller sample and more in-depth exploration

The multilayered nature of the collected data as well as time constraints contributed to rethinking of the sample size and the depth of the data analysis. One possible option would have been to explore fewer cases but more in depth.

c) different data collection tools

The use of focus groups could provided an opportunity to explore the teachers' discourse and explore how they talk collectively. Adding observations of school staff and parents meetings could have contributed to a more diverse and wider picture of teachers' talk.

\section{Limitations of the study}

1. The study is not a pre/post study, i.e. there was no data collection before the attendance of NLP-based CPD programmes thus leaving it open for speculations as to whether the detected patterns among the NLP-based CPD attendees/ teachers were present even before attending the CPD modules.

2. The self-selection issue, which meant that those who first enrolled on the CPD programme were selecting themselves for the NLP-based CPD attendees group, whereas those who were late, formed the group of other teachers. 
3. Only 5 of the 10 CPD modules were NLP-based (not sufficient evidence that exactly those 5 modules (and not any other) made a difference.

4. It could have been useful to draw on a wider selection of literature on identity.

5. Quantifying data could have been done in a more sophisticated way, though the sample size did not really justify this.

6. There is always a risk of 'Hawthorne effect' (if human subjects know that they are part of a study, they automatically change their behavior). This is probably one of the hardest inbuilt biases and one of the strongest limitations of this study. Teachers were freely voicing thoughts and beliefs about their professional identity and their work, and that could be taken as a demonstration of it being an exploratory and reflective study rather than as a demonstration of the 'Hawthorne effect'. The fact that the original three-phase project including this study lasted for nearly 10 years might exclude any fear of having achieved only short-term behavioural changes due to the teachers being studied. On the other hand, there was an obvious feeling of pride among all the involved teachers caused by the fact that they were part of the study; the fact that they were quite willing to participate in the study might indicate the presence of a 'Hawthorne effect'. Yet, the 'Hawthorne effect' emphasizes the changes in behaviour as consequences of simply being studied. The study focused on teachers thoughts, beliefs, values and their identity rather than on their behaviour and if any changes have occurred, it was more noticeable in their beliefs, values, and their perception of professional identity than in their behaviour.

7. It would be also fair (albeigt rather immodest) to take into account my own expertise (as an NLP trainer), enthusiasm about and commitment to personal development and NLP; they could be seen as either contributors to the potential 'Hawthorne effect' mentioned above or as elements that influenced the personal 
development based CPD attendees/teachers in the way they perceived their professional identity and their work. It is worth remembering that we spent five years together and my enthusiasm and commitment to personal development could have got transferred to them thus resulting in their positive self-image, the use of words with positive connotations, creative metaphorical linguistic patterns etc. Even though I am reluctant to believe that, I need to acknowledge that possibility. If that is to be true, the question remains how much my enthusiasm and commitment to personal development is part of my professional identity. That might lead us back to where we started - the importance and relevance of the notion and perception of one's own professional identity as a teacher (or teacher educator) and its (possibly powerful) influence on the interactions with 'students' i.e. CPD attendees.

\section{Strengths of the study}

1. A detailed data analysis that involved a complex, but well-defined, coding scheme encompassing both inductive and deductive coding processes, that have provided considerable insights into the teachers' perception of their professional identity and work.

2. Added value of the study for the teachers (self-modelling skills and thus generating idea for enhancing their professional practice), which led to a higher level of awareness/self-reflection. This was particularly noticeable in the reflective diaries and the video-stimulated interviews combined with feedback sessions. In other words, the methodology adopted in the study may have also contributed to the teachers' continuing professional development (CPD). 


\section{Researcher journal}

○ My personal and professional development

As mentioned earlier in the thesis, the greatest contribution to my own reflexivity was keeping a researcher's journal. It was a springboard for many insights and deep parallel exploration of my own subjective experience of teachers' professional identity and the respondents' ideas, opinions and accounts of their professional identity and their work. Thus my own reflective journal contributed to my own personal and professional development both as a teacher and as a researcher. My own constructive action research cycle took place, or better to say, the process of "self-reflective enquiry undertaken by participants in social situations in order to improve the rationality and justice of their own practices" (Carr and Kemmis (1986) cited in Hammersley, 2004, p. 162) took place.

Today I am a different teacher/teacher educator and a different researcher due to the study I carried out. My own emotional, intellectual and ethical investment in the study contributed to the parallel process of my own action-research cycle and wish to enhance my own professional practice. My research journal recorded mainly a rather emotional journey of my own personal development during the period of four years of carrying out the study. The parallel process of analysing my own professional identity, beliefs and values, thinking and linguistic patterns yielded data that made me aware of the following: my professional identity as a teacher/teacher educator is closely intertwined with my identity in general; in my role of a teacher/teacher educator I see myself as a developer (of myself and others) and an awakener of inner potentials (of my own and of 
others). This revelation helped me understand better why I needed to leave Serbia and my students, when my basic roles of a developer and awakener were repressed by the political regime at the time. It is very hard for me to write about other revelations that my journal brought, because even the one I mentioned left me in tears due to the realisation of myself and my students being 'robbed' of the potentially wonderful experience of personal development, due to the limitations that the political climate at the time imposed. I am aware that both my students and I found other ways of developing our potentials further in spite of not finishing the creative and fulfilling learning process we started together nearly 20 years ago. Even though I planned and 'promised' I would share the thoughts from my journal with the readers, I will need to excuse myself for not being able to share more than I already did due to its rather emotional and intimate nature. It did, however, contribute to my professional/personal development just like all the steps on this four-year long journey did.

Even right now, while writing up my thesis, I have the feeling that the writing process itself is contributing to my personal/professional development. I suppose as a researcher, one should pay attention to Goodall's (2000) comment that "in writing, as in speaking, we come to know" (p.127). In writing up my thesis, I have come to know both the teachers in the study and myself better. The writing process itself has opened new avenues of inquiry into my past and possibly future research experiences and those inquiries need to be taken into account in order to enhance my own professional practice.

I believe that the potential implications of the research for professional practice may depend on the research rationale and aims. The reasons for undertaking a research degree may strongly influence the plans for drawing out the implications for 
professional practice. Crayer (2000) makes a distinction between 'essential' and supporting reasons for undertaking a research degree. Although many authors and postgraduate students may disagree with her classification (e.g. career advancement is defined as a supporting reason) one needs to acknowledge the impact her classification has on stimulating the reflective process about one's own reasons for doing postgraduate research. In his discussion of Crayer, Potter (2006) lists his own table of five essential reasons for undertaking a research degree:

1. Personal development.

2. To be able to make a difference - for example, a desire to change practice in work or to learn more about a 'condition' that a student or members of their family have experienced.

3. To follow a new or better career.

4. Burning interest in a topic (intellectual curiosity).

5. To keep one's mind active (ibid., p.23).

Even though I can place myself and my research within at least three of the above mentioned essential reasons, it is fair to expose the first and second one as the dominant ones. My personal experience of being a teacher in the midst of the wars in exYugoslavia has contributed to a burning interest in the topic of teachers' professional identity in order for me to be able to personally develop, and above all to make a difference within the teaching professional practice (my own and others'). This is in alignment with the constructive critical theory framework I have used as an overarching conceptual framework for the study. The potential implications of my research for my own professional development and professional practice can only be along the lines of 
potential changes (for the better) within CPD for teachers, above all in Slovenia, but hopefully also beyond. Some of the ideas are:

- More diverse and perhaps more overtly personal development and identityfocussed (NLP based) CPD programmes for teachers in Slovenia (and in other countries).

- More EU (or from other sources) funded adult education projects focusing on wider perspectives of CPD for teachers and adult educators (including NLP and other personal development elements).

- More focus on self-modelling skills and modelling of good practice as a tool for improving teaching practice.

- More focus on the benefits teachers can gain by participating in educational research related to their own professional identity and work.

- My own personal and professional development as a reflective practitioner, researcher and as a teacher-trainer and educator.

- Change in the teacher-trainings portfolio in my own professional practice within the Further Education centre in which I work.

Burgess et al. (2006) pointed out that improving educational action (which implies change for the better) is what a professional doctorate is concerned with. Thus, a wish to make a difference and undertake professional doctorate research seem to be in harmony with the present project. Kincheleo (cited in Burgess et al., 2006) claims that we live in an age of mediocrity and points out that dreaming about 'what could be' is both undervalued and discouraged. Doing educational research, in his view, helps empower educators and thereby initiate a move towards change. Considering the current academic 
final phase of my research, it might still be too early to dare to dream, and then again it might also be too late to stop dreaming, since a dream of a better professional practice during the conflicts in ex-Yugoslavia started it all. 


\section{LOOKING AHEAD}

\section{Further research questions/issues}

The study has opened many new questions and issues to be explored further:

1. A need to design and carry out a pre/post study, which would explore teachers' subjective experiences of their professional identity and their work before and after taking part in personal development (NLP) based CPD programmes.

2. It might be worthwhile exploring further the benefits and pitfalls of the intertwining of identity in general and professional identity.

3. The role of metaphors in teachers' talk proved to be quite important and it would be good to design and carry out a study, which would have a more in-depth focus on them.

4. Since the study has been carried in Slovenia, some of the findings might be typical of the Slovenian cultural context. It might be interesting to design and carry out a study, which would consider similarities and differences in the perceptions of teacher identity and work across cultures.

5. As mentioned earlier in the thesis, the Good Work Project explored institutional identity as well, and it might be good to explore further the presence, or the lack of, connections between institutional identity and teacher identity. There might be a relationship between institutional culture and the way a teacher constructs his or her professional identity, thus making it context driven/influenced. 
6. It might be the subject of a whole new study to explore what consequences the perception of one's own and one's public image as a professional has on one's work, i.e. on how ethical and socially responsible one's work is.

7. The role of personal development modules as a contribution to CPD of teachers and teacher educators.

\section{Further potential implications}

For teaching professional practice, teacher education and educational research

Keeping in mind that the study was relatively small-scale, and that the findings should not be generalized far beyond the participants, though I would certainly consider the findings trustworthy in the sense suggested by Ely et al. (1991, see page 99), it would still be justifiable to consider the potential implications for teaching professional practice, teacher education and educational research.

The literature review showed the dominance of skills and knowledge in CPD trainings for teachers. The study can have interesting implications for the design of continuing professional development (CPD) courses, where less focus on skills and knowledge and more focus on beliefs, values and identity might be more effective.

The study also added its piece to the notion of identity as an analytic tool or a lens for research in education in general (Gee, 2001). Many authors agree that the notion of identity is experiencing a 'renaissance' recently (see Sfard and Prusak, 2005; Hoffman, 1998). Wenger (2006) talks about identity as a "learned experience of agency" (p.19) 
and sees the $21^{\text {st }}$ century as a "century of identity". Perhaps more educational research into designing and maintaining teachers' professional identity would be desirable. The notion of teachers' (professional) identity may need also to be explored more carefully during Initial trainings for teachers as well as in CPD.

NLP as one modality of personal development was in this study defined as an approach to developing professional practice through modelling. Such an approach can certainly be useful in many different areas. Tosey and Mathison (2003) state that they have found NLP of immense value, not only in their professional practice in higher education, but also "as a topic for research, and as a prospective tool for qualitative research" (p.372). The study might have contributed to the consideration of the use of linguistic modelling (based on NLP) as a qualitative research tool for the purposes of analysing respondents' accounts.

From my own experience as a researcher, who went through her own action research cycle and through an additional reflective process while keeping a researcher's journal, I can add another piece to the 'puzzle' of professional learning. My professional learning happened as a consequence of the inquiry I carried out and thus indicates that conceptualising professional experience through inquiry might need to be considered as a potential source for teachers' personal and professional development. 


\section{CONCLUSION}

No previous studies have explored the ways in which personal development CPD attendees/ teachers talk about their work and their professional identity. One of the aims of the study was to contribute to bridging that gap.

Carrying out a small-scale study and having a rationale rooted in a personal experience, as I have done here, may not be an ideal foundation for drawing any wideranging conclusions. Nevertheless, I hope that teachers and teacher educators reading the accounts may recognise similar thoughts, feelings and ideas arising in their own professional settings. Such recognition may validate the study further and highlight the relevance of studying other cases in depth. There are teachers all over the world, whose personal stories, ideas and feelings about teachers' professional identity and work have the potential to inform the development of our professional practice.

Let me finish with the words of Hargreaves (1993) who says:

- $\quad$ [T] $]$ eachers don’t just have jobs. They have professional and personal lives as well. Although it seems trite to say this, many failed efforts in in-service training, teacher development and educational change more widely are precisely attributable to this neglect of the teacher as a person - to abstracting the teacher's skills from the teacher's self, the technical aspects of the teacher's work from the commitments embedded in the teacher's life. Understanding the teacher means understanding the person the teacher is (p. viii). 


\section{REFERENCES}

Adelman, C. (1993) 'Kurt Lewin and the origins of action research', Educational Action Research, Vol 1, pp.7-24.

Alder, H. (1992) 'NLP: managing a revolution', Management Decision, 30, p. 154-159. DOI: $10.1111 / \mathrm{j} .1467-8691.1992 . t b 00047 . x$

Alheit, P. (1995) The biographical approach in European adult education, Vienna, Verband Wiener Volksbildung.

Ashby, W. (1956/1965) An Introduction to Cybernetics, London, Methuen.

Austin, J. L. (1962) How to Do Things with Words, Oxford, Clarendon Press.

Baddeley, M (1989) 'NLP the academic verdict so far', The Australian Journal of Clinical Hypnotherapy and Hypnosis, Vol 10(2).

Bandler, R. and Grinder, J. (1976/1977, 1996) Patterns of the Hypnotic Techniques of Milton H. Erickson, M.D, Vols. I \& II, Grinder, DeLozier \& Associates.

Bandler, R. \& Grinder, J. (1975) The Structure of Magic I: A Book about Language and Therapy, Palo Alto, California, Science and Behavior Books.

Bandler, R., Grinder, J. \& Andreas, S. (1990) Frogs into princes: the introduction to neuro-linguistic programming, Enfield, Eden Grove.

Bandler, R., Grinder, J. J. A. \& Satir, V. (1976) Changing with families: a book about further education for being human, Palo Alto, Calif., Science and Behavior Books.

Bandura, A. (1985) Social Foundations of Thought and Action: A Social Cognitive Theory, Prentice Hall.

Barnett, R. (1997) Higher Education: a critical business, Buckingham, Society for Research into Higher Education and Open University Press.

Bassey, M. (1999) Case Study Research in Educational Settings, Buckingham, Open University Press.

Bateson, G., (1972/2000) Steps to an Ecology of Mind, Chicago, University of Chicago Press.

Bauman, Z. (1996). From pilgrim to tourist-Or a short history of identity. In S. Hall \& P. du Guy (Eds.), Questions of cultural identity (pp. 18-36). London: Sage.

Blasé, J. and Anderson, G. (1995) The Micropolitics of Educational Leadership, London, Cassell.

Beck, U. Giddens, A. and Lash, S. (1994) Reflexive Modernisation. Cambridge: Policy Press.

Beijaard, D. (1995) 'Teachers' Prior Experiences and Actual Perceptions of Professional Identity, Teachers and Teaching: Theory and Practice 1(2):281294.

Beijaard, D., Meijer, P. C. and Verloop, N. (2004) 'Reconsidering Research on Teachers' Professional Identity', Teacher and Teaching Education, 20:107-128.

BERA Revised Ethical Guidelines for Educational Research, http://www.bera.ac.uk/files/guidelines/ethica1.pdf (2004).

Berger, P. L. \& Luckmann, T. (1966/1971) The social construction of reality: a treatise in the sociology of knowledge, Harmondsworth, Penguin.

Blumenthal, D. (1999) 'Representing the divided self', Qualitative Inquiry 5:377-393

Blumer, H. (1969) Symbolic interactionism : perspective and method, Englewood Cliffs, N.J., Prentice-Hall. 
Bogdan, R. and Biklen, S.K. (1992) Qualitative Research for Education, Boston, Allyn and Bacon.

Booth, S (2005) 'Method, Research, Science, and Methodology: Doing, acting, understanding, and committing', Scandinavian Journal of Educational Research, 49(3): pp.325-328

Bostic St. Clair, C. \& Grinder, J. (2001) Whispering In The Wind, Scotts Valley, California, J \& C Enterprises.

Bowring-Carr, C. (1993), "'How shall we know quality in teaching and learning? Some problems associated with classroom observation", Curriculum Journal, Vol. 4 No. 3, pp. 319-26.

Brookfield, S. D. (1987) Developing Critical Thinkers: Challenging Adults to Explore Alternative Ways of Thinking and Acting, Milton Keynes, Open University Press.

Brown, N. (2004) 'What makes a good educator? The relevance of meta programmes', Assessment and Evaluation in Higher Education, Vol 29(5), pp.515-533.

Buchanan, K., Anand, P., Joffe, H. and Thomas, K. (2002): 'Perceiving and understanding the social world' in Miell, D., Phoenix, A. \& Thomas, K. (eds.) Mapping Psychology 2, Milton Keynes, The Open University.

Bullough, R. V. (1997) 'Practicing Theory and Theorizing Practice' in Loughran, J. and Rusell, T. (eds) Purpose, Passion and Pedagogy in Teacher Education, London, Falmer Press.

Burgess, H., Sieminski, S. and Arthur, L., (2006) (Eds) Achieving Your Doctorate in Education, Thousand Oaks, London, New Delhi, Sage Publications.

Burr, V. (2003) Social Constructionism, London, Routledge.

Carr, W. and Kemmis, S. (1986) Becoming Critical: Education, Knowledge and Action Research, London, Falmer Press.

Cepik, S. (2006) 'Positive Neutral Negative evaluation in connotation', IBSU Scientific Journal, International Refereed Multi-disciplinary Scientific Journal, No 1.

Chandler, D. (2002) Semiotics: the basics, London, Routledge

Chomsky, N. (1965) Aspects of the Theory of Syntax, The Hague, Mouton.

Clements, P. (1999) Autobiographical Researach and the Emergence of the Fictive Voice, Cambridge Journal of Education, Vol. 29, No 1, 1999.

Coffey, A. and Atkinson, P. (1996) Making Sense of Qualitative Data, London, Sage.

Collin, A. (1998) Re-thinking the relationship between theory and practice, London, Routledge, The Open University.

Collins, A., Brown, J. S. \& Newman, S. E. (1987) Cognitive apprenticeship:

Teaching the craft of reading, writing and mathematics, Cambridge, MA, University of Illinois.

Collins, J. D. \& Brown, I. A. (1989) Steps in understanding mathematics, Murray.

Connely, F. M. and Clandinin, D.J. (1990) 'Stories of experience and narrative inquiry', Educational Researcher 19(5):2-14.

Craft, A. (2000) Continuing Professional Development, London, RoutledgeFalmer.

Craft, A. (2001) 'Neuro-linguistic Programming and learning theory', The Curriculum Journal, Vol.12 (1), pp. 125-136.

Crayer, P. (2000) The Research Student's Guide to Success, Buckingham, Open University Press.

Crebbin, W. (1997) 'Defining quality teaching in higher education: An Australian example' in Teaching in Higher Education, Vol. 2, No. 1 (pp.21-33).

Crème, P. (1999) 'A reflection on the education of the 'critical person', Teaching in

Higher Education, 4, 4:461-473 
Cohen, L., Manion, L. and Morrison, K. (2004) Research Methods in Education (5 ${ }^{\text {th }}$ edition), London, New York, Routledge Falmer.

Cohen, L. J. \& Dragovic-Soso, J. (2007) State Collapse in South-eastern Europe, West Lafayette, Ind., Purdue University Press.

Cook, T. D., \& Campbell, D. T. (1979) "Quasi-experimentation: Design and analysis issues for field settings", Chicago, Rand-McNally.

Day, C. (1998) 'Working with the different selves of teachers: beyond comfortable collaboration', Educational Action Research 6:255-272.

Day, C. (1999) Developing teachers: the challenges of lifelong learning, London Falmer Press.

Day, C. (2000) 'Teachers in the Twenty-first Century: time to renew the vision', Teachers and Teaching: theory and practice, 6 (1): 101-115.

De Botton, A. (1997) How Proust can change your life: not a novel, New York, Pantheon Books.

Denzin, N. and Lincoln, Y. (1998) The Landscape of Qualitative Research: theories and issues, California, Sage.

Dewey, J. (1960) The Quest for Certainty, New York, Putnam Pub Group.

Dilts, R. (2000) NLP Encyclopaedia [on line], Available at: http://www.nlpuniversitypress.com [last accessed 2nd April 2006].

Dilts, R. \& Delozier, J. (2000) Encyclopaedia of systemic neuro-linguistic programming and NLP new coding, Scotts Valley, Calif., NLP University Press.

Dilts, R. (1990) Changing Belief Systems with NLP, Meta Publications.

Dowlen, A. (1996) 'NLP - help or hype?' Investigating the uses of neurolinguistic programming in management learning. Career Development International, 1, 27-34.

Drenth, P. (1999) 'Prometheus chained: Social and ethical constraints on psychology', European psychologist, 4.4, 233-239.

Durkheim, E. \& Giddens, A. (1972) Emile Durkheim: Selected Writings, Cambridge, Cambridge University Press.

Einspruch, E. L. \& Forman, B. D. (1985) 'Observations concerning research literature on Neuro-Linguistic Programming', Journal of Conseling Psychology, 32, 589596.

Elich, M., Thompson, R. W. \& Miller, L. (1985) 'Mental imagery as revealed by eye movements and spoken predicates: A test of neurolinguistic programming', Journal of Conseling Psychology, 32, 622-625.

Elliot, J. (1991) Action Research for Educational Change, Buckingham, Open University Press

Ely., M., Anzul, M., Friedman, T., Garner, D and McCormick Steinmitz, A. (1991) Doing Qualitative Research: Circles within Circles, Philadelphia, Falmer.

Erickson, F. (1986) 'Qualitative Methods in Research on Teaching' in Wittrock, M.C. (Ed.) Handbook of Research on Teaching ( $3^{\text {rd }}$ edition) New York, Macmillan.

Eysenck, H. (1971) Race, Intelligence and Education, London, Maurice Temple Smith. Feyerabend, P. (1993) Against Method ( $3^{\text {rd }}$ edition), London/New York, Verso.

Finlay, L. (2002) 'Negotiating the swamp: the opportunity and challenge of reflexivity in research practice' Qualitative Research, 2, 209-230.

Flood, G. (1999) Beyond Phenomenology: Rethinking the Study of Religion, London, Cassell.

Friedman, A. and Philips, M (2004) 'Continuing Professional Development: developing a vision', Journal of Education and Work, Vol. 17(3) pp. 361-376

Fullan, M. (2001) The New Meaning of Educational Change, London, New York, Routledge Falmer, Teachers College Press. 
Gardner, H., Gregory, A., Csikszentmihalyi, M., Damon, W., and Michaelson (1997/2001), The Empirical Basis of Good Work: Methodological consideration, Good Work Project Report Series, Number 3, June 1997, Updated February 2001.

Gardner, H., Csikszentmihalyi, M. \& Damon, W. (2001) Good work: when excellence and ethics meet, New York, Basic Books.

Gavin, H. (2008) Understanding research methods and statistics in psychology, London, Sage.

Gee, J. P. (2001) 'Identity as an Analytic Lens for research in Education' in Secada, W. G. (ed) Review of Research in Education, 25:99-125, Washington DC, American Educational Research Association.

Geertz, C. (1973) The interpretation of cultures : selected essays, London, Fontana.

Georges, D.P. (1996) 'Improved employee selection and staffing through meta programmes', Career Development International, Vol 1(5) pp.5-9.

Glaser, B. G. A. S. \& Strauss, A. L. (1968) The Discovery of grounded theory. Strategies for qualitative research, London, Weidenfeld \& Nicolson.

Glasersfeld, E. von (1996) Radical Constructivism: A Way of Learning (Studies in Mathematics Education), London, Falmer Press.

Good Work Project web-site, [on line] http://pzweb.harvard.edu/research/GoodWork.htm (last access 12/10/2009).

Goodall, H.L. (2000) Writing the New Ethnography, New York, Altamira Press.

Gould, S. J. (1981) The Mismeasure of Man, Harmondsworth, Penguin.

Graue, M. E. and Walsh, D. J. (1998) Studying Children in Context Theories, Methods and Ethics, London, SAGE Publications.

Grinder, J. \& Bandler, R. (1976) The Structure of Magic II, A Book About Communication and Change, Palo Alto, California, Science and Behavior Books.

Grinder, J. \& Elgin, S. (1973) A Guide to Transformational Grammar, New York, Holt, Rinehart \& Winston.

Guba, E., Lincoln, Y. (1998), 'Competing paradigms in qualitative research', in Denzin, N., Lincoln, Y. (Eds) (1998), The Landscape of Qualitative Research: Theories and Issues, Sage, Thousand Oaks, CA, pp.195-220.

Gudmundsdottir, S. (1996) 'The teller, the tale, and the one being told: the narrative nature of the research interview', Curriculum Inquiry 26:293-305

Guy's (2007) King's \& St.Thomas's Hospitals Medical \& Dental Schools gazette.

Habermas, J. (1978) Knowledge and Human Interests. London, Heinemann ( $2^{\text {nd }}$ edn)

Haigh, G. (1995) 'To be Handled with Care', The Times Educational Supplement, 10 February: 3-4.

Hall, M. \& Bodenhamer, B. G. (2007) Introducing NLP. Equilibrio web-site. www.equilibrio.com.au (accessed 10/10/2007).

Hammersley, M. (1989) The dilemma of qualitative method: Herbert Blumer and the Chicago tradition, London, Routledge.

Hammersley, M. (1992) What's Wrong With Ethnography? Methodological Explorations, London and New York, Routledge.

Hammersley, M. (1993) 'On the teacher as researcher', in: M. Hammersley (Ed.) (1993) Educational research: current issues, London, Paul Chapman.

Hammersley, M. and Atkinson, P. (1995) Ethnography, Principles in Practice, London and New York, Routledge, Taylor and Francis Group.

Hammersley, M. (2001) FirstClass On-Line Seminars Series, Reviewing The Literature 8 May - 15 June 2001 [on line] OU First Class-EdD Conference (accessed 5 June 2005). 
Hammersley, M. (2004) 'Action research: a contradiction in terms?' in Oxford Review of Education, Vol. 30, No. 2 (pp.165-180).

Hanson, N. R. (1965) Patterns of discovery: in inquiry into the conceptual foundations of science, Cambridge, Cambridge University Press.

Hargreaves, A. (1993) Series Editor's Foreword in Huberman, A. M. The Lives of Teachers, London, Cassell.

Hargreaves, A. (1994) Changing Teachers, Changing Times, London, Falmer Press.

Hargreaves, A. (1999) Series Editor's Foreword in Acker, S. The Realities of Teachers' Work: never a dull moment, London, Cassell.

Hargreaves, A. (1998) 'The Emotional Politics of Teaching and Teacher. Development: with implications for educational leadership', International Journal of Leadership in Education, 1(4): 315-336.

Harris, C. (1992) 'NLP: a pathway to personal effectiveness'. Personnel Management. 24, 7, 44-7.

Hart, C. (1998) Doing a Literature Review, London, Thousand Oaks, New Delhi, Sage Publications.

Heaton, R. M. (1994) Creating and studying a practice of teaching elementary mathematics for understanding. Unpublished doctoral dissertation, Michigan State University, East Lansing, MI.

Helsby, G. (1999) Changing Teachers' Work: The Reform of Secondary Schooling, Milton Keynes, Open University Press.

Heylighen F. \& Joslyn C. (2001): "Cybernetics and Second Order Cybernetics", in: R.A. Meyers (ed.), Encyclopedia of Physical Science \& Technology, Vol. 4 (3rd ed.), (Academic Press, New York), p. 155-170.

Holland, D., Lachicotte Jr., W., Skinner, D., \& Cain, C. (1998) Identity and agency in cultural worlds. Cambridge, MA, Harvard University Press.

Holland, D., \& Lave, J. (Eds.). (2001). History in person: Enduring struggles, contentious practice, intimate identities. Santa Fe, NM: School of American Research Press; Oxford, UK: James Currey

Hollander, J. (1999) 'NLP and Science - Six recommendations for a better relationship', NLP World, 6.

Horkheimer, M. (1982) Critical Theory. New York: Seabury Press.

Horkheimer, M. (1993) Between Philosophy and Social Science. Cambridge, MIT Press.

Husserl, E. (1931) Ideas : general introduction to pure phenomenology, London, George Allen and Unwin.

INLPTA (International NLP Trainers Aassociation) INLPTA web-site, http://www.inlpta.com (last access 10/10/2009).

Irving, J. A. \& Williams, D. I. (1995) 'Critical thinking and reflective practice in Counseling', British Journal of Guidance and Counselling, 23, 107-114.

Irving, J. A. and Williams, D. I. (1999) 'Personal Growth and Personal Development: concepts clarified', British Journal of Guidance and Counselling, 27 (4):517526

James, W. (1950) The Principles of Psychology vol. 1, Dover Publications.

Johnson, R. (1993) 'Coaching for success', Training and Development, July 1993.

Joyce, B. and Showers, B. (1996) 'Staff Development as a Comprehensive service Organization', Journal of Staff Development, 17(1):2-6

Kamp, D. (1992) 'Tapping your own excellence using NLP', Executive Development, Vol. $15 / 1$.

Kant, I. (1966) Kritik der reinen Vernunft (Critique of Pure Reason), Stuttgart, Phillip Reclam jun. 
Keeney, B. P. \& Sprenkle, D. H. (1992) Ecosystemic epistemology: Critical implications for the aesthetics and pragmatics of family therapy, Washington, DC, American Psychological Association.

Kelchtermans, G. (1993), Getting the story, understanding the lives: From career studies to teachers' professional development', Teaching and Teacher Education, 9 (5/6), pp. 443-456.

Kellner, D. (1989) Critical Theory, Marxism, and Modernity, Cambridge, UK and Baltimore, MD, Polity Press and John Hopkins University Press.

Kemmis, S. and McTaggart, R. (1984) (eds.) The Action Research Planner, Geelong, Australia, Deakin University Press.

Kidd, J. M., Killeen, J., Jarvis, J. \& Offer, M. (1994) 'Is guidance an applied science?: the role of theory in the careers guidance interview', British Journal of Guidance and Counselling, 23, 385-403.

Knowles, G. J. (1992) 'Models for Understanding Pre-Service and Beginning Teachers' Biographies: illustrations from case studies' in Goodson, I. F. (ed) (1992) Studying Teachers' Lives, London, Routledge.

Korzybski, A.(1933) Science and Sanity, Lakeville, Connecticut, The International Non-Aristotelian Library Publishing Company, $4^{\text {th }}$ edition.

Krejsler, J. (2002) Loring, magt og individualitet - Når poedagogik iscenescettes som selvbestemmelse [Learning, power, and individuality - Orchestrating education as self-determination; in Danish] Copenhagen, Denmark, Gyldendal Uddannelse.

Krejsler, J. (2005) ,Professions and their Identities: How to explore professional development among (semi-) professions', Scandinavian Journal of Educational Research, Vol.49, No.4, pp. 335-357.

Kudliskis,V. and Burden, R. (2009) 'Applying 'what works' in psychology to enhancing examination success in schools: The potential contribution of NLP, Thinking Skills and Creativity, Vol.4, Issue 3, December 2009, pp.170-177.

Kuhn, T. S. (1996) The Structure of Scientific Revolutions ( $3^{\text {rd }}$ edition), Chicago/London, The University of Chicago Press.

Kuhne, G.W. and Quigley, B.A. (1997) 'Understanding and using action research in practice settings' in New Directions for Adult and Continuing Education, Spring 97, No. 73 (pp.23-40).

Kvorning-Hansen, K and Lam, A. (1990) 'Tale er handling - Den vellykkede kommunikation' [Speech is action - Successful communication; in Danish] in Jensen, T.K. et al. (Eds) (1990) Grundlagsproblemer i sygeplejen - Etik, videnskabsteori, ledelse og samfund, Aarhus, Denmark, Philosophia.

Lakoff, G. (1987) Women, fire, and dangerous things: what categories reveal about the mind, Chicago, University of Chicago Press.

Lakoff, G. \& Johnson, M. (1980) Metaphors we live by, London/Chicago, University of Chicago Press.

Lather, P. (1986) 'Research as Praxis', Harvard Educational Review, Vol. 56, No. 3, pp.257-277.

Lave, J. \& Wenger, E. (1991) Situated learning: legitimate peripheral participation, Cambridge, Cambridge University Press.

Lewin, K. (1951) Field Theory in Social Science, Chicago, University of Chicago Press.

Lewin, K. (1999) The Complete Social Scientist: A Kurt Lewin Reader, American Psychological Association.

Lincoln, Y. S. and Guba, E. G. (1985) Naturalistic inquiry, Beverly Hills, California, Sage. 
Louis, K. S. (1994) 'Beyond “Managed Change”: Rethinking how Schools Improve', School Effectiveness and Improvement, 5,1, pp.2-24

Lund, T. (2005) 'The Qualitative-Quantitative Distinction: Some comments', University of Oslo, Scandinavian Journal of Educational Research, 49(2) pp.115-132.

Lutrell, W. (2000) 'Good enough' methods for ethnographic research', Harvard International Review 70, p. 449-521.

Lyotard, J.-F. (1979) The Post-Modern Condition, Manchester, Manchester University Press.

MacLure, M. (1993) 'Arguing for Your Self: identity as an organising principle in teachers' jobs and lives', British Education Research Journal, 19(4).

Marrow, A. (1969) The Practical Theorist: the life and work of Kurt Lewin, New York, Teachers College Press.

Maslow, A.H. (1996) The Psychology of Science, New York, Harper and Row.

Maturana, H. R. \& Varela, F. J. (1992/1998) The tree of knowledge : the biological roots of human understanding, London.

McClendon, T.(1989) The Wild Days, NLP 1972-1981, Meta Publications, Cupertino, California.

McCormick, D. (1984) 'Neurolinguistic programming: a resource guide and review of the research', in Pfeiffer, J.W. and Goodstein, L.D. (Eds), The 1984 Annual: Developing Human Resources, San Diego, CA, University Associates.

McCulloch, J. R. (1995) The collected works of J. R. McCulloch. [2], The principles of political economy, London, Routledge/Thoemmes.

McLeod, P., Plunkett, K. \& Rolls, E. T. (1998) Introduction to Connectionist Modelling of Cognitive Processes, Oxford, Oxford University Press.

Mead, G. J. (1934) Mind, Self and Society, Chicago, University of Chicago Press

Miller, G., Galanter, E., \& Pribram, K, (1960) Plans and the Structure of Behavior, New York, Holt, Rinehard \& Winston.

Milne, T. (1988) Executive career counselling. British Journal of Guidance and Counselling, 16/3.

Moran, S. (2009) What Role Does Commitment Play Among Writers with different levels of creativity?, Creativity Research Journal, Vol. 21, Issue 2\&3, 243-257.

Nash, R. (1976) 'Pupils' Expectations of Their Teachers' in Stubbs, M. and Delamont, S. (eds) (1976) Explorations in Classroom Observations, London, Wiley and Sons.

NHS Institute for innovation and improvement, NHS Institute for innovation and improvement web-site, http://www.institute.nhs.uk (last accessed 12/10/2006).

Nias, J. (1981) 'Teacher Satisfaction and Dissatisfaction: Herzberg's 'two factor' hypothesis revisited', in British Journal of Sociology of Education, Vol. 2, No.3, p. 235-246.

Nias, J. (1989) Primary Teachers Talking, London, Routledge and Kegan Paul.

Open University Research Ethics procedures website, http://www.open.ac.uk/researchethics/index.shtml (accessed 18/9/2009)

Orland-Barak, L. (2002) 'The Theoretical Sensitivity of the Researcher: reflections on a complex construct', Reflective Practice, 3(3): 263-278.

OU E835 Study Guide (1996), Milton Keynes, Open University.

Papert, S. and Harel, I. (1991) Situating Constructionism, http://namodemello.com.br/pdf/tendencias/situatingconstrutivism.pdf (accessed 18/9/2009)

Peirce, C. S., Houser, N. \& Kloesel, C. J. W. (1992) The essential Peirce : selected philosophical writings. Vol.1, (1867-1893), Bloomington, Indiana University Press. 
Perls, F. (1973) The Gestalt Therapy and Eye Witness to Therapy, Science and Behavior Books.

Piaget, J. and Inhelder, B. (1969) The Psychology of the Child, London, Routledge and Kegan Paul.

Pimm, D. (1994) 'Spoken Mathematical Classroom Culture: Artifice and Artificiality' in Lerman, S. (ed.) (1994) Cultural Perspectives on the Mathematics Classroom, Netherlands, Kluwer Academic Publishers.

Popkewitz, T.S. and Brennan, M. (1998) 'Restructuring of social and political theory in education: Foucault and a social epistemology of school practices', in Popkewitz, T. S. and Brennan, M. (Eds) (1998), Foucault's challenge, New York, Teachers College Press

Potter, S. (2006) Doing Postgraduate Research, London, Thousand Oaks, New Delhi, Sage Publications.

Reason, P. and Bradbury, H. (2001) 'Introduction: Inquiry and participation' in Reason, P. and Bradbury, H. (Eds) Handbook of action research: participative inquiry and practice, London, Sage.

Redman, P. (1999) The Challenge of the Social Sciences, D820 Study Guide, Milton Keynes, The Open University.

Reeve, F., Cartwright, M. and Edwards, R. J. (2002) Organizing learning, London, RoutledgeFalmer.

Rex, J. and Moore, R. (1967) Race, Community and Conflict, Oxford, Oxford University Press.

Rogers, C. (1998) The interpersonal relationship in the facilitation of learning in Crawford, M. et al. (eds) Taking Issues, London, Routledge

Roth, W.M. (2004). Identity as dialectic: Re/making self in urban school. Mind, Culture, and Activity, 11(1), 48-69.

Rudduck, J. and Flutter, J. (2000), 'Pupil participation and pupil perspective: Carving a new order of experience', Cambridge Journal of Education, Vol. 30, No 1, p. 75-89.

Savickas, M. L. (1994) Convergence prompts theory renovation, research unification, and practice coherence, Palo Alto, CA, CPP Books.

Schön, D. A. (1983) The Reflective Practitioner: How Professionals Think in Action, New York, Basic Books.

Sfard, A. And Prusak, A. (2005) Telling Identities: In Search of an Analytic Tool for Investigating Learning as a Culturally Shaped Activity, Educational Researcher, Vol.34, pp.14-22

Shacklock, G. and Smyth. J. (1998) (eds.) Being Reflexive in Critical Educational and Social Research, London, Falmer Press.

Sharpley, C. F. (1987) 'Research findings on neurolinguistic programming: nonsupportive data or an untestable theory?' Journal of Conseling Psychology, 34, 103-107.

Skelton, A. (2005) Understanding teaching excellence in higher education: towards a critical approach, London, Routledge.

Smith, M. J. (1998) Social Science in Question, London, Sage.

Steffe, L. P. \& Gale, J. (1995) Constructivism in Education, Hillsdale, NJ, Lawrence Erlbaum.

Stenhouse, L. (1975) An Introduction to Curriculum Research and Development, London, Heinemann.

Stierer, B. and Antoniou, M. (2004) 'Are there distinctive methodologies for pedagogic research in higher education', Teaching in Higher Education, 9(3), pp 275-285. 
Strauss, A. (1962) 'Transformations of identity' in Rose, A. M. (ed) (1962) Human Behaviour and Social Processes, London, Routledge \& Kegan Paul.

Strauss, A. L. (1987) Qualitative analysis for social scientists, Cambridge, Cambridge University Press.

Strauss, A. and Corbin, J. (1990) Basics of Qualitative Research: grounded theory procedures and techniques, Newbury Park, CA, Sage.

Stringer, E.T. (1999) Action Research, London, Sage.

Stroh, M. (2000) 'Qualitative Interviewing' in Burton, D. (Ed.) Research Training for Social Scientists: a Handbook for Postgraduate Researchers, London, Sage Publications.

Sumsion, J. (2002) 'Becoming, Being and Unbecoming an Early Childhood Educator: a phenomenological case study of teacher attrition', Teaching and Teacher Education, 18:869-885.

Taylor, P.H. (1962) 'Children's Evaluations of the Characteristics of the Good Teacher', British Journal of Educational Psychology, 32.

Thomas, A. (1993) Controversies in Management, London, Routledge.

The Open University (2002) E835 Educational Research in Action, Milton Keynes, The Open University.

Tosey, P. and Mathison, J. (2003) 'Neuro-linguistic programming and learning theory: a response' The Curriculum Journal, Vol. 14(3), pp.371-388.

United Kingdom Council for Psychotherapy, United Kingdom Council for Psychotherapy web-site http://www.psychotherapy.org.uk/ (accessed 10/10/2008).

Vaihinger, H. (1924) The Philosophy of "As If", London, Routledge, Kegan and Paul, Ltd.

Van den Berg, R. (20020 'Teachers' Meanings Regarding Educational Practice', Review of Educational research, 72(4):577-625.

Vygotsky, L. S. (1934/1986) Thought and language, Cambridge, MA, MIT Press.

Wallace, S. (2003) 'Figuratively speaking: six accounts of the PhD viva', Quality Assurance in Education: An international Perspective; Vol. 11 Issue 2, p. 100108.

Watson, C. (1994) 'Improving the quality of career guidance: towards an understanding of the development of personal models', British Journal of Guidance and Counselling, 19, 230-245.

Watzlawik, P., Beavin, J. \& Jackson, D. (1967) Pragmatics of Human Communication, New York, W.W. Norton and Company.

Weber, M., Lassman, P. \& Speirs, R. (1994) Political writings, Cambridge, New York, Cambridge University Press.

Wenger, E. (1998) Communities of practice: learning, meaning and identity, Cambridge, Cambridge University Press.

Wenger, E. (2006) Learning for a small planet: a research agenda; http://ewenger.com/research/LSPfoundingdoc.doc [last accessed 24/10/2009].

Wetherell, M., Taylor, S. \& Yates, S. J. (2001) Discourse Theory and Practice, A Reader London, Sage/The Open University.

White, H. (1973), Metahistory, Baltimore, Johns Hopkins University Press.

White, H. (1978), Tropics of Discourse, Baltimore, Johns Hopkins University Press.

Wittgenstein, L. (1953) Philosophical investigations, Oxford, Blackwell.

Woods, P. (1981) 'Strategies, commitment and identity: making and breaking the teacher role', in Barton, L. and Walker, S. (eds.) School, Teachers and Teaching, Lewes, Falmer Press. 
Woods, P. (1996) in E835 Educational Research in Action, Study Guide, Open University, Milton Keynes.

Woolgar, S. (1988) 'Reflexivity is the Ethnographer of the Text', in Woolgar, S. (ed.) New Frontiers in the Sociology of Knowledge, London, Sage.

Yates, S. J. (2004) Doing Social Science Research, Milton Keynes, Thousand Oaks, London, New Delhi, The Open University and Sage Publications.

Young, R. (1991) Critical Theory and Classroom Talk, Clevedon, Multilingual Matters. 


\section{APPENDICES}




\section{Appendix 1 - The contents of the personal development trainings for teachers}

The modules' titles and contents are approximate translations from Slovenian into English:

$1^{\text {st }}$ module: Satisfied teacher $=$ efficient teacher $(16$ hours $)$

- teacher's self-image

- communication skills

- building self-esteem and self confidence

- attitudes towards work and job satisfaction

- state-management

- $\quad$ handling demanding situations

$2^{\text {nd }}$ module: Motivation strategies (for motivating others and self-motivation) (16 hours)

- discovering own values

- motivation programmes

- motivation and performance

- well-formed outcomes

- personal-professional life balance

- the use of metaphors

$3^{\text {rd }}$ module: Relaxation, music and visualisation in the classroom and everyday life (24 hours)

- brainwaves

- neuro-pathways

- guided and semi-guided relaxations

- Musical Library (Lozanov) for 'recharging batteries'

- Visualisation techniques

$4^{\text {th }}$ module: How to use mind maps in the classroom and everyday life (16 hours)

- the origins of mind maps (T. Buzan)

- the art and craft of mind maps

- the use of mind maps in private and professional life

- hemisphericity

$5^{\text {th }}$ module: Communication skills in the classroom and everyday life (16 hours)

- listening skills

- communication model (Neurolinguistic Programming)

- establishing rapport

- interpersonal relationship and communication skills

- behavioural flexibility

- language patterns

- non-verbal communication

$6^{\text {th }}$ module: Rapport in the classroom and everyday life (16 hours) 
- strategic communication

- establishing rapport

- behavioural flexibility

- brain gymnastics

$7^{\text {th }}$ module: Different learning and thinking styles in the classroom and everyday life (16 hours)

- thinking styles (Gregorc)

- learning styles (VAKOG, Honey and Mumford, 4-mat)

- detecting thinking and learning styles

- matching thinking and learning styles

$8^{\text {th }}$ module: Classroom management (16 hours)

- anchoring space, text, students

- handling stress and "stage-freight"

- conflict resolution

- creating positive classroom climate

$9^{\text {th }}$ module: Rhetorical and moderating skills in the classroom and everyday life (24 hours)

- the use of ethos and pathos

- the use of voice

- attention drawing skills

- the use of 'story loops'

- the use of silence

- time-management skills

- 'bottomlining' skills

- summarizing skills

$10^{\text {th }}$ module: The influence of beliefs on performance in the classroom and everyday life (16 hours)

- definition of beliefs

- detecting beliefs

- supporting and limiting beliefs

- framing and reframing beliefs (V. Satir)

- beliefs and performance 


\section{Appendix 2 - Semi-structured interview schedule}

I) Introduction

1) Have you attended any personal development trainings so far?

a) If yes, which trainings?

b) Was that during the last five years?

II) Professional identity

2) How would you describe yourself as a teacher?

3) How would you think others would describe you as a teacher?

III) Job satisfaction

4) How would you describe the level of satisfaction with your work?

a) Has it changed over the years?

IV) Work attitude (Attitude towards work)

5) How would you describe your attitude towards your work? (What kind of attitude do you have towards your work?)

a) Has it changed over the years?

V) Motivation skills

6) How do you motivate yourself for work?

7) How do you motivate your students?

VI) Communication skills

8) How would you describe your communication skills in the classroom?

9) What do you do to establish good rapport in the classroom?

VII) Handling demanding situations

10) How do you handle demanding situations at work?

a) What do you do? How do you react?

b) Has anything changed over years?

VIII) Future plans

11) What are your plans for the future in terms of your work/career?

IX) Closing

12) Is there anything you would like to add (or explore further)? 


\section{Appendix 2a - Semi-structured interview schedule - Slovenian version}

I) Uvod

1) Ali ste se udeležili kakšnega izobrazevanja s podrocja osebnostnega razvoja?

a) Katerega?

b) Ali je to bilo v zadnjih 5 let?

II) Profesionalna identiteta

2) Kako bi opisali sebe kot ucitelja?

3) Kako mislite da bi vas drugi opisali kot ucitelja?

III) Zadovoljstvo $\mathrm{z}$ delom/na delu

4) Kako bi opisali nivo svojega zadovoljstva $z$ delom?

a) Ali se je z leti kaj spremenilo?

IV) Odnos do dela

5) Kako bi opisali svoj odnos do dela?

a) Ali se je z leti kaj spremenilo?

V) Motivacijske veščine/strategije

6) Kako se motivirate za delo?

7) Kako motivirate učence-dijake?

VI) Komunikacijske veščine

8) Kako bi opisali svoje komunikacijske vescine v razredu?

9) Kaj naredite da bi vzpostavili dober stik v razredu?

VII) Obvladovanje zahtevnih situacijah

10) Kako bi opisali svojo sposobnost obvladovanja zahtevnih situacij pri svojem delu?

a) Kaj naredite v zahtevnih situacijah? Kako odreagirate v zahtevnih situacijah?

b) Ali se je z leti kaj spremenilo?

VIII) Načrti za prihodnost

11) Kakšni so vaši načrti za prihodnost glede vašega dela/karijere?

IX) Zaključek

12) Ali bi se kaj dodali (ali se bolj raziskali)? 


\section{Appendix 3 - An extract from the transcript of semi-structured interview (in English)}

T5: To try hard, to be honest, fair, and to justify the mark I give... and I try to talk to them on the way, to sort things out if something is wrong, rather than wait until problems get accumulated...

Tatjana: How old are your pupils?

T5: Ah, Year 5 to year 9, that is from 10 to 15 years old. Or 11 to 15.

Tatjana: How would you describe yourself as a teacher? And how, do you think, would your pupils describe you as a teacher?

T5: Yes, it is diffcult to answer that question...I believe I am fair. I think that the majority of the pupils accept me. For example, right now ...just before the interview I was stepping in for my colleague - the PE teacher and I played volleyball with the pupils and we really enjoyed it. I loke doing other things with them, too, not just teach them Slovenian.

Tatjana: What about your colleagues? How would they describe you as a teacher?

T5: Some say that it is easy to talk to me about subject-related topics. They also trust me - they know I will not spread anything I hear from them, I am confidential. Some think that in spite of me looking so serious I have a good sense of humour, particularly when it gets tough (laughter).

Tatjana: (laughter) How would you desribe your job satisfaction?

T5: Well if I can use a 1 to 5 scale, I would say 4. Mostly I am satisfied with my work, with my pupils and my colleagues but I admit there are some pupils in some classes ... it is impossible to establish communication or their behaviour is disturbing the lessons...that is why I would say 4.

Tatjana: Has this mark changed over years? Or is it the same as before?

T5: No, in the beginning, the first 2 and a half years I was in charge of the after-school club and then I would say $2-3$.

Tatjana: How would you describe your attitude towards your work?

T5: I think I am quite serious about my work, with all the preparations, talking to my colleagues. I think I have a responsible attitude towards my work, after all that is what is expected of me, I am obliged to take it seriously.

Tatjana: There might be days when your motivation is not at its highest. How do you motivate yourself in the moments like that?

T5: Yes, there are days like that indeed. Sometimes it is an argument at home or something similar, then I say to myself that this is the profession I chose and that I need to leave everything that happened at home behind and have a professional attitude in the classsroom.

Tatjana: What do you do if it is one of your pupils that is not motivated?

T5: Ahh, you mean when they are not eager to cooperate and to do what is expected?

Tatjana: Yes. How do you motivate them?

T5: I try to go to them, ask them whether there is any isssue, check if they do not feel like doing what we do or it is simply not interesting for them, tell them that there might be other things in life they would not feel like doing and would not find interesting but they would need to do them anyway. Sometimes they simply tell me tha they have a bad day, I try to understand, I usually suggest that we talk about that topic tomorrow... 


\section{Appendix 4 - An extract from a coded semi-structured interview}

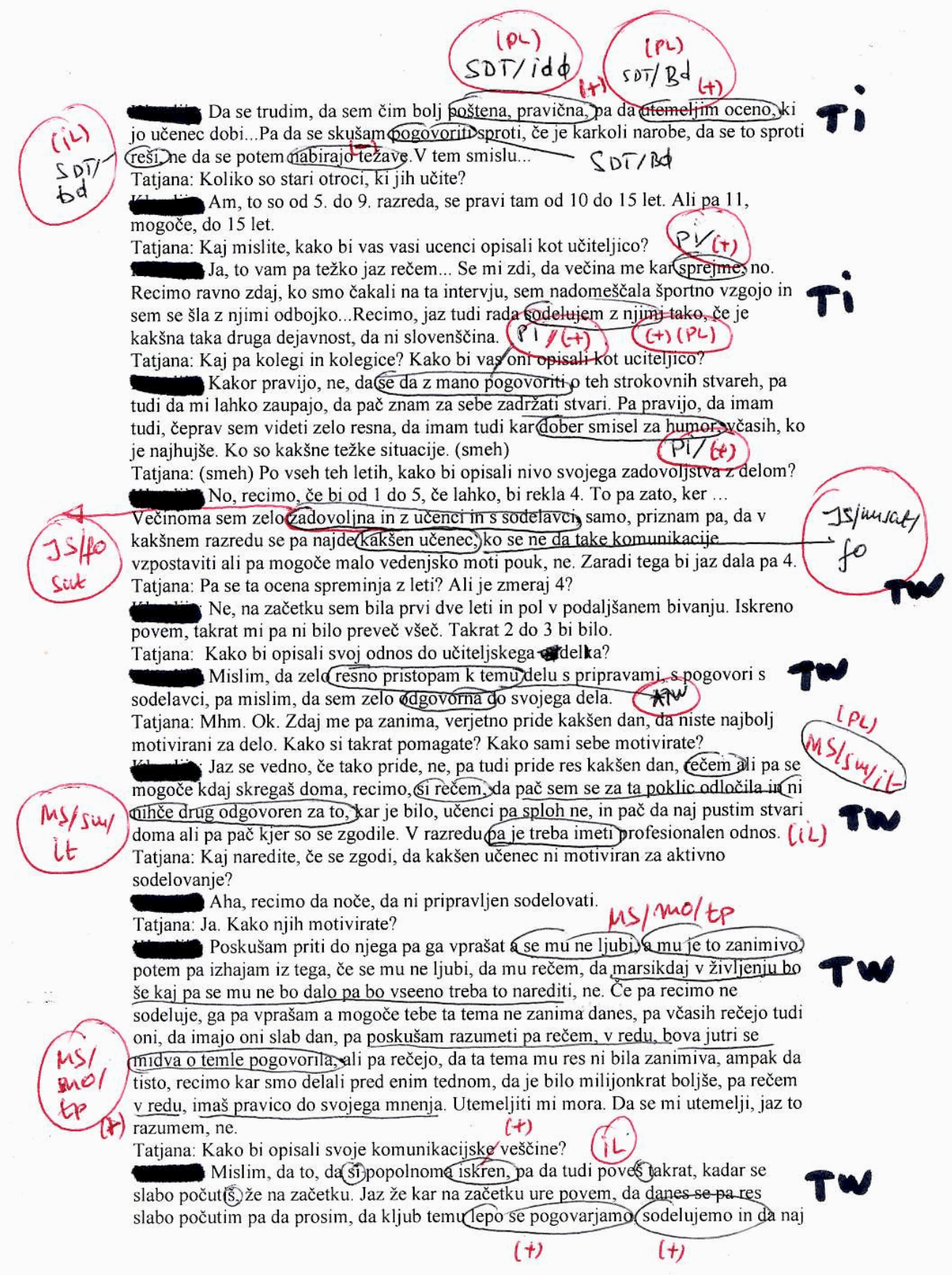

